Programa de Doctorado en Biociencias Moleculares

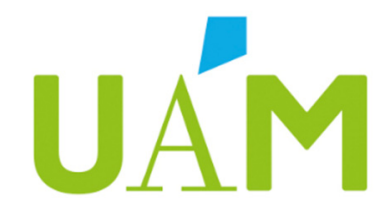

Universidad Autónoma

de Madrid

\title{
Novel Mechanisms Underlying Macrophage \\ Contribution to Cardiac Injury after \\ Myocardial Infarction
}

Laura Alonso Herranz

Madrid, 2019 



\title{
UÁM \\ Universidad Autónoma de Madrid \\ Departamento de Bioquímica \\ Facultad de Medicina \\ Novel Mechanisms Underlying Macrophage Contribution to Cardiac Injury after Myocardial Infarction
}

\author{
Laura Alonso Herranz, licenciada en Biología
}

Directora: María Mercedes Ricote Pacheco

Tutor: Miguel Ángel Íñiguez Peña

Este trabajo se ha realizado en el laboratorio de Señalización de los Receptores Nucleares de la Fundación Centro Nacional de Investigaciones Cardiovasculares Carlos III (CNIC). 



\section{CERTIFICADO DEL DIRECTOR DE TESIS}

La Dra. María Mercedes Ricote Pacheco CERTIFICA que la doctoranda Laura Alonso Herranz ha desarrollado y concluido su trabajo de Tesis Doctoral titulado "Novel mechanisms underlying macrophage contribution to cardiac injury after myocardial infarction" bajo su supervisión, en el Centro Nacional de Investigaciones Cardiovasculares (CNIC), con la financiación de una beca predoctoral La Caixa - Severo Ochoa, concedida por la Fundación Obra Social La Caixa.

En Madrid, a 4 de Julio de 2019

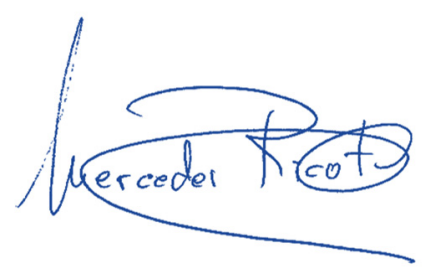

Fdo: María Mercedes Ricote Pacheco

Jefa de Grupo

Laboratorio de Señalización de los Receptores Nucleares

Centro Nacional de Investigaciones Cardiovasculares-Carlos III (CNIC) 

Filip K. Swirski, PhD

Patricia and Scott Eston MGH Research Scholar

Principal Investigator, Center for Systems

Biology, Massachusetts General Hospital

Associate Professor, Harvard Medical School
Center for Systems Biology

Simches Research Building, Room 5-216

185 Cambridge Street, Boston, MA, 02114

Tel: 617.724.6242 | Fax: 617.643.6133

Url: http://csb.mgh.harvard.edu/filip_swirski

E-mail: fswirski@mgh.harvard.edu

July 3, 2019

To whom it may concern,

With this letter I would like to confirm that Laura Alonso-Herranz, a PhD student at the Universidad Autonoma de Madrid was a graduate research assistant in my lab at the Center for Systems Biology at the Massachusetts General Hospital and Harvard Medical School, beginning in August 2018 for a period of 3 months. During this time, Laura worked on a project related to her PhD work on Madrid.

The CSB is one of five thematic centers at the MGH. Within the CSB, my lab focuses on leukocyte biology in inflammatory diseases. To date, our studies have contributed to a deeper understanding of how various leukocytes contribute to disease but many questions remain. As a graduate research assistant in my laboratory, Laura worked on questions related to cardiovascular disease. She employed a combination of state-ofthe-art animal models, classical cell biology techniques, and profiling assays.

Laura has now completed her thesis, titled "Identifying novel mechanisms of macrophage contribution to cardiovascular disease." This is a well written thesis combining her published work with a more detailed and nuanced elaboration of macrophage biology in cardiovascular disease.

Sincerely,

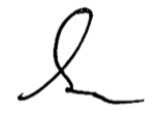

Fil Swirski 

Cameron S. McAlpine, Ph.D.

Instructor, Banting Fellow

Center for Systems Biology

Massachusetts General Hospital

Harvard Medical School
Center for Systems Biology

Simches Research Building

185 Cambridge Street, Boston, MA, 02114

Tel: 617.643-0500 I Fax: 617.643.6133

E-mail: csmcalpine@mgh.harvard.edu

Re: Evaluation of Laura Alonso-Herranz's thesis "Novel mechanisms underlying macrophage contribution to cardiac injury following myocardial infarction"

To Whom it May Concern;

Here-in is a brief report and evaluation of Laura Alonso-Herranz's Ph.D. thesis titled "Novel mechanisms underlying macrophage contribution to cardiac injury following myocardial infarction".

Cardiovascular disease remains the leading cause of death worldwide. As such, identifying novel mechanisms that contribute to disease progression is an important step in the development of next generation therapeutics. Laura's work exploring the contribution of cardiac macrophages to myocardial infarction is timely and innovative.

Laura's thesis begins with a comprehensive introduction outlining the current state of the scientific literature on the inflammatory networks that underpin myocardial infarction. In the first objective, Laura characterizes two mouse models of sterile cardiac injury: cryoinjury and permanent ligation of the LAD coronary artery. Her data clearly demonstrates that these two models vary in the degree of induced cardiac injury as measured by ultrasound and heart function. Further, Laura demonstrates that inflammatory responses in the heart are divergent in these two models. Cryoinjury results in enhanved Ly6Chi monocyte infiltration into the heart and exacerbated IL6, Nos2 and Timp3 expression by these cells on day 3 post-injury. Conversely, cardiac macrophages express higher levels of Mmp14 in the coronary ligation model, an intriguing finding Laura expands upon in objective 2.

In objective 2, Laura evaluates the role of myeloid cell-derived MT1-MMP (Mmp14) in cardiac function and healing post-MI. She demonstrates that MT1-MMP deletion from myeloid cells improves post-MI cardiac function, reduces cardiac collagen content and fibrosis, and preserves the cardiac capillarity network improving tissue oxygenation. Laura goes on to identify a molecular mechanism by which MT1-MMP, via TGF 31 and SMAD2, controls endothelial to mesenchymal cell transition (EndoMT). Strikingly, myeloid MT1-MMP deletion abrogates EndoMT, increasing endothelial cell numbers and enhancing angiogenesis and heart vascularization. Laura concludes her thesis with an in-depth discussion highlighting the importance of her work, its translation to humans, and situates it in the context of the existing literature.

Laura's thesis is exceptional. It is a tour-de-force utilizing innovative techniques and models. Comparing multiple cardiac injury models illustrates alternative mechanisms in cardiac healing and the contribution of the immune system to this process. It will serve as an excellent resource for further studies investigating cardiovascular disease. Further, Laura's comprehensive analysis of myeloid derived MT1-MMP in cardiac function post-MI is conceptually exciting. It is striking that deletion of a metalloprotease would enhance, rather than suppress, microvessel formation. Her identification of impaired EndoMT is creative and provides an innovative explanation for her findings. Further, it identifies an exciting mechanism by which 
macrophages communicate with endothelial cells to regulate their function. Laura clearly identify's a novel mechanism of cell-to-cell cross-talk in the post-MI heart that may be targeted therapeutically.

In sum, Laura's thesis is outstanding. She contributes remarkable data, analysis, and context on which the broader scientific community can rely and build upon.

Sincerely,

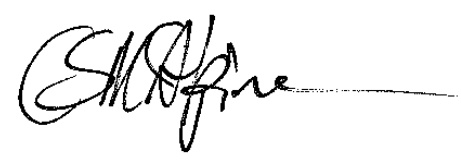

Cameron McAlpine, Ph.D. 
Filip K. Swirski, PhD

Patricia and Scott Eston MGH Research Scholar

Principal Investigator, Center for Systems

Biology, Massachusetts General Hospital

Associate Professor, Harvard Medical School
Center for Systems Biology

Simches Research Building, Room 5-216

185 Cambridge Street, Boston, MA, 02114

Tel: 617.724.6242 | Fax: 617.643.6133

Url: http://csb.mgh.harvard.edu/filip_swirski

E-mail: fswirski@mgh.harvard.edu

April 30, 2019

To whom it may concern,

I certify the visit of Laura Alonso Herranz as a graduate research assistant in my lab at the Center for Systems Biology at the Massachusetts General Hospital and Harvard Medical School, for a period of 3 months (from $6^{\text {th }}$ August 2018 to $6^{\text {th }}$ November 2018), in a full-time, 40 hours/week position.

During her visit, Laura worked on questions related to cardiovascular disease, employing a combination of state-of-the-art animal models, classical cell biology techniques, profiling assays, and molecular in vivo imaging.

Sincerely,

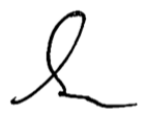

Filip K. Swirski, PhD 

A mi abuelo 

Y el final de todas nuestras exploraciones será llegar al lugar donde comenzamos y conocerlo por primera vez.

T.S. Elliot 

ACKNOWLEDGEMENTS 

Hay momentos que forjan nuestro pasado. Que alimentan nuestro presente. Que son imprescindibles para tener un futuro. Momentos de los que podemos aprender algo. Que hacen de nuestra existencia una fábula. Hay momentos que pasan volando. Ayer era verano de 2013, puse un pie por vez primera en el CNIC. Y hoy me despido de él con una tesis y numerosos momentos mágicos atesorados en la memoria. Durante estos últimos años, son muchas las personas que, de forma directa o indirecta, han llenado mi vida de momentos inolvidables. Que son responsables de que haya llegado hasta aquí y de que el camino haya sido increíble. A todas ellas, me gustaría dar las gracias de corazón.

En primer lugar, quiero dar las gracias a Mercedes por darme la oportunidad de hacer la tesis en su laboratorio. Durante esta etapa formativa he desarrollado muchas más aptitudes de las que jamás habría imaginado y que me servirán para afrontar tanto mi vida profesional como personal. También quiero agradecer a Alicia G. Arroyo su implicación, tutorización y pensamiento crítico en los diferentes proyectos en los que hemos trabajado juntas. A Miguel Ángel Íñiguez, tutor de esta tesis, por hacer de nexo entre la UAM y el CNIC, y guiarme a través de todos los trámites para llegar hasta este día.

A todos mis compañeros de laboratorio, que son importantísimos y extraordinarios. Gracias por hacer que estos 6 años parezcan 6 días. Gracias a Vane, pilar fundamental de grupo. Eres la mejor carta de presentación del laboratorio. No hay protocolo o aproximación que se te resista, y has sabido inculcarme ese empeño por superar los retos que se nos presentan día a día. Queda pendiente ese Jove y yo quiero verlo cuando ocurra (:) A Piedad, me llevaste de la mano en los inicios. Eres un ejemplo de que el mundo de la ciencia está lleno de mujeres inspiradoras, fuertes y maravillosas, que solo necesitan que se les dé voz.

A mis pivotes, Ana y Jesús. Ana, tienes un don que te permite mirar igual, pero ver diferente. Un don para ver en las cosas lo que las cosas cuentan y casi nadie entiende. Nunca encontraré a alguien con tu desparpajo, carisma y buen corazón. Gracias por enseñarme Sevilla, pero sobre todo Triana, por vestirme de flamenca, por animarnos los días de trabajo, por mantenernos al día con el reggaetón nuevo y recordarnos el antiguo. Eres una científica extraordinaria, muy asertiva, que va a conseguir todo lo que se proponga. No te olvides de llamarnos cuando montes tu propio laboratorio (-). Jesús, es pensar en ti y escuchar a la vez Vetusta Morla, Tu Otra Bonita, Lana del Rey... Incontables son las horas las que hemos compartido con ellos de fondo o en sus conciertos (hablaremos de cómo de cerca tuvimos y tocamos al cantante de Tu Otra Bonita cuando se hagan famosos). Contigo me he reído hasta dolerme la tripa, y he aprendido mucho, pero que mucho sobre muchas cosas. Que la futura nos depare más aventuras juntos. Lo que ha unido el paper que se forjó en el sofá de mi casa después de comer chino, que no lo separe nadie. Gracias por estar ahí siempre, directo como tú eres. 
A Eleftheria, pura energía griega que viene para insuflar aire freso al laboratorio.

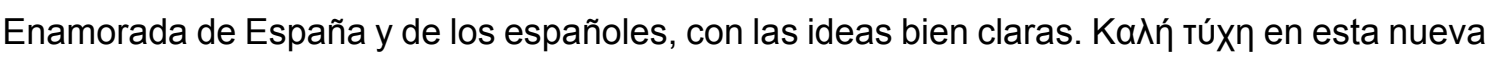
etapa. Me gustaría haber tenido más tiempo para conocerte mejor, así que espero que sigamos viéndonos fuera del CNIC. A Carmen, la ya no tan nueva adquisición del grupo (Eleftheria te ha quitado el título). Tus manos me han dado suerte en la puesta a punto de protocolos, ahora te toca seguir repartiendo esa suerte con los demás. Me alegro mucho de que hayas entrado a formar parte de nosotros.

A la larga lista de oldies del laboratorio: Damiana, Wencke, Ali, Claudia, Annia, Ángel, Jose... Muchas gracias a todos por hacer que el trabajo sea más humano, entusiasta y sobre todo divertido. A Lorenzo, una de las personas más entusiasmadas por la ciencia que he conocido. Gracias por la confianza depositada en mí y las correcciones de mi TFM y de mi inglés allá por el lejano 2014. A Marta, que afrontó los retos que supone iniciar una nueva línea de investigación en el lab y me pasó el legado. A Verdiana, por tu valentía y ganas de plantar batalla, luchando por lo que querías y merecías. Al poco de llegar a Madrid ya removiste algo dentro de mí, y espero que esta amistad dure hasta que seamos viejecitas. Contigo todo ha sido siempre muy fácil. Gracias por descubrirme Terni y Roma, por hacerme reír con tus expresiones (recercadora, me desperté en el corazón de la noche), por ese desparpajo ítalo-andaluz que llevas dentro y nos cautiva. A Inés (te amo), eres única y quiero seguir teniéndote cerca. El ciclo de la vida ha querido que se junte en el tiempo y el espacio lo que yo acabo con lo que tú comienzas. Que no pierdas nunca la ilusión y sigas disfrutando de esta bonita profesión. Tienes un corazón enorme, integridad y valentía. Que nada te cambie. A Ana G, que vuela libre para hacer lo que le gusta y cómo le gusta. Si no encajas, no es porque no valgas, si no porque eres única y excepcional. Como a Inés, te deseo mucho ánimo con el Doctorado. Nos seguiremos viendo por el barrio, vecina.

No puedo dejar de expresar mi agradecimiento a la gente de Alicia G. Arroyo, con los que he tenido la oportunidad de trabajar mano a mano. Su laboratorio ha sido mi segunda casa en el CNIC. A Cris, Xenia, Ángel, Susana, Sergio, Ricardo... Gracias por todo el soporte técnico, científico y humano que me habéis brindado. Os deseo mucha suerte en vuestras nuevas andaduras. A Álvaro Sahún, responsable directo de que mi tesis tenga color. Ha sido un placer trabajar contigo durante este último año y medio, incluso con los retos que nos ha planteado el proyecto. ¡¡A por el último año que te queda!!

A Pilar Gonzalo, por su generosidad, inteligencia y compromiso. Siempre dispuesta a revisar conmigo los últimos resultados, hacer brainstorming, solucionar problemas técnicos... Millones de gracias por estar siempre ahí, por hacer mucho más de lo que te correspondía, por ser mi gurú de la microscopía, por compartir cada paper que veías que podía resultarme útil. Por preocuparte por mí y por todo el apoyo y horas de escucha, dentro y fuera del CNIC. Porque contigo no hay horarios, gracias. 
A todas las unidades técnicas del CNIC. Sois la matriz que sustenta y permite la investigación de calidad que se desempeña en nuestro centro. Muchas gracias por hacernos la vida un poco menos complicada. Por darnos soluciones cuando nos acercamos con dudas y planteamientos experimentales que a priori parecen imposibles. En especial me gustaría dar las gracias a la Unidad de Celómica (esta sería mi tercera casa en el CNIC), a Jose, Raquel, Mariano y Elena, por la de veces que me habéis ayudado con compensaciones y paneles imposibles y porque sois unos cracks en vuestro trabajo. A nuestros técnicos de animalario, Merche, Raquel, Frank e Iván, tan atentos y comprensibles la infinidad de veces que os he dado la lata para vigilar el postoperatorio de mis ratoncitos. A Rubén, Iria y Lorena por la compañía en las largas horas de cirugía y vuestra ayuda siempre que necesitaba algo. A la Unidad de Microscopía, en especial a Vero, que conoce todos los secretos del ImageJ y siempre te ofrece un plugin adaptado a lo que necesitas :-).

A Fátima Sánchez-Cabo y Carlos Torroja, por su paciencia cuando he necesitado un cable con los análisis bioinformáticos. A las Unidades de Genómica e Histología (Antonio de Molina, Roisin, Pedro). A toda la gente de bioseguridad, cultivos, esterilización compras, logística, recepción, cafetería, limpieza, almacén, seguridad... Muchas gracias a Mari, por ser la mejor técnico de logística, la más cercana y con la que, además, me he reído un montón. Al equipo de informáticos del CNIC, en especial a Juan Carlos, Alicia, Pablo y Eduardo, por ayudarme con mis incidencias y con cierto problema de encriptación de archivos...

Gracias a Sonia Rodríguez, Ángel Ciprés, Ana Gutiérrez y Amada por hacer la burocracia más liviana. A Beatriz Ferreiro y Cristina Giménez por hacer lo propio y resolver mis dudas. A Irene Maseda, por su dominio del Endnote y siempre recibirme con una sonrisa y ganas de ayudar. A Simon, por su inestimable ayuda con el inglés y su espíritu pedagógico (:). A Antonio Ureña, por tener siempre la puerta abierta y sacar tiempo para resolver cualquier problema.

A todos aquellos que me han brindado su ayuda con protocolos, reactivos o simplemente una sonrisa al cruzarnos por el pasillo. Los baches, por desgracia, no son infrecuentes durante esta etapa, de modo que una mirada cómplice o una leve sonrisa pueden ayudarte a superar un mal día. Continúo agradeciendo a aquellos que se han interesado sobre mi trabajo en seminarios y congresos y me han planteado cuestiones o críticas que han servido para reforzar y mejorar mis investigaciones. La ciencia es un mundo asombroso que te permite seguir madurando, aprendiendo y maravillándote día a día. Que te exige y te entrena duramente, pero que te recompensa con brillantes destellos de revelación.

Estos 6 años han dado para mucho...También he tenido tiempo para hacer amigos geniales y atesorar grandes momentos fuera del CNIC. Gracias a Javito, Jose, Maruchi, Itziar, Sergio, Julio, Jesús, Rebeca, Maca, Fran, Víctor, Paula, Eli, Marina, Carles, Sara, Alberto, 
Miriam, Ángel, Noelia y un largo etcétera, por todas las barbacoas, fiestas, tardes en la Yoli, ferias de abril... A mis vecinos, los Sanchos, Sabios y Toños, por hacer más entretenidos los largos días de trabajo. Por los potlucks para celebrar Halloween, Navidad... También quiero aprovechar para pedir perdón si alguna vez la situación se nos ha ido de las manos y hemos armado demasiado "barullo" $:-$.

I would like to thank Fil and the rest of the guys (Cameron, Chris, Colin, Floriant, John) for hosting me during my short stay and for making me feel I was at home. Thank you for making me remember the beauty of science and supportive team working. Special thanks to Wolfram, an excellent and patient mentor in the magic field of neuroscience. I wish you all the best in your American adventure!

No quiero dejar de mencionar a la familia española que encontré en Boston. 3 meses que parecen 6 al compartir tantas horas juntos. Fines de semana en Cape Cod, las White Mountains, el Liberty...Gracias por arroparme durante ese tiempo. ¡Os deseo mucho éxito en vuestra andadura científica y que el camino nos vuelva a juntar!

Gracias a mis amigos de Biología: Sara, Irene, Ana, Laura, Cris, Mario, Alberto, Álex, Ángel. Porque, aunque sigamos sendas diferentes, hay atajos que nos conectan y nos mantienen unidos, como una familia. $Y$ como no, a la familia ampliada que ahora formamos; bienvenidos Pietro, Celia, Caru y Luca. Gracias por ser la constante de mi aventura en Madrid.

Y si hablo de mi llegada a Madrid, no puedo olvidar el paso por el Johnny. Ha sido una suerte elegir un camino que me ha llevado a forjar amistades que perduran después de 10 años. Durante estos años nos hemos reconocido asustados y tímidos en la mirada de recién llegados, sin saber muy bien qué nos deparaba Madrid y la Universidad. Nos hemos visto avanzar, no sin dificultades, en la carrera y posterior salida al mercado laboral. $Y$ hoy puedo decir que estoy muy orgullosa de todos vosotros, Chema, Pablo, Germán, Cristian, Ale, Miriam y Yasmina (aunque a vosotras ya os tenía de antes). De lo que habéis llegado a ser y de lo que me habéis hecho ser. Gracias por los innumerables momentos que hemos vivido juntos.

A mis amigas de siempre. A Yasmina, Miriam, Clara, Carmen. Porque estamos cambiando constantemente. Nunca somos las mismas. $Y$ a pesar de todo nuestra amistad es un ejercicio constante de adaptación. Por aguantar mis ausencias en los últimos meses y hacerme sentir que el tiempo no ha pasado cuando nos reencontramos.

Gracias a mi familia. A mis abuelos, tíos y primos, que siempre se han preocupado por preguntarme por el avance de mi trabajo y por cómo me iba en los momentos no tan buenos. Por darme ánimos y esperanza. Por hacerme ver que todo, incluso lo malo, acaba pasando. Gracias por estar siempre ahí. A mi abuelo, su recuerdo es indeleble. Por su 
paciencia e ilusión por enseñarme a leer con dos añitos, a jugar al guiñote, y por lo orgulloso que siempre ha estado de sus nietos. A mi abuela, a la que quiero con locura y los ratos que paso con ella son de lo mejor que tengo. A la familia de Ale, a la que tengo mucho cariño y con los que paso muy buenos momentos.

A Teresa, mi hermana, mi Chu. Por mantenerme siempre adolescente cuando nos juntamos, pero en una mejor versión de la que fui. Por muchos más conciertos de Izal, tardes de Harry Potter, capítulos de Los Hombres de Paco, etc. Por ese torrente que tienes por dentro y que te llevará a hacer grandes cosas. No te dejes amilanar por nadie. Tu vida es tuya y de nadie más. Lo siento si no te digo lo suficiente lo mucho que te admiro. Tienes un corazón de oro, deja que nos deslumbre aún más.

A mis padres, Isidro y Azucena, por apoyarme en mi loca decisión de elegir la Biología frente a la Medicina (si esto le parece insensato a alguien apasionado por la ciencia, imaginad a unos padres que con tanto esfuerzo han intentado asegurarle a su retoño un buen trabajo para toda la vida). Por los valores que me han enseñado, por inculcarme que lo importante es el esfuerzo y la perseverancia. Gracias, papá y mamá, porque sin vosotros no habría recorrido ni una décima parte del camino ni sería lo que soy a día de hoy. El título de doctor ha ser compartido con vosotros; merecéis ser doctores honoris causa de esta gesta.

A Ale, jab, mi compañero. Apareciste por casualidad. Sin previo aviso. Como esas tormentas de verano que te pillan en la playa y no sabes si correr o dejarte empapar. Y yo me dejé empapar. Llegaste para quedarte. Eres, sin duda, la persona que más de cerca ha vivido esta intensa etapa. Gracias por la resignación con la que me escuchas hablarte de cirugías, citometrías, células contaminadas, virus, ratones verdes... Porque con todo ello tendrías convalidadas un par de asignaturas de biología :) Por aquel día que tuve que volver a pasar muestras al citómetro a las 10 de la noche, y me acompañaste con fiebre para que fuera un poco más llevadero. Por tu paciencia, esa que muchas veces a mí me falta, cuando anulaba planes de fin de semana por visitas al CNIC. Por cuidar tan bien de mí y no reprocharme nada durante las largas jornadas el tramo final, en la que nos veíamos solo para cenar y directos a dormir. Por suavizar ese nervio que aflora de vez en cuando en mí. Por el apoyo incondicional, respeto y cariño que llevas regalándome desde hace 8 años. Porque eres la familia elegida, eres hogar.

La felicidad es la toma de conciencia de que estás en el lugar que quieres estar con las personas que quieres estar. Hoy soy feliz, y os doy las gracias a todos. 

SUMMARY 

Myocardial infarction (MI) is a recognized inflammatory condition that triggers monocyte infiltration and subsequent macrophage differentiation aiming to heal the damage. In the last few years, a growing body of evidence that a timely macrophage expansion and transition from inflammatory to reparative phenotype are crucial for proper infarct healing has led to macrophages being proposed as potential therapeutic targets for Ml. However, cellular and molecular mechanisms involved in these processes remain not well defined. In this study, we aimed to identify novel mechanisms underlying macrophage contribution to cardiac repair, paying special attention to the crosstalk with other cell types. For that purpose, we studied cardiac healing response in adult mice using two models of sterile tissue injury: cryoinjury and permanent occlusion of the left anterior descendant coronary artery (LADligation), employing a combination of state-of-the-art confocal microscopy techniques and algorithms for automatized image analysis, classical cell biology techniques, flow cytometry, and luciferase report assays.

We found that infarcts produced by LAD-ligation largely affected myocardium integrity and left ventricular function and remodeling. In contrast, cryoinjury led to mild cardiac dysfunction and remodeling, although it triggered a boosted inflammatory response. Interestingly, elevated levels of the protease MT1-MMP (Mmp14) were detected in post-injury macrophages found in LAD-ligation versus cryoinjury. Based on these observations, we hypothesized that macrophage-derived MT1-MMP may play a role in post-MI adverse cardiac remodeling and dysfunction.

Our study demonstrated that MT1-MMP deletion from macrophages (MT1-MMP ${ }^{\Delta L y s M}$ mice) attenuates post-MI cardiac dysfunction, reduces cardiac collagen content and fibrosis, and preserves the cardiac capillary network, improving tissue oxygenation. Mechanistically, we showed that MT1-MMP activates latent TGF $\beta 1$ in macrophages, leading to paracrine SMAD2mediated signaling in endothelial cells (ECs), myofibroblasts, and vascular smooth muscle cells. Post-MI hearts from MT1-MMP ${ }^{\triangle L y s M}$ mice contained fewer cells transitioning from an endothelial to a mesenchymal phenotype than their wild-type counterparts, and MT1-MMP-deficient macrophages showed a reduced ability to induce endothelial to mesenchymal transition (EndMT) in co-cultures with ECs.

Collectively, this is the first study to demonstrate that post-MI macrophages induce EndMT contributing to adverse cardiac remodeling and to identify MT1-MMP as a key regulator of this process via macrophage-EC crosstalk. This novel mechanism of macrophagemediated EC regulation in the post-MI heart has potential as a therapeutic target in ischemic heart disease. 

RESUMEN 

El infarto de miocardio (IM) es una patología inflamatoria que desencadena el reclutamiento de monocitos y su diferenciación a macrófagos tratando de reparar el daño. En los últimos años, la evidencia de que tanto una respuesta apropiada de los macrófagos en el tiempo como la transición de fenotipo inflamatorio a reparador son cruciales para la correcta reparación post-IM ha convertido a los macrófagos en potenciales dianas terapéuticas frente al IM. Sin embargo, los mecanismos celulares y moleculares involucrados en estos procesos no se conocen por completo. En este trabajo tratamos de identificar nuevos mecanismos a través de los cuales los macrófagos participan en la reparación cardiaca, prestando especial atención a la interacción con otros tipos celulares. Para ello usamos dos modelos quirúrgicos de daño en ratones adultos: criolesión y oclusión permanente de la arteria coronaria LAD; y recurrimos a técnicas avanzadas de microscopía confocal, algoritmos para el análisis automatizado de imágenes, técnicas clásicas de biología celular, citometría de flujo y ensayos de luciferasa.

Demostramos que el modelo de oclusión permanente afecta severamente a la integridad del miocardio, así como a la función y remodelado del ventrículo izquierdo. Por el contrario, la criolesión provoca una disfunción y remodelado cardiaco leve, aunque desata una mayor respuesta inflamatoria. Descubrimos asimismo que los macrófagos encontrados tras la oclusión expresan mayores niveles de la proteasa MT1-MMP (Mmp14) que los de la criolesión. En base a estos resultados, hipotetizamos que la proteasa MT1-MMP producida por macrófagos podría participar en el remodelado adverso y disfunción cardiaca tras el IM.

Nuestro estudio demuestra que la deleción de MT1-MMP en macrófagos (ratones MT1$\mathrm{MMP}^{\Delta \mathrm{LysM}}$ ) atenúa la disfunción cardiaca, reduce el contenido de colágeno y la fibrosis, preserva la red capilar del miocardio y mejora la oxigenación de este tras el IM. En cuanto al mecanismo molecular subyacente, demostramos que MT1-MMP activa TGF $\beta 1$ en macrófagos, promoviendo la señalización paracrina a través de SMAD2 en células endoteliales (ECs), miofibroblastos y células vasculares de músculo liso. Además, los corazones infartados de ratones MT1-MMP ${ }^{\Delta}$ LysM presentan menos células en transición de fenotipo endotelial a mesenquimal, y observamos que los macrófagos deficientes en MT1-MMP muestran una disminución de la capacidad para inducir la transición endotelial-mesenquimal (EndMT) en co-cultivos con ECs.

En resumen, este es el primer estudio que demuestra que los macrófagos post-IM inducen EndMT, contribuyendo al remodelado cardiaco adverso, y que identifica a MT1MMP como regulador de este proceso a través de la interacción entre macrófagos y ECs. Este nuevo mecanismo por el cual los macrófagos regulan la función de las ECs en el corazón infartado representa una potencial diana terapéutica frente al IM. 

INDEX 



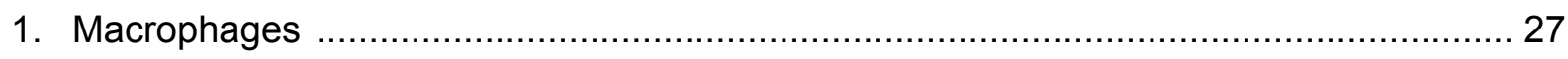

1.1 Macrophage overview: definition, origin and activation ....................................... 27

1.2 Tissue resident macrophages (TRMs): macrophage diversity in the body ............... 29

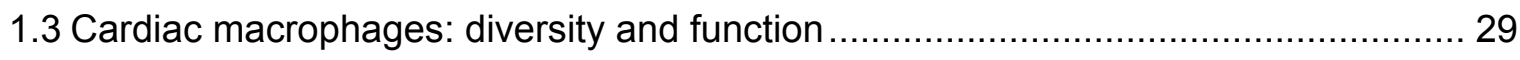

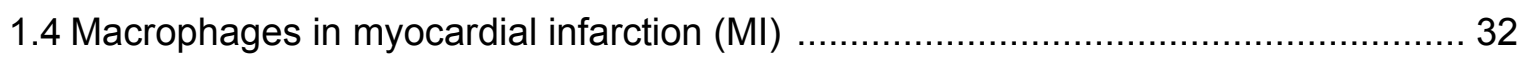

2. Membrane type 1-matrix metalloproteinase (MT1-MMP) ……..................................... 36

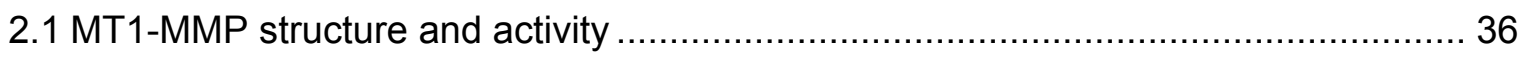

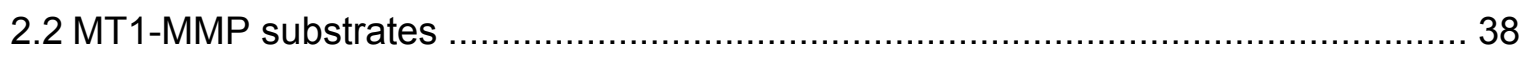

2.3 MT1-MMP expression in tissues and cellular populations ..................................... 39

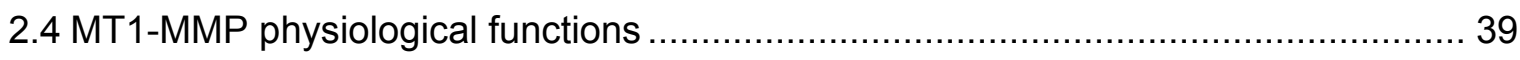

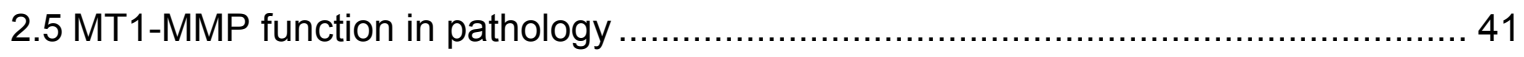

3. Endothelial to Mesenchymal Transition (EndMT) in MI ......................................... 42

4. Models of sterile cardiac injury: cryoinjury and LAD-ligation ...................................... 43

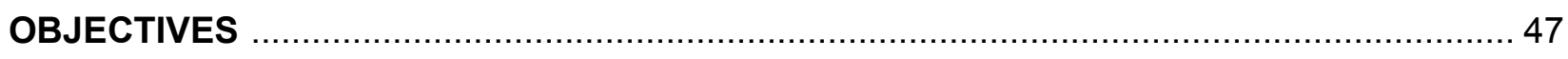

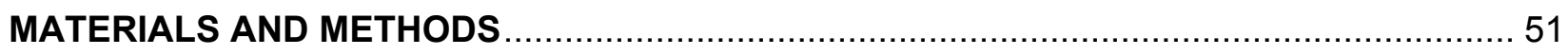

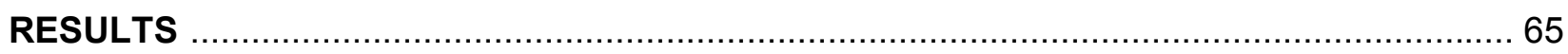

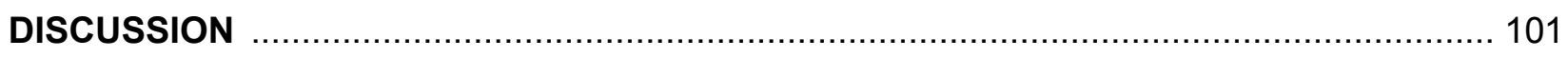

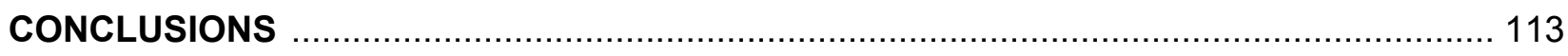

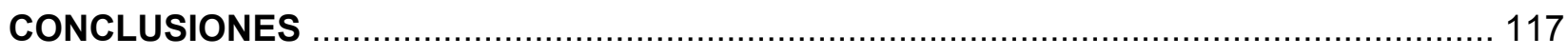

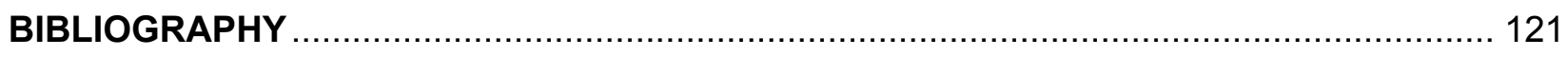

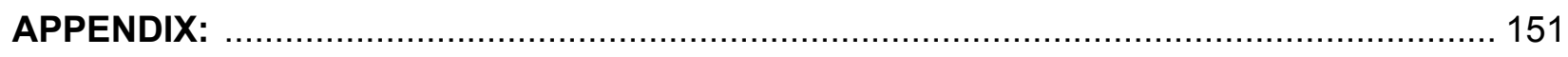

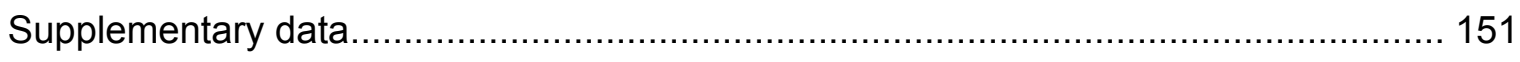

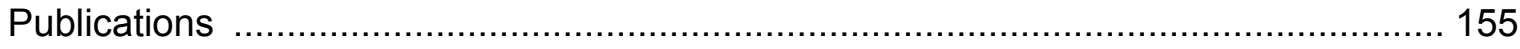



ABBREVIATIONS 



$\begin{array}{ll}\text { ADAM9 } & \text { ADAM Metallopeptidase Domain 9 } \\ \text { ALU } & \text { Arbitrary Luciferase Units } \\ \text { ANOVA } & \text { Analysis Of VAriance } \\ \text { ARG1 } & \text { Arginase 1 } \\ \text { BM } & \text { Bone Marrow } \\ \text { BMDM } & \text { Bone Marrow-Derived Macrophage } \\ \text { BMP } & \text { Bone Morphogenetic Protein } \\ \text { BMPR } & \text { Bone Morphogenetic Protein Receptor } \\ \text { BSA } & \text { Bovine Serum Albumin } \\ \text { CA-IX } & \text { Carbonic Anhydrase IX } \\ \text { CANTOS } & \text { Canakinumab Anti-Inflammatory Thrombosis Outcome Study } \\ \text { CCL } & \text { C-C motif Chemokine Ligand } \\ \text { CCR } & \text { C-C motif Chemokine Receptor } \\ \text { CD11b } & \text { Integrin, Alpha M (complement component 3 receptor 3 subunit) } \\ \text { CD163 } & \text { Hemoglobin Scavenger Receptor } \\ \text { CD16/CD32 } & \text { Fc gamma RII/RIII } \\ \text { CD31 } & \text { Platelet Endothelial Cell Adhesion Molecule 1 (PECAM-1) } \\ \text { CD45 } & \text { Leukocyte Common Antigen } \\ \text { CD64 } & \text { Fc Fragment Of Igg, High Affinity la, Receptor } \\ \text { CDH5 } & \text { Cadherin 5 } \\ \text { CDNA } & \text { Complementary DNA } \\ \text { Col } & \text { Collagen } \\ \text { COX2 } & \text { Cyclooxygenase 2 } \\ \text { CRM } & \text { Cardiac Resident Macrophage } \\ \text { CVD } & \text { Cardiovascular Disease } \\ \text { DAB } & 3,3 \text {-Diaminodenzidine } \\ \text { DAPI } & 4 \text { ',6-Diamino-2-Fenilindol } \\ \text { DMEM } & \text { Dulbecco's Modified Eagle Medium } \\ \text { EC } & \text { Endothelial Cell } \\ \text { ECGS/H } & \text { Endothelial Cell Growth Supplement/ Heparin } \\ \text { ECM } & \text { Extracellular Matrix } \\ \text { EDTA } & \text { Ethylenediaminetetraacetic Acid } \\ \text { EMMPRIN } & \text { Extracellular Matrix Metalloproteinase Inducer (CD147) } \\ \text { EMT } & \text { Epithelial to Mesenchymal Transition } \\ \text { EndMT } & \text { Endothelial to Mesenchymal Transition } \\ \text { EGR1 } & \text { Early Growth Response 1 } \\ \end{array}$


F4/80 Egf-like module containing, mucin-like, Hormone receptor-Like 1 (EMR1)

FACS Fluorescence-Activated Cell Sorting

FAK Focal Adhesion Kinase

FB Fibroblast

FBS Fetal Bovine Serum

FGF Fibroblast Growth Factor

FL Fetal Liver

FMO Fluorescence Minus One

FS Fraction Shortening

FSC Forward Scatter

FSP1 Fibroblast Specific Protein 1

GM-CSF Granulocyte-Macrophage Colony-Stimulating Factor

GPI Glycosylphosphatidylinositol

HBBS Hank's Balanced Salt Solution

H\&E Hematoxylin and Eosin

HEK293 Human Embryonic Kidney 293 Cell Line

HRP Horseradish Peroxidase

ICAM1 Intercellular Adhesion Molecule 1

ICAM2 Intercellular Adhesion Molecule 2

IFN $\gamma \quad$ Interferon gamma

IL Interleukin

I/R Ischemia/Reperfusion

IZ Injury Zone

KLF6 Kruppel Like Factor 6

KDR Vascular Endothelial Growth Factor Receptor 2 (FLK1)

KO Knock Out

LysM Lysozyme M

LAD Left Anterior Descending

LAD-ligation Permanent LAD-Coronary Artery Ligation

LAP Latency Associated Peptide

L-GIn L-Glutamine

lincRNA Long Interspaced Non-Coding RNA

LPS Lipopolysaccharide

LV Left Ventricle

LVEF Left Ventricular Ejection Fraction

LVIDd Left Ventricular End-Diastolic Internal Diameter 


\begin{tabular}{|c|c|}
\hline LVIDs & Left Ventricular End-Systolic Internal Diameter \\
\hline LVVold & Left Ventricular End-Diastolic Volume \\
\hline LVVols & Left Ventricular End-Systolic Volume \\
\hline Ly6C & Lymphocyte Antigen 6C \\
\hline LYVE1 & Lymphatic Vessel Endothelial Hyaluronan Receptor 1 \\
\hline M199 & Medium 199 \\
\hline $\mathbf{M} \phi$ & Macrophage \\
\hline MAEC & Mouse Aortic Endothelial Cell \\
\hline M-CSF & Macrophage Colony-Stimulating Factor \\
\hline MerTK & MER proto-oncogene Tyrosine Kinase \\
\hline MFI & Mean Fluorescence Intensity \\
\hline MHC-II & Major Histocompatibility Complex, class II \\
\hline MI & Myocardial Infarction \\
\hline miRNA & Micro RNA \\
\hline MMP & Matrix Metalloproteinase \\
\hline MPEF & Multiphoton Excitation Fluorescence \\
\hline MPS & Mononuclear Phagocyte System \\
\hline MRC1 & Mannose Receptor, C type 1 (CD206) \\
\hline mRNA & Messenger RNA \\
\hline MT1-MMP & Membrane Type 1 Matrix Metalloproteinase (Mmp14) \\
\hline MyoFB & Myofibroblast \\
\hline NB & Newborn \\
\hline NO & Nitric Oxide \\
\hline NOS2 & Nitric Oxide Synthetase (iNOS) \\
\hline NR4A1 & Nuclear Receptor Subfamily 4 Group A Member 1 \\
\hline $\mathrm{O} / \mathrm{N}$ & Overnight \\
\hline PAl1 & Plasminogen Activator Inhibitor-1 \\
\hline PBS & Phosphate-Buffered Saline \\
\hline PDGF-BB & Platelet-Derived Growth Factor beta \\
\hline PDGFR $\beta$ & Platelet-Derived Growth Factor Receptor beta \\
\hline PFA & Paraformaldehyde \\
\hline PI3K $\delta$ & Phosphoinositide 3-Kinase \\
\hline P-IZ & Peri-Injury Zone \\
\hline PMN & Polymorphonuclear Neutrophil \\
\hline PMSF & Phenylmethylsulfonyl Fluoride \\
\hline
\end{tabular}




\begin{tabular}{ll} 
PROX1 & Prospero Homeobox 1 \\
PIS & Penicillin/Streptomycin \\
pSMAD2 & Phosphorylated SMAD Family Member 2 \\
qPCR & Quantitative Real-Time Polymerase Chain Reaction \\
RAC1 & Rac Family Small GTPase 1 \\
RBC & Red Blood Cell \\
RIPA & Radioimmunoprecipitation Assay \\
RPMI & Roswell Park Memorial Institute Medium \\
RT & Room Temperature \\
RXR & Retinoid X Receptor \\
RZ & Remote Zone \\
SDF1 & Stromal Cell-Derived Factor 1 \\
SDS & Sodium Dodecyl Sulfate \\
SEM & Standard Error of the Mean \\
SHG & Second Harmonic Generation \\
SM22 $\alpha$ & Smooth Muscle Protein 22 alpha \\
SMA & Smooth Muscle Actin \\
SMAD2 & SMAD Family Member 2 \\
SNAl1 & Snail Family Transcriptional Repressor 1 \\
SNAI2 & Snail Family Transcriptional Repressor 2 (SLUG) \\
SPF & Specific Pathogen-Free \\
SSC & Side Scatter \\
STAT1 & Signal Transducer and Activator of Transcription 1 \\
STAT6 & Signal Transducer and Activator of Transcription 6 \\
TET2 & Tet Methylcytosine Dioxygenase 2 \\
TfR & Transferrin Receptor \\
TGF $\beta$ & Transforming Growth Factor beta \\
TIE1 & Tyrosine-Protein Kinase Receptor 1 \\
TIE2 & Tyrosine-Protein Kinase Receptor 2 \\
TIMP & Tissue Inhibitor of MMP \\
TNF $\alpha$ & Tumor Necrosis Factor alpha \\
TRM & Tissue Resident Macrophage \\
TSP1 & Thrombospondin 1 \\
TWIST & Twist Family BHLH Transcription Factor \\
TX100 & Triton X-100 \\
\hline
\end{tabular}




$\begin{array}{ll}\text { VEGF } & \text { Vascular Endothelial Growth Factor } \\ \text { VSMC } & \text { Vascular Smooth Muscle Cell } \\ \text { vWF } & \text { von Willebrand Factor } \\ \text { WMSI } & \text { Wall Motion Score Index } \\ \text { WT } & \text { Wild Type } \\ \text { YM1 } & \text { Chitinase-like 3 (Chil3) } \\ \text { YS } & \text { Yolk Sac } \\ \text { ZEB1 } & \text { Zinc Finger E-Box Binding Homeobox 1 } \\ \text { ZEB2 } & \text { Zinc Finger E-Box Binding Homeobox 2 }\end{array}$



LIST OF FIGURES 

Figure 1. Heterogeneity of tissue resident macrophage (TRM) ontogeny in adult organs in steady state conditions

Figure 2. Tissue macrophage diversity in the body

Figure 3. Diversity, origin and maintenance of cardiac macrophages in the adult heart 30

Figure 4. Biphasic macrophage response after myocardial infarction 33

Figure 5. Macrophage-mediated angiogenesis following myocardial infarction 34

Figure 6. Phenotypic modulation and activation of fibroblasts into myofibroblasts during the reparative phase after $\mathrm{MI}$

Figure 7. Left ventricular remodeling following myocardial infarction 35

Figure 8. Multidomain structure of MT1-MMP 37

Figure 9. Endothelial to mesenchymal transition

Figure 10. LAD-ligation leads to a more severe cardiac dysfunction and LV dilation than cryoinjury 66

Figure 11. LAD-ligation results into a greater lesion extent than cryoinjury..... 68

Figure 12. Cryoinjury results in modest scarring and small tissue remodeling compared to LADligation

Figure 13. Cardiac injury causes a progressive drop in $\mathrm{CD} 31^{+}$vessel density within the lesion 71

Figure 14. Cryoinjury leads to higher lymphangiogenic response than LAD-ligation 72

Figure 15. Cryoinjury leads to higher density of arterioles than LAD-ligation 73

Figure 16. Cryoinjury results in a boosted macrophage response at early post-injury stages than LAD-ligation 74

Figure 17. Isolation and gene expression profile of cardiac macrophages after cryoinjury or LADligation 76

Figure 18. Mouse model of macrophage-specific MT1-MMP deletion 78

Figure 19. Macrophage MT1-MMP deletion ameliorates LV dysfunction and remodeling after MI

Figure 20. Macrophage MT1-MMP deletion attenuates collagen deposition after MI 83

Figure 21. The absence of macrophage MT1-MMP ameliorates cardiac dysfunction and reduces collagen deposition in a model of transient ischemia 
Figure 22. Macrophage MT1-MMP deletion preserves the microvasculature network and improves tissue oxygenation after MI

Figure 23. Macrophage MT1-MMP deletion does not affect post-MI lymphangiogenesis

Figure 24. Macrophage MT1-MMP deletion reduces arteriole wall thickening after MI

Figure 25. Macrophage MT1-MMP deletion blunts mature TGF $\beta 1$ release from small latent complex (SLC)

Figure 26. Macrophage MT1-MMP deletion impairs pSMAD2-mediated signaling in ECs and MyoFBs/VSMCs after MI

Figure 27. Macrophage MT1-MMP deficiency attenuates pSMAD2-mediated activation of MyoFBs and VSMCs after MI

Figure 28. Mice with macrophage-deficiency of MT1-MMP had fewer MyoFBs and cells undergoing EndMT transition post-MI 94

Figure 29. MT1-MMP is required for macrophage-mediated induction of EndMT in vitro 96

Figure 30. Post-MI cardiac macrophages induce EndMT through MT1-MMP-mediated TGF $\beta 1$ activation

Figure 31. Cryoinjury and LAD-ligation lead to disparate patterns of macrophage activation resulting in distinct cardiac healing responses

Figure 32. Macrophage MT1-MMP deletion preserves cardiac function after MI by impairing TGF $\beta 1$ signaling in the myocardium 
INTRODUCTION 



\section{Macrophages}

\subsection{Macrophage overview: definition, origin and activation}

Macrophages were first described in 1882 by Elias Metchnikoff, who referred to them as 'big eaters'. They are innate immune cells specialized in host defense, with a great capacity to engulf apoptotic cells and pathogens and to produce immune effector molecules. They can be found in all organs, where they fulfill a diversity of tissue-specific roles contributing to homeostasis, development and repair (1). Besides, macrophages participate into pathological processes, making them potential targets for therapeutic intervention $(2,3)$.

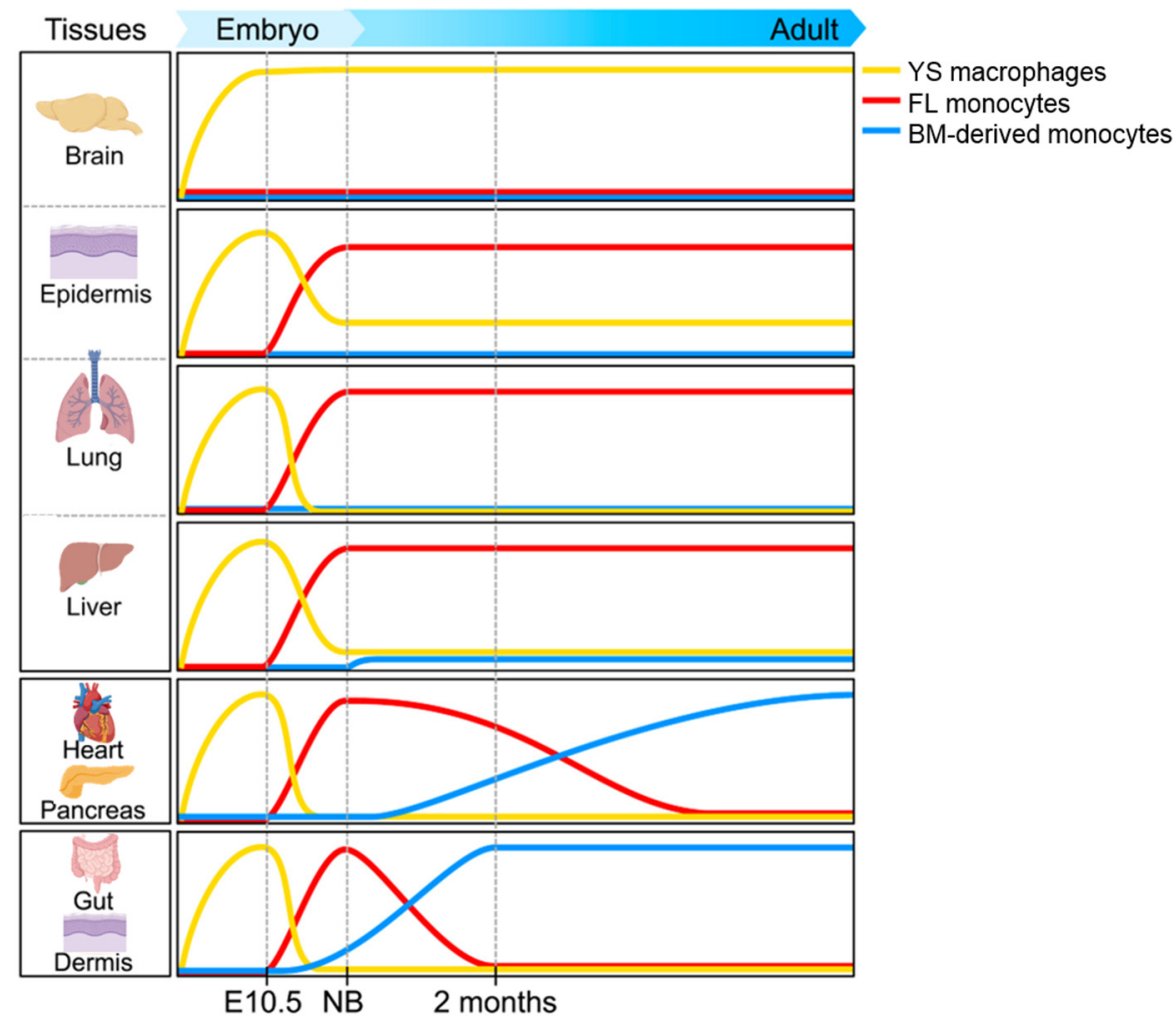

Figure 1. Heterogeneity of tissue resident macrophage (TRM) ontogeny in adult organs in steady state conditions. Some tissues harbor almost exclusively embryonic-derived macrophages, such as the brain, the epidermis, the lung and the liver. In every case, TRMs may arise only from yolk sac (YS) macrophages, as is the case for the microglia, from both YS macrophages and fetal liver (FL) (Langerhans cells in the epidermis), or mostly from FL monocytes (alveolar macrophages and Kupffer cells in the liver). In contrast, in other organs, bone marrow (BM)-derived monocytes are mobilized and replenish embryoderived macrophages with slow (heart and pancreas) or fast (gut and dermis) kinetics of replacement. $\mathrm{E}$ : embryonic stage; NB: newborn. Adapted from (4).

Over the past decades, macrophages have been thought to arise exclusively from circulating BM-derived monocytes undergoing macrophage differentiation when entering the tissues. This concept gave rise to the definition of the mononuclear phagocyte system (MPS) by 
van Furth and colleagues (5). Lately, a growing body of evidence has challenged this dogma and transformed our understanding of macrophage heterogeneity and origins (4, 6-12). In some organs, like the brain, epidermis, liver, kidney, and lung, yolk sac (YS) and/or fetal liver (FL) macrophage progenitors first seed the tissue during embryonic development and persist into adulthood through local proliferation, nearly independently of monocyte recruitment $(6,7,11,12)$. In contrast, intestinal or dermal macrophages are constantly replenished from blood monocyte precursors (Figure 1) $(10,13)$.

Macrophages possess an immense plasticity and modulate their phenotype in response to environmental changes $(3,14)$. In an attempt to understand macrophage function, Charlie Mills introduced the M1/M2 macrophage polarization paradigm in 2000 (15). It was built on the in vitro observation that macrophages from prototypical Th1 mouse strains (eg, C57BL/6) are easily activated to produce nitric oxide (NO) with either lipopolysaccharide (LPS) or interferon $\gamma$ (IFN $\gamma$ ), whereas the same trigger stimulates arginine metabolism to ornithine in macrophages from Th2 mouse strains (eg, BALB/c).

With time, this M1/M2 model was incorrectly fused with the concept of classical versus alternative macrophage activation, coined by Siamon Gordon (16). He showed that interleukin 4 (IL4), the typical Th2 cytokine, augments expression of the mannose receptor (MRC1) in macrophages without tumor necrosis factor $\alpha$ (TNF $\alpha$ ) production (16). This alternative activation of less inflammatory macrophages became synonymous with M2 macrophages. Therefore, nowadays M1-like macrophages are thought of pro-inflammatory cells activated in response to LPS or IFN $\gamma$, and depend on STAT1 to produce TNF $\alpha$, IL $1 \beta$, and nitric oxide synthase (NOS). In contrast, M2-like macrophages are frequently defined as IL4-stimulated cells that rely on STAT6 to produce arginase 1 (ARG1) and express augmented levels of MRC1 and YM1. Over the years, multiple cytokines and surface markers have been sorted into M1 or M2 markers, depending on its link to inflammatory processes (eg, CCR2, CCL2, IL6, TNF $\alpha$, and IL1 $\beta$ ) or to resolution of inflammation (eg, IL10, TGF $\beta 1$, VEGF, and MerTK), respectively (17).

Nevertheless, in vivo macrophage activation occurs as a continuum rather than as discrete entities, and thus M1/M2 classification is an oversimplified model to get over $(3,18,19)$. For instance, we have shown that post-injury cardiac macrophages exhibit overlapping activation of pro-inflammatory and anti-inflammatory programs, rather than aligning to canonical M1/M2 phenotypes (20). Therefore, we propose using the terms inflammatory versus reparative macrophages instead of M1 and M2 macrophages. 


\subsection{Tissue resident macrophages (TRMs): macrophage diversity in the body}

Metchnikoff described macrophages as phagocytic cells that protect the organism against pathogens. More recently, it has become clear that they populate all tissues and pursue organspecific functions (Figure 2) $(1,21,22)$. For example, macrophages contribute to electrical conduction in the heart (23), iron recycling in the spleen and liver (24), dendritic cell activation and maturation in the lung (25), thermogenesis regulation in adipose tissue (26), hematopoietic control in BM and spleen (27), generation of oral tolerance to dietary antigens in the gut (28), and synaptic pruning in the brain (29). These non-canonical activities highlight macrophage functional diversity and emphasize their ability to execute tissue-specific tasks beyond host defense.

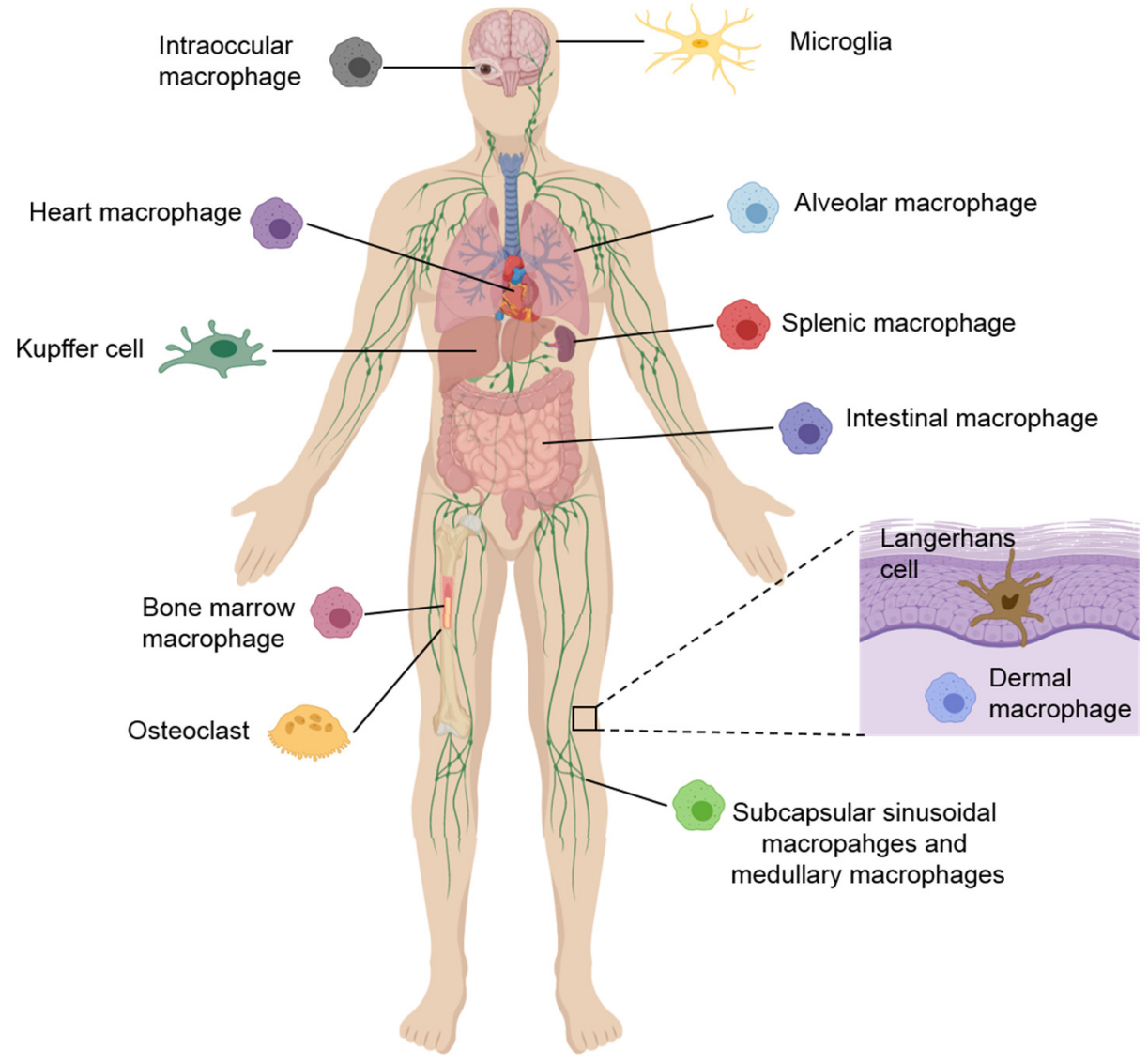

Figure 2. Tissue macrophage diversity in the body. Various populations of TRMs are strategically located throughout the body and perform important immune surveillance activities, including phagocytosis, antigen presentation and immune suppression, as well as tissue-specific functions, contributing to homeostasis. Adapted from (30).

\subsection{Cardiac macrophages: diversity and function}

Studies dating back to 1980 have proposed that the adult mammalian heart contains other cell populations than cardiomyocytes, including macrophages (31). However, thanks to the 
development of state-of-the-art tools to track macrophages (advanced flow cytometry, genetic fate mapping, parabiosis, and adoptive transfer techniques), we are now becoming conscious of the abundance, functional heterogeneity and diverse ontogeny of cardiac macrophages (8, 9, 32-34).

The healthy myocardium harbors macrophages, where they appear as spindle-like cells interspersed among myocytes, fibroblasts (FBs), and endothelial cells (ECs) $(32,35)$. They arise from precursors of embryonic origin and are maintained through local proliferation in homeostatic conditions (8). Embryo-derived macrophages persisted into adulthood, although they show declining self-renewal with age and are progressively replaced by blood monocyte derivedmacrophages (Figure 1) (36). All cardiac macrophages are CD45+CD11 b ${ }^{+} \mathrm{F} 4 / 80^{+} \mathrm{CD} 64^{+} \mathrm{MerTK}^{+}$ cells, but they differ in the expression of the surface markers CC-chemokine receptor (CCR2), major histocompatibility complex II (MHC-II), and lymphocyte antigen 6C (Ly6C). Embryo-derived cardiac macrophages are CCR2- cells, while circulating monocyte-derived macrophages are $\mathrm{CCR} 2^{+}$cells. Within the embryonic pool of macrophages, there are two major populations: MHCII high Ly6C ${ }^{\text {low }}$ cells and MHC-IllowLy6Clow cells. There is a third population of embryonic macrophages, which are Ly6C ${ }^{\text {high }}$ cells (8).

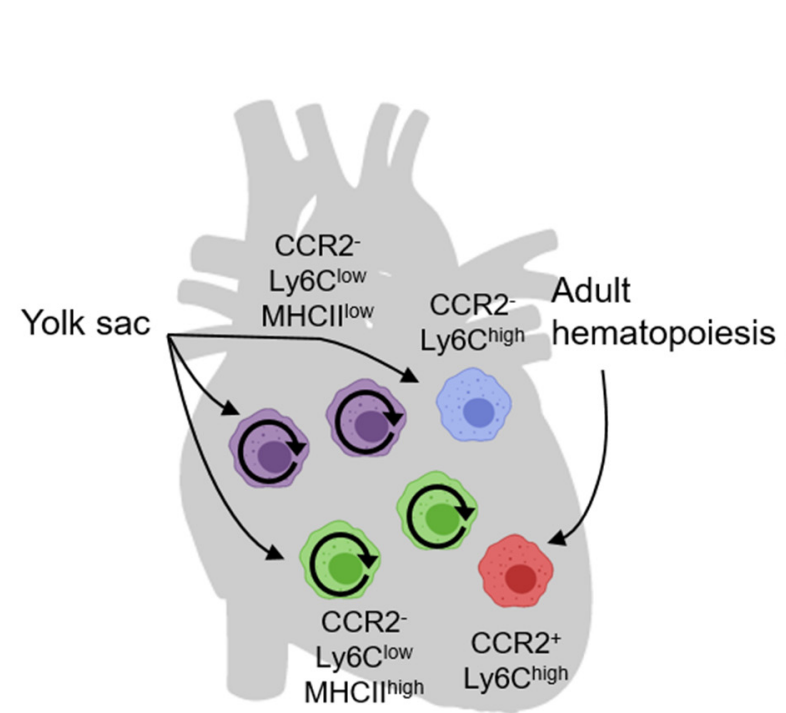

Homeostasis

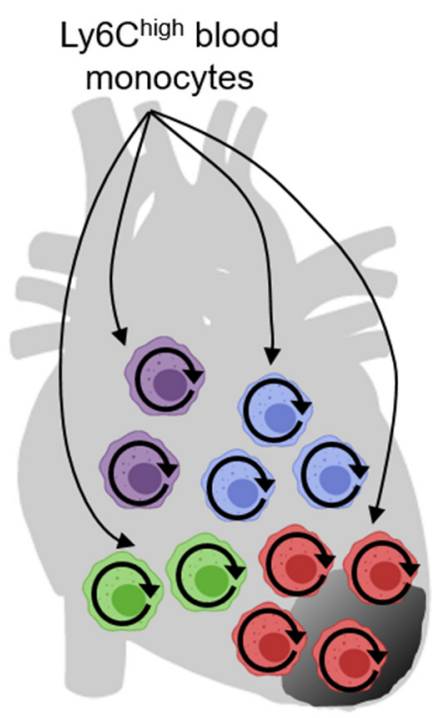

Stress

Figure 3. Diversity, origin and maintenance of cardiac macrophages in the adult heart. CRMs can be divided in two groups based on their origin (left). The first macrophage pool (CCR2 ${ }^{-}$) includes the majority of MHC-IIIigh (green), MHC-IIlow (purple), and Ly6C ${ }^{\text {high }}$ (blue) macrophages. These macrophages represent an embryonically established lineage from YS. The second macrophage pool is much smaller numerically and derives from blood CCR2 ${ }^{+}$Ly6 $\mathrm{C}^{\text {high }}$ monocytes (red). During cardiac stress (right), recruited Ly6C ${ }^{\text {high }}$ blood monocytes can differentiate into all cardiac macrophage subsets, which can subsequently expand and proliferate. Adapted from (38). 
Cardiac macrophages are maintained through distinct mechanisms at steady state and during inflammation (Figure 3). When cardiac inflammation occurs, for instance triggered by myocardial infarction (MI), blood monocytes rapidly replenished cardiac resident macrophages (CRMs) and they expand within the myocardium. Afterwards, in the post-MI chronic phase, macrophages residing in the heart regain independence from monocyte pool, thanks to local proliferation, and return to the steady-state situation $(8,35,37)$.

A very recent study has proved that the human myocardium also contains separate subsets of CCR2- and $\mathrm{CCR}^{+}$macrophages, which are functionally analogous to healing CCR2and inflammatory $\mathrm{CCR} 2^{+}$macrophages in the mouse heart. In parallel to mouse scenario, human CCR2- macrophages are maintained through local proliferation, while CCR2 ${ }^{+}$macrophages are replaced by monocyte recruitment and subsequent proliferation (9).

In the past years, growing evidence supports that CRMs make seminal contribution to cardiac development, composition and function. They participate in essential housekeeping functions, ranging from immune surveillance to extracellular matrix (ECM) and cell turnover, as well as the removal of material shed by local cells (39-41). In addition to these typical macrophage activities, it has been shown that CRMs abound in the mouse and human atrioventricular nodes, where they couple to cardiomyocytes via connexin-43 and facilitate electrical conduction (23). Furthermore, YS-derived CCR2- macrophages, but not monocyte-derived CCR2+ macrophages, contribute to coronary development through the remodeling of the primitive coronary plexus (42). Our laboratory found that CRMs highly express the lymphatic vessel endothelial hyaluronan receptor 1 (LYVE1), supporting the role of these immune cells in blood vessel development in the heart (20).

Transcriptional analysis of in vivo cardiac macrophages carried out in our laboratory revealed that CRMs exhibited enrichment of cardiac development-associated genes and elevated retinoid signaling (Rxra, Rarb, Rarg) (20), a crucial pathway in cardiac development (43). Moreover, the downregulation of miRNAs suppressing heart development process in CRMs (mmu-miR-1a, mmu-miR-126a, and mmu-miR-342-5p) allows the expression of genes related to this process and to cardiac muscle contraction, further supporting the role of macrophages in this processes (20). Macrophages are also critical mediators of cardiac regeneration in mouse neonatal heart. This heart harbors macrophages that generate minimal inflammation and promote complete post-infarction cardiac recovery through neovascularization $(44,45)$. 


\subsection{Macrophages in myocardial infarction (MI)}

Although the mortality rate from cardiovascular disease (CVD) has declined over the last 50 years, MI continues to be one of the most lethal diseases worldwide, and many pathologies arise from insufficient repair of cardiac injury (eg, heart failure and cardiac rupture) $(46,47)$. Therefore, new strategies are urgently needed to promote cardiac healing and function after MI.

$\mathrm{Ml}$ is usually provoked by plaque rupture in a coronary artery, resulting in insufficient oxygen supply to the myocardium, which undergoes necrosis. The onset of MI triggers a cascade of events, including cardiomyocyte death, acute inflammation, angiogenesis, and scar formation $(48,49)$. Ischemic injury mobilizes a diverse repertoire of innate and adaptive immune cells, which can either propagate or defend against disease (50). Neutrophils are the first innate immune cells to reach the injured myocardium and they peak within the first day after the ischemic event (51). However, macrophages outpace neutrophils within the first 30 minutes after the onset of ischemia (52) and they are recruited at high levels during the first two weeks after infarction (35). Other leukocytes invading the infarct are dendritic cells (53), lymphocytes (54) and mast cells (55), but in a less extent than neutrophils and macrophages do.

Cardiac healing is impaired by both excessive and insufficient expansion of macrophages, prompting interest in the potential of these cells as therapeutic targets for CVD $(34,51,56,57)$. Nonetheless, the exact macrophage phenotypes and mechanisms that might enhance tissue repair are not clearly defined. We and others have shown that post-injury macrophages are distinct from resident cardiac macrophages (20,37). Monocytes and macrophages are sequentially mobilized from BM and spleen to the infarcted myocardium in two phases (Figure 4) $(51,58,59)$. During day 1 to day 4 after injury, Ly6C ${ }^{\text {high }}$ inflammatory macrophages clear necrotic cellular debris and damaged extracellular matrix (ECM) from the tissue and attract other immune cells through the secretion of pro-inflammatory cytokines (TNFa, IL1 1 , and IL6) that further fuel inflammation. The phagocytosis of cellular and ECM debris is fundamental for replacing the injured tissue with granulation tissue in the later healing phase $(51,60)$. Though, an excessive inflammatory response can be harmful due to the release of cytotoxic mediators $(61,62)$. Over the course of several days, the inflammatory phase gives way to a healing phase, dominated by a second wave of macrophages, this time Ly6Clow reparative macrophages with the capacity to dampen inflammation and promote ECM reconstruction and angiogenesis $(20,51,60)$. These latter macrophages are characterized by the secretion of anti-inflammatory (IL10), angiogenic (VEGF) and pro-fibrotic (TGF $\beta 1$ ) factors, as well as matrix metalloproteinases (MMPs), which promote tissue remodeling $(51,60,63)$. However, how these factors produced by macrophages crosstalk with other cell types and orchestrate cardiac repair is still not-fully elucidated. 

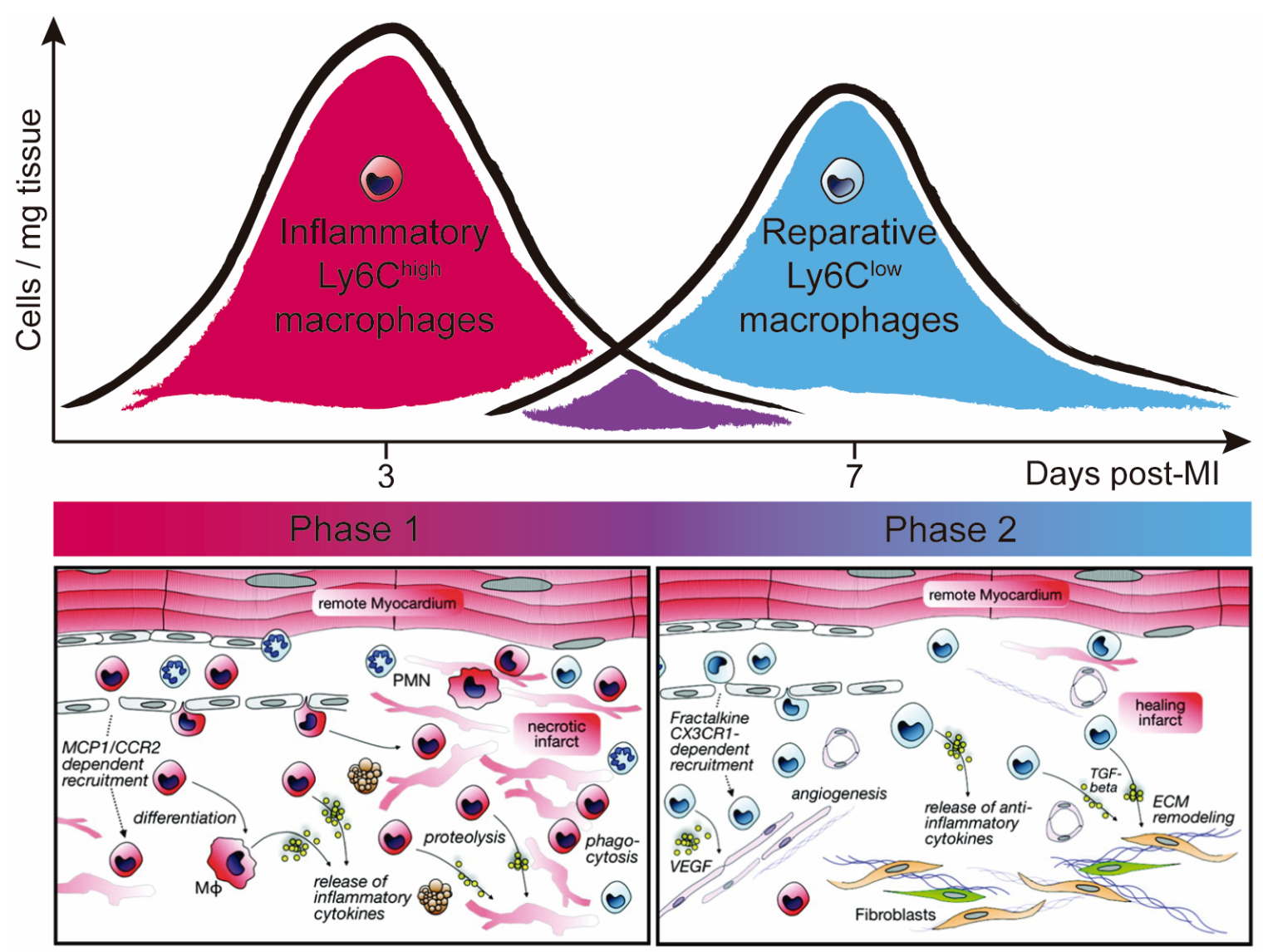

Figure 4. Biphasic macrophage response after myocardial infarction. Time course of Ly6Chigh and Ly6 $\mathrm{C}^{\text {low }}$ macrophage subset infiltration and their functions in the inflammatory and the reparative phases. PMN: polymorphonuclear neutrophil; M $\phi$ : macrophage. Adapted from (64).

In the last few years, macrophages have emerged as therapeutic targets for CVD. It has been reported that hematopoietic stem cells lacking TET2 exhibited clonal expansion, which led to increased monocyte recruitment to atherosclerotic plaques or injured myocardium, where they differentiate to IL1 $\beta$-producing macrophages and accelerate atherosclerosis progression or heart failure, respectively $(61,62)$. Thus, excessive monocyte mobilization to the tissue associates with adverse outcomes in CVD. Accordingly, a very recent and promising clinical trial (the CANTOS) applied an anti-inflammatory therapy targeting the IL $1 \beta$ pathway in patients with atherosclerosis that mitigated the incidence of cardiovascular events (65). However, therapeutic options are not that simple and do not limit to blocking monocyte and macrophage intervention. As previously mentioned, macrophages are critical for early postnatal heart regeneration and for cardiac repair in the adult mouse $(45,66)$, and therefore either excessive or insufficient post-Ml expansion in macrophage numbers have been linked to pathology $(37,45,51,56,57,67)$. Hence, macrophages can play both protective and deleterious roles, suggesting that appropriated cell recruitment and timely controlled transition from pro-inflammatory towards reparative phenotype are essential for correct healing (68). 
The transition from a pro-inflammatory towards an anti-inflammatory phenotype in postinjury macrophages is orchestrated by distinct mechanisms. First, intrinsic signals, such as the nuclear receptor NR4A1, helped macrophages to dampen IL6 and TNF $\alpha$ production, and to switch to the release of anti-inflammatory mediators (60). Furthermore, simulated dynamics and experimental validation of a regulatory core of the underlying gene-regulatory network in postinjury macrophages revealed a negative-feedback loop that limits initial inflammation via hypoxiamediated upregulation of IL10 (20). Our laboratory has also highlighted the prominence of posttranscriptional regulation (miRNAs, mRNA decay, and lincRNAs) in attenuating the myocardial injury-induced inflammatory response in macrophages (20).

In addition, angiogenesis is an essential mechanism in post-MI regeneration and repair, where myeloid and endothelial cell crosstalk seems to be especially important to develop the new vasculature (Figure 5) $(45,69,70)$. Indeed, depletion of cardiac macrophages following cryoinjury results in reduction of VEGF production and capillary density (57). Therefore, a detailed analysis of the microvasculature-macrophage interaction in the damaged heart is required for a complete understanding of cardiac functional recovery.

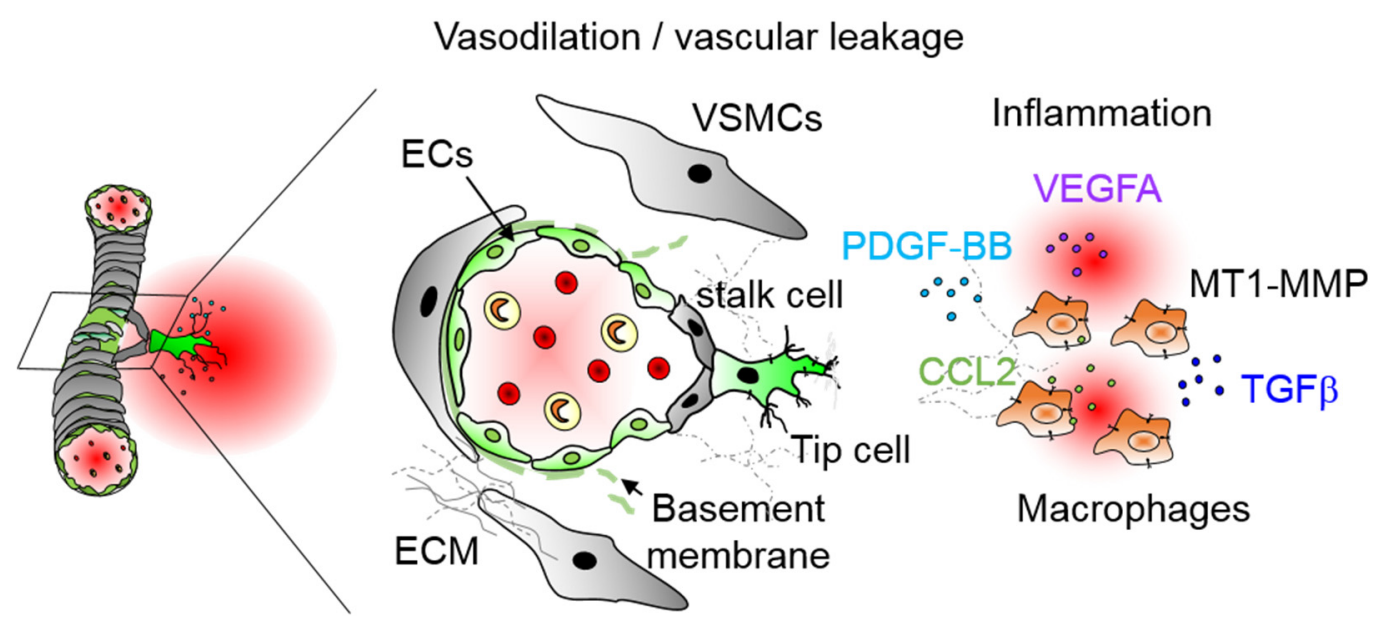

Figure 5. Macrophage-mediated angiogenesis following myocardial infarction. Inflammatory situations, such us $\mathrm{MI}$, result in CCR2/CCL2-dependant monocyte recruitment and macrophage differentiation. These macrophages produce MT1-MMP and diverse growth factors (eg, VEGFA, PDGF-BB, and TGF $\beta$ ) that act over ECs and vascular smooth muscle cells (VSMCs), regulating angiogenesis and vascular stabilization.

Among the plethora of functions executed by macrophages in cardiac healing, they contribute to ECM remodeling through MMP production (71-73), including matrix type 1 metalloproteinase (MT1-MMP/Mmp14), as well as to FB activation by secreting TGF $\beta 1$ (60). Consequently, FBs get activated into myofibroblasts (MyoFBs), which are the major cell contributors to collagen deposition and to the emerging fibrotic scar in order to contain the lesion 
following MI (Figure 6) (74-76). Impaired collagen deposition or accelerated degradation of ECM, largely attributable to high MMP activity, can result in adverse cardiac remodeling and consequent heart failure or cardiac rupture (Figure 7) (77). Thus, mechanistic insight into macrophagemediated left ventricular (LV) remodeling and interplay with FBs and MyoFBs is critical for understanding cardiac repair and developing new therapeutic strategies for MI patients.

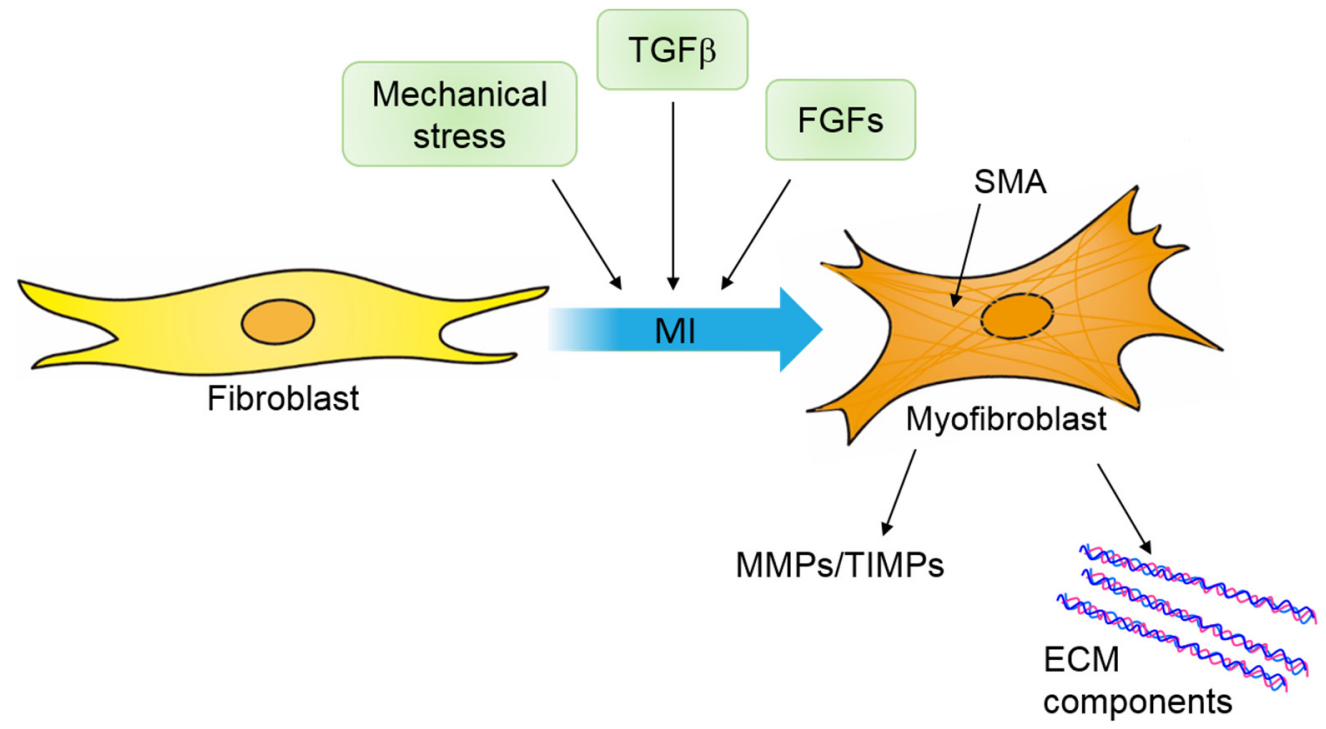

Figure 6. Phenotypic modulation and activation of fibroblasts into myofibroblasts during the reparative phase after MI. Mechanical stress due to ECM degradation and stiffness, and TGF $\beta$ and FGF signaling induce MyoFB transdifferentiation. MyoFBs actively contribute to cardiac healing by secreting MMPs, tissue inhibitors of MMPs (TIMPs) and ECM components, such as collagen, and they express smooth muscle actin (SMA). Adapted from (78).

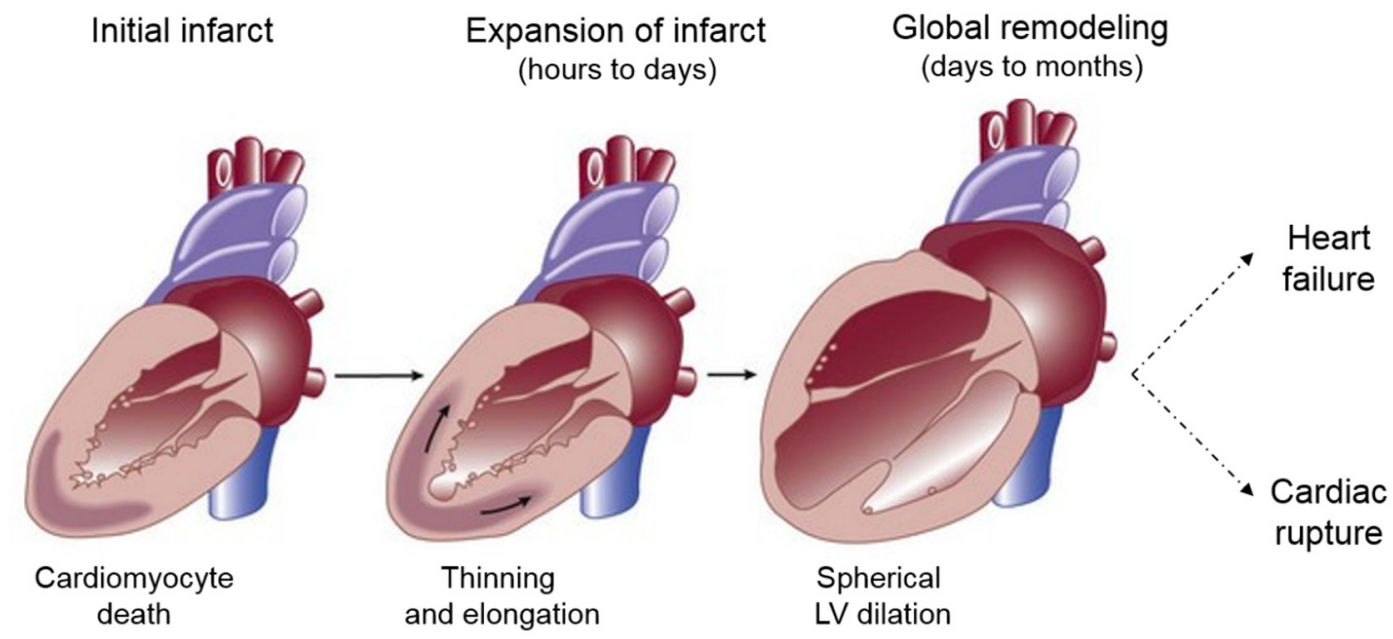

Figure 7. Left ventricular remodeling following myocardial infarction. The early phase is characterized by thinning and elongation of the fibrous scar within the infarcted zone. Subsequent LV dilation, with transition from an elliptical to a more spherical configuration, compromises cardiac contractile properties leading to LV dysfunction, eventually leading to heart failure or cardiac rupture. Adapted from (79). 


\section{Membrane type 1-matrix metalloproteinase (MT1-MMP)}

Tissue remodeling after $\mathrm{MI}$ involves the action of $\operatorname{MMPs}(72,77,80-84)$. MMPs are a large family of highly homologous zinc-dependent endopeptidases which have been traditionally associated with the degradation and turnover of ECM components (85). MMPs are now known to directly and indirectly regulate cell behavior and microenvironment through the proteolytic processing of a large variety of molecules, such as membrane receptors and growth factors (86).

Membrane-type matrix metalloproteinases (MT-MMPs) form a subgroup of the MMP family, and they are further classified into type I transmembrane-type (MT1-, MT2-, MT3- and MT5MMPs) and glycosylphosphatidylinositol (GPI)-anchored type (MT4- and MT6-MMPs). In either case MT-MMPs are tethered to the plasma membrane, and the cell surface location provides those enzymes with exclusive functions affecting cellular behavior (87).

\subsection{MT1-MMP structure and activity}

MT1-MMP (Mmp14) was the first membrane-anchored MMP to be described (88). It is a protein composed by 582 aminoacids with a structure similar to the rest of the members of the MMP family. It presents six different domains $(88,89)$ (Figure 8):

1. Propeptide domain (M1-R111): maintains the enzyme in its latent form while occupies the catalytic site, where a cysteine sulphydryl group interacts with the zinc ion in the active site. MT1-MMP has a furin recognition motif inserted between the propeptide and the catalytic domain.

2. Catalytic domain (Y112-G285): consists of five stranded $\beta$-sheets and three $\alpha$-helices that form a spherical pocket. This structure is highly conserved among MMP members.

3. Hinge region or linker peptide (E286-I318): is a flexible proline-rich linker region that facilitates MT1-MMP association with the substrates via its glycosylated sites. It enables appropriate orientation of both the catalytic and hemopexin domains.

4. Hemopexin domain (C319-C508): is folded into a large, four blade-shaped $\beta$ sheet. It mediates protein-protein interactions that regulate activation, localization, internalization and degradation of the MMP $(90,91)$.

5. Transmembrane domain (A539-F562): anchors MT1-MMP to the cell membrane such that the C-terminal domain extends into the cytoplasm.

6. Cytoplasmic tail (R563-V582): is critically involved in trafficking of MT1-MMP to discrete regions of the plasma membrane and in communicating with putative intracellular components $(92,93)$. 
In addition to these domains, MT1-MMP is synthetized with a signal peptide involved in trafficking the MMP through the secretory pathway to the cell surface (85).

Signal peptide

Propeptide

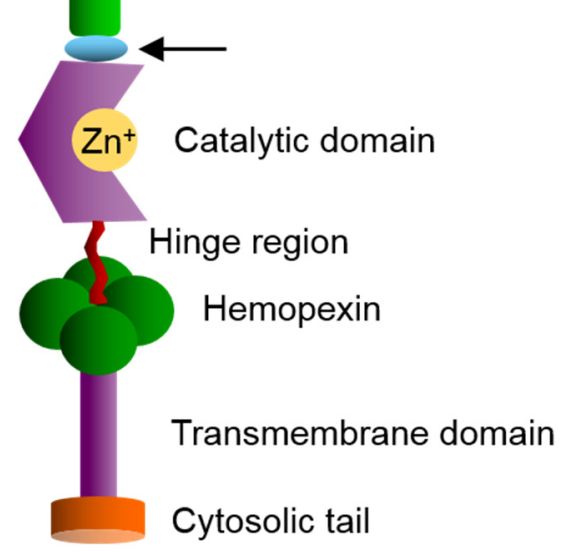

Figure 8. Multidomain structure of MT1-MMP. Arrow indicates the furin recognition motif. Adapted from (94).

All MMPs are synthesized as latent forms or zymogens that need to be catalytically activated. Such activation requires the elimination of the propeptide domain (85), and can occur either during secretion by proprotein convertases, such as furin (95), or outside the cell, where the propetide can be cleaved by other MMPs, serine proteases or plasmin, among others $(88,96)$. The latter is the case of pro-MMP2, activated by MT1-MMP on the cell surface. While pro-MT1-MMP is intracellularly activated by a furin endopeptidase $(97,98)$.

MT1-MMP activity is regulated at multiple levels, including mRNA expression, activation of the latent zymogen to the active form, and the counteracting actions of endogenous tissue inhibitors of MMPs (TIMPs) (eg, TIMP2).

\section{a) Transcriptional regulation:}

MT1-MMP expression can be influenced by transcription factors (eg, EGR1, KLF6, PROX1) (99-101), and cytokines, (eg, IL1 $\beta$, IL8, TNF $\alpha$, GM-CSF, FGFb, VEGF, TGF $\beta$, CCL2) (102-107). MT1-MMP expression also increases during the inflammatory process, being secreted by pro-inflammatory cells responding to pro-inflammatory cytokines (eg, TNF $\alpha, \mathrm{CCL} 2)$ and LPS $(102,103)$.

\section{b) Post-translational regulation:}

Proteolytic cleavage: MT1-MMP is synthesized as pre-pro-MT1-MMP, from which the signal peptide is removed in the endoplasmic reticulum to generate pro-MT1-MMP. MT1-MMP has a furin-like pro-protein convertase recognition sequence at the C-terminus of the prodomain and is first intracellularly activated by the furin endopeptidase family, and then proceeds to the cell surface where it can cleave and activate other pro-MMPs (eg, MMP2) $(97,98)$.

Inhibitors: TIMPs are essential for the formation of non-inhibitory pro-MMP/TIMP/MT-MMP complexes (eg, pro-MMP2/TIMP2/MT1-MMP). Increased MMP expression/activity or decreased TIMPs could lead to MMP/TIMP imbalance and results in various pathological conditions, most notably heart failure, osteoarthritis and cancer (108-110). 
Subcellular localization: the formation of MT1-MMP complexes with other proteins in different membrane domains (caveolae in lamellipodia and filopodia, podosomes, and focal adhesions) regulates MT1-MMP activity and accessibility to the substrates (94, 111-116). MT1-MMP has also been identified in extracellular vesicles (ECVs) and exosomes produced by ECs and tumor cells $(117,118)$.

Internalization: Catalytic activity of MT1-MMP is retained via its internalization from, and subsequent recycling to, the plasma membrane. These intricate trafficking and recycling routes are regulated via sequential post-translational modifications on the residues Tyr573, Cys574, and Lys581, located at the C-terminal end of the cytoplasmic domain (119).

Dimerization: MT1-MMP dimerization through the Cys546 within the hemopexin domain and the transmembrane domain increases its proteolytic activity, for example activating pro-MMP2 (120).

\section{$2.2 \quad$ MT1-MMP substrates}

Historically, MMPs were thought to function mainly as enzymes that degrade structural components of the ECM, and they have been traditionally classified on the basis of their substrates in collagenases, gelatinases, stromelysins and matrilysins (121). However, MMP proteolysis can create substrate-cleavage fragments with independent biological activity, and activate, deactivate or modify signaling molecules. Consequently, MMP functions are not only limited to degradation of structural components, but also to regulation of cell microenvironment, impacting in cell behavior and signaling pathways depending on the specific substrate cleavage (86).

Among MT-MMPs, MT1-MMP has the widest range of substrates. Many of these substrates were identified by incubating recombinant soluble MT1-MMP with potential substrate in a test tube, whereas others were identified in cell culture systems and by proteomics approaches (106). MT1-MMP substrates include ECM components, such as collagen I, II, and III, laminins 1, 2, 4, and 5, nidogen, TSP1, and Cyr61 (106, 122-127). Collagens are the most abundant ECM element and act as a major structural component and barrier matrix in tissues. The

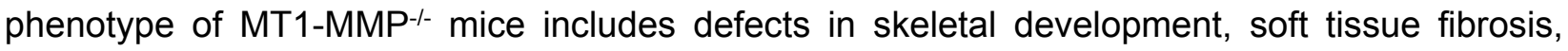
angiogenesis, submandibular gland development and lung development (128-130). It is thought that many of those phenotypes arise from a lack of cellular collagenase activity (128).

MT1-MMP is also capable of cleaving other MMPs and unrelated proteases (pro-MMP2, pro-MMP8, pro-MMP13, and ADAM9) on the cell surface (88, 131-133). Therefore, while MT1MMP cannot degrade type IV collagen, a major component of basement membrane (122), activated MMP2 can do it. Indeed, it has been proved that MT1-MMP/MMP2-mediated basement membrane degradation plays a role in growth of epithelial cancers in vivo (134). 
MT1-MMP also promotes the shedding of cell adhesion molecules, such as CD44, E- and $\mathrm{N}$-cadherins, integrin $\alpha \mathrm{V}$, EMMPRIN, and Syndecan 1, favoring cell migration (135-139). In monocytes, MT1-MMP interacts with intracellular adhesion molecule-1 (ICAM1) through the cytoplasmic tail of ICAM1 and results in ectodomain cleavage of the protein, facilitating monocyte transmigration (140). Similarly, MT1-MMP has been also shown to cleave LYVE1 on the surface of lymphatic ECs (141). MT1-MMP may exert its proteolytic activity not only at the cell surface, but also over intracellular proteins such as pericentrin, and focal adhesion kinase (FAK) $(142,143)$.

Different chemokines and cytokines (pro-TGF $\beta$, pro-TNF $\alpha$, SDF1, CCL7, IL8) are evidenced substrates of MT1-MMP (144-147). In fact, a key role of MT1-MMP is to mobilize growth factors through cleavage and release of the bioactive form. This is the case of transforming growth factor $\beta$ (TGF $\beta$ ), which forms an inactive extracellular complex consisting of TGF $\beta$ and latency associated peptide (LAP), and several mechanisms, including MT1-MMP-mediated proteolysis, have been proposed to release the active cytokine from this complex $(144,148-152)$.

\subsection{MT1-MMP expression in tissues and cellular populations}

MT1-MMP was originally discovered and characterized as a cell surface pro-MMP2 activator expressed in invasive cancer cells (88). Nevertheless, this enzyme has a ubiquitous tissue distribution and it has been reported to be expressed in vascular (153) and connective tissues $(128,129,154,155)$, brain (156), heart (157-159), lung (130), kidney (160), uterus, ovary, placenta, prostate, spleen, and intestine (161).

Besides, MT1-MMP is produced by many different cell types, including mesenchymal stem cells (162), FBs (157-159), osteoblasts (154), osteoclasts (163), chondrocytes (155), epithelial cells (160), ECs $(106,126)$, adipocytes (164), neuronal cells (156), T-cells (165), B-cells (166), platelets (167), cardiomyocytes $(157,159)$, MyoFBs (157), and VSMCs $(168,169)$. MT1-MMP is also expressed in macrophages mainly regulating cellular processes unrelated to its collagenase activity (170-172).

\subsection{MT1-MMP physiological functions}

MT1-MMP causes degradation of ECM proteins such as collagen, gelatin and fibrin, but may also affect bioactive molecules on the cell surface (pro-MMP2, pro-TGF $\beta 1$, LYVE1, CD44, integrins $\alpha v$ ), controlling various cellular and signaling pathways. In addition to its proteolytic activities, MT1-MMP can also modulate intracellular responses through molecular interactions of its cytosolic tail leading to induction of signaling pathways such as ERK (173). In this sense, MT1MMP plays a role in many biological processes including cell proliferation, migration, and 
differentiation, apoptosis, tissue invasion (174) and vascularization during numerous physiological processes such as angiogenesis (126), lymphangiogenesis (141), embryogenesis, morphogenesis $(160,174)$, skeletal development $(128)$, immune response $(170,175)$ and wound healing $(176,177)$.

MT1-MMP is essential for pericellular collagenolysis and modeling of skeletal and extraskeletal connective tissues during development (123). Thus, MT1-MMP-/- mice suffered from osteopenia, ankylosis, and progressive fibrosis of soft tissues, due to inadequate collagen turnover, and premature death $(128,129)$. Moreover, MT1-MMP plays a pivotal role in lung organogenesis, since MT1-MMP-/- mice present impaired alveolization, the final process of lung development (130).

Furthermore, as MT1-MMP-deficient mice also exhibit aberrant angiogenic processes, MT1-MMP is identified as a crucial regulator of blood vessel growth $(126,178,179)$. MT1-MMP is selectively expressed at the tip of growing vessels where ECM degradation is required (180). The role of MT1-MMP during angiogenesis is likely to be promoting invasion of ECs by degrading ECM components, especially fibrillar collagens and fibrin, in the vascular basement membrane, and tubulogenesis $(126,178,179)$.

In addition, MT1-MMP is a key protease for angiogenesis in inflammatory contexts (Figure 5). The recently identified MT1-MMP degradome shows a combinatorial MT1-MMP proteolytic program in endothelial tip-like cells during inflammatory angiogenesis (106). Furthermore, MT1MMP is expressed in monocyte/macrophage cells and it regulates their morphology, motility and fusion behavior (171). This might be relevant to the proposed role for myeloid cells in promoting angiogenic branching $(181,182)$ and anastomosis by acting as vascular fusion cells $(69)$. Besides, MT1-MMP regulates vessel wall architecture in vivo. MT1-MMP interacts with PDGFR $\beta$, directing the migration and proliferation of VSMCs, which results in mural cell investment and vascular stabilization $(183,184)$. Moreover, MT1-MMP plays a dual role as endogenous repressor of lymphatic vessel growth. First, MT1-MMP directly cleaves LYVE1 on lymphatic ECs to inhibit LYVE1-mediated lymphangiogenic responses. Second, MT1-MMP-mediated phosphoinositide 3kinase $\delta(\mathrm{PI} 3 \mathrm{~K} \delta)$ signaling restrains the production of VEGFC from macrophages through repressing the activation of NF-кB signaling (141).

It was also reported that MT1-MMP modulates inflammatory responses of macrophages in a proteolytic-independent fashion. MT1-MMP translocates to the nucleus and triggers the expression of PI3K $\delta$, which turns in activation of Akt/GSK3b signaling cascade. Accordingly, MT1MMP-dependent $\mathrm{PI} 3 \mathrm{~K} \delta$ activation controls the immunoregulatory Mi-2/NuRD nucleosome remodeling complex that is responsible for limiting the transcription of genes involved in the 
immune response (172). Additionally, PI3K $\delta$ activation also reduces inflammation via suppression of nuclear translocation of NF-kB protein in macrophages (141).

MT1-MMP plays a crucial role in the maintenance of the normal balance between ECM synthesis and degradation in tissues. Besides, remodeling of the ECM is of particular importance in wound healing and tissue repair. Following skeletal muscle injury, MT1-MMP activity increases and is paramount for skeletal muscle regeneration (177), which requires satellite cell activation, migration, and fusion. Cleavage of laminin-2 and -4 by MT1-MMP is of particular relevance for matrix invasion as these laminin isoforms are found in the basal lamina surrounding myofibers $(123,185)$. Moreover, CD44, a substrate of MT1-MMP, is also known to be a critical regulator of both myoblast migration and differentiation $(135,186)$. Furthermore, independently of catalytic activity, MT1-MMP increases localization of RAC1 to the membranes, which turns into an increase in membrane protrusive activity, cell elongation and thus would facilitate cell fusion (171).

Skin wound healing also depends on cell migration and ECM remodeling, and MT1-MMP participates in both processes. MT1-MMP activates pro-gelatinase A at the stromal cell surface and contributes to the restoration of the connective tissue (176). In addition, studies using a macrophage-specific MT1-MMP knock out mice have demonstrated the role of transendothelial migration of monocytes and T-cell attraction in dermatitis (187). Interestingly, this protease has been implicated in epithelial- and endothelial- to mesenchymal transition (EndMT and EMT, respectively) in development, cancer, and lung fibrosis providing the resultant cells with an invasive phenotype $(149,152,188,189)$.

\subsection{MT1-MMP function in pathology}

If MT1-MMP production and activity are not properly balanced, the protease could also contribute to harmful pathological conditions such as adverse remodeling in $\mathrm{Ml}(80,110$, 190, 191), atherosclerosis (169, 192), cancer and metastasis (175, 193-195), aneurysm formation (196), fibrotic and vascular disorders (197), lung inflammatory diseases, tissue damage (198), obesity (164), and rheumatoid arthritis (199).

Importantly, high levels of MT1-MMP often correlated with poor prognosis in human patients (200-202). As a consequence, MT1-MMP has been proposed as biomarker for numerous pathological conditions and is being examined as potential therapeutic target in various cardiovascular and musculoskeletal disorders as well as cancer (203-205). Different therapies targeting MMP activity have attempted to limit the detrimental influence of these proteases in disease. Yet, these therapies failed due to the incomplete knowledge about MMP substrates and functions and the lack of a MMP-type specific inhibitor $(206,207)$. The complexity of MT1-MMP 
physiological and pathological functions derives from its multidomain structure, diverse substrate repertoire, interacting proteins and co-factors, and their differential cell and tissue expression, among other processes (86). However, a recent study targeting MT1-MMP with a blocking antibody in Influenza-infected mice showed promising results ameliorating tissue damage and mortality (198).

Following the report of elevated levels of MT1-MMP in patients with cardiomyopathy (158, $159,208)$, different studies attempted to investigate the role of this protease in CVD $(80,110,190$, 191). These studies pointed out a deleterious effect of MT1-MMP in post-MI cardiac remodeling, mostly related to its collagenase activity in FBs, leading to reduced LV function and decreased survival $(80,190)$. Besides FBs, MT1-MMP is produced by other cardiac cell types, such as macrophages, ECs, and VSMCs $(106,157,158,169,171,209)$. Although myeloid MT1-MMP is implicated on detrimental tissue remodeling in other pathological contexts (198), the effects of MT1-MMP in macrophages in the context of MI have been disregarded over years. In this study, we aim to decipher the specific role of macrophage-derived MT1-MMP in post-MI cardiac remodeling to provide critical insight into developing more accurate therapeutic strategies to enhance cardiac repair.

\section{Endothelial to Mesenchymal Transition (EndMT) in MI}

EndMT is a special type of cellular transdifferentiation, in which ECs lose their specific phenotype and progressively acquire mesenchymal features, including a spindle-shaped cell morphology, loss of cell-to-cell junctions and polarity, and the acquisition of cellular motility, contractility and invasiveness. At the molecular level, EndMT results in the downregulation of hallmark EC markers (eg, CD31, KDR, TIE1, TIE2, CDH5, von Willebrand factor, and collagen IV) and initiation of production of mesenchymal cell specific proteins including $\alpha$ SMA, SM22 $\alpha, F S P 1$, vimentin, fibronectin, and collagen I/III (Figure 9) (210-212).

Recent studies have identified the essential role of EndMT in the cardiovascular system, where contributes to cardiac valve formation and septation $(213,214)$ and vascular development (215) in embryogenic stages, as well as the pathogenesis of diverse CVDs, such as congenital heart disease $(216,217)$, atherosclerosis $(218)$, myocardial fibrosis (219), and MI (220).

Regarding the regulatory mechanisms, TGF $\beta$ is considered the master mediator of EndMT, and the three isoforms (TGF $\beta 1$, TGF $\beta 2$, and TGF $\beta 3$ ) are implicated $(210,211,219)$. Several BMPs and their receptors (BMPRs) are also required for EndMT, contributing to valve formation and cardiac septation $(221,222)$. Moreover, NOTCH receptors and ligands are expressed in the endocardium at the onset of EndMT and are relevant to valve development (217). Furthermore, a 
very recent study has shown that in the reparative phase after $\mathrm{MI}$, the classical $\mathrm{Wnt} / \beta$-catenin pathway is activated to induce the transition of ECs into FBs and smooth muscle cells and promote angiogenesis (220). All these pathways converge and induce the expression of transcription factors, such as SNAIL, SLUG and TWIST, which mediate EndMT (210) (Figure 9).

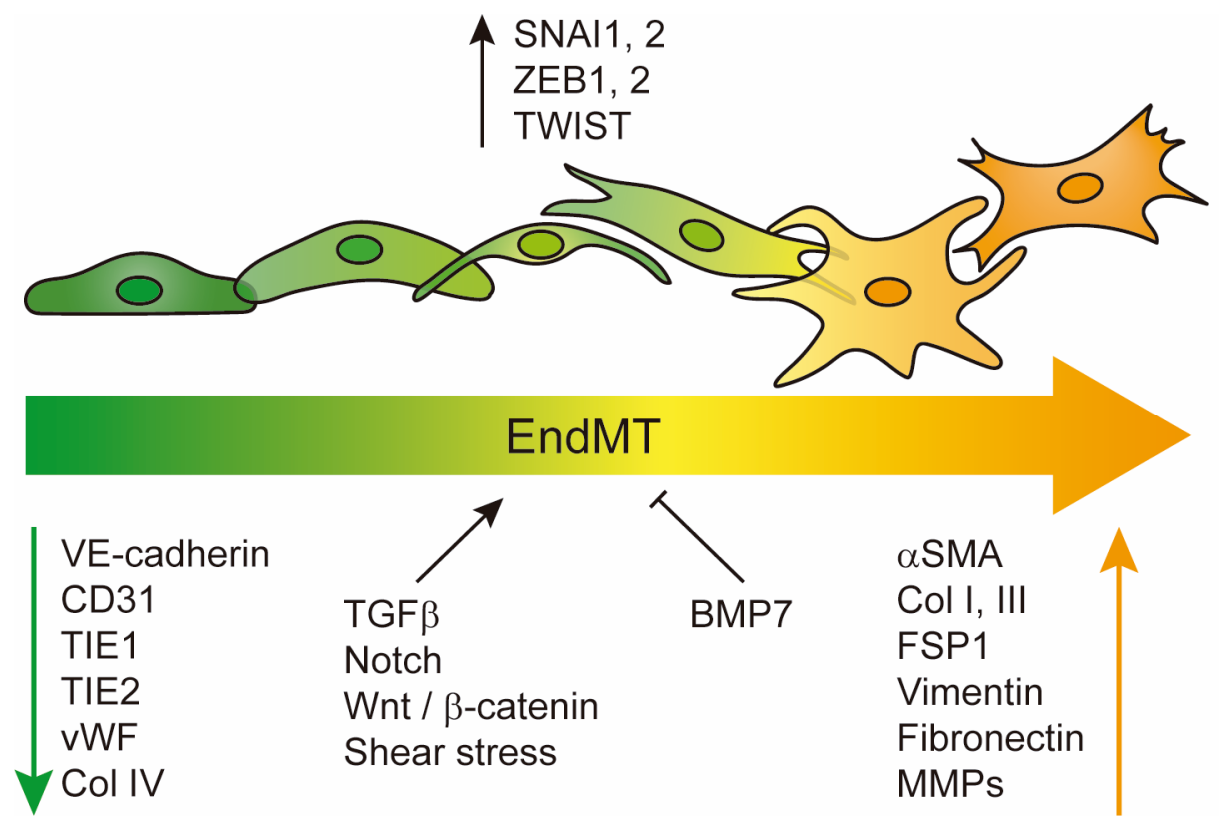

Figure 9. Endothelial to mesenchymal transition. ECs form a monolayer with expression of hallmark proteins such as VE-cadherin, CD31, TIE1, TIE2, and von Willebrand factor (VWF). EndMT is induced by diverse stimuli, including TGF $\beta$ proteins, Notch signaling, canonical Wnt pathway, and shear stress. EndMT is modulated by the transient expression of EndMT transcriptional factors such as SNAI1, SNAI2, ZEB1, ZEB2, and TWIST, which are involved in repressing endothelial proteins and activating the expression of mesenchymal-related genes. Mesenchymal-like cells derived from EndMT lose the cell-tocell junctions, acquire migratory and invasive capacities, and express mesenchymal markers such as alpha-smooth muscle actin (aSMA), Collagens I and III, vimentin, fibronectin, fibroblast specific protein 1 (FSP1) and MMPs. The process may be inhibited via bone morphogenetic protein 7 (BMP7) . Adapted from (212).

A recently emerged report in atherosclerosis pointed to macrophages as partial inducers of EndMT, as they enhance mesenchymal marker expression in ECs during in vitro co-culture (223). Therefore, a reevaluation of macrophage functions in cardiac repair is required in order to interrogate EndMT-related processes.

\section{Models of sterile tissue injury: cryoinjury and LAD-ligation}

Many CVDs, MI among them, have been recognized as inflammatory conditions characterized by the infiltration of monocytes and later macrophage differentiation to promote localized inflammation (51). Then, it is clear that macrophage biology must be comprehensively 
understood to appreciate the role of these cells in the onset of cardiac injury and subsequent repair.

If the healthy myocardium contains immune cell populations $(8,9,32)$, why mammalian hearts are so prone to perturbed immune responses that lead to detrimental inflammation and scarring upon injury? Clues can be obtained from the central role played by macrophages in the resolution of cardiac injury in different scenarios. In other words, the evaluation of alternative models of cardiac damage is highly appreciated to elucidate the shared mechanisms from those alternatively activated pathways in macrophages during repair. Hence, we propose to explore cardiac healing response from macrophage perspective in either cryoinjury or LAD-ligation, which are two well established models of sterile tissue injury. On the one hand, cryoinjury is an extended wound healing model, in which a frozen probe is applied directly to the left ventricular epicardial surface to inflict cardiac damage and necrosis with high reproducibility $(20,224)$. On the other hand, occlusion of the left anterior descendent coronary artery (LAD-ligation) is perhaps the most widely used experimental model for MI (225). By closing the LAD, no further blood flow is permitted in the downstream area, while the surrounding myocardial tissue is nearly not affected. This surgical procedure reproduces the pathophysiological features occurring in MI-related ischemia (226). A parallel between cryoinjury and MI produced by LAD-ligation is that the initial injury, whether traumatic or ischemic, initiates a general healing response of the heart, which involves many cardiac systems in the task of restoring equilibrium and ensuring survival, including monocyte mobilization and macrophage expansion $(20,51)$. 
OBJECTIVES 

Macrophages are nowadays examined as targets for therapeutic intervention in CDV. They produce several factors (eg, MT1-MMP) that participate in cardiac repair and remodeling after MI; however, how these factors crosstalk with other cell types mediating repair is not fully understood.

The main objective of this thesis is to dissect the contribution of macrophages to myocardial healing and the interplay with other cell types in order to improve the heart's intrinsic ability to repair. For that purpose, we propose the following specific aims:

1. To characterize macrophage-associated cardiac healing response in two injury models: cryoinjury and permanent ligation of the LAD coronary artery.

1.1. To investigate the effects of cryoinjury and LAD-ligation on cardiac function and fibrosis establishment at different post-injury stages.

1.2. To analyze vascular remodeling and macrophage-microvasculature crosstalk following the injury.

1.3. To describe in vivo macrophage kinetics and activation in the context of injuryinduced sterile cardiac inflammation.

2. To determine the impact of macrophage MT1-MMP deletion on post-MI LV remodeling and function.

2.1. To assess in vivo the cardiac functional outcome of macrophage-deletion of MT1-MMP in a mouse model of acute MI.

2.2. To comprehensively describe the role of macrophage MT1-MMP on post-MI tissue and vasculature remodeling.

2.3. To decipher the molecular mechanism underlying the potential role of macrophage-derived MT1-MMP in cardiac healing after MI. 

MATERIALS AND METHODS 



\section{Mice}

All the animals used in this study were on the C57BL/6 background. Experiments were performed in 8- to 12-week-old male and female mice, unless otherwise indicated, kept in a specific pathogen-free (SPF) facility at Centro Nacional de Investigaciones Cardiovasculares Carlos III (CNIC) under a $12 \mathrm{~h}$ light/dark cycle (lights on from 07:00 to 19:00 h), with water and chow available ad libitum.

All animal procedures were conducted in accordance with EU Directive 86/609/EEC and approved by the Animal Subjects Committee of the Instituto de Salud Carlos III (Madrid, Spain) and Madrid Community Organs in the PROEX 188/26.

The following mouse strains were used in the study:

1. C57BL/6 wild-type mice, purchased from Charles Rivers.

2. MT1-MMP ${ }^{\Delta L y s M}$ transgenic mice:

In order to conditionally ablate the protease MT1-MMP (Mmp14) produced by macrophages, we crossed mice expressing the bacteriophage $\mathrm{P} 1$-derived Cre/loxP recombinase under the control of the lysozyme 2 (Lyz2) promoter (LysMCre mice) (227) with mice bearing loxP. flanked Mmp14/f/f sequences (MT1-MMPf/f mice) (228). MT1-MMPf/f mice were kindly donated by Dr. López-Otín (Universidad de Oviedo). LysM-Cre+/MT1-MMPf/f mice (MT1-MMP ${ }^{\Delta L y s M}$ ) lack MT1MMP in macrophages, while LysM-Cre-/MT1-MMPf/f littermates (MT1-MMP/f) were used as WT controls.

\section{DNA extraction and mice genotyping}

Genotyping was performed by PCR of genomic DNA extracted from tail snips. Total DNA was obtained using REDExtract-N-Amp Tissue PCR Kit (Sigma). The following primers were used: Cre Forward: 5'- AGGTGTAGAGAAGGCACTTAGC - 3'

Cre Reverse: 5'- CTAATCGCCATCTTCCAGCAGG - 3'

MT1-flox recombination:

Forward: 5'- CCCTGGGTCAACTACAGCA - 3'

Reverse: 5'- TTTGTGGGTGACCCTGACTTG - 3' 


\section{Mouse models of sterile cardiac injury}

\section{Cryoinjury}

Cryoinjury was performed as previously described (20). Briefly, mice were anesthetized with sevoflurane ( $5 \%$ for induction, $2 \%-3 \%$ for maintenance), and intubated using a 24 -gauge intravenous catheter with a blunt end. Mice were artificially ventilated with a mixture of $\mathrm{O}_{2}$ and air [1:1 (vol/vol)] using rodent ventilator (minivent 845) with 160 strokes/min in a total volume of 250 $\mu \mathrm{l}$. The mouse was placed on heating pad to maintain body temperature at $37^{\circ} \mathrm{C}$. A thoracotomy was performed through the fourth left intercostal space, the pericardium was opened, and the heart was exposed. Cryoinjury was induced applying a $3 \mathrm{~mm}$ diameter cryoprobe, cooled to $-196^{\circ} \mathrm{C}$ with liquid nitrogen, to the anterior LV free wall for 10 seconds. After this, the procedure was repeated twice. The exact position of the probe was carefully set using the left atrium and pulmonary artery as anatomic landmarks. The thorax and the skin incision were closed with 6/0 silk sutures (Lorca Marín) and buprenorphine $(0.01 \mathrm{mg} / \mathrm{kg}$, Buprex, Merck \& Co. Inc) was given for pain relief. Mice were sacrificed by $\mathrm{CO}_{2}$ inhalation 3,7 and 28 days post-injury. Animals not subjected to surgery were included as the physiological condition (day 0 ).

\section{Left anterior descending coronary artery ligation (LAD-ligation)}

Permanent ligation of the left anterior descendent (LAD) coronary artery was performed as previously described $(229,230)$, following the same anesthetic and thoracotomy protocol as in cryoinjury. Once the heart was exposed and the pericardium removed, LAD coronary artery was permanently ligated with 7/0 silk suture (Lorca Marín). The thorax and the skin incision were closed with 6/0 silk sutures (Lorca Marín) and buprenorphine (0.01 mg/kg, Buprex, Merck \& Co. Inc) was given for pain relief. Mice were sacrificed by $\mathrm{CO}_{2}$ inhalation 3,7 and 28 days post-injury. Animals not subjected to surgery were included as the physiological condition (day 0 ).

\section{Ischemia/Reperfusion (I/R)}

I/R protocol was performed as previously described (231), following the same anesthetic and thoracotomy protocol as in cryoinjury. Once the heart was exposed, the LAD coronary artery was ligated approximately $1 \mathrm{~mm}$ below the edge of the left atrial appendage with an 8/0 silk suture (EthiconEndo-surgery, OH, USA). Regional ischemia was verified by visual pallor and QRS alterations within the first seconds of occlusion. After occlusion for $45 \mathrm{~min}$, the suture was loosened to start reperfusion. The thorax and the skin incision were closed with $6 / 0$ silk sutures (Lab Arago, Spain) and buprenorphine $(0.01 \mathrm{mg} / \mathrm{kg}$, Buprex, Merck \& Co. Inc) was given for pain relief. Mice with lack of ST-elevation during ischemia or lack of ST-recovery at reperfusion were excluded from 
further evaluation. Mice were sacrificed by $\mathrm{CO}_{2}$ inhalation 21 days post-MI. Animals not subjected to surgery were included as the physiological condition (day 0 ).

For the three injury models, mice with less than two LV segments affected in terms of contractility after the surgery were considered non-properly injured and excluded from the study.

\section{Echocardiographic analysis}

Transthoracic echocardiography was performed on mice subjected to cryoinjury, LADligation or I/R at basal, 3, 7, and 21 or 28 days post-surgery. Shaved mice were anesthetized by inhalation of isoflurane and oxygen (1.25\% and $98.75 \%$, respectively) and placed in a biofeedback warming station that maintained core body temperature. Anesthesia depth was adjusted to maintain heart rate between 450 and 550 beats per minute. Warm ultrasound gel was applied to the chest of the animals, and echocardiography measurements were obtained using the VEVO 2100 high frequency ultrasound system with a linear transducer MS400 18-38 MHz (Visual Sonics, Toronto, Canada). Parasternal short- and long-axis views at 3 levels (base, middle and apex) in two-dimensional and M-mode were obtained as described previously (232). The LV end-systolic and end-diastolic volume (LVVols and LVVold, respectively) were acquired from the parasternal two-dimensional long-axis view, and LV ejection fraction (LVEF) was calculated using the area-length method (233). Wall thickness at the end of the systole and diastole was measured from the M-mode short-axis view. Analysis was performed off-line by two blinded echocardiography experts. Ultrasounds were performed in collaboration with Dr. María VillalbaOrero at CNIC.

Regional kinetic abnormalities within the LV were assessed. LV wall motion score index (WMSI) was calculated in order to assess global and regional cardiac function by a 12-based segment model, considering parasternal two-dimensional short and long axis views at 3 levels (basal, medial, and apical), as previously described (234). In each level, the LV was further divided in 4 segments (anterior, lateral, posterior, and septal) and every segment was scored according its severity in terms of contraction as 1 (normal), 2 (hypokinesia), 3 (akinesia), 4 (dyskinesia or aneurysm). Infarct size was estimated as the percentage of segments scored $>1$ (reflecting contractility abnormalities) over the total of 12 segments, and WMSI was defined as the ratio of the sum of the score of every segment over the total number of segments evaluated.

\section{Histology and immunohistochemistry}

For histological analysis, hearts were perfused with cold phosphate-buffered saline (PBS), fixed in $4 \%$ paraformaldehyde (PFA) overnight $(\mathrm{O} / \mathrm{N})$ and embedded in paraffin. Transverse 
sections $(5 \mu \mathrm{m})$ were stained with hematoxylin-eosin (H\&E) and Masson trichrome stain according to standard procedures. For immune labelling of blood vessels, arterioles and lymph vessels, samples were stained with anti-CD31, anti-SMA and anti-LYVE1 primary antibodies, respectively. Subsequently the samples were incubated with appropriate HRP conjugated antibodies and revealed with 3,3'-Diaminobenzidine (DAB) following standard protocols. Whole slide images were acquired with a digital slide scanner (Hamamatsu, Nanozoomer-RS C110730) and then visualized, and exported to TIFF images using NDP.view2 software (Hamamatsu Photonics).

Manual and automated quantifications were performed with Fiji Image J Software (NIH, https://imagej.nih.gov/ij/). In order to limit the analysis to capillary vessels in CD31-stained sections, circularity restrictions were applied to exclude lymphatics. Accordingly, only CD $31^{+}$ vessels with a circularity between 0.2 and 1 were included in the analysis. The injury (IZ), periinjury $(P-I Z)$ and remote $(R Z)$ zones were defined on the basis of H\&E-stained sections. In particular, areas containing dying or dead cardiomyocytes (picnotic or absent nuclei, wavy fibers) or fibrotic areas were defined as IZ. The P-IZ was defined as a band of $300 \mu \mathrm{m}$ immediately adjacent to the damaged boundary. The RZ was considered the healthy LV free wall. Measurements were performed on sections obtained from the midpoint of the lesion.

\section{Multi-Photon and Second Harmonic Generation Imaging}

Collagen fibers were visualized in H\&E-stained heart sections with a Zeiss LSM 780 microscope coupled to a Spectra-Physics Mai Tai DS [pulse $<70$ ps] laser, by second harmonic generation (SHG) and multi-photon excitation fluorescence (MPEF) microscopy imaging technique (235-237). SHG signal (acquisition range 390-413 nm) and multi-photon autofluorescence (acquisition range $508-570 \mathrm{~nm}$ ) allow simultaneous visualization of fibrillar collagen and myocyte components, respectively.

Optical sections were acquired every $3 \mu \mathrm{m}$ (25x objective) and stitched using Zeiss Zen2 software (2011 Blue edition). The images were then stacked and flattened with Image J software $(\mathrm{NIH}$, https://imagej.nih.gov/ij/) to create maximum intensity Z-projections. Collagen density was calculated using a simple threshold pixel counting method within the $I Z$, the $P-I Z$ and the $R Z$, and expressed as the area fraction (\% SHG). Skewness (asymmetry of pixel distribution) and kurtosis (gray-tone spread-out distribution) were assessed as an indicative of fiber arrangement (236). Measurements were performed on sections obtained from the midpoint of the lesion.

\section{Tissue immunofluorescence and confocal microscopy}

Transverse paraffin sections $(7 \mu \mathrm{m})$ of infarcted hearts were deparafinated, rehydrated and 
finally washed in PBS 5 minutes twice. Antigen retrieval was performed by means of $\mathrm{pH}=6$ citrate buffer for 20 minutes in the microwave at maximum intensity. Afterwards, sections were cooled down at room temperature (RT) for $1 \mathrm{~h} 30$ minutes and then washed with PBS 5 minutes twice. Sections were blocked for $1 \mathrm{~h}$ at RT (0.3\% TX100,5\% goat serum and 5\% BSA in PBS) and primary antibodies were incubated $\mathrm{O} / \mathrm{N}$ at $4^{\circ} \mathrm{C}(0.3 \% \mathrm{TX} 100,2.5 \%$ goat serum and $2.5 \% \mathrm{BSA}$ in PBS). Antibodies used for immunofluorescence assay are listed in Table 1. Next, sections were washed with $0.1 \%$ TX100 in PBS at RT for 10 minutes three times and secondary antibodies and DAPI (1/5000) for nuclear staining were then incubated for $1 \mathrm{~h} 30$ minutes at RT $(0.3 \%$ TX100, $2.5 \%$ goat serum and $2.5 \%$ BSA in PBS). After four washing steps with $0.1 \%$ TX100 in PBS at RT for 10 minutes plus 10 minutes more with PBS alone, slides were mounted with Fluoromont-G (0100-01, Southern Biotech). Images were acquired with a Nikon A1R confocal microscope with sections every $1.5 \mu \mathrm{m}$. Three to four areas were acquired within the $I Z$ (the two most distal edges and the center of the infarcted area), and other three to four within the RZ (LV free wall most distal to the infarct).

For CA-IX quantifications, the total area covered by the CA-IX signal in every image was normalized by the total area, and this ratio was averaged in between individuals. For pSMAD2 quantification in VSMCs and MyoFBs, DAPI nuclei within arteriolar SMA signal were considered VSMCs and DAPI nuclei in non-arteriolar SMA signal were considered MyoFBs. The number of pSMAD2 ${ }^{+}$VSMCs and the number of pSMAD2 ${ }^{+}$MyoFBs were normalized by the total number of VSMCs or MyoFBs, respectively, and expressed as percentage. Finally, percentages obtained in each region were averaged within individuals. Measurements were performed on sections obtained from the midpoint of the lesion.

\begin{tabular}{|l|l|l|l|}
\hline Antibody & Concentration & Provider & Reference \\
\hline Rabbit anti-CA-IX & $1: 100$ & Abcam & ab15086 \\
\hline Goat anti-Rabbit Alexa 546 & $1: 500$ & ThermoFisher & A-11035 \\
\hline Rat anti-CD31 & $1: 200$ & Dianova & DIA-310 \\
\hline Goat anti-Rat Alexa 488 & $1: 500$ & ThermoFisher & A-11006 \\
\hline Rabbit anti-pSmad2 & $1: 100$ & Cell Signaling & 3108 \\
\hline Goat anti-Rabbit Alexa 647 & $1: 500$ & ThermoFisher & A-21245 \\
\hline Mouse anti-SMA-Cy3 & $1: 400$ & Sigma-Aldrich & C6198 \\
\hline
\end{tabular}

Table 1. List of antibodies used for immunofluorescence assay

\section{D fully automated microvasculature image analysis}

Transverse paraffin sections $(15 \mu \mathrm{m})$ of infarcted hearts were stained with anti-CD31 and anti-SMA antibodies (Table 1) and DAPI for nuclear staining. Images were acquired with a Nikon 
A1R confocal microscope using a 40x objective (NA 1.25) with oil immersion with z-stacks captured every $1 \mu \mathrm{m}$. The microvasculature was characterized by means of a fully automated pipeline developed in Dr. Arroyo's laboratory (238). Modules of the pipeline were adapted as previously described (239) in order to account for the different animal model (mouse) as well as the use of the relatively thinner tissue sections $(15 \mu \mathrm{m})$ compared to the thick tissue sections of $\sim 100 \mu \mathrm{m}$ used in the original work. Moreover, since images included both tissue areas and areas belonging to the microscope slide, it was necessary to separate the tissue volume from the background glass area. For this purpose, firstly the images were denoised by means of non-local means filtering (240). Subsequently, 3D tissue segmentation was performed by applying Otsu multi-level thresholding technique (241) on the nuclei channel. It should be noted that the intensity levels used for thresholding varied between three and four depending on the image and they were automatically defined. Voxels of all intensities levels but the lower one were considered to belong to the tissue. Lastly, holes within the segmented area were automatically identified and filled. It should be noted that apart from normalization purposes, the tissue mask was used to exclude from the corresponding segmentation mask of vessels and $\mathrm{SMA}^{+}$cells non-tissue voxels that were incorrectly identified as belonging to vessels or SMA respectively. To this end, element-wise multiplications of the segmentations of vessels and $\mathrm{SMA}^{+}$cells with the tissue mask were performed.

Following tissue segmentation, we applied modules of the pipeline that permit the automatic segmentation of nuclei, vessels and $\mathrm{SMA}^{+}$cells from the corresponding image channels. Classification of microvessels according to their size and relation with $\mathrm{SMA}^{+}$cells into different physiologically meaningful categories was performed as previously described (239). Lastly, quantitative parameters regarding the morphology and angioarchitecture of the network as well as the relation of vessels with $\mathrm{SMA}^{+}$cells were extracted. The parameters are summarized in Supplementary Table 1.

\section{Flow cytometry and cell sorting}

Cardiac single-cell suspensions were obtained as previously described (242). Briefly, mice were euthanized by $\mathrm{CO}_{2}$ fixation and immediately perfused by intracardiac injection of cold PBS. Right and left atria were removed and the whole ventricles were minced with fine scissors, and digested in collagenase IV $0.1 \%\left(528 \mathrm{U} / \mathrm{mg}\right.$ Sigma) in PBS at $37^{\circ} \mathrm{C}$ for 45 minutes under gentle shaking. Cells were then filtered through nylon mesh of $100 \mu \mathrm{m}$ (BD biosciences) to obtain a homogeneous cell suspension and subjected to red blood cells lysis with RBC Lysis buffer solution (eBioscience). Single-cell suspensions were Fc-blocked using anti-mouse CD16/CD32 antibody (BD Pharmingen) 10 minutes at $4^{\circ} \mathrm{C}$ in FACS buffer (PBS $2 \%$ FBS $5 \mathrm{mM}$ EDTA). Antibodies were 
incubated for 30 minutes at $4^{\circ} \mathrm{C}$ in FACS buffer. Where appropriate, cells were further incubated with streptavidin conjugates for 30 minutes at $4^{\circ} \mathrm{C}$. For nuclear pSMAD2 staining, cells were fixed and permeabilized using a commercial kit (Foxp3/Transcription Factor Staining Buffer Set, eBioscience). Antibodies used for flow cytometry are listed in Table 2. Flow cytometry studies were performed in a BD FACSCantoTM II flow cytometer (BD BioSciences) or on a Sony SP6800 Spectral Analyzer (Sony Biotechnology, Japan), and analyzed with FlowJo Software (Tree Star). Cell sorting was performed with BD FACS-ARIATM II cell sorter (BD Biosciences) and all the samples were sorted into PBS supplemented with 10\% FBS.

After pre-selection in side scatter (SSC) versus forward scatter (FSC) dot plot to exclude debris and doublets, cardiac macrophages were identified as CD45+CD11 b+F4/80 cells, ECs as CD45-CD31+PDGFR $\beta^{-}$cells, 'transitioning' cells as CD45-CD31 lowPDGFR $\beta^{\text {low }}$ cells, and VSMCs and MyoFBs as CD45-CD31-PDGFR ${ }^{+}$cells. Within the CD45+CD11 b ${ }^{+}$cells, the F4/80+Ly6Clow cardiac macrophages were sorted for 0,7 , and 28 days post-injury, whereas F4/80+Ly6Chigh cardiac macrophages were purified for 3 days post-injury.

Fluorescence minus one (FMO) controls were included during acquisition for gating analyses to distinguish positive from negative staining cell populations. The standardized median fluorescence intensity (MFI) of TGF $\beta 1$, LAP and pSMAD2 for each cardiac cell type was calculated as previously described (20):

$$
\text { Standardized MFI }=\frac{\left(\text { Median }_{\text {positive }}-\text { median }_{\mathrm{FMO}}\right)}{2^{*} \mathrm{SD}_{\mathrm{FMO}}}
$$

\begin{tabular}{|c|c|c|c|}
\hline Antibody & Dilution & Provider & Reference \\
\hline CD16/CD32 Rat Anti-Mouse & $1: 100$ & BD Biosciences & 553141 \\
\hline CD45-PerCP/Cy5.5 Rat Anti-Mouse & $1: 100$ & Biolegend & 103132 \\
\hline CD45-APC/Cy7 Rat Anti-Mouse & $1: 100$ & Biolegend & 103116 \\
\hline CD45-eFluor 450 Rat Anti-Mouse & $1: 100$ & eBioscience & $48-0451$ \\
\hline CD11b-PE-Cy7 Rat Anti-Mouse & $1: 100$ & BD Biosciences & 552850 \\
\hline CD11b-Biotin Anti-Mouse & $1: 100$ & BD Biosciences & $51-017125$ \\
\hline CD11b-FITC Rat Anti-Mouse & $1: 100$ & Biolegend & 101206 \\
\hline CD115-PE Rat Anti-Mouse & $1: 100$ & Tonbo Biosciences & $50-1152$ \\
\hline Ly6C-APC Rat Anti-Mouse & $2: 100$ & BD Biosciences & 560595 \\
\hline Ly6C-FITC Rat Anti-Mouse & $1: 100$ & AbD Serotec & 553104 \\
\hline Ly6G-PerCPCy5.5 Rat Anti-Mouse & $1: 100$ & Biolegend & 127615 \\
\hline CD31-APC Rat Anti-Mouse & $1: 100$ & BD Biosciences & 551262 \\
\hline PDGFR- $\beta$-PE Rat Anti-Mouse & $2: 100$ & BioLegend & 136005 \\
\hline F4/80-PE/Cy7 Rat Anti-Mouse & $3: 100$ & BioLegend & 123114 \\
\hline
\end{tabular}


MATERIALS AND METHODS

\begin{tabular}{|l|l|l|l|}
\hline F4/80-PE Rat Anti-Mouse & $3: 100$ & BioLegend & 123110 \\
\hline $\begin{array}{l}\text { Phospho-Smad2 (Ser245/250/255) } \\
\text { Rabbit Anti-Mouse }\end{array}$ & $1: 100$ & Cell Signaling & 3104 \\
\hline Streptavidin-Alexa 488 conjugate & $1: 500$ & ThermoFisher & S11223 \\
\hline LAP-APC Mouse Anti-Mouse & $3: 100$ & Biolegend & 141405 \\
\hline TGFß1 Rabbit Anti-Mouse & $1: 100$ & Abcam & ab92486 \\
\hline Goat anti-Rabbit Alexa 647 & $1: 500$ & ThermoFisher & A-21245 \\
\hline Chicken Anti-Rabbit Alexa 488 & $1: 500$ & ThermoFisher & A-21441 \\
\hline
\end{tabular}

Table 2. List of antibodies used for flow cytometry

\section{RNA isolation and quantitative real time PCR (qPCR)}

Cells were lysed with TRIzol Reagent (Ambion) for RNA isolation. Total RNA was isolated from at least 3 independent biological replicates, and RNA quality and quantity measured using the NanoDrop ND100 (Thermo Scientific). Total RNA was reverse-transcribed to cDNA using the High Capacity cDNA Reverse Transcription Kit (Applied Biosystems). qPCR assays were performed using Sybr Green Probes in the AB7900 FAST 384 Detection System (Applied Biosystems), according to the manufacturer's instructions. Gene expression values were normalized to the housekeeping genes $36 b 4$ and Cyclophilin, and expressed as relative mRNA level. Data were analyzed by qBASE program (Biogazelle) obtaining the $\mathrm{Ct}$ of the amplification products. Primer sequences are listed in Table 3.

\begin{tabular}{|l|l|l|}
\hline Gene & Sequence Forward Primer & Sequence Reverse Primer \\
\hline $36 \mathrm{~b} 4$ & GCGACCTGGAAGTCCAACTA & ATCTGCTGCATCTGCTTGG \\
\hline Cyclophilin & ACAGGTCCTGGCATCTTGTC & CATGGCTTCCACAATGTTCA \\
\hline Mmp14 & CCCTTTTACCAGTGGATGGA & TGTCAAAGTTCCCGTCACAG \\
\hline Mmp 2 & GTCGCCCCTAAAACAGACAA & GGTCTCGATGGTGTTCTGGT \\
\hline Mmp13 & ATCCTGGCCACCTTCTTCTT & TTTCTCGGAGCCTGTCAACT \\
\hline Timp3 & GCCTCAATTACCGCTACCAC & CCCAAAATTGGAGAGCATGT \\
\hline Cd163 & TCTTTGTTGTGGCTGTGAGC & CCCCACTTGTCATGGATCTT \\
\hline Mrc1 & ATTGTGGAGCAGATGGAAGG & TGAATGGAAATGCACAGACG \\
\hline Lyve1 & AGAATGGCAAAGGTGTCCTG & GTCCAACACGGGGTAAAATG \\
\hline Mertk & GACTCCCTATCCCGGAGTTC & CTGCAGCCTCAACACAGAGA \\
\hline Nos2 & CAGCTGGGCTGTACAAACCTT & CATTGGAAGTGAAGCGTTTCG \\
\hline Ptgs2 & ATTCTTTGCCCAGCACTTCA & GGGATACACCTCTCCACCAA \\
\hline Ly6C & GGACTGCAGTGCTACGAGTG & AAGGCACTGACGGGTCTTTA \\
\hline Il6 & CAAAGCCAGAGTCCTTCAGAG & GCCACTCCTTCTGTGACTCC \\
\hline Pecam & TGCACAGTGATGCTGAACAA & CCATGAGCACAAAGTTCTCG \\
\hline
\end{tabular}


MATERIALS AND METHODS

\begin{tabular}{|l|l|l|}
\hline$K d r$ & GATCACCATTCATCGCCTCT & CCCAGGAAATTCTGTTTCCA \\
\hline Col4a2 & CAGGATTCCAAGGTGCTCAT & CTGGAAGGCCTCTCATTGAA \\
\hline Tagln & GATGGAACAGGTGGCTCAAT & AACTGCCCAAAGCCATTAGA \\
\hline Acta2 & GAAAATGAGATGGCCACGGC & TAGGTGGTTTCGTGGATGCC \\
\hline Pai1 & GTAGCACAGGCACTGCAAAA & GCCGAACCACAAAGAGAAAG \\
\hline
\end{tabular}

Table 3. List of primer sequences used for qPCR assays

\section{Cell culture}

Bone marrow-derived macrophages (BMDMs): BMDMs were harvested from 8-10-weekold MT1-MMPf/f and MT1-MMP ${ }^{\Delta L y s M}$ mice by flushing femurs and tibias with PBS. Cells were filter through a $100 \mu \mathrm{m}$ nylon cell strainer (Falcon) and cultured in RPMI (Lonza) supplemented with 20\% L929-cell conditioned medium, 10\% FBS (Gibco), 1\% penicillin/streptomycin (P/S) (Lonza), and $1 \mathrm{mM}$ L-glutamine (L-GIn) (Lonza) in sterile non-tissue culture treated $10 \mathrm{~cm}$ petri dish. BMDMs were activated with $10 \mathrm{ng} / \mathrm{ml}$ LPS (Peprotech) O/N to stimulate TGF $\beta 1$ production.

Mouse aortic endothelial cells (MAECs): Six to eight aortas from 4-week-old male C57BL/6 mice were pooled to obtain a single-cell suspension (243). Briefly, after carefully aorta dissection and fat removal under a microscope, aortas were incubated in collagenase type I solution $\left(3.33 \mathrm{mg} / \mathrm{ml}\right.$, Worthington) for 5 minutes at $37^{\circ} \mathrm{C}$. Then, adventitia was removed with forceps, the aortas were then cut into small pieces $(1-2 \mathrm{~mm})$ and incubated for 45 minutes at $37^{\circ} \mathrm{C}$ in a type I collagenase $(6 \mathrm{mg} / \mathrm{ml}$, Worthington) and elastase $(2.5 \mathrm{mg} / \mathrm{ml}$, Worthington) solution DMEM (Lonza) solution. The obtained single-cell suspension was plated on $0.5 \%$ gelatin-coated plates in DMEM/F12 supplemented with $20 \%$ FBS, 2 mM L-GIn, $1 \%$ $\mathrm{P} / \mathrm{S}$, and $\mathrm{ECGS} / \mathrm{H}$. When culture became confluent, MAECs were positively selected with an antibody against intercellular adhesion molecule 2 (anti-ICAM2; 553325 BD Biosciences) coupled to magnetic beads (Dynabeads ${ }^{\mathrm{TM}}$ Sheep Anti-Rat IgG, ThermoFisher), and cultured as indicated in M199 supplemented with 20\% FBS, 1\% P/S, 2 mM L-Gln, 1\% HEPES, and ECGS/H (106).

Human embryonic kidney (HEK293) cells: HEK293 cells (Lonza) were cultured in DMEM (Lonza) with 10\% FBS.

Cardiac macrophages: FACS-sorted macrophages $\left(\mathrm{CD} 45^{+} \mathrm{CD} 11 \mathrm{~b}^{+} \mathrm{F} 4 / 80^{+}\right.$Ly6 $6 \mathrm{C}^{\text {low }}$ cells $)$ were purified from MT1-MMPf/f and MT1-MMP ${ }^{\Delta L y s M}$ hearts on day 7 after MI. They were cultured in DMEM supplemented with 10\% FBS, and $10 \mathrm{ng} / \mathrm{ml}$ M-CSF (Peprotech). 


\section{Cell extract preparation and Western blot analysis}

MT1-MMPf/f or MT1-MMP ${ }^{\text {LysM }}$ BMDMs were treated with $1 \mathrm{ng} / \mathrm{mL}$ LPS (Peprotech) for 24 $\mathrm{h}$ to stimulate TGF $\beta 1$ production. Prior to lysate collection, cell viability was determined by microscopy under bright field and cell debris removed by 2 washes of monolayers with PBS.

For preparation of total lysates, $4 \times 10^{6}$ BMDMs were incubated in RIPA buffer, containing $50 \mathrm{mM}$ Tris- $\mathrm{HCl}, \mathrm{pH} 8,150 \mathrm{mM} \mathrm{NaCl}, 1 \%$ TX100, 0.5\% sodium deoxycholate, $0.1 \%$ SDS, $1 \mathrm{mM}$ PMSF (Sigma), and protease and phosphatase inhibitor cocktail (Sigma), for 30 minutes at $4^{\circ} \mathrm{C}$ in the rotor. The lysates were centrifuged (14,000 g, 10 minutes), and the supernatant containing the proteins were transferred to a new tube.

For subcellular fractioning, $4 \times 10^{6}$ BMDMs were incubated in HES buffer, containing $20 \mathrm{mM}$ HEPES, 1mM EDTA, 250mM sucrose and a protease and phosphatase inhibitor cocktail (Sigma), for 10 minutes at $4^{\circ} \mathrm{C}$. Cells were lysed through a $22 \mathrm{G}$ needle followed by a $25 \mathrm{G}$ needle, and centrifuged at $500 \mathrm{~g}$ for 8 minutes to pellet the unbroken cells. Then, the supernatant was transferred to an empty tube and centrifuged at $10,000 \mathrm{~g}$ for 12 minutes to separate the cytosolic (supernatant) and the membrane (pellet) protein fractions.

Protein concentration was estimated using Bradford Assay (Bio-Rad) and $30 \mu \mathrm{g}$ of total protein were separated by $10 \%$ SDS-PAGE and transferred to a nitrocellulose membrane (BioRad). Correct protein loading was confirmed by Ponceau staining. Membranes were incubated O/N with antibodies against TGF $\beta 1$ (Santa Cruz, sc-146), TfR (Abcam, ab84036), and $\alpha$-tubulin (Sigma, T6074) at 1:500 (for TGF $\beta 1$ ) or 1:1000 dilutions (for TfR and $\alpha$-tubulin), and then washed and incubated with HRP-conjugated anti-rabbit (Jackson, 11-035-003) or anti-mouse (Jackson, 115-035-003) antibodies (1:7500). Blots were visualized using the chemiluminescent Immobilon Classico Western HRP substrate (Millipore). Chemiluminiscent signal was detected using Image Quant ${ }^{\mathrm{TM}}$ LAS 4000 and densitometry analysis performed using ImageJ. The ratio between proteins of interest (TGF $\beta 1$ ) and endogenous control (TfR) was calculated for data normalization. Graphs represent fold change calculated based on normalized data.

\section{HEK293 transfection and luciferase assay}

HEK293 cells (40\%-50\% confluence) were transfected over $6 \mathrm{~h}$ with the plasmid p3TP-lux (Addgene plasmid \# 11767; http://n2t.net/addgene:11767; RRID:Addgene_11767) with 2.5M $\mathrm{CaCl}_{2}$ in HEPES Buffered Saline (HBS). This plasmid contains luciferase downstream of the PAI1 promoter, therefore the luciferase activity is proportional to the production of bioactive TGF $\beta$ (244). p3TP-lux was kindly provided by Dr. Carmelo Bernabeu. 
Luciferase assay was carried out as described (245). In brief, transfected HEK293 cells were plated at 30,000 cells per well on p96-well plates in DMEM 10\% FBS and allowed to attach for $6 \mathrm{~h}$. The medium was then removed and treatments were added in the same medium. HEK293 cultures were overlaid with 40,000 LPS-activated (10 ng/ml LPS O/N) MT1-MMPf/f or MT1-MMP ${ }^{\Delta L y s M}$ BMDMs, or with 50,000 cardiac macrophages from 7-day post-MI MT1-MMPf/f or MT1-MMP ${ }^{\Delta L y s M}$ mice. Co-cultures were maintained for $24 \mathrm{~h}$, cells were then lysed with Passive Lysis Buffer (Promega), and luciferase activity was assayed with the Promega Luciferase Assay according to manufacturer's instructions. As a positive control, HEK293 cells were treated with $10 \mathrm{ng} / \mathrm{ml}$ TGF $\beta 1$.

When the assay was performed with cardiac macrophages, $C D 45^{+} \mathrm{CD} 11 \mathrm{~b}^{+} \mathrm{F} 4 / 80^{+} \mathrm{Ly} 6 \mathrm{C}^{\text {low }}$ cells were sorted as indicated in Figure 16A from 7-day post-MI MT1-MMPf/f or MT1-MMPLLsM hearts, and M-CSF (10 ng/ml) was added to the culture media.

\section{Lentiviral transduction}

The full-length MT1-MMP sequence (FL) or mutated version to disable catalytic activity (E240A) were cloned into the SFFV-IRESGFP lentiviral backbone. Lentiviruses expressing Mock, MT1-MMP FL, or MT1-MMP E240A were prepared and titered as previously described (246). For viral transduction, we incubated MT1-MMP $\triangle$ LysM BMDMs with the viral supernatants $(\mathrm{MOI}=10)$ in RPMI supplemented with $20 \%$ L929-cell conditioned medium, $10 \% \mathrm{FBS}, 1 \% \mathrm{P} / \mathrm{S}$, and $1 \mathrm{mM} \mathrm{L-GIn}$ for $48 \mathrm{~h}$. GFP signal was detected by fluorescent microscopy in transduced BMDMs. We then removed the viral supernatants and stimulated the cells with 10 $\mathrm{ng} / \mathrm{ml}$ LPS O/N. Afterwards, the media was removed and cells were cultured in DMEM $10 \%$ FBS for $24 \mathrm{~h}$ to obtain conditioned media. Conditioned media was then added to HEK293 cells for luciferase assay as described above.

\section{Co-cultures and cellular immunofluorescence assay}

Mouse aortic ECs (MAECs) were plated at 20,000 per well on 0.5\%-gelatin-coated optical p96-well plates in M199 supplemented with 20\% FBS, 1\% P/S, 2 mM L-GIn, 1\% HEPES, and ECGS/H, and allowed to attach for $6 \mathrm{~h}$. The medium was then removed and treatments were added in the same medium with reduced serum (5\% FBS). The MAEC cultures were overlaid with 30,000 LPS-activated MT1-MMP/f $^{\mathrm{f}}$ or MT1-MMP ${ }^{\Delta L y s M}$ BMDMs, or with 50,000 cardiac macrophages from 7-day post-MI MT1-MMPf/f or MT1-MMP ${ }^{\Delta L y s M}$ mice. Co-cultures were maintained for 4 days. As a positive control for EndMT, MAEC monocultures were treated with $10 \mathrm{ng} / \mathrm{ml}$ TGF $\beta 1$. 
After two washes in HBBS, cultures were fixed for 10 minutes at room temperature (RT) in $4 \%$ PFA. Cells were then permeabilized for 10 minutes at RT in $0.2 \%$ Triton X-100 in PBS and blocked for $1 \mathrm{~h}$ at RT in 5\% goat serum and 5\% BSA in PBS. After overnight incubation with primary antibodies (Table 1 ) at $4^{\circ} \mathrm{C}$ in $2.5 \%$ goat serum and $2.5 \%$ BSA in PBS, cells were washed three times with PBS at RT and then incubated with secondary antibodies (Table 1) and DAPI for $1 \mathrm{~h} 30$ minutes at RT in $2.5 \%$ goat serum and $2.5 \%$ BSA in PBS. Cells were then washed four times with PBS. Cells were visualized under a Nikon A1R microscope, and images were acquired as $2 \times 2$ tile scans of $5 \times 1 \mu \mathrm{m}$ sections. Maximal projections were used for quantifications.

\section{Co-cultures and qPCR assay}

MAECs were plated at 150,000 per well on 0.5\%-gelatin-coated optical p6-well plates in M199 supplemented with 20\% FBS, 1\% P/S, 2 mM L-Gln, 1\% HEPES, and ECGS/H, and allowed to attach for $6 \mathrm{~h}$. The medium was then removed and treatments were added in the same medium with reduced serum (5\% FBS). The MAEC cultures were overlaid with 250,000

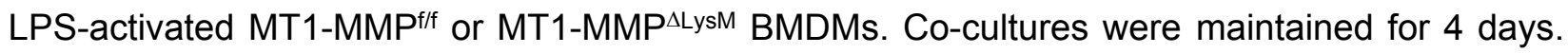
As a positive control for EndMT, MAEC monocultures were treated with $10 \mathrm{ng} / \mathrm{ml}$ TGF $\beta 1$. Afterwards, cells were lysed with TRIzol Reagent (Ambion) for RNA isolation following manufacturer's instructions. Primer sequences are listed in Table 3.

\section{Statistical Analysis}

Data are presented as mean \pm SEM. Unpaired $t$-test was used when two groups were compared, and comparison of more than two datasets was done using one-way analysis of variance (ANOVA) with Tukey's post-test. Comparisons of two-time curves were performed using two-way ANOVA followed by Tukey's post-test. All statistical analyses were performed using Prism v7 (GraphPad Software, California, USA). Differences were considered significant when $p$ $<0.05$, and represented as ${ }^{*} p<0.05$, ${ }^{* *} p<0.01$, ${ }^{* * *} p<0.001$, and ${ }^{* * * *} p<0.0001$. Sample exclusion was not performed unless statistically significant outliers were identified using Grubb's test (ESD method). 



\section{Characterization of macrophage-associated cardiac healing response in two injury models: cryoinjury and permanent ligation of the LAD coronary artery.}

Macrophages are fundamental mediators in tissue repair processes. Here, we propose the use of cryoinjury and permanent occlusion of the LAD coronary artery (LAD-ligation) in mice as sterile injury models to dissect the specific role of macrophages in cardiac healing response.

\subsection{LAD-ligation results in more severe cardiac dysfunction and greater LV dilation than cryoinjury}

First, we followed up the effects of cryoinjury and LAD-ligation on cardiac function by echocardiography. Two-dimensional guided M-mode revealed that cryoinjury did not provoke LV dilation (Figure 10A, left, and Supplementary Videos 1-2), whereas LAD-ligation led to marked LV enlargement (Figure 10A, right, and Supplementary Videos 3-4). The LV ejection fraction (LVEF), and the LV volume in end-diastole (LVVold) and end-systole (LVVols) were measured to assess systolic function and LV remodeling (Figure 10B). The LVEF describes, in percentage, the amount of blood the LV pumps out with each contraction. We found that, in both approaches, mice showed a decrease in the LVEF when compared to healthy controls (Day 0). However, the reduction in the LVEF was significantly accentuated in the LAD-ligation group compared to the cryoinjury group. Furthermore, LAD-ligation led to significant LV dilation while cryoinjury preserved LV geometry, as LVVold and LVVols indicated (Figure 10B). Therefore, LV function and structure were severely affected along time following LAD-ligation, whilst they were better preserved in cryoinjured hearts. 
A
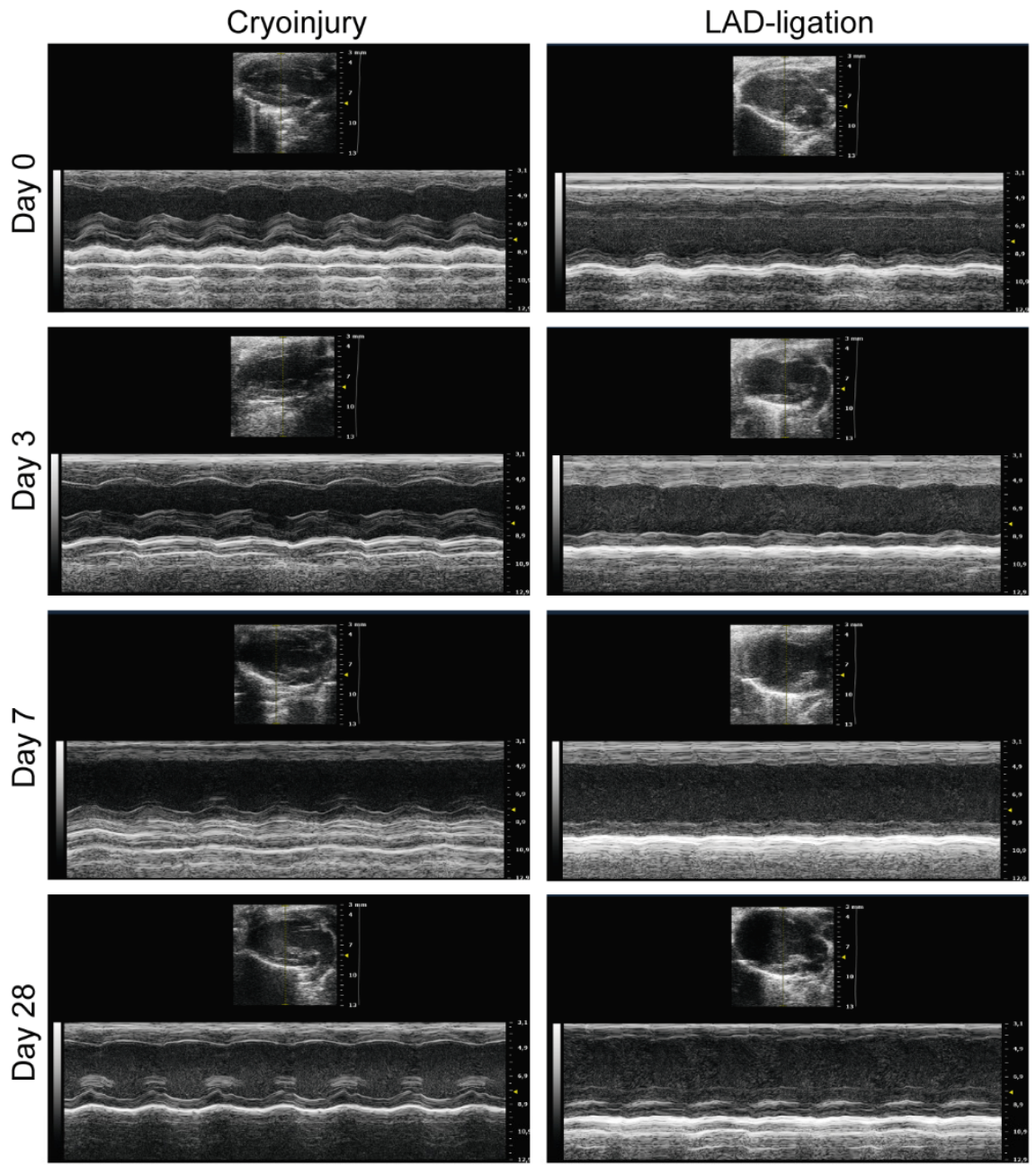

B
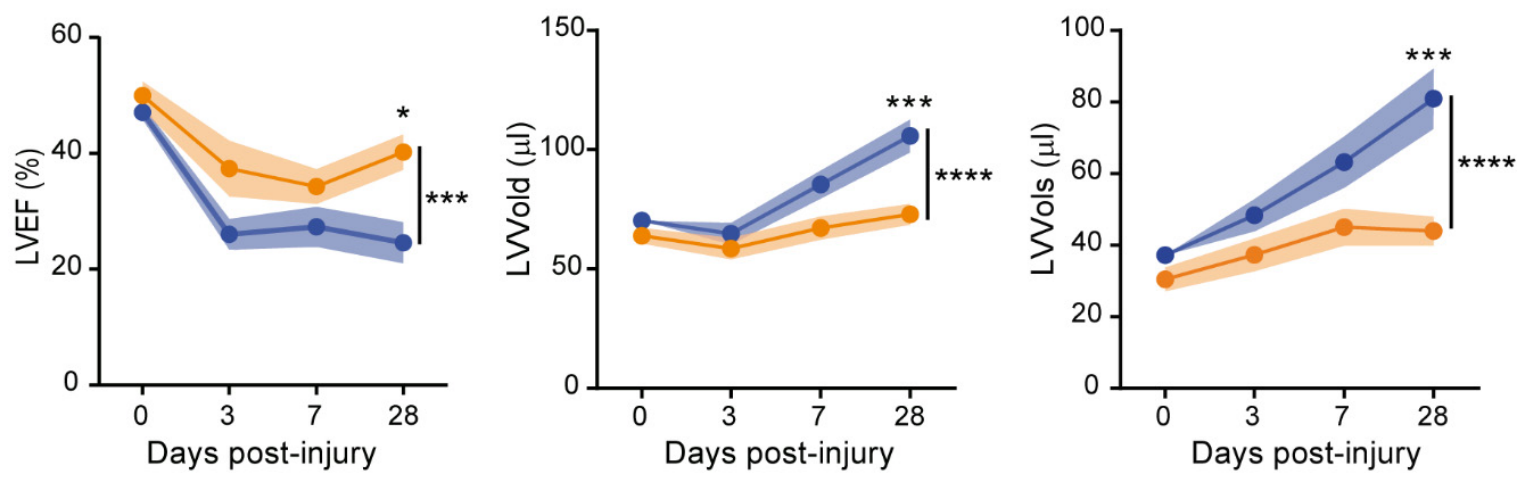

Figure 10. LAD-ligation leads to a more severe cardiac dysfunction and LV dilation than cryoinjury. (A) Representative LV two-dimensional and corresponding M-mode long-axis echocardiographic views on healthy (day 0 ) or damaged hearts at the indicated post-injury stages following cryoinjury (left) or LADligation (right). (B) Post-injury progression of LVEF, LVVold, and LVVols in mice that underwent cryoinjury or LAD-ligation. Data are means \pm SEM of 6-8 mice per model. Two-way ANOVA followed by Tukey's multiple comparisons test. Significant differences are indicated as ${ }^{*} p<0.05$, ${ }^{* * *} p<0.001$, and ${ }^{* * * *} p<$ 0.0001 . 


\subsection{The damage produced by cryoinjury progressively declines while LAD- ligation leads to a lesion that worsens with time}

Afterwards, histological analysis was performed to compare the structural effects on the myocardium and the extent of the lesion caused by each model. On day 3 after cryoinjury, hearts displayed an extensive area of necrosis with hemorrhage as well as a dense inflammatory infiltrate (Figure 11A, top). At variance, hearts subjected to LAD-ligation exhibited coagulation and hemorrhage content in the damaged area, concomitant with an inflammatory infiltrate, but without any sign of a necrotic core (Figure 11A, bottom). On day 7 after cryoinjury, the necrotic core was still maintained and a fibrotic scar was already formed in the affected area. Finally, at 28 days after cryoinjury, necrosis was resolved, only small amount of scar tissue remained on the epicardial part of the LV, and the thickness of the LV wall was preserved (Figure 11A, top). Conversely, the fibrotic scar observed at day 7 in mice subjected to LAD-ligation further developed into a large area of fibrosis, which on day 28 occupied the vast majority of the LV, resulting in severe thinning of the LV wall (Figure 11A, bottom). Quantification of lesion size unveiled that the damage caused by cryoinjury was attenuated along time, while the lesion produced by LAD-ligation worsened progressively (Figure 11B). In summary, LAD-ligation represents an injury model with a huge impact on the integrity of the myocardium, while cryoinjury produces a mild lesion that declines with time. 

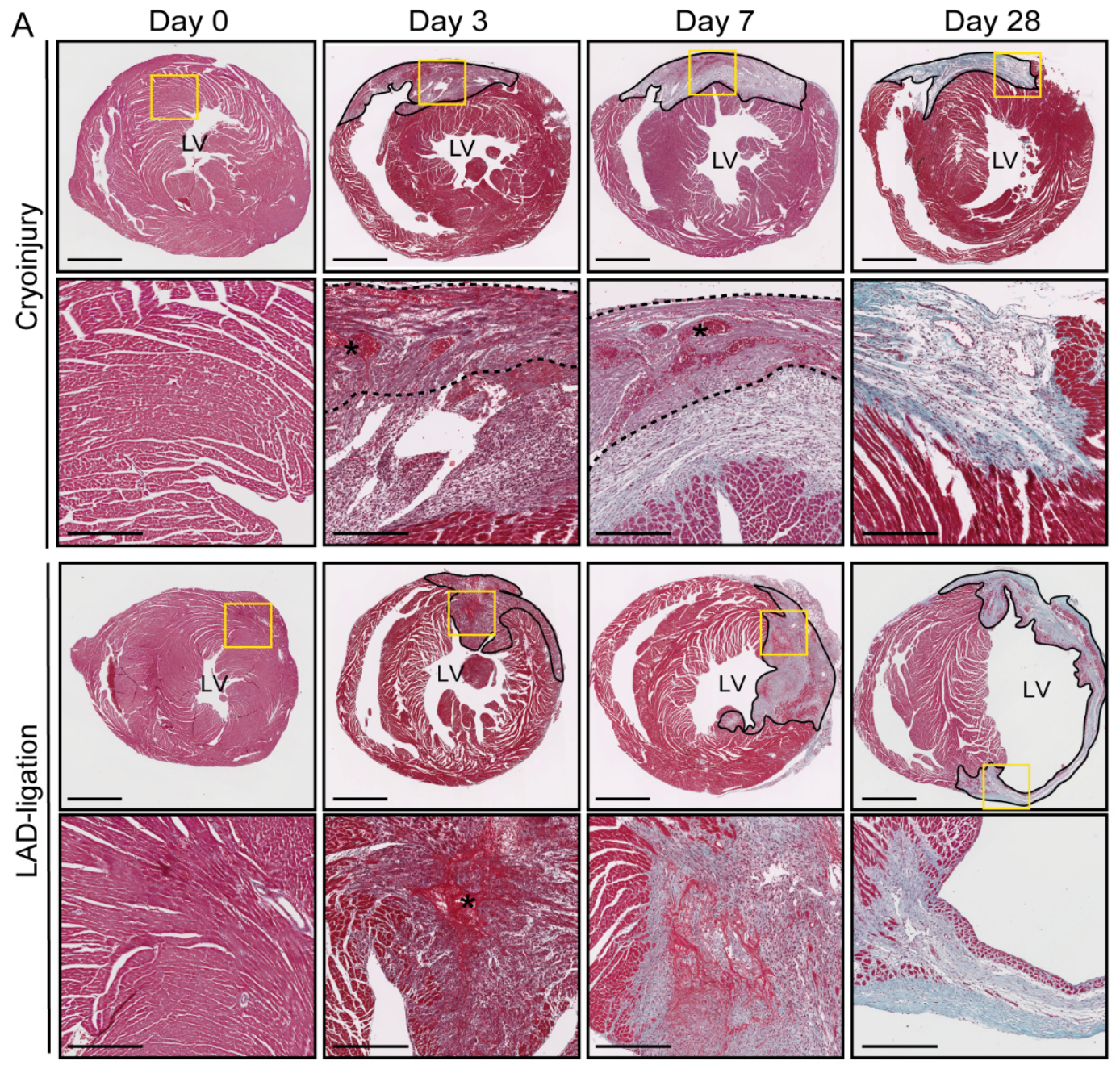

B

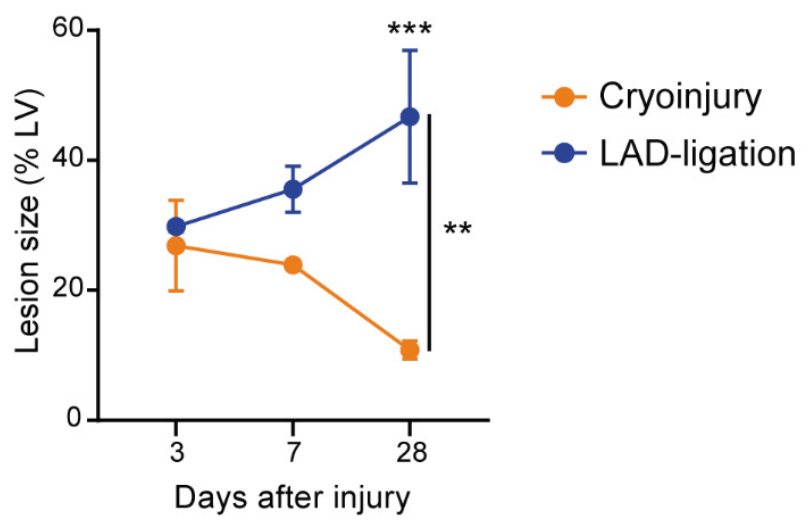

Figure 11. LAD-ligation results into a greater lesion extent than cryoinjury. (A) Representative images of Masson's Trichrome staining in transverse sections of hearts subjected to cryoinjury (top) or LAD-ligation (bottom) at $0,3,7$, and 28 days post-injury. Scale bar, $1 \mathrm{~mm}$. Solid outlines highlight the lesion. Magnified views of boxed areas are shown in the lower panels. Scale bar, $250 \mu \mathrm{m}$. Dashed lines delimitate necrosis. Asterisks mark the hemorrhage. (B) Progression of lesion size produced by cryoinjury or LAD-ligation. Data are means \pm SEM of 3-6 mice per model. Two-way ANOVA followed by Tukey's multiple comparisons test. Significant differences are indicated as ${ }^{* *} p<0.01$, and ${ }^{* * *} p<0.001$. 


\subsection{LAD-ligation leads to a greater scarring and tissue remodeling than cryoinjury}

We next sought to determine if different types of injury lead to alternative remodeling of myocardial ECM. Transverse sections of hearts subjected to cryoinjury or LAD-ligation were assessed using a multi-photon laser scanning microscope to capture multi-photon excitation fluorescence (MPEF) and second harmonic generation (SHG) signals, allowing the visualization of myocyte components and fibrillary collagen, respectively (247) (Figure 12A).

Quantification of SHG signal was carried out in the injury (IZ), the peri-injury (P-IZ) and the remote (RZ) zones, which were defined based on H\&E staining (see Materials and methods). Low percentages of SHG signal were detected in response to both cryoinjury and LAD-ligation in the $I Z$, the $P-I Z$, and the RZ on day 3 post-injury (Figure 12B). At later time points, collagen deposition increased in the $I Z$, with an exacerbated fibrotic response observed after LAD-ligation (Figure 12A, B). Remarkably, LAD-ligation produced a fibrotic scar with a progressive transition towards the healthy myocardium, whereas cryoinjury led to a scar with a sharp edge (Figure 11A, and 12A). This observation translated to increased values of SHG signal in the P-IZ in LAD-ligation versus cryoinjury (Figure 12B). At variance, low $S H G$ signals were observed in the $R Z$ at any time post-injury in both models (Figure 12B), suggesting that ECM remodeling limits to the injured myocardium.

Collectively, the histological observations together with the echocardiography analysis demonstrated that cryoinjury is a model of sterile tissue injury that results in slight worsening of the LV function and mild tissue remodeling compared to infarcts produced by LAD-ligation. 
A

Day 3

Day 7

Day 28
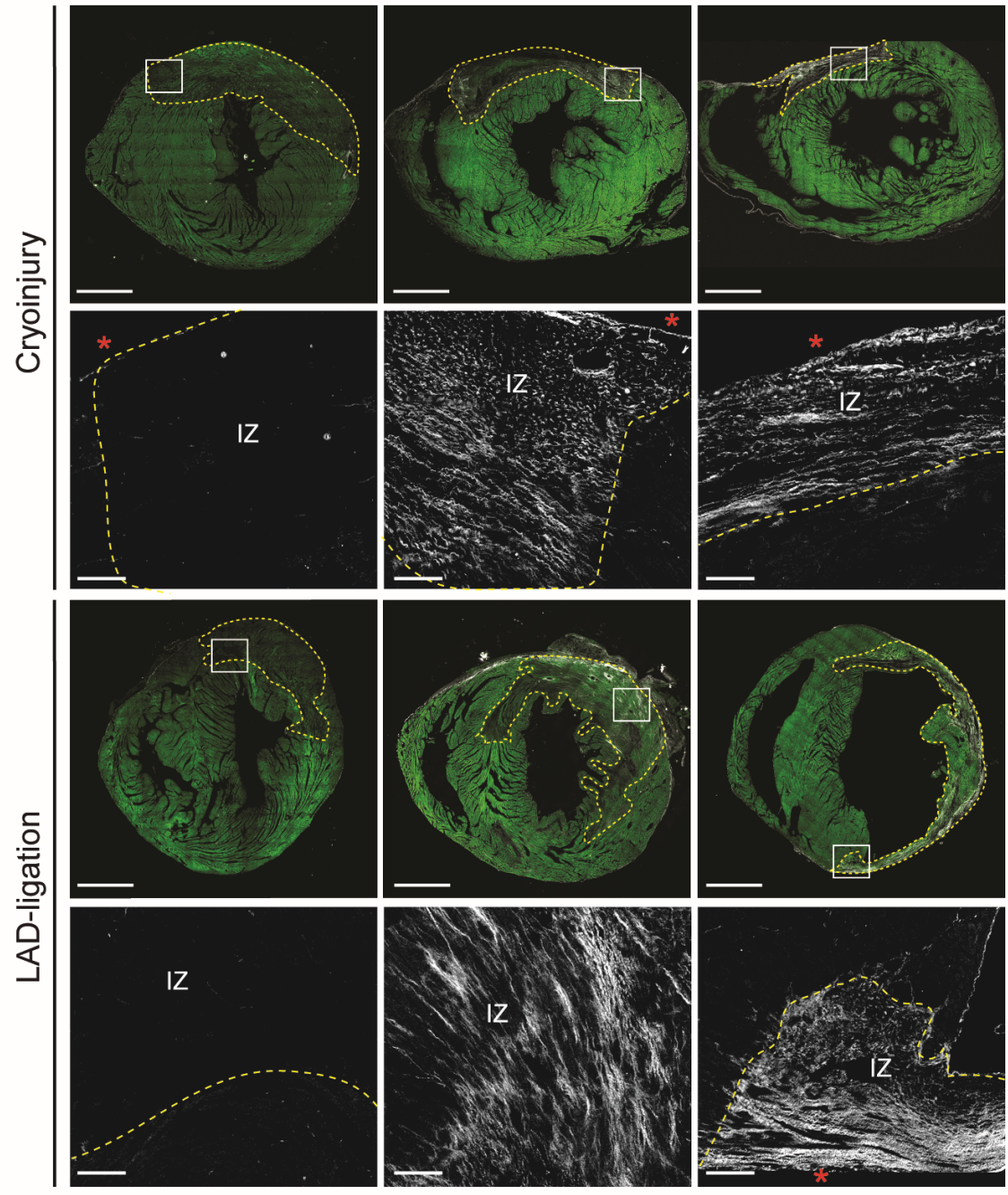

B

$\rightarrow$ Cryoinjury $\rightarrow$ LAD-ligation
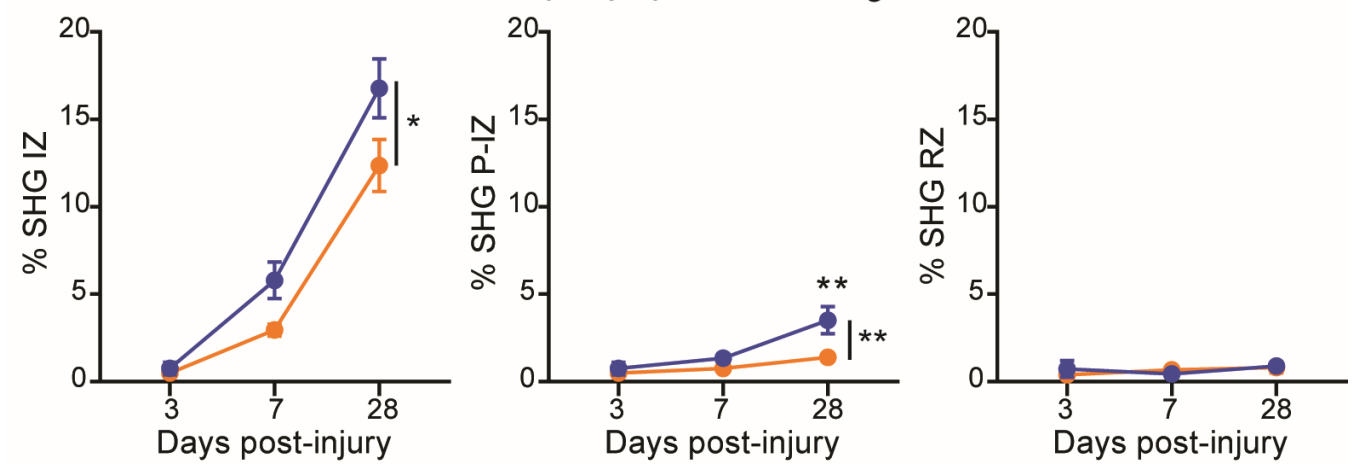

Figure 12. Cryoinjury results in modest scarring and small tissue remodeling compared to LADligation. (A) Representative SHG (white) and MPEF (green) microscopy images of transverse cardiac sections of mice subjected to cryoinjury or LAD-ligation at 3, 7, and 28 days post-injury. Scale bar, $1 \mathrm{~mm}$. Dashed lines highlight the lesion. Magnified views of boxed areas are shown in the lower panels. Scale bar, $100 \mu \mathrm{m}$. Asterisks mark the epicardium. (B) Percentage of SHG at IZ, P-IZ, and RZ following cryoinjury or LAD-ligation at the indicated post-injury stages. Data are means \pm SEM of 3-5 mice per group. Two-way ANOVA followed by Tukey's multiple comparisons test. Significant differences are indicated as * $p<0.05$, and ${ }^{* *} p<0.01$. 


\subsection{Cryoinjury leads to enhanced lymphangiogenic response and arteriole formation compared to LAD-ligation}

We then performed histological studies to assess capillary, lymphatic and arteriolar network remodeling following cardiac injury. Consequently, transverse cardiac sections of healthy (day 0 ) and injured hearts ( 3,7 , and 28 days) were stained with anti-CD31, anti-LYVE1, and antiSMA antibodies, and quantifications were carried out within the IZ.

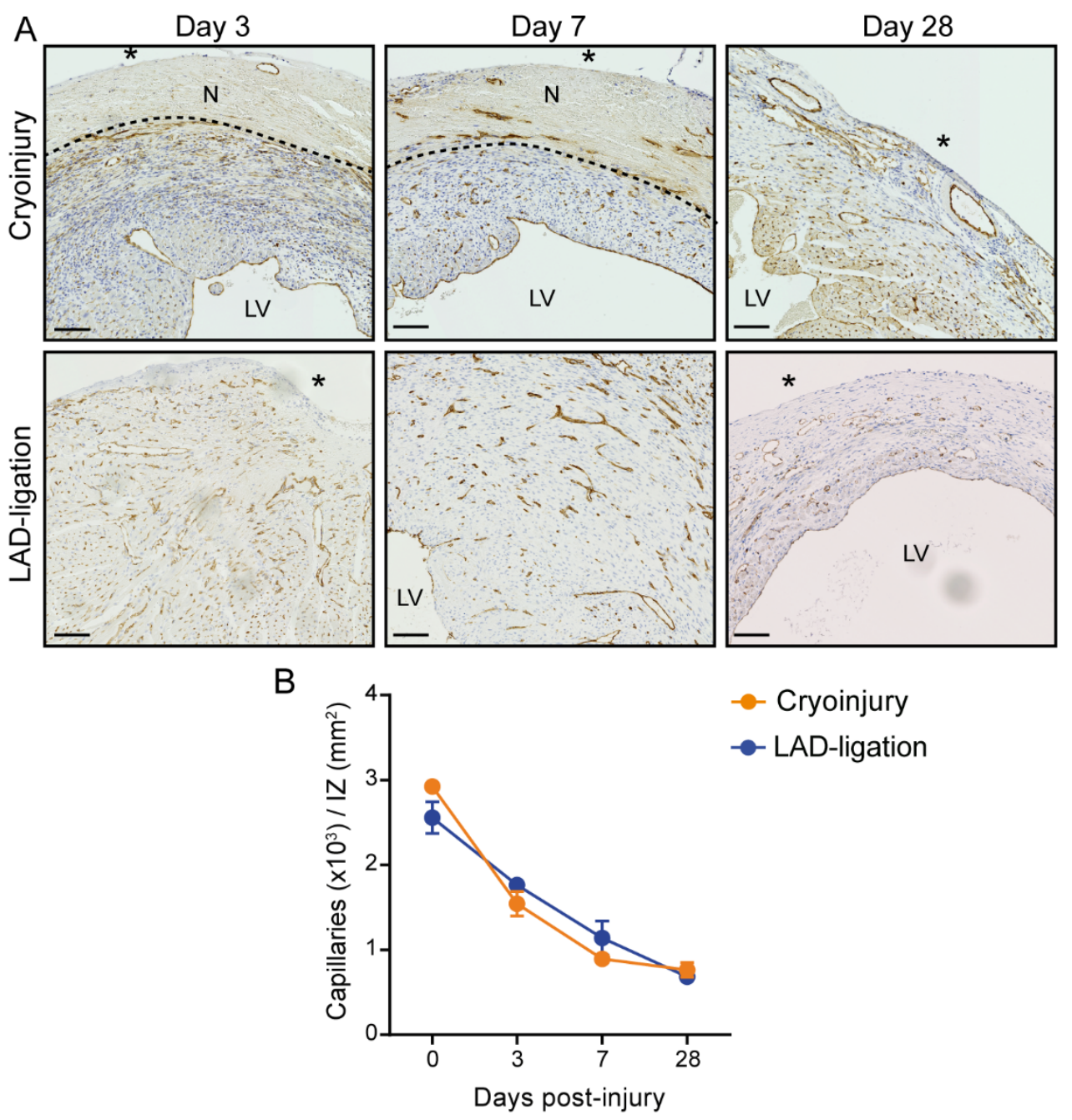

Figure 13. Cardiac injury causes a progressive drop in $\mathrm{CD} 31^{+}$vessel density within the lesion. Representative images of CD31-stained transverse cardiac sections at 3, 7, and 28 days after cryoinjury (top) or LAD-ligation (bottom) showing the IZ. Scale bar, $100 \mu \mathrm{m}$. Dashed lines delimitate necrotic tissue (N). Asterisks mark the epicardium. (B) CD31+ vessels were counted in a blinded fashion in the IZ and capillary density was calculated as the number of CD31 ${ }^{+}$vessels per $\mathrm{mm}^{2}$ of tissue. Data are means $\pm \mathrm{SEM}$ of 3-5 mice. Two-way ANOVA followed by Tukey's multiple comparisons test.

Whereas both models of cardiac injury resulted in identical progressive drop in capillary density and enlargement of CD31+ vessel size within the IZ (Figure 13A), we observed a boost in lymphangiogenesis (LYVE1+ vessels) after injury (Figure 14A, B). In both approaches, newly 
formed large and sac-like lymphatic vessels appeared in the border of the $\mathrm{IZ}$ as early as 3 days post-injury, and this preferential location was maintained over time within the damaged myocardium (Figure 14A). Lymph vessel development further increased during the healing phase (days 7 and 28) in both models but presented a significantly augmented expansion in cryoinjured hearts (Figure 14A, B). A progressive enlargement of lymph vessel size was also patent after injury (Figure 14A).

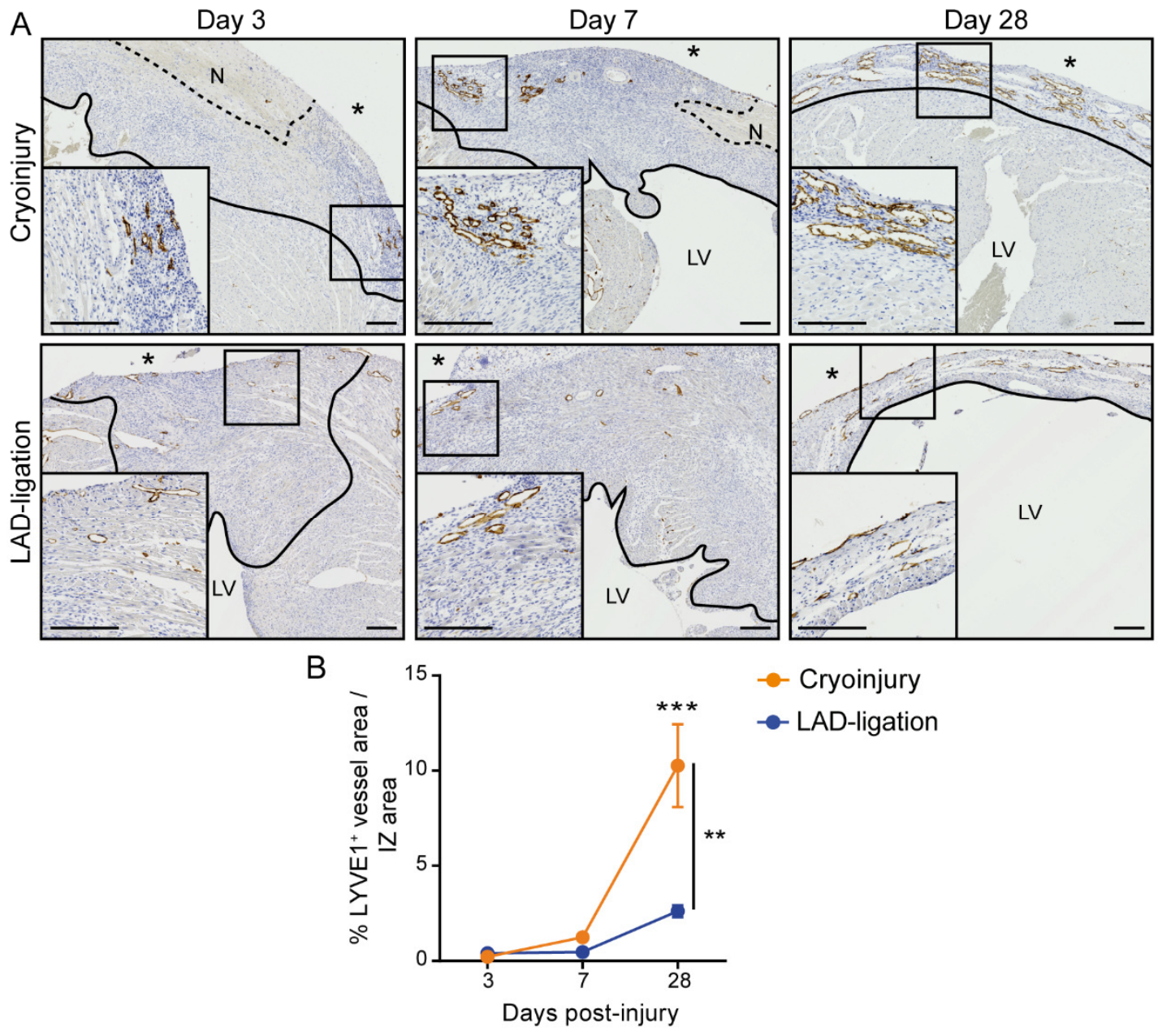

Figure 14. Cryoinjury leads to higher lymphangiogenic response than LAD-ligation. (A) Representative images of LYVE1-stained transverse cardiac sections at 3, 7, and 28 days following cryoinjury (top) or LAD-ligation (bottom) within the IZ. Scale bar, $100 \mu \mathrm{m}$. Outlines highlight injured area and dashed lines delimitate necrotic tissue (N). Asterisks mark the epicardium. Magnified views of depicted insets within the lesion are shown. Scale bar, $100 \mu \mathrm{m}$. (B) Progression of percentage of LYVE1 $1^{+}$vessel area in the IZ at the indicated post-injury stages. Data are means \pm SEM of 4-5 mice. Two-way ANOVA followed by Tukey's multiple comparisons test. Significant differences are indicated as ${ }^{* *} p<0.01$, and ${ }^{* * *} p<0.001$.

Regarding the arteriolar network (SMA ${ }^{+}$vessels), LAD-ligation initially impaired $\mathrm{SMA}^{+}$ vessel density, although basal levels were reestablished on day 7 post-injury and maintained over time. In contrast, cryoinjured hearts underwent significant increase in arteriole numbers at 28 days post-injury (Figure 15A, B). 

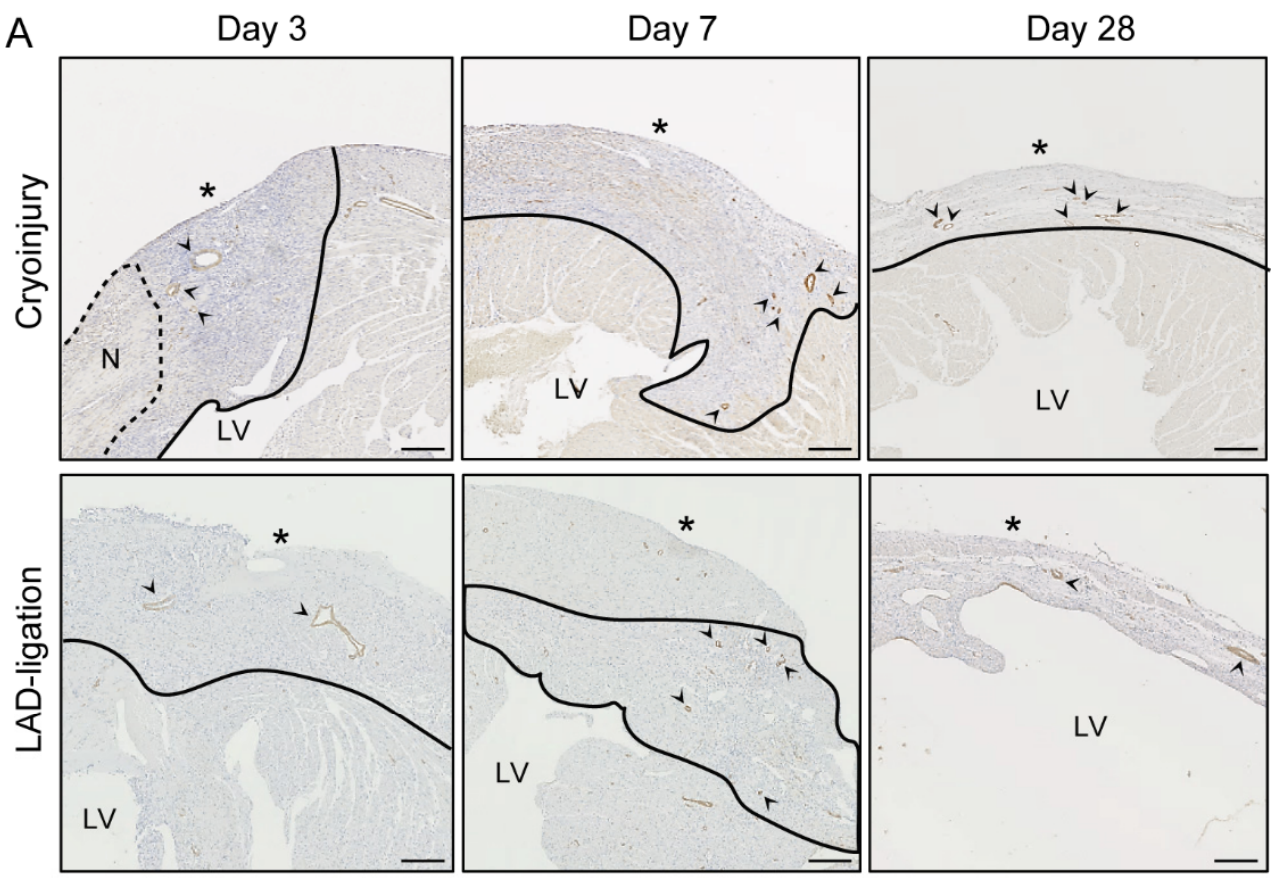

B

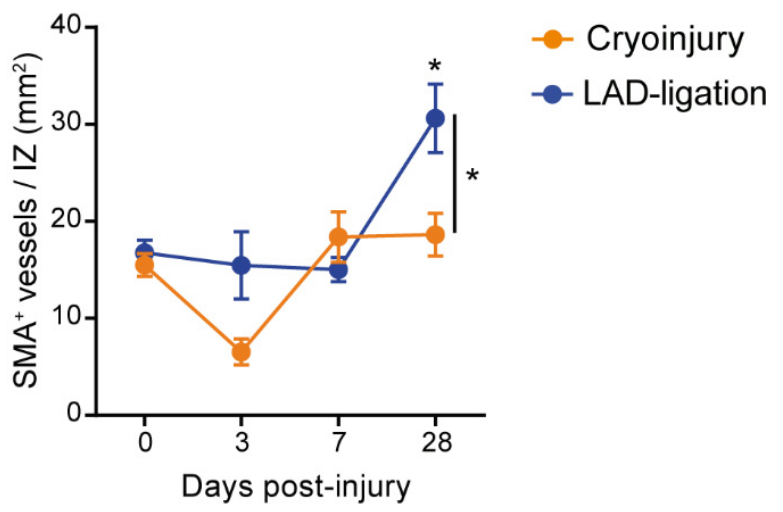

Figure 15. Cryoinjury leads to higher density of arterioles than LAD-ligation. (A) Representative images of SMA-stained transverse cardiac sections at 3, 7, and 28 days after cryoinjury or LAD-ligation. Outlines highlight injured area and dashed lines delimitate necrotic tissue $(N)$. Asterisks mark the epicardium. Arrows point to the arterioles. Scale bar, $100 \mu \mathrm{m}$. (B) SMA ${ }^{+}$vessels were counted in a blinded fashion in the $\mathrm{IZ}$ and arteriolar density was calculated as the number of SMA+ vessels per $\mathrm{mm}^{2}$ of tissue. Data are means \pm SEM of 3-6 mice. Two-way ANOVA followed by Tukey's multiple comparisons test. Significant differences are indicated as * $p<0.05$.

\subsection{Cryoinjury provokes a boosted macrophage mobilization during the inflammatory phase compared to LAD-ligation}

Afterwards, we investigated whether macrophages may differentially contribute to inflammation and myocardial healing after LAD-ligation or cryoinjury. Following a widely used gating strategy (20), we studied inflammatory (F4/80+Ly6C high) and reparative (F4/80+Ly6Clow) macrophages in 3, 7, and 28 day-post-injury hearts by flow cytometry (Figure 16A). Using either cryoinjury or LAD-ligation as injury model, cell quantification revealed that the number of 
$\mathrm{F} 4 / 80^{+}$Ly $6 \mathrm{C}^{\text {high }}$ cells was very low in healthy hearts, reached a maximum peak on day 3 after injury, and started to decline on day 7 . In contrast, F4/80+Ly6Clow cells represented the predominant cardiac macrophage population in homeostasis, gradually increased after injury, reaching a maximum peak on day 7 , and dropped again on day 28 post-injury (Figure 16B). Interestingly, although the described kinetics was similar in hearts that underwent either cryoinjury or LADligation, cryoinjury triggered a significantly higher recruitment of $F 4 / 80^{+}+\mathrm{L} 6 \mathrm{C}^{\text {high }}$ macrophages during the inflammatory phase (Figure 16B), suggesting a greater capacity of cryoinjury model to mobilize inflammatory cells than LAD-ligation.

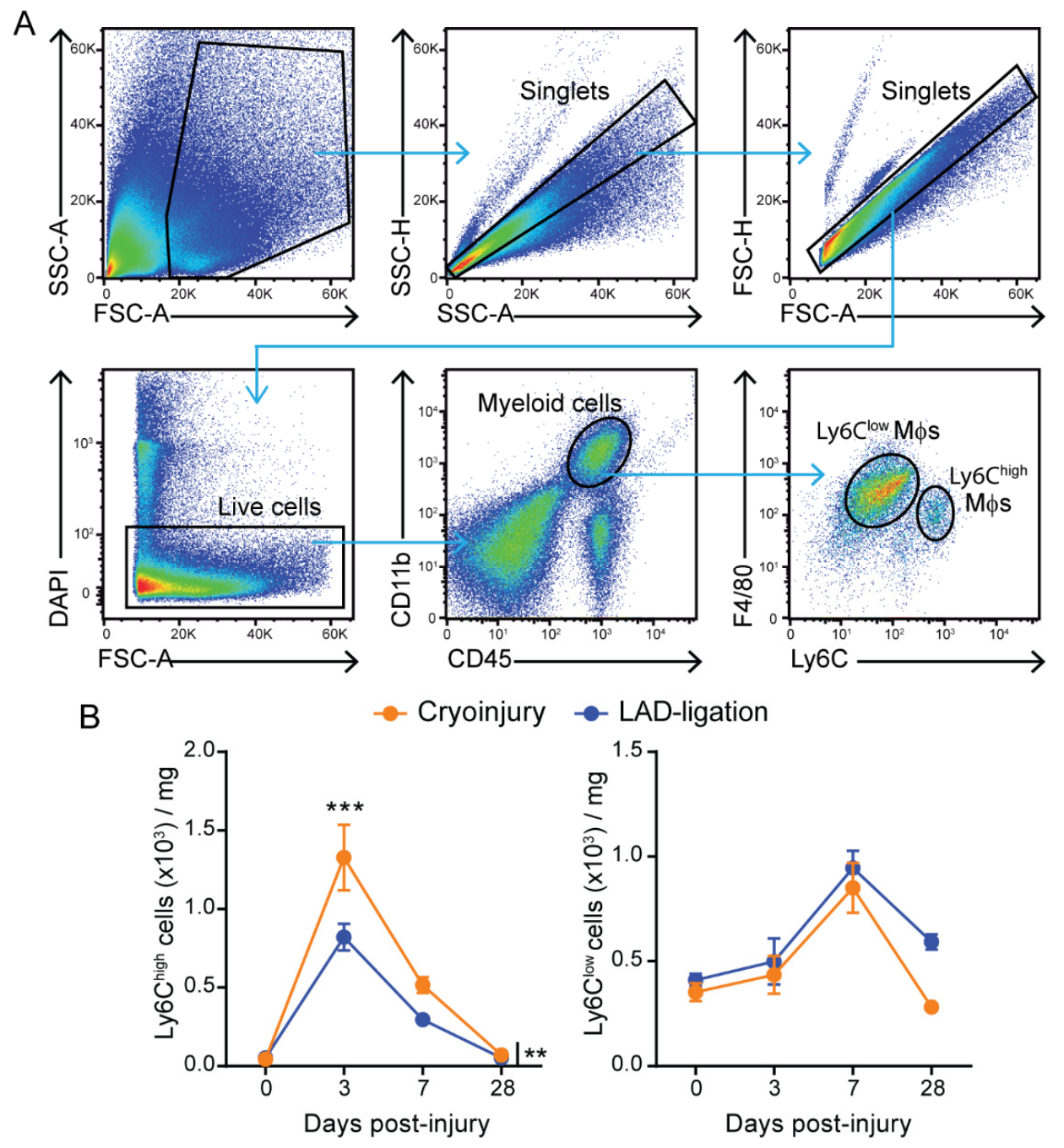

Figure 16. Cryoinjury results in a boosted macrophage response at early post-injury stages than LAD-ligation. Single-cell suspensions from healthy (day 0 ) and injured hearts (days 3,7 , and 28 ) were analyzed by flow cytometry following cryoinjury or LAD-ligation. (A) Representative plots showing the gating strategy for the identification of $\mathrm{F} 4 / 80^{+} \mathrm{Ly} 6 \mathrm{C}^{\text {low }}$ and $\mathrm{F} 4 / 80^{+} \mathrm{Ly} 6 \mathrm{C}^{\text {high }}$ cardiac macrophage subsets. (B) Quantification of $\mathrm{F} 4 / 80^{+} \mathrm{Ly} 6 \mathrm{C}^{\text {high }}$ cells (left) and F4/80+Ly6Clow cells (right) per mg of cardiac tissue before and after cryoinjury or LAD-ligation at the indicated post-injury stages. Data are means \pm SEM of 3 independent experiments with a total number of 10-15 mice per group. Two-way ANOVA followed by Tukey's multiple comparisons test. Significant differences are indicated as ${ }^{* *} p<0.01$, and ${ }^{* * *} p<0.001$. M $\phi s:$ macrophages. 


\subsection{Cryoinjury and LAD-ligation lead to disparate patterns of macrophage activation}

To gain insight into macrophage phenotype during myocardial repair, F4/80+Ly6Clow cells were purified to characterize CRMs (day 0) and macrophages in the reparative phase (7 and 28 days post-injury), while $\mathrm{F} 4 / 80^{+} \mathrm{Ly} 6 \mathrm{C}^{\text {high }}$ cells were isolated to assess the characteristics of macrophages in the inflammatory phase (3 days post-injury) following cryoinjury or LAD-ligation (Figure 17A). Myocardial injury resulted in decreased expression of CRM-associated markers (Lyve1, Mertk, Mrc1, and Cd163) (20), with significantly better preserved Mertk mRNA levels in post-cryoinjury macrophages (Figure 17B). Expression of CRM-related genes was almost completely restored on day 28 after injury (Figure 17B). We next investigated the expression of pro-inflammatory genes. As expected, these genes were upregulated in macrophages during the inflammatory phase (day 3 ) and some of them were remarkably higher expressed by macrophages isolated after cryoinjury ( $L y 6 C$, II6 and Nos2) (Figure 17B), confirming the inflammatory potential of this model. Myocardial injury induced expression of genes related to ECM remodeling, such as Mmp14 (MT1-MMP) and its substrate Mmp2, in cardiac macrophages during the reparative phase (Figure 17B). In contrast, other MMP family members (i.e. Mmp13) were downregulated after injury (Figure 17B). The expression of tissue inhibitor metalloproteinase 3 (Timp3) raised in macrophages found after cryoinjury but not in post-LAD-ligation macrophages. Notably, we found that cardiac macrophages purified from mice subjected to LAD-ligation expressed significantly higher levels of Mmp14 than those obtained from cryoinjured hearts (Figure 17B). According to the greater LV remodeling and severe cardiac dysfunction observed in the LAD-ligation versus cryoinjury model (Figure 10 and 12), this finding suggests that exacerbated macrophage MT1MMP production may mediate adverse ECM remodeling in an experimental model of MI. 
A Gated on $\mathrm{CD} 45^{+} \mathrm{CD} 11 \mathrm{~b}^{+}$cells

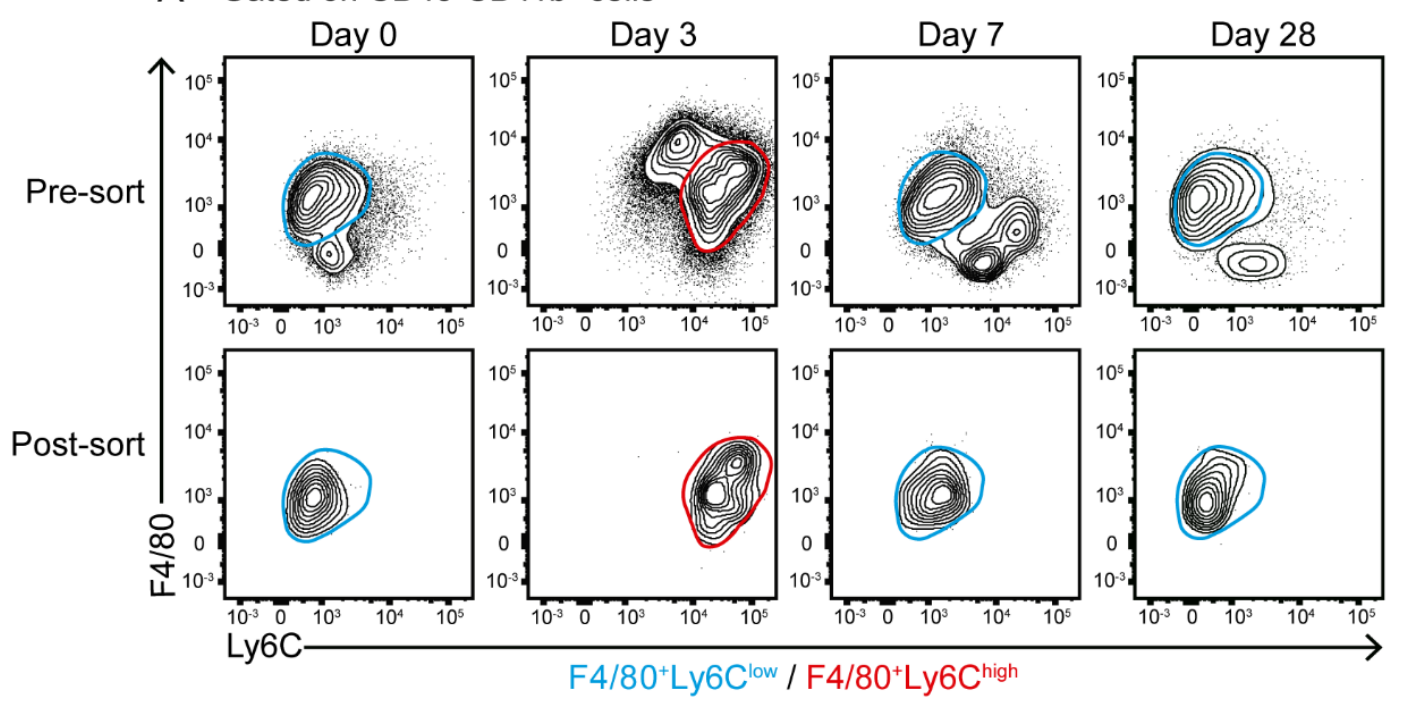

B

Lyve1

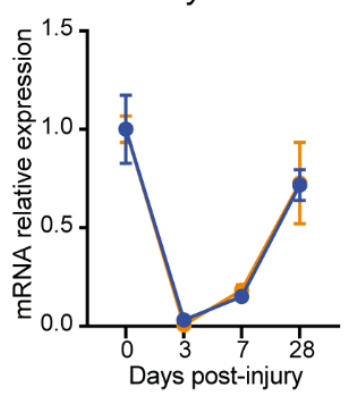

Ly6C

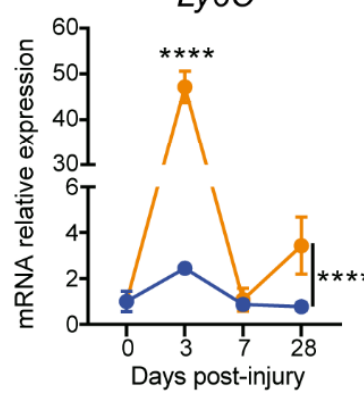

Mmp14

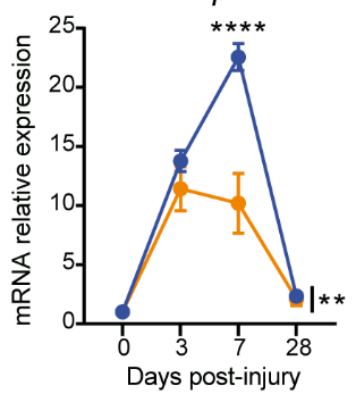

$\rightarrow$ Cryoinjury $\rightarrow$ LAD-ligation

MerTK

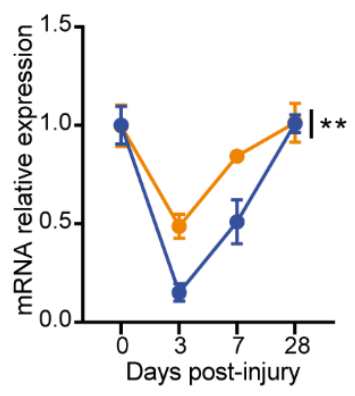

116

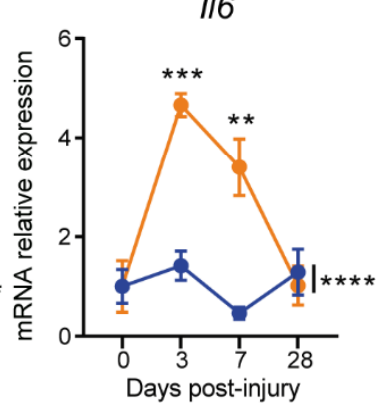

Mmp2

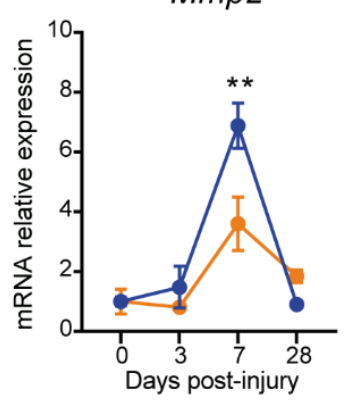

Mrc1

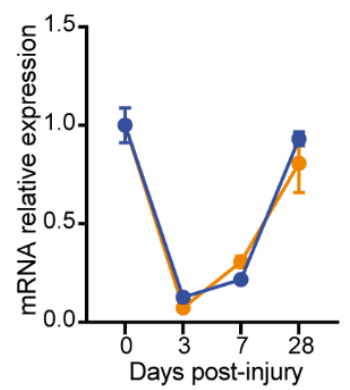

Nos2

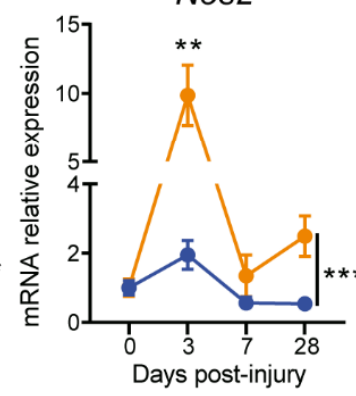

Mmp13

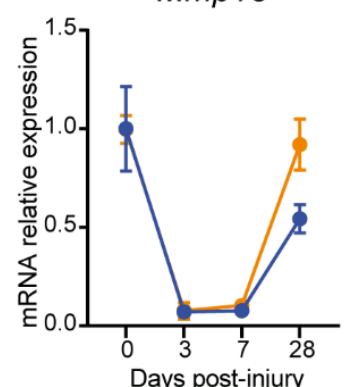

Cd163

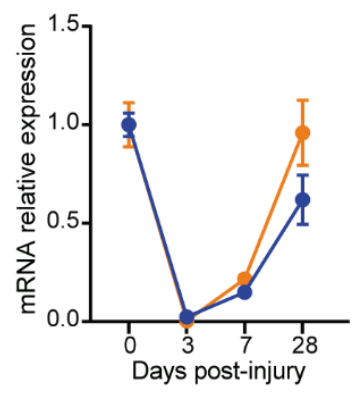

Ptgs2

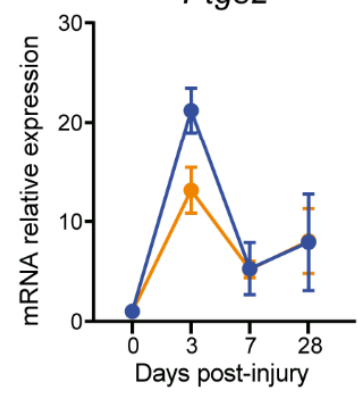

Timp3

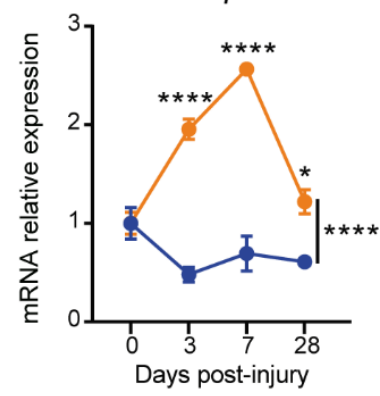

Figure 17. Isolation and gene expression profile of cardiac macrophages after cryoinjury or LADligation. FACS gating strategy to purify cardiac macrophages is indicated in Figure 16A. (A) From the myeloid cell population $\left(C D 45^{+} C D 11 b^{+}\right.$cells), F4/80+Ly6Clow cells (blue) were sorted for 0,7 , and 28 days post-injury, while $\mathrm{F} 4 / 80^{+} \mathrm{Ly} 6 \mathrm{C}^{\text {high }}$ cells (red) were purified for 3 days post-injury. Representative post-sort 
plots of macrophages are shown in the lower panel. Sorting was performed with a pool of 3-5 mice per time point. (B) mRNA expression levels of genes assessed by qPCR in sorted macrophages at the indicated post-injury stages. Data are means \pm SEM of 3 independent pools of 3-5 mice per time point. Two-way ANOVA followed by Tukey's multiple comparisons test. Significant differences are indicated as * $p<0.05$, ${ }^{* *} p<0.01,{ }^{* * *} p<0.001$, and ${ }^{* * * *} p<0.0001$.

\section{Unraveling the role of macrophage MT1-MMP on post-MI LV remodeling and function}

Our discovery of MI-induced Mmp14 expression in macrophages prompted us to decipher the potential contribution of macrophage-derived MT1-MMP to cardiac remodeling after MI.

\subsection{Analysis of the suitability of the mouse model employed for macrophage-specific MT1-MMP deletion}

To explore the role of macrophage-derived MT1-MMP in post-MI LV function and remodeling, we generated a macrophage-specific KO mouse for Mmp14. LysM-Cre mice (227) were crossed with MT1-MMP/f mice (228), resulting in the deletion of exons 4 and 5 in the floxed Mmp14 allele in MT-MMP ${ }^{\triangle L y s M}$ mice $\left(\mathrm{Cre}^{+}\right.$mice) (Figure 18A). MT1-MMP ${ }^{\text {f/f }}$ littermates (Cre-) were used as controls. MT1-MMP ${ }^{\triangle L y s M}$ mice and their control MT1-MMPf/f littermates showed no significant differences either in heart and body weight or in baseline cardiac function (Table 4). Furthermore, no differences were found in baseline circulating monocytes and neutrophils between genotypes (Figure 18B, C, and Table 5).

Mmp14 was efficiently deleted in BM-derived macrophages (BMDMs) and in cardiac macrophages sorted from MT1-MMP ${ }^{\Delta L y s M}$ mice 7 days after post-MI, following the gating strategy depicted in Figure 16A (Figure 18D). In contrast, Mmp14 expression did not differ between ECs purified at 7 days post-MI from MT1-MMPf/f and MT1-MMP ${ }^{\Delta L y s M}$, following the gating strategy indicated in Figure 26A (Figure 18D). Additionally, the low efficiency recombination of the LysMCre system in other myeloid cells (i.e. monocytes and dendritic cells) rather than macrophages (248) makes MT1-MMP ${ }^{\Delta L y s M}$ mouse a suitable model to study the functional impact of macrophage MT1-MMP deletion in acute MI. 


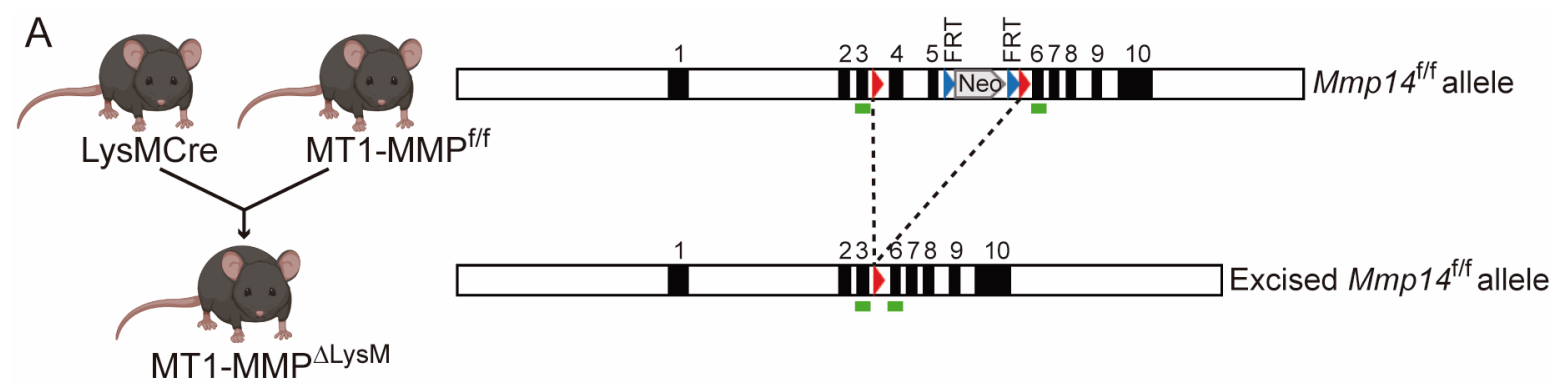

B Gated on live cells
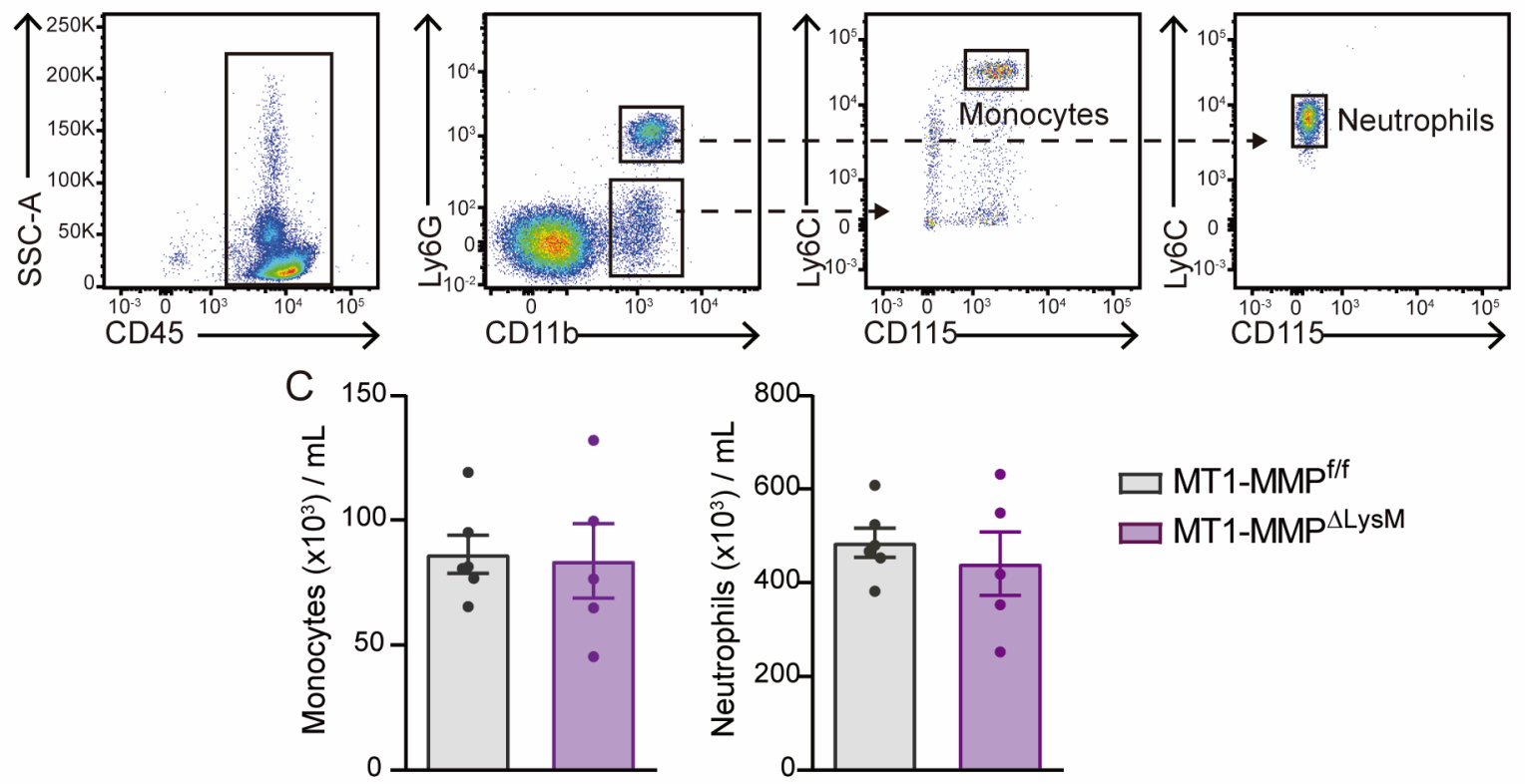

D

\section{BMDMs}

Cardiac $M \phi s$

Cardiac ECs
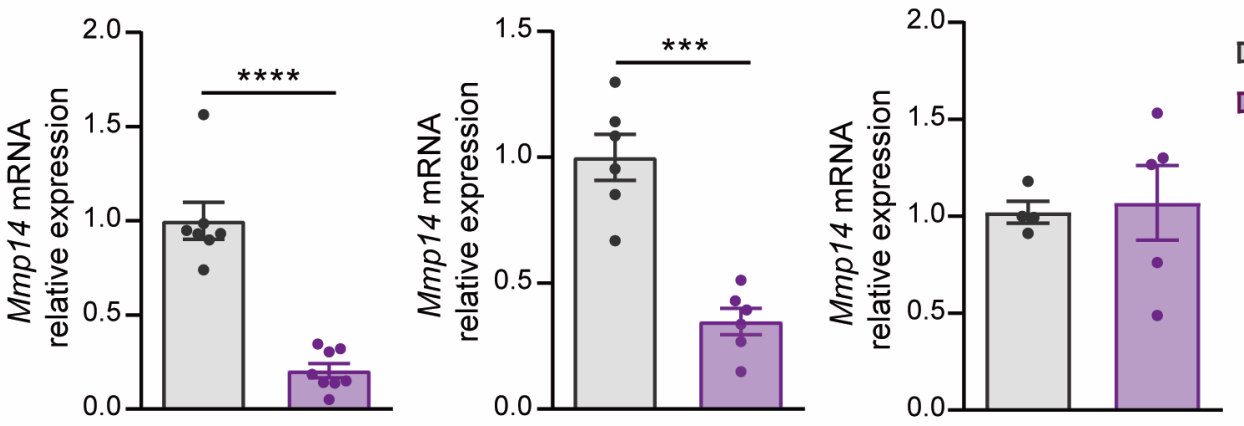

Figure 18. Mouse model of macrophage-specific MT1-MMP deletion. (A) Strategy for generating the transgenic mouse line used for macrophage Mmp14 deletion. LoxP sites (red arrowheads) were introduced flanking exons 4 and 5, and a FRT-PGK-Neo-FRT-cassette was inserted between exons 5 and 6 to generate the $M m p 14^{f / f}$ construct (top, right). To obtain macrophage Mmp14 deletion, MT1-MMPf/f mice were crossed with LysM-Cre mice, yielding the floxed Mmp14 allele (bottom, right) in MT1-MMP ${ }^{\Delta \text { Lys }}$ mice. Green rectangles indicate alignment position for genotyping primers. (B) Representative plots showing the gating strategy for the identification of circulating monocytes (CD45+CD11 $\mathrm{b}^{+}$Ly6G-CD115 $5^{+}$Ly6 $\mathrm{C}^{\text {high }}$ ) and neutrophils

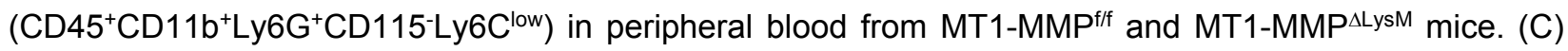
Total numbers of baseline circulating monocytes and neutrophils as depicted in B. Data are means \pm SEM of 5-6 mice per genotype Unpaired $t$-test. (D) qPCR analysis of Mmp14 deletion efficiency in BMDMs and FACS-sorted 7-day-post-MI cardiac macrophages $\left(\mathrm{CD} 45^{+} \mathrm{CD} 11 \mathrm{~b}^{+} \mathrm{F} 4 / 80^{+} \mathrm{Ly} 6 \mathrm{C}^{\text {low }}\right.$ cells) and ECs (CD45$\mathrm{CD} 11 \mathrm{~b}^{-C D} 31^{+}$cells) from MT1-MMP/f and MT1-MMP ${ }^{\Delta L y s M}$ mice. Data are means \pm SEM of 7 mice per 
genotype (for BMDMs) or 4-6 independent pools of 2 mice per genotype (for cardiac macrophages and cardiac ECs). Unpaired $t$-test. Significant differences are indicated as ${ }^{* * *} p<0.001$, and ${ }^{* * *} p<0.0001$. M $\phi$ : macrophages.

\begin{tabular}{lcc}
\hline & MT1-MMP $^{\text {f/f }}$ & MT1-MMP $^{\Delta \text { LysM }}$ \\
\hline BW $(\mathrm{g})$ & $18.62 \pm 2.00$ & $19.53 \pm 2.25$ \\
HW/BW $(\mathrm{mg} / \mathrm{g})$ & $4.91 \pm 0.28$ & $4.94 \pm 0.19$ \\
HR (beats/min) & $462 \pm 14$ & $463 \pm 17$ \\
PR (ms) & $39.82 \pm 1.18$ & $37.70 \pm 1.21$ \\
QRS $(\mathrm{ms})$ & $25.41 \pm 1.06$ & $26.18 \pm 0.88$ \\
LVEF $(\%)$ & $53.52 \pm 1.72$ & $53.14 \pm 2.31$ \\
LVVols $(\mu \mathrm{L})$ & $21.53 \pm 1.36$ & $19.98 \pm 1.60$ \\
LVVold $(\mu \mathrm{L})$ & $25.26 \pm 0.96$ & $22.22 \pm 0.90$ \\
FS $(\%)$ & $26.58 \pm 0.89$ & $26.33 \pm 1.51$ \\
LVIDs $(\mathrm{mm})$ & $3.67 \pm 0.06$ & $3.54 \pm 0.08$ \\
LVIDd $(\mathrm{mm})$ & $2.7 \pm 0.06$ & $2.62 \pm 0.10$ \\
\hline
\end{tabular}

Table 4. Macrophage MT1-MMP deletion does not affect homeostatic cardiac function. Echocardiography and electrocardiography comparisons between 10-week-old MT1-MMPf/f and MT1$M_{M P}^{\triangle L y s M}$ mice. Data are means \pm SEM of 10 mice per group. Unpaired $t$-test. BW, body weight; HW, heart weight; HR, heart rate; LVEF, LV ejection fraction; LVVols, LV end-systolic volume; LVVold, LV end-diastolic volume; FS, fraction shortening; LVIDs, LV end-systolic internal diameter; LVIDd, LV end-diastolic internal diameter.

\begin{tabular}{lcccc}
\hline & \multicolumn{2}{c}{ MT1-MMP/f } & \multicolumn{2}{c}{ MT1-MMP ${ }^{\text {aLysM }}$} \\
\hline Neutrophils & $9.50 \pm 0.98$ & $0.74 \pm 0.11$ & $11.01 \pm 1.43$ & $0.88 \pm 0.13$ \\
Lymphocytes & $86.75 \pm 1.29$ & $6.97 \pm 1.00$ & $84.79 \pm 1.68$ & $6.84 \pm 0.54$ \\
Monocytes & $0.89 \pm 0.14$ & $0.08 \pm 0.02$ & $1.20 \pm 0.13$ & $0.10 \pm 0.01$ \\
Eosinophils & $2.45 \pm 0.44$ & $0.21 \pm 0.06$ & $2.48 \pm 0.51$ & $0.20 \pm 0.04$ \\
Basophils & $0.41 \pm 0.08$ & $0.03 \pm 0.01$ & $0.53 \pm 0.09$ & $0.05 \pm 0.01$ \\
\hline
\end{tabular}

Table 5. Macrophage MT1-MMP deletion does not affect circulating bone-marrow derived populations. Hematograms from 10-week-old MT1-MMPf/f and MT1-MMP $\Delta$ LysM mice. Data are means \pm SEM of 8 mice per group. Unpaired $t$-test. 


\subsection{Macrophage-restricted MT1-MMP deficiency attenuates LV dysfunction and dilation after $\mathrm{MI}$ in mice}

To gain insight into the relevance of macrophage-produced MT1-MMP to cardiac healing, we induced $\mathrm{Ml}$ in adult MT1-MMP ${ }^{\mathrm{fff}}$ and $\mathrm{MT1}$-MMP ${ }^{\triangle L}$ ysM mice by permanent coronary ligation (LADligation). LV function and remodeling were followed up by echocardiography at 0,7 , and 28 days post-MI (Table 4). Infarction was confirmed by the presence of wall-motion abnormalities (Supplementary Video 5). Echocardiography revealed that macrophage-specific deletion of MT1MMP ameliorated LV dysfunction and prevented LV dilation post-MI, with MT1-MMP ${ }^{\triangle L y s M}$ mice having a significantly higher LV ejection fraction (LVEF) and lower LV end-diastolic volume (LVVold) (Figure 19A, B, and Supplementary Video 5). Infarct size and LV wall motion score index (WMSI) were calculated by echocardiography to assess global and regional cardiac contractility abnormalities (234) (Figure 19B, C, and see Materials and methods). This analysis showed that LAD-ligation produced smaller infarcts and a lower WMSI in MT1-MMP ${ }^{\triangle L y s M}$ mice (Figure 19B, C), indicating better preservation of cardiac function and less pronounced wallmotion abnormalities in the LV when macrophage MT1-MMP was absent. 

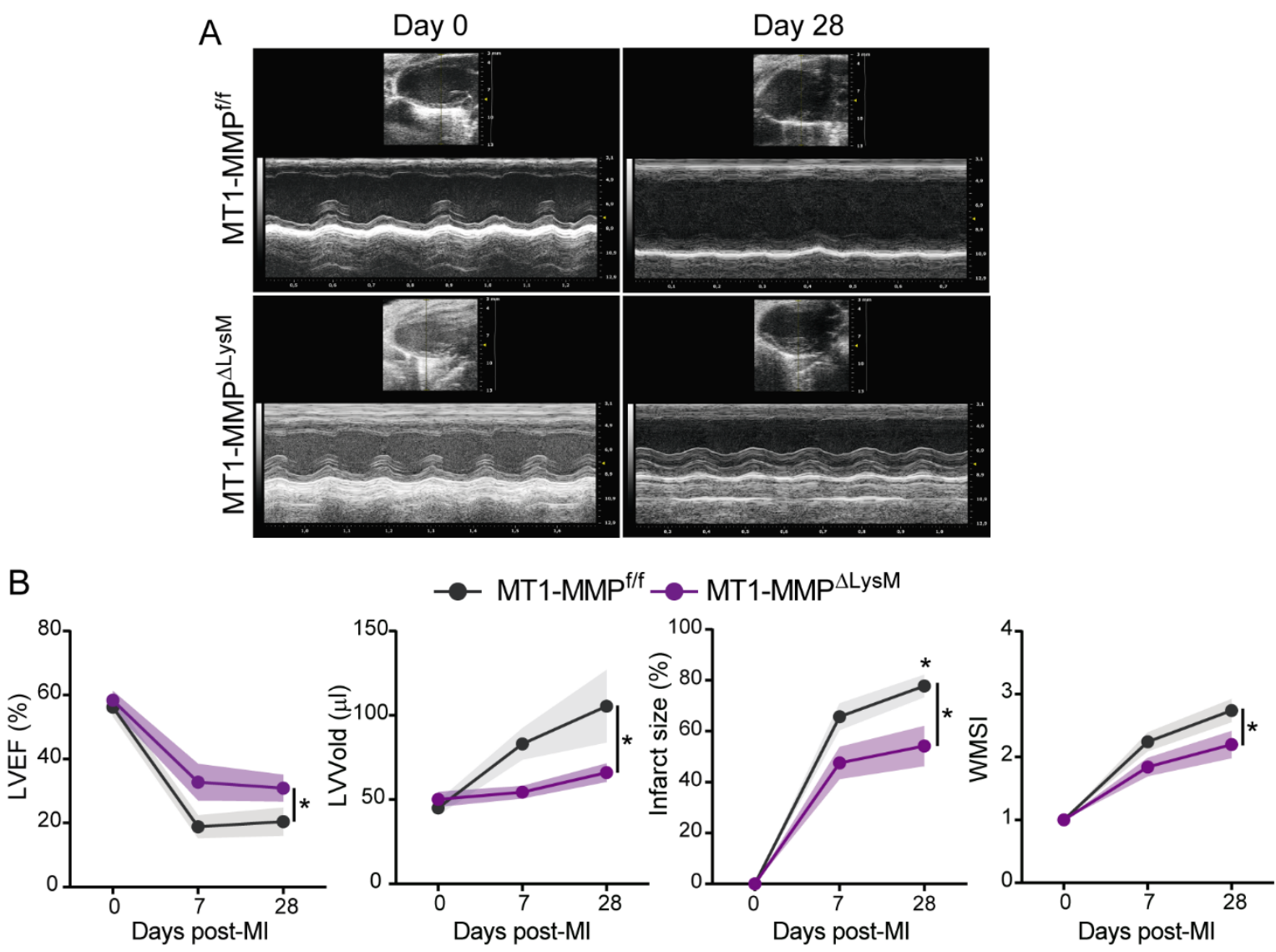

C
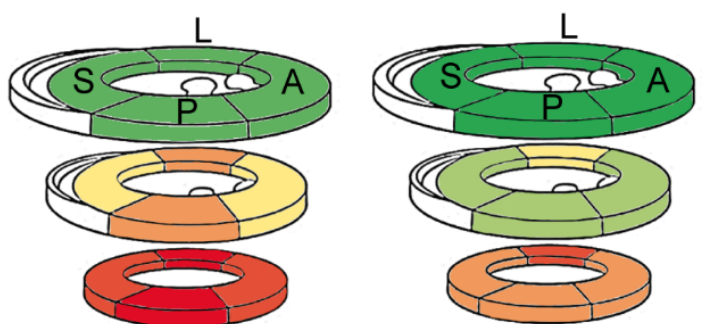

Basal
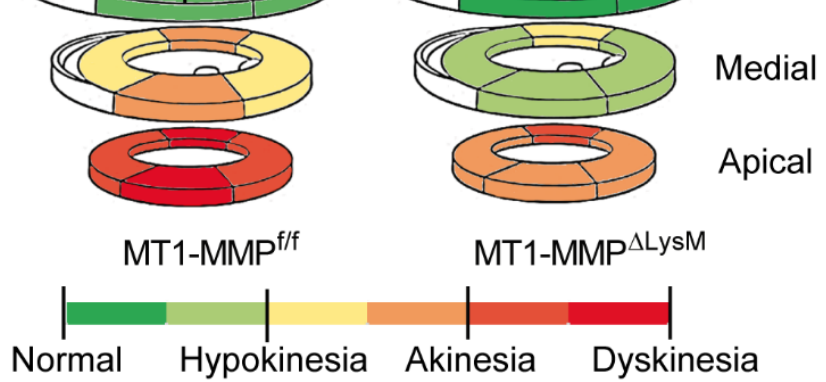

MT1-MMP ${ }^{\Delta L y s M}$

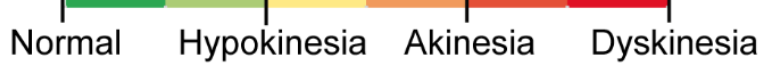

Figure 19. Macrophage MT1-MMP deletion ameliorates LV dysfunction and remodeling after MI. (A) Representative LV M-mode long-axis echocardiography views at end-diastole on day 0 and day 28 post-MI in MT1-MMPf/f and MT1-MMP ${ }^{\triangle L y s M}$ mice. (B) Post-MI progression of LVEF, LVVold, infarct size (\% of LV segments with contractility alterations), and WMSI assessed by echocardiography. Data are means \pm SEM of 9-10 mice per genotype. Two-way ANOVA followed by Tukey's multiple comparisons test. Significant differences are indicated as * $p<0.05$. (C) Quantitative assessment of LV contractility at 28 days post-MI, showing mean scores for every LV segment at the basal, medial, and apical levels throughout all samples. $\mathrm{L}$, lateral; $\mathrm{A}$, anterior; $\mathrm{P}$, posterior; $\mathrm{S}$, septal. Segment scores are colored-coded from green to red: green = normal, yellow $=$ hypokinesia, orange $=$ akinesia $=$, and red $=$ dyskinesia or aneurysm. 


\subsection{Macrophage-restricted MT1-MMP deficiency reduces post-MI fibrosis}

MT1-MMP can process a variety of ECM components, so we next analyzed the fibrotic response to MI. Transverse sections of 28-day-post-MI hearts were assessed using a multi-photon laser scanning microscope to capture MPEF and SHG signals. SHG images of the infarct revealed a highly directional and organized collagen fibril morphology in the MT1-MMPf/finfarcted group, whereas a less-organized and sparse collagen structure was observed in MT1-MMP ${ }^{\Delta L y s M}$ infarcted hearts (Figure 20A). Quantification of SHG signal unveiled a marked drop in fibrillary collagen density in MT1-MMP ${ }^{L L y s M}$ compared to MT1-MMPf/finfarcted hearts (Figure 20B). In addition, the analysis of first-order features of collagen fibrils in SHG microscopy images showed augmented skewness and kurtosis in MT1-MMP ${ }^{\Delta L y s M}$ mice, indicating thinner and underdeveloped, disarrayed collagen fibers and thus lower tissue stiffness (Figure 20B). Overall, these data indicate that macrophage MT1-MMP-deficiency altered myocardial ECM remodeling, leading to a reduced and underdeveloped fibrotic scar. This observation correlates with the attenuation of LV dysfunction found in MT1-MMP ${ }^{\Delta L y s M}$ mice after MI (Figure 19).

\subsection{The absence of macrophage MT1-MMP ameliorates cardiac dysfunction and reduces collagen deposition in a model of transient ischemia}

We also investigated the effect of macrophage-specific MT1-MMP deletion during transient myocardial ischemia. After an ischemic event, some patients are rapidly admitted to the hospital for reperfusion therapy to restore blood flow in the myocardium. Nevertheless, there are distinct circumstances that could prolong the ischemia before the patient can be treated at the hospital to eliminate the coronary obstruction. Accordingly, the establishment of different models of $\mathrm{MI}$ in experimental mice is highly valuable to adequate to both contexts.

Similar to the permanent occlusion model, ischemia/reperfusion (I/R) impaired LV function in both genotypes, but MT1-MMP ${ }^{\triangle L y s M}$ mice had a significantly higher LVEF and lower LV endsystolic and end-diastolic internal diameters (LVIDs and LVIDd, respectively) (Figure 21A), indicating better preserved LV function and milder LV dilation. Moreover, SHG imaging analysis after I/R revealed a weaker fibrotic response, with thinner and sparser collagen fibers in MT1$M_{M P}^{\triangle L y s M}$ hearts (Figure 21B, C). Altogether, these data indicate that macrophage MT1-MMPdeficiency decreases collagen fiber deposition, producing a smaller and underdeveloped fibrotic scar that prevents early post-MI LV dilation and systolic dysfunction after transient or permanent cardiac ischemia. 


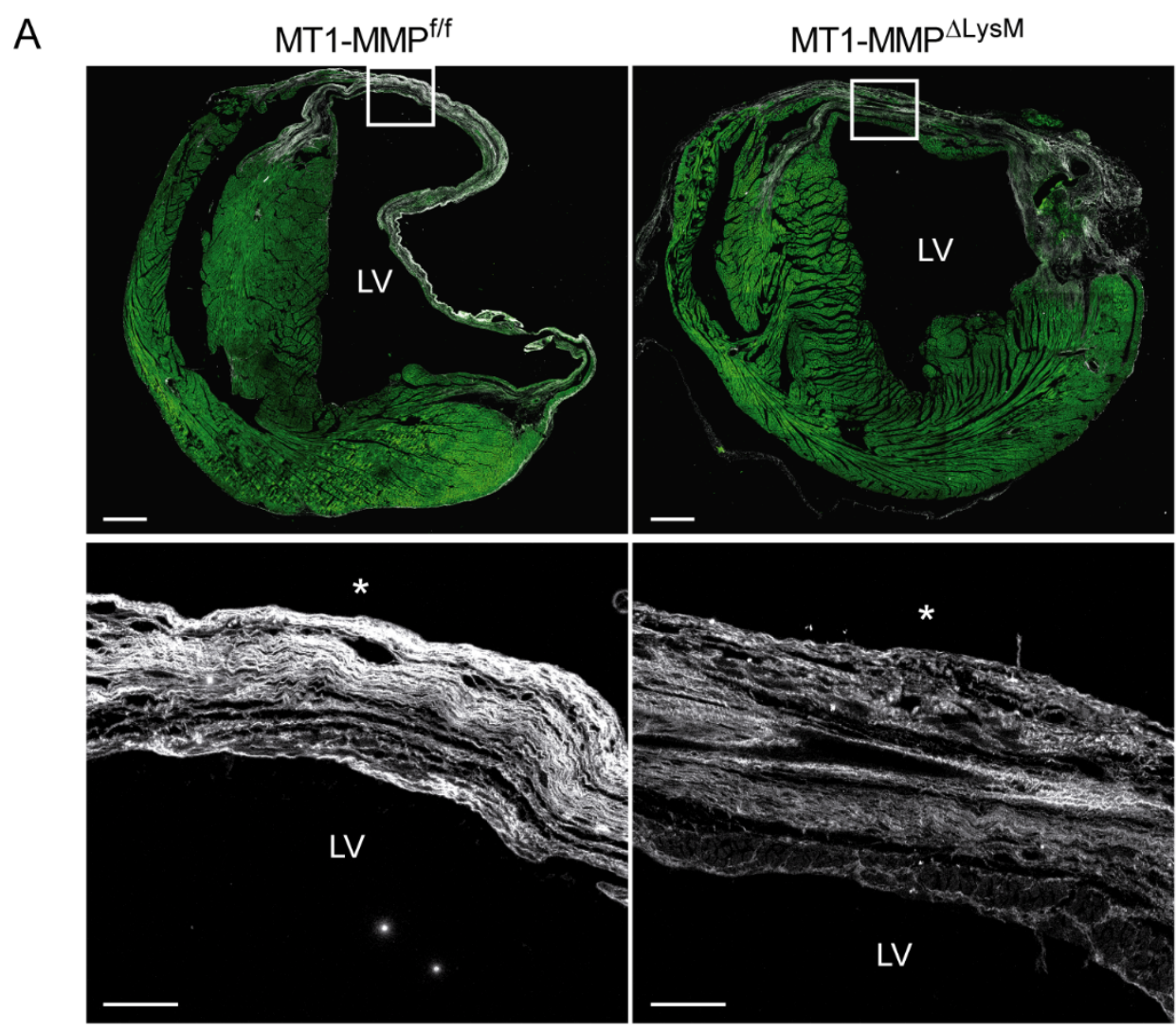

B

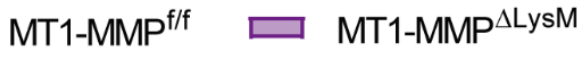
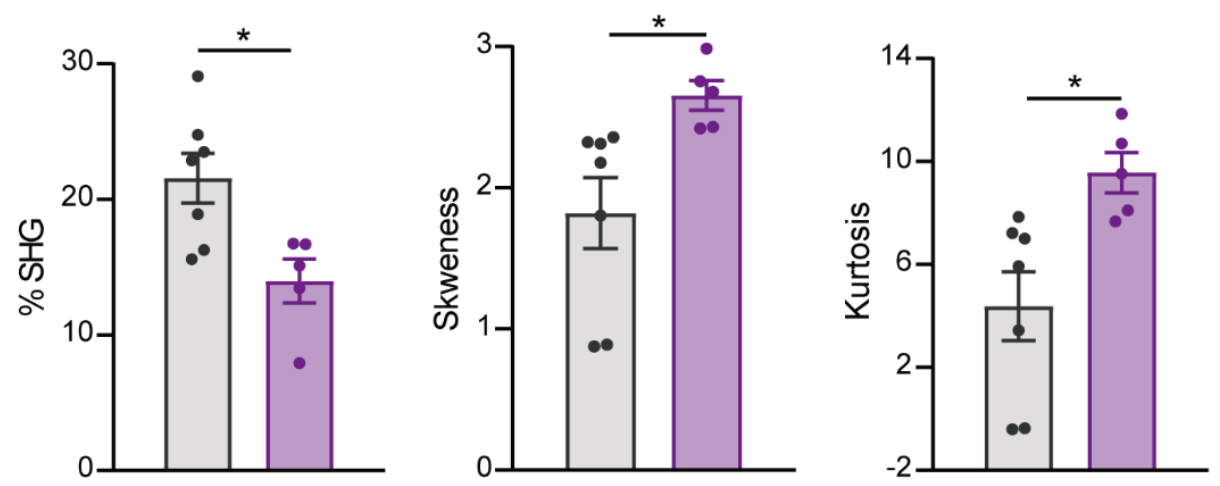

Figure 20. Macrophage MT1-MMP deletion attenuates collagen deposition after MI. (A) Representative SHG (white) and MPEF (green) microscopy images of transverse cardiac sections at 28 days after LADligation. Scale bar, $500 \mu \mathrm{m}$. Magnified views of boxed areas within the infarct are shown in the lower panels. Scale bar, $100 \mu \mathrm{m}$. Asterisks mark the epicardium. (B) Percentage SHG, skewness, and kurtosis in infarcts at 28 days post-MI. Data are means \pm SEM of 5-7 mice per genotype. Unpaired $t$-test. Significant differences are indicated as * $p<0.05$. 

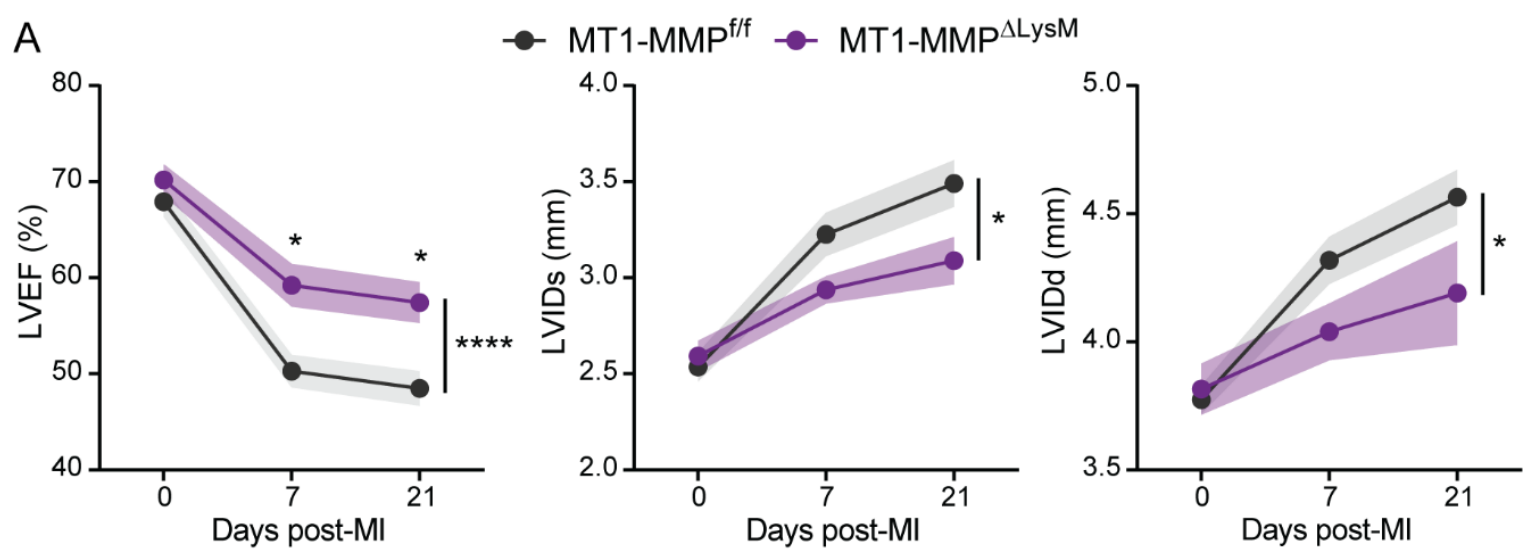

B

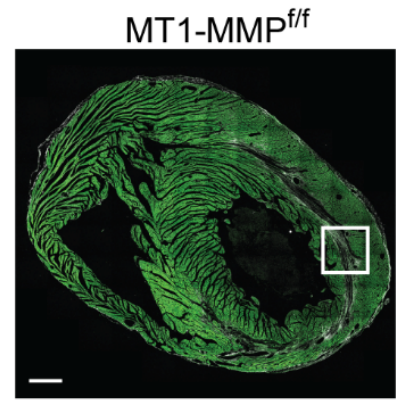

MT1-MMP ${ }^{\Delta L y s M}$
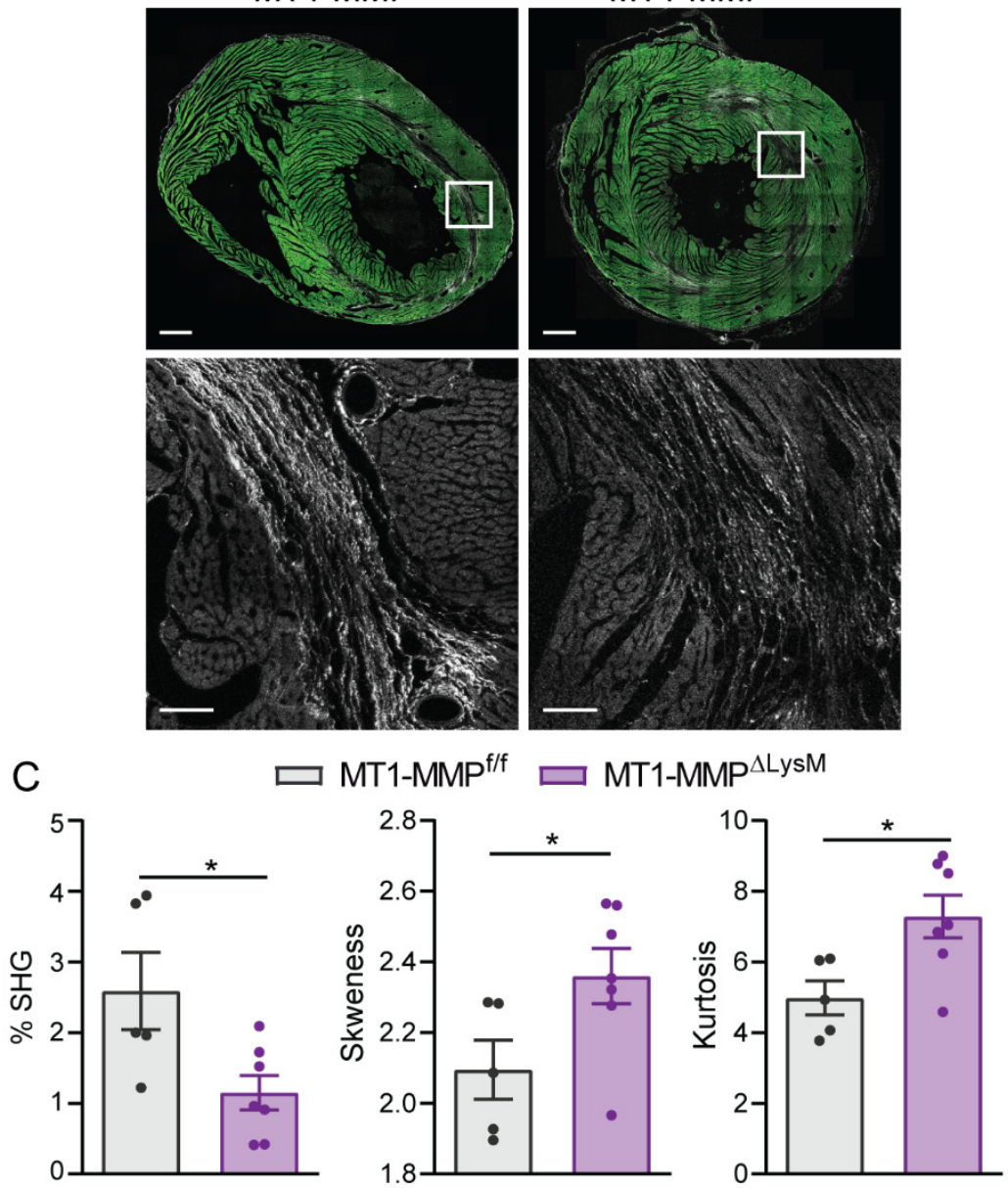

Figure 21. The absence of macrophage MT1-MMP ameliorates cardiac dysfunction and reduces collagen deposition in a model of transient ischemia. (A) Progression of LVEF, LVIDs, and LVIDd in

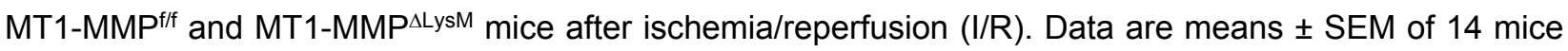
per genotype. Two-way ANOVA followed by Tukey's multiple comparisons test. Significant differences are indicated as ${ }^{*} p<0.05$, and ${ }^{* * * *} p<0.0001$. (B) Representative SHG (white) and MPEF (green) microscopy images of transverse cardiac sections from MT1-MMPf/f and MT1-MMP ${ }^{\Delta L y s M}$ mice at 21 days after I/R. Scale bar, $1 \mathrm{~mm}$. Magnified views of boxed areas in the infarct are shown in the lower panels. Scale bar, $100 \mu \mathrm{m}$. (C) Percentage SHG, skewness, and kurtosis in infarcts at 21 days post-l/R. Data are means \pm SEM of 5-7 mice per genotype. Unpaired $t$-test. Significant differences are indicated as ${ }^{*} p<0.05$. 


\subsection{Macrophage MT1-MMP deficient mice have a preserved microvasculature network and better myocardial oxygenation after ischemic injury}

From now on, we continued working with permanent ischemia (LAD-ligation) as MI model to fully characterize the role of macrophage MT1-MMP on cardiac healing as well as the underlying molecular mechanism. It has been demonstrated that neovascularization of the ischemic myocardium plays an essential role in fibrous tissue formation and infarct healing (249). Besides, because MMPs elicit varied biological functions that extend well beyond ECM degradation (250), we studied whether macrophage-specific MT1-MMP deletion affected post$\mathrm{MI}$ remodeling of the cardiac microvasculature. Confocal images of MT1-MMPf/f and MT1$M^{M M}{ }^{\triangle L y s M}$ 7-day-post-MI hearts stained for CD31 (endothelial marker) and SMA (smooth muscle actin) (Figure 22A) were evaluated with a fully automated 3D pipeline developed in Dr. Arroyo's laboratory (Material and Methods), which allows precise reconstruction of the microvasculature and extraction of parameters that quantify major features (238) (Supplementary Table 1). MT1-MMP ${ }^{\Delta L y s M} 7$-day-post-MI hearts had a higher vascular volume density and more capillaries and ECs than controls (Figure 22A, B). Oxygen diffusion from blood to tissue critically depends on the density and arrangement of the microvascular bed (251). Accordingly, in MT1-MMP ${ }^{\Delta L y s M}$ hearts, we observed increased capillary density and reduced intercapillary and diffusion distances, parameters proposed as indices of oxygen diffusion (252), suggesting better oxygen diffusion in the infarcted myocardium (Figure 22B).

To evaluate tissue oxygenation directly, we assessed hypoxia in the post LAD-ligation myocardium by carbonic anhydrase IX (CA-IX) staining (253) (Figure 22C, D). Overexpression of CA-IX is regulated by hypoxia inducible factor $1 \alpha$ (HIF1 $\alpha)$ and is considered a bona fide marker of hypoxia (254). CA-IX+ signal was quantified in infarct (IZ) (Figure 22D, top) and remote (RZ) (Figure 22D, bottom) zones, defined in the basis of the autofluorescence emitted by the healthy myocardium (Figure 22C) (255). Confocal analysis of CA-IX-immunostaining revealed smaller CA-IX+ area in the IZ of 7-day-post-MI MT1-MMP ${ }^{\Delta L y s M}$ hearts than in controls (Figure 22C, D), confirming better preserved tissue oxygenation after MI. No of CA-IX+ signal was found in the non-infarcted tissue (Figure 22C, D), demonstrating the ischemia is limited to the infarction and does not affect remote areas of the myocardium. In sum, vascular remodeling analysis and CA-IX staining indicate better vascular perfusion and oxygen supply in infarcted MT1-MMP ${ }^{\Delta L y s M}$ mice, according to the enhanced microvasculature displayed by these mice. 

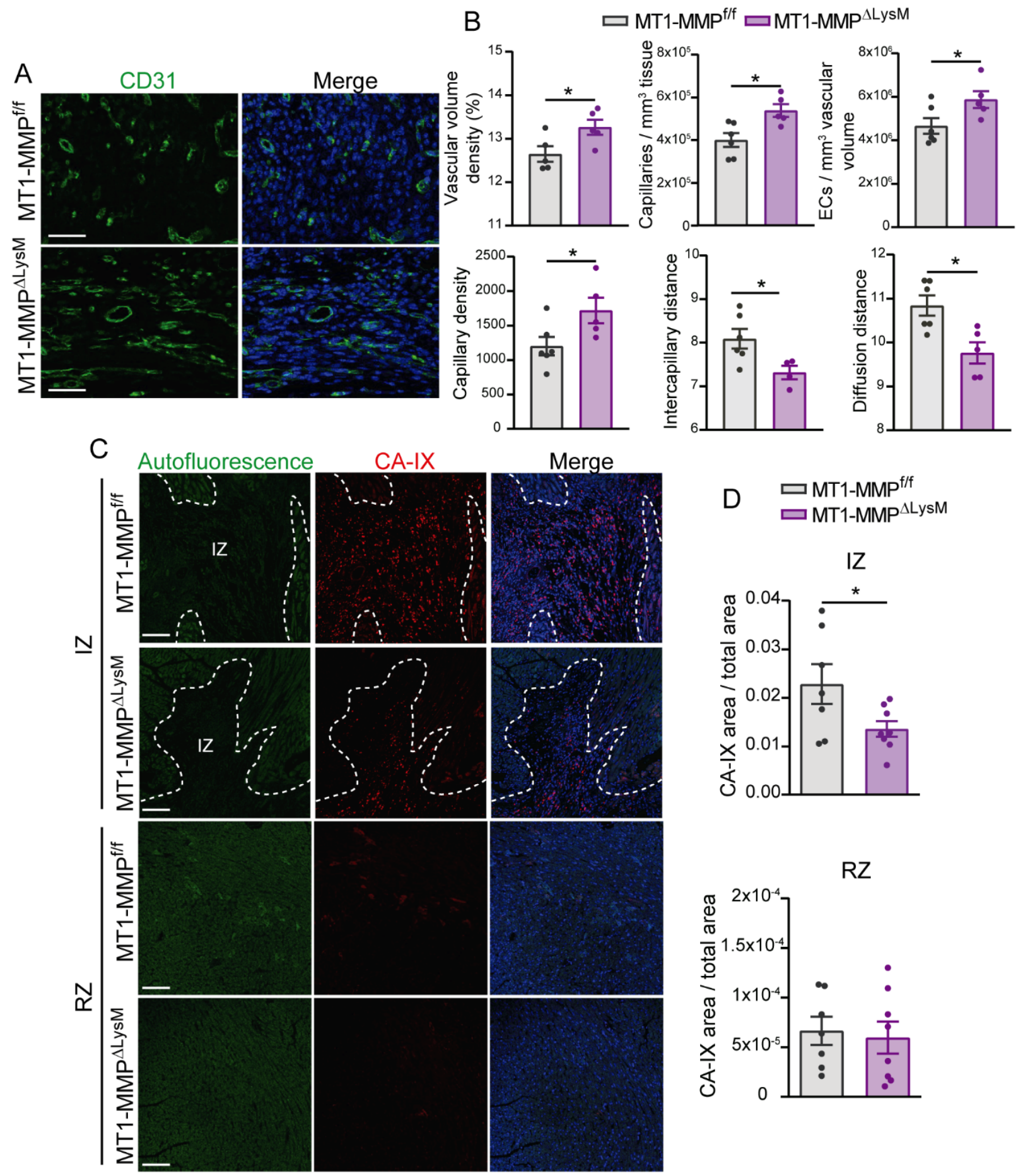

Figure 22. Macrophage MT1-MMP deletion preserves the microvasculature network and improves tissue oxygenation after MI. (A) Representative confocal microscopy images showing immunostaining for CD31 (green) and nuclei (blue) within the infarction in MT1-MMP/f and MT1-MMP ${ }^{\Delta L y s M}$ hearts at 7 days postMI. Scale bar, $50 \mu \mathrm{m}$. (B) Vasculature-related parameters within the infarction at 7 days post-MI. Data are means \pm SEM of 5-6 mice per genotype. Unpaired $t$-test. Significant differences are indicated as ${ }^{*} p<0.05$. (C) Representative confocal immunofluorescence microscopy images of CA-IX (red) in the infarcted (top) or remote (bottom) regions of MT1-MMP/f and MT1-MMP ${ }^{\Delta L y s M}$ hearts at 7 days post-MI. Scale bar, 100 $\mu m$. Nuclei are stained with DAPI (blue). (D) CA-IX+ area:total area ratio in the infarct (IZ) and the remote (RZ) zones. Data are means \pm SEM of 7-8 mice per genotype. Unpaired $t$-test. Significant differences are indicated as * $p<0.05$. 


\subsection{Ml-induced lymphangiogenesis is not altered by the absence of macrophage-derived MT1-MMP}

It is reported that MT1-MMP acts an endogenous suppressor of physiological lymph vessel growth in the retina (141). We wondered whether macrophage MT1-MMP could have an impact in Ml-associated lymphangiogenesis. We thus assessed lymph vessels by immunostaining of LYVE1 in MT1-MMP/f and MT1-MMP ${ }^{\triangle L y s M}$ mice on days 7 and 28 following $\mathrm{Ml}$ (Figure 23A). In contrast to changes observed in $\mathrm{CD} 31^{+}$vessels, there was no difference in post-MI lymph vessel density between genotypes, suggesting that Ml-induced lymphangiogenesis is independent of macrophage MT1-MMP (Figure 23A, B).
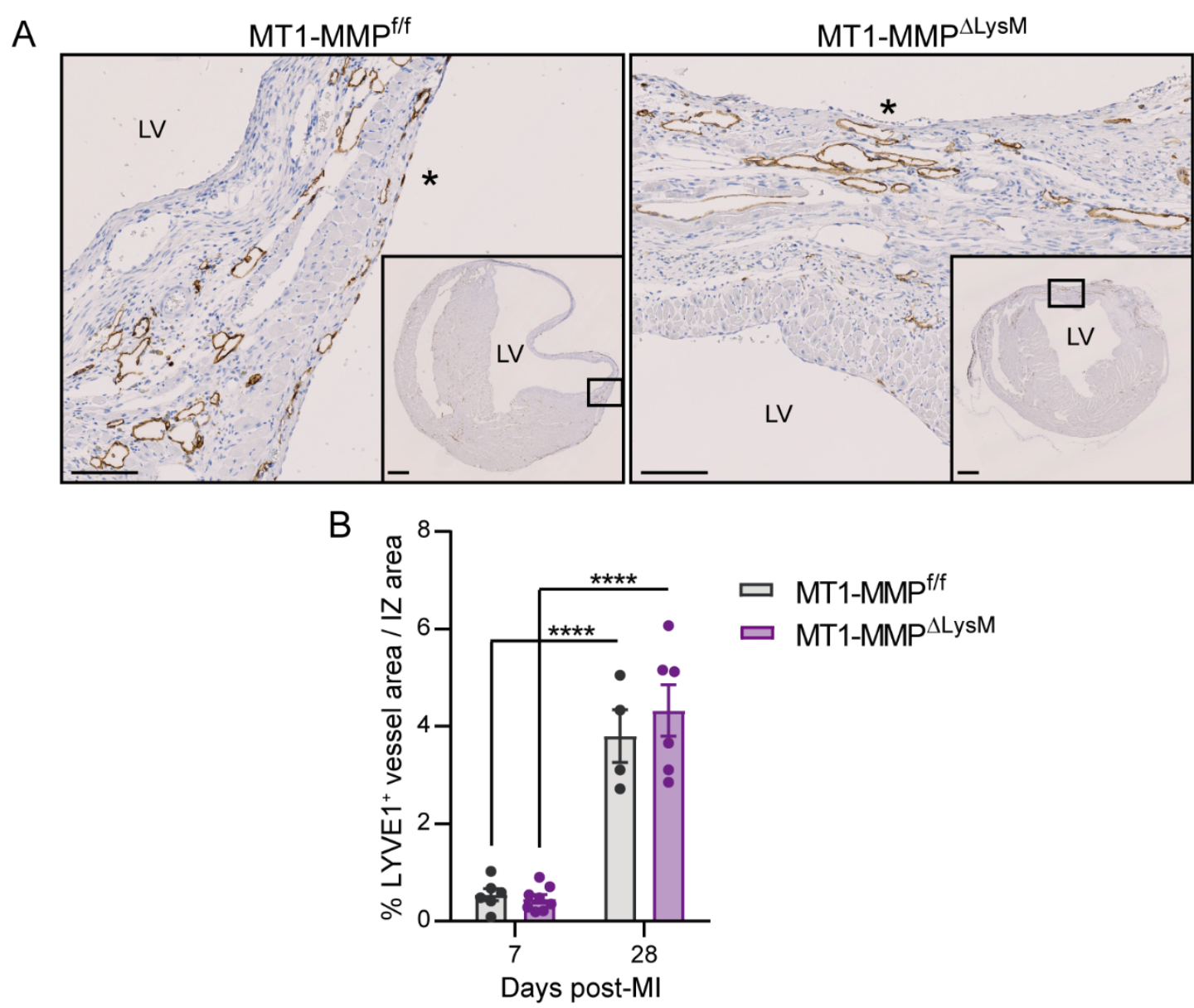

Figure 23. Macrophage MT1-MMP deletion does not affect post-MI lymphangiogenesis. (A) Representative images of LYVE1-stained transverse sections of MT1-MMPf/f and MT1-MMP ${ }^{\Delta L y s M}$ hearts at 28 days post-MI. Scale bar, $1 \mathrm{~mm}$. Magnified views of boxed areas in the infarct are shown. Scale bar, 100 $\mu \mathrm{m}$. Asterisks mark the epicardium. (B) Percentage of LYVE1 ${ }^{+}$vessel area respect to the infarcted area at the indicated post-MI stages. Data are means \pm SEM of 5-7 per group. Two-way ANOVA followed by Tukey's multiple comparisons test. Significant differences are indicated as ${ }^{* * * *} p<0.0001$. 


\subsection{Macrophage-targeting of MT1-MMP attenuates post-MI arteriole smooth muscle hyperplasia}

In the developing vasculature, mural cell recruitment is associated with MT1-MMP expression, and MT1-MMP-deficient tissues display a marked reduction in mural cell density as well as abnormal vessel wall morphology (184). Hence, in order to further depict the Ml-induced remodeling of cardiac vasculature when macrophage MT1-MMP was absent, we assessed arteriole vessels by immunostaining of SMA in MT1-MMP ${ }^{f / f}$ and MT1-MMP ${ }^{\Delta L y s M}$ mice on days 7 and 28 following $\mathrm{MI}$ (Figure 24A). Although there were no between-genotype differences in arteriole (SMA ${ }^{+}$vessels) density, arterioles were thicker and formed by many layers of VSMCs in MT1-MMPf/f infarcted hearts as compared to MT1-MMP ${ }^{\triangle L y s M}$ mice (Figure 24A, B), suggesting amelioration of Ml-induced arterial hyperplasia (63) in the absence of macrophage MT1-MMP (184).
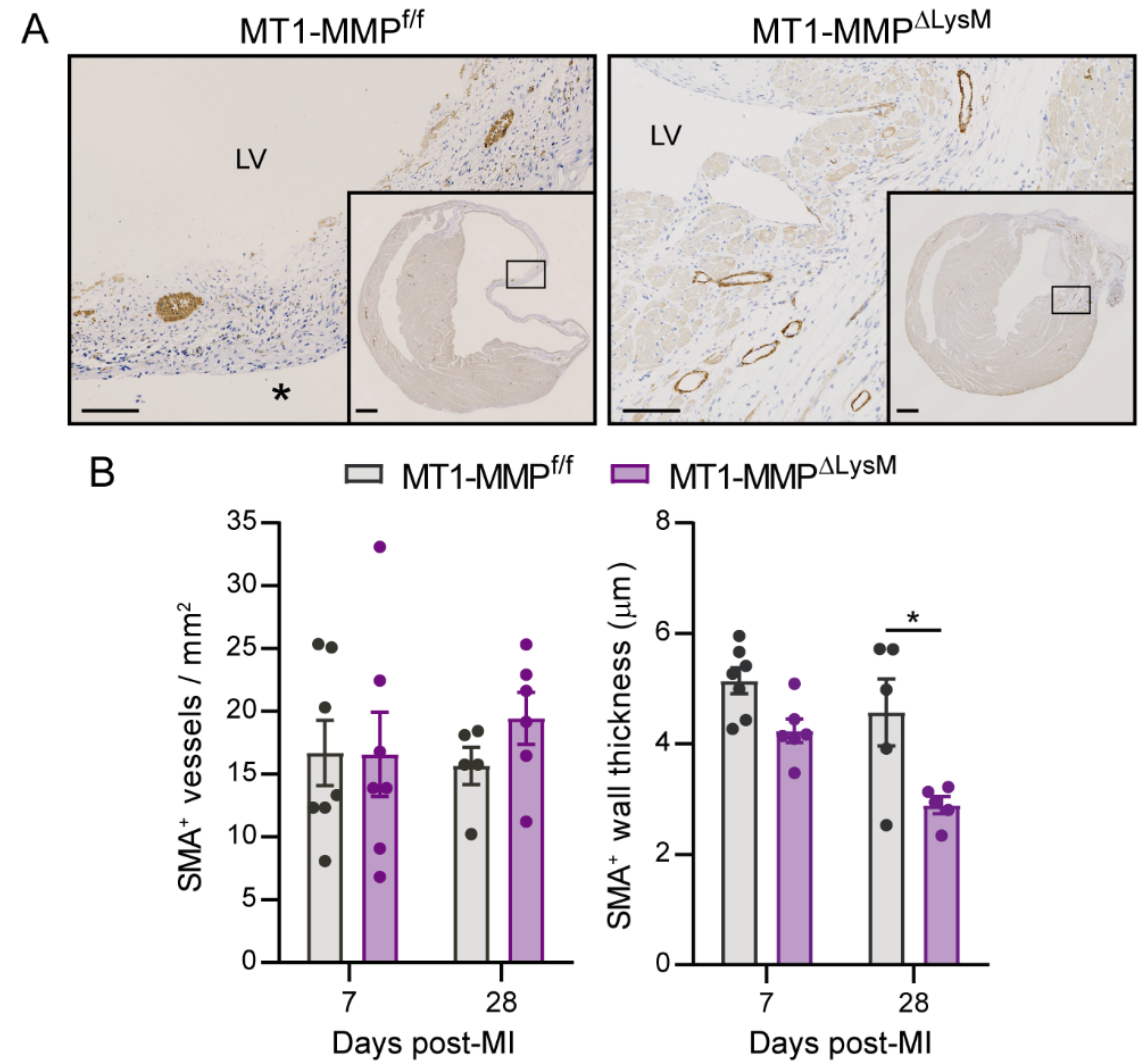

Figure 24. Macrophage MT1-MMP deletion reduces arteriole wall thickening after MI. (A) Representative images of SMA-stained transverse sections of MT1-MMP/f and MT1-MMP ${ }^{\Delta L y s M}$ hearts at 28 days post-MI. Scale bar, $1 \mathrm{~mm}$. Magnified views of boxed areas in the infarct are shown. Scale bar, $100 \mu \mathrm{m}$. Asterisks mark the epicardium. (B) $\mathrm{SMA}^{+}$vessel density and $\mathrm{SMA}^{+}$vessel wall thickness in the IZ at the indicated days post-MI. Data are means \pm SEM of 5-7 per group. Unpaired $t$-test. Significant differences are indicated as * $p<0.05$. 


\subsection{The absence of macrophage MT1-MMP impairs active TGF $\beta 1$ release from LAP-TGF $\beta 1$ complex on the cell surface}

To elucidate the mechanism by which macrophage MT1-MMP regulates microvascular density and fibrosis, we sought soluble factors whose release might be affected by the presence of MT1-MMP-deficient macrophages. Macrophages have shown to secrete growth factors which regulate different aspects of the infarcted region environment (eg, FGF2, PDGF $\beta$, TGF $\beta$, VEGF). Specifically, TGF $\beta 1$ seems to importantly modulate myocardial healing though effects on the fibrotic and angiogenic responses (256-258) (Figures 5 and 7). Two independent proteomics studies previously performed in Dr. Arroyo's laboratory detected a 1.25- to 2-fold increase in TGF $\beta 1$ content in the microsomal fraction of MT1-MMP ${ }^{-/-}$BMDMs. The small latent complex (SLC) consisting of latency associated peptide (LAP) and mature TGF $\beta 1$ can be retained at the cell surface through LAP binding to membrane receptors (e.g. integrin $\alpha v \beta 8$ ) (Figure 25A), and MT1MMP promotes TGF $\beta 1$ activation via integrin $\alpha$ v $\beta 8$ (148).

To investigate the possible role of macrophage-derived MT1-MMP in TGF $\beta 1$ release after $\mathrm{MI}$, we used flow cytometry to measure latent TGF $\beta 1$ (LAP-TGF $\beta 1$ complex) on the surface of LPS-stimulated MT1-MMPf/f and MT1-MMP $\mathrm{M}^{\Delta \mathrm{LysM}}$ BMDMs (Figure 25A). MT1-MMP ${ }^{\Delta L y s M}$ macrophages had a higher content of LAP and TGF $\beta 1$, revealing significantly higher surface retention of LAP-TGF $\beta 1$ than observed in WT macrophages (Figure 25 B, C).

To validate this observation, we detected TGF $\beta 1$ by immunoblot in membrane and cytosolic subcellular fractions and total cell lysates of LPS-stimulated MT1-MMPf/f and MT1$M^{M M P}{ }^{\triangle L y S M}$ BMDMs (Figure 25D). Latent TGF $\beta 1$ ( $\left.50 \mathrm{kDa}\right)$ consisting of LAP (35kDa) covalently bound to the mature TGF $\beta 1(12.5 \mathrm{kDa})$ preferentially located in the membrane and was more abundant in MT1-MMP ${ }^{\triangle L y s M}$ macrophages (Figure 25D, E). In line with the reported role of MT1MMP in posttranslational processing of pro-TGF $\beta$, we found no difference in Tgfb1 transcript levels between MT1-MMP ${ }^{\Delta L y s M}$ and MT1-MMPf/f BMDMs (Figure 25F).

We next queried whether impaired processing of LAP-TGF $\beta 1$ complex in MT1-MMPdeficient macrophages affects secretion of active TGF $\beta 1$. Since active TGF $\beta 1$ has an estimated half-life of $2-3$ minutes, and only $2 \%-5 \%$ of total TGF $\beta 1$ is thought to be activated at any given time (259), we measured bioactive TGF 1 1 using a standardized luciferase assay (Figure 25G, H and see Materials and Methods). Briefly, we transfected HEK293 cells with a plasmid (p3TP-lux plasmid) containing a TGF $\beta 1$-responsive plasminogen activator. In this bioassay, the luciferase activity is directly proportional to the extracellular level of activated TGF $\beta 1$. Responsiveness of the luciferase construct to TGF $\beta 1$ was confirmed by treating transfected HEK293 cells with TGF $\beta 1$ 
(2.94 \pm 0.06 fold-increase in arbitrary luciferase units (ALU) with respect to the control). Luciferase activity was then assessed in transfected HEK293 cells cultured in the presence of LPS-stimulated MT1-MMPf/f or MT1-MMP $\triangle$ LysM BMDMs for 24 h. HEK293 co-culture with MT1-MMP/f BMDMs produced abundant levels of active TGF $\beta 1$, whereas active TGF $\beta 1$ was undetectable after coculture with MT1-MMP $\triangle$ LysM BMDMs (Figure 25F), identifying a decrease in TGF $\beta 1$ activation by MT1-MMP $\triangle$ LysM macrophages. TGF $\beta 1$ levels in KO BMDMs were restored by transduction with fulllength (FL) MT1-MMP but not with a catalytic mutant (E240A), demonstrating that MT1-MMPdependent TGF $\beta 1$ activation requires MT1-MMP catalytic activity (Figure 25G). Collectively, our results point to a pivotal role of macrophage MT1-MMP in post-translational activation of latent TGF $\beta 1$.

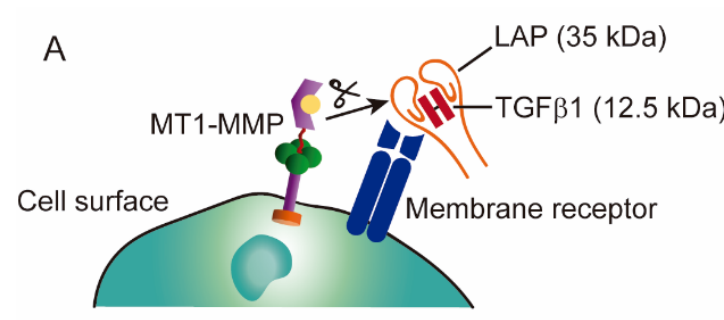

B Gated on $\mathrm{CD} 45^{+} \mathrm{CD} 11 \mathrm{~b}^{+}$cells
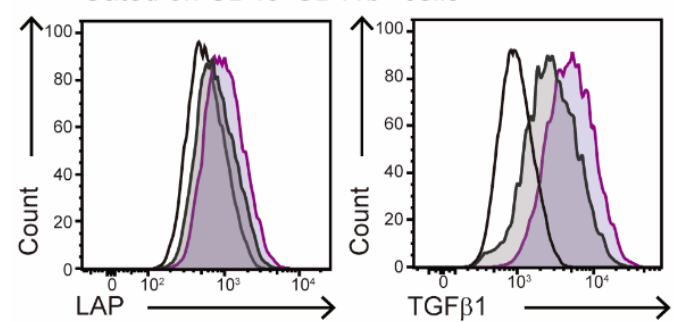

口 FMO $\square \mathrm{MT1}-\mathrm{MMP}^{\mathrm{f} / \mathrm{f}} \square \mathrm{MT1}$-MMPALysM
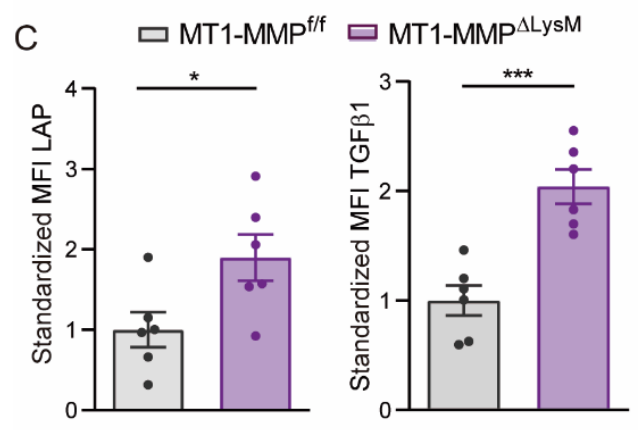

SLC

D

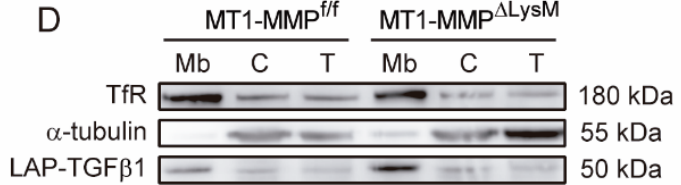

\section{E}
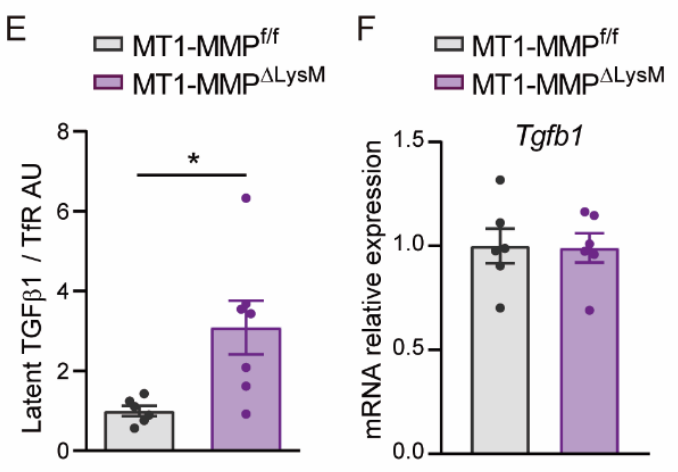

G

$$
\begin{aligned}
& \square \text { Ctrl } \\
& \square \mathrm{MT1} 1 \mathrm{MMP}^{\mathrm{f} / \mathrm{f}} \\
& \square \mathrm{MT1}-\mathrm{MMP}^{\Delta \mathrm{LysM}}
\end{aligned}
$$

$\mathrm{H}$

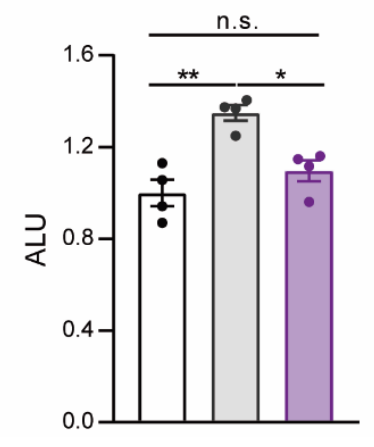

口Ctrl

- MT1-MMP ${ }^{\Delta L y s M} B M D M s+$ Mock LV

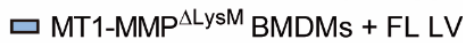

口 MT1-MMP ${ }^{\Delta L y s M}$ BMDMs + E240A LV

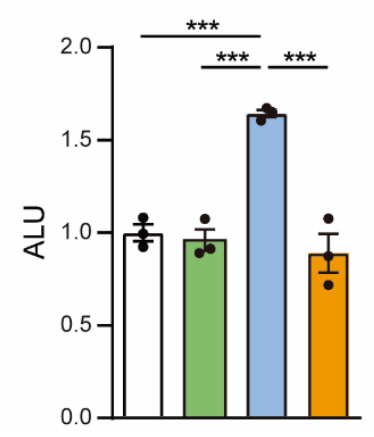

Figure 25. Macrophage MT1-MMP deletion blunts mature TGF $\beta 1$ release from small latent complex (SLC). (A) Scheme of LAP-TGF $\beta 1$ complex retention in the cell surface through LAP-binding to membrane receptors. (B) Representative flow cytometry histogram plots of LAP and TGF $\beta 1$ staining in LPS-activated MT1-MMPf/f and MT1-MMP $\triangle$ LysM BMDMs. (C) Standardized mean fluorescence intensity (MFI) of LAP and TGF $\beta 1$ in experiments as in B. Data are means \pm SEM of 7 mice per group. Unpaired $t$-test. Significant differences are indicated as ${ }^{*} p<0.05$, and ${ }^{* * *} p<0.001$. (D) Western blot of transferrin receptor (TfR), $\alpha$ tubulin, and LAP-TGF $\beta 1$ complex in membrane fraction (Mb), cytosolic fraction (C), and total lysate (T) from 
LPS-activated MT1-MMP/f/ and MT1-MMP ${ }^{\triangle L y s M}$ BMDMs. (E) Quantification of LAP-TGF $\beta 1$ complex in the membrane fraction. Data are means \pm SEM of 6-7 mice per genotype. Unpaired $t$-test. Significant differences are indicated as * $p<0.05$. (F) Tgfb1 mRNA expression in LPS-activated MT1-MMP/f and MT1-MMPLysM BMDMs. Data are means \pm SEM of 6 mice per genotype. Unpaired $t$-test. (G) Arbitrary luciferase units (ALU) in HEK293 cells co-cultured with LPS-activated MT1-MMP ${ }^{\mathrm{f} / \mathrm{f}}$ or MT1-MMP ${ }^{\Delta L y s M}{ }^{\mathrm{BMDM}}$. Control corresponds to transfected HEK293 cells cultured alone. Data are means \pm SEM of a representative experiment of three performed with four technical replicates per condition. One-way ANOVA followed by Tukey's multiple comparisons test. Significant differences are indicated as * $p<0.05$, and ${ }^{* *} p<0.01$. (H) ALU in HEK293 cells co-cultured with or without conditioned media from LPS-activated MT1-MMP ${ }^{\triangle L y s M}$ BMDMs transduced with mock lentivirus (GFP), or lentivirus containing full-length MT1-MMP (FL) or catalytic MT1-MMP mutant (E240A). Control corresponds to transfected HEK293 cells cultured alone. Data are means \pm SEM of a representative experiment of three performed with three technical replicates per condition. One-way ANOVA followed by Tukey's multiple comparisons test. Significant differences are indicated as ${ }^{* * *} p<0.001$.

\subsection{The absence of macrophage MT1-MMP reduces TGFbeta-pSMAD2 signaling in cardiac ECs, MyoFBs, and VSMCs}

Previous studies have identified SMAD2/3 signaling as a critical pathway in FB activation and VSMC proliferation, affecting fibrotic response and arteriole formation, maturation, and stabilization $(75,256,260,261)$. We next explored if defective release of active TGF $\beta 1$ by MT1MMP-deficient macrophages could affect TGF $\beta 1$-mediated SMAD2/3 signaling not only in macrophages but also in ECs, MyoFBs, and VSMCs $(256,261)$. We quantified nuclear phosphorylated SMAD2 (pSMAD2) in these cardiac cell types by flow cytometry at 7 days postMI (Figure 26A-C). Macrophages were defined as CD45 ${ }^{+} \mathrm{CD} 11 \mathrm{~b}^{+} \mathrm{F} 4 / 80^{+}$cells, and ECs as CD45CD31+PDGFRß - cells (Figure 26A). Cardiac FBs convert to MyoFBs with injury to mediate healing after $\mathrm{MI}$ and platelet-derived growth factor receptor $\beta$ (PDGFR $\beta$ ) induction is an early feature of MyoFB activation in a broad range of tissues, including the heart, although it is also expressed by VSMCs $(238,239,262)$. Therefore, MyoFBs and VSMCs were described as CD45-CD31PDGFR $\beta^{+}$cells (Figure 26A). There was no between-genotype difference in pSMAD2 abundance in macrophages; however, pSMAD2 was significantly less abundant in ECs and MyoFBs/VSMCs from MT1-MMP ${ }^{\triangle L y s M}$ hearts (Figure 26B, C), suggesting that lack of macrophage MT1-MMP impairs paracrine TGF $\beta 1-p S M A D 2$ signaling in ECs and MyoFBs/NSMCs.

Since PDGFR $\beta$ is a marker of MyoFBs and VSMCs, we performed pSMAD2 immunofluorescence staining in transverse cardiac sections in co-staining with SMA and CD31 (Figure 27A) to distinguish between pSMAD2 in MyoFBs (non-vascular-related $\mathrm{SMA}^{+}$cells) and in VSMCs (vascular-related $\mathrm{SMA}^{+}$cells). Confocal imaging analysis at 7 days post-MI revealed that pSMAD2-positive MyoFBs and VSMCs were both less abundant in MT1-MMP ${ }^{\triangle L y s M}$ hearts than in MT1-MMPf/f hearts (Figure 27A, B). 
A Gated on single viable cells
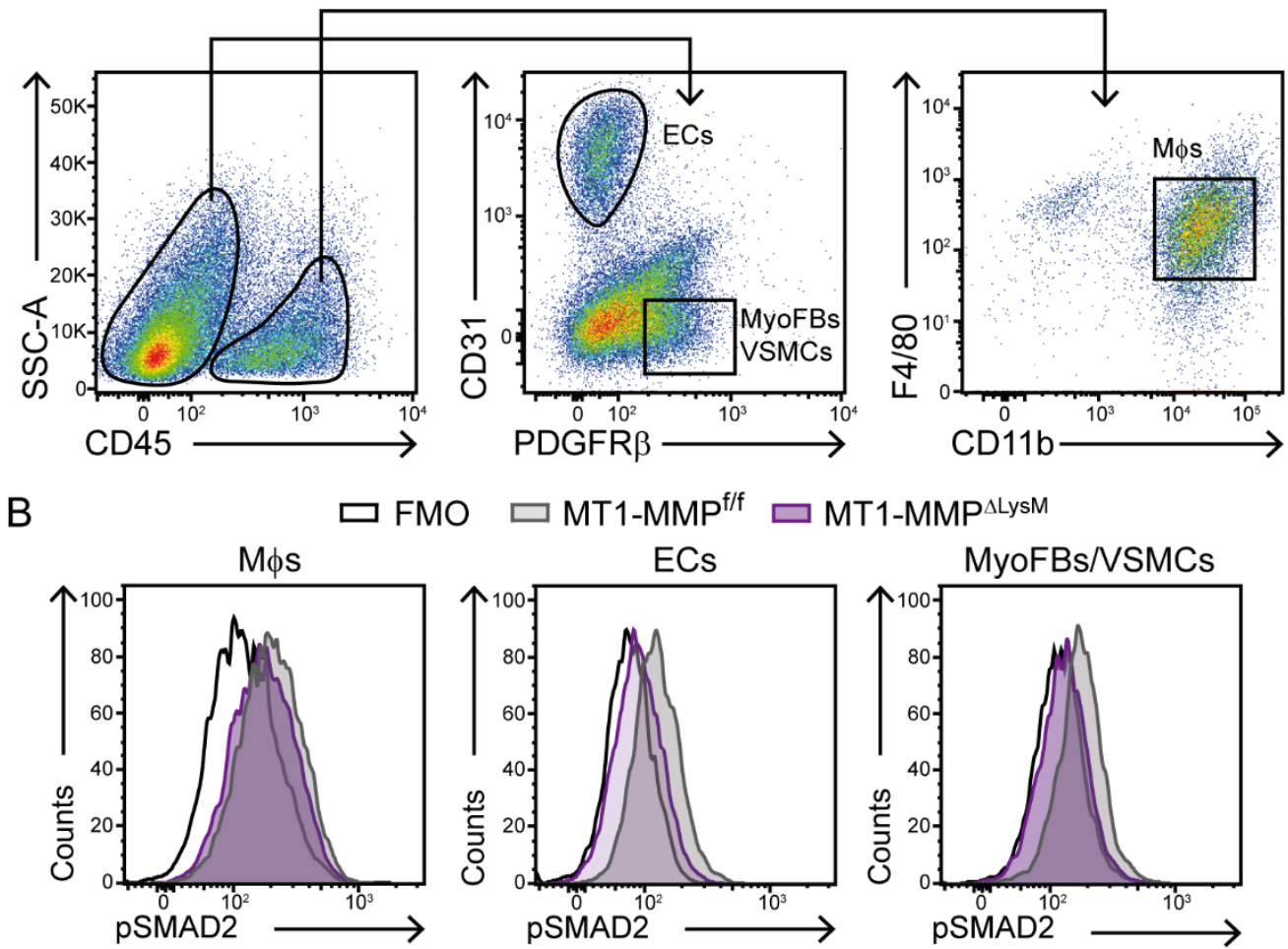

FMO $\square M T 1-M_{M P P^{f / f}}$
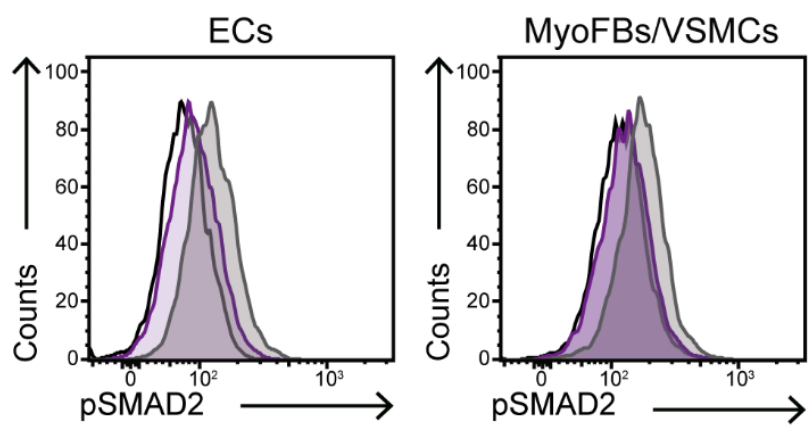

C

$$
\text { MT1-MMP/f } \square M T 1-M M P^{\Delta L y s M}
$$
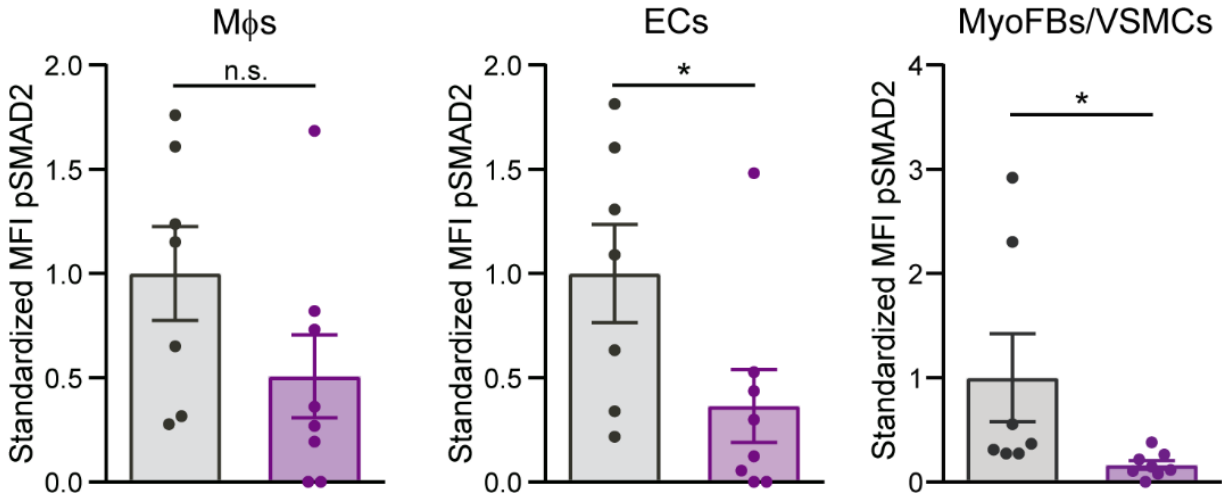

Figure 26. Macrophage MT1-MMP deletion impairs pSMAD2-mediated signaling in ECs and MyoFBs/VSMCs after MI. (A) Gating strategy used to assess pSMAD2 signaling in ECs, MyoFBs/VSMCs, and macrophages. (B) Representative flow cytometry histogram plots of pSMAD2 staining in the indicated cells from 7-day-post-MI hearts. (C) Standardized MFI of pSMAD2 in experiments as in B. Data are means \pm SEM of 7-8 mice per genotype. Unpaired $t$-test. Significant differences are indicated as * $p<0.05$. M $\phi$ s: macrophages. 

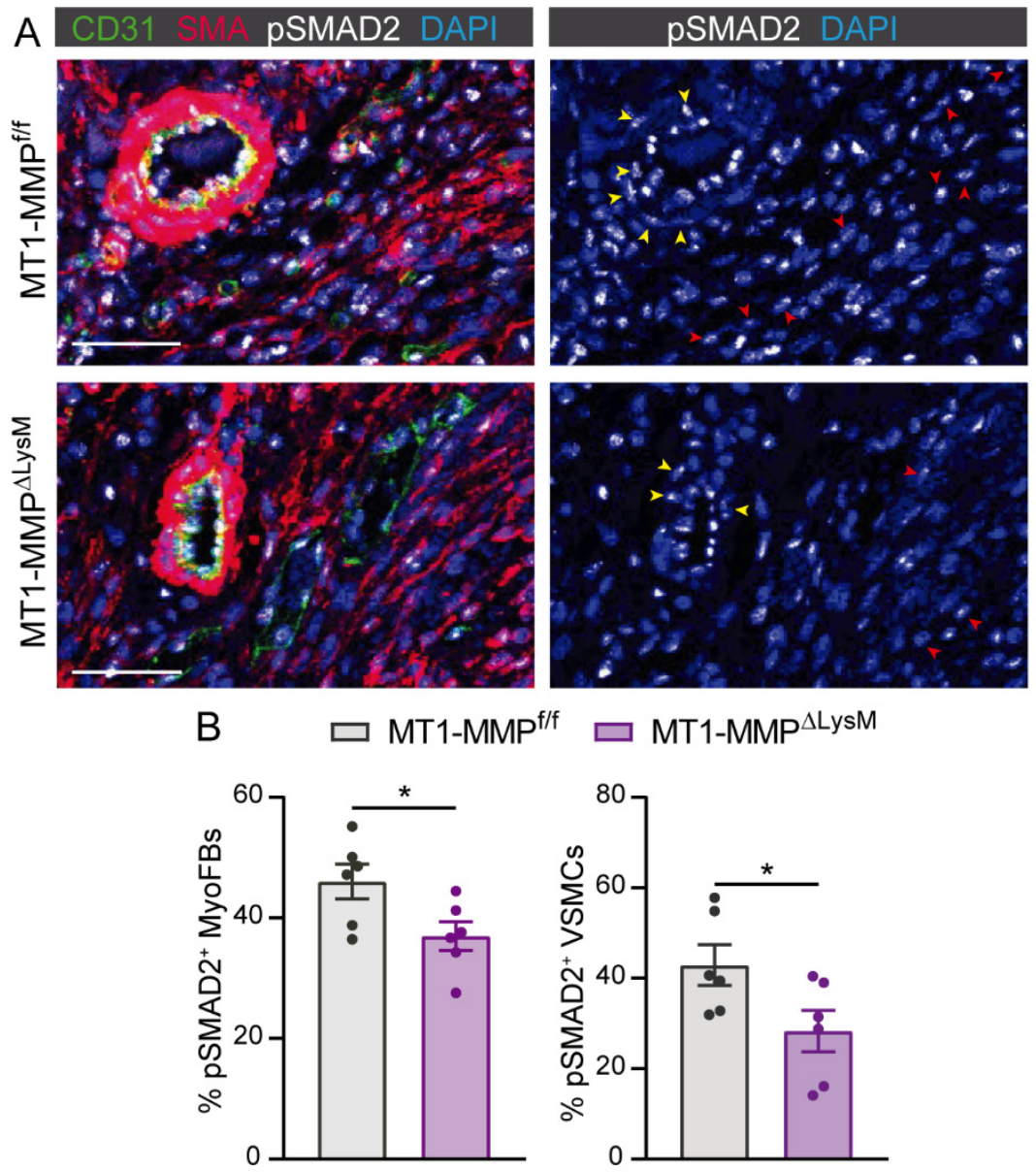

Figure 27. Macrophage MT1-MMP deficiency attenuates pSMAD2-mediated activation of MyoFBs and VSMCs after MI. (A) Representative immunofluorescence staining of CD31 (green), SMA (red), and pSMAD2 (white) in infarcted cardiac tissue from MT1-MMPf/f mice (top) and MT1-MMP $\triangle$ LysM mice (bottom) at 7 days post-MI. Nuclei are stained with DAPI (blue). Red and yellow arrowheads point to pSMAD2 ${ }^{+}$ MyoFBs and pSMAD2 ${ }^{+}$VSMCs, respectively. (B) Percentages of pSMAD2 ${ }^{+}$MyoFBs and pSMAD2 ${ }^{+}$VSMCs within the total MyoFB or VSMC populations, respectively, in the infarcted zone. Scale bar, $50 \mu \mathrm{m}$. Data are means \pm SEM of 6 mice per genotype. Unpaired $t$-test. Significant differences are indicated as ${ }^{*} p<0.05$.

\subsection{Macrophage MT1-MMP is required for EndMT induction post-MI}

We next conducted a flow cytometry quantitative analysis of macrophages $\left(C D 45^{+} \mathrm{CD} 11 \mathrm{~b}^{+} \mathrm{F} 4 / 80^{+}\right)$, ECs (CD45-CD31+PDGFR $\beta^{-}$cells) and MyoFBs (CD45-CD31-PDGFR ${ }^{+}$ cells) in 7-day-post-MI hearts. Despite there was no between-genotype difference in cardiac macrophages numbers, ECs were more abundant in $\mathrm{MT1}^{-M M P^{\triangle L y s M}}$ hearts, in line with the microvasculature image analysis data (Figure 22). This was paralleled by significantly lower abundances of MyoFBs in MT1-MMP ${ }^{\Delta L y s M}$ hearts, in agreement with the reduced fibrotic response reported in these mice (Figure 20).

We detected an intermediary population of cells with mild levels of both CD31 (EC marker) and PDGFR $\beta$ (mesenchymal marker). This population is suggestive of transitioning cells 
undergoing endothelial to mesenchymal transition (EndMT) $(211,220)$, and they were less abundant in macrophage-MT1-MMP deficient hearts, indicating that EndMT might be impaired in the absence of macrophage MT1-MMP. TGF $\beta 1$ triggers EndMT in a SMAD-dependent manner, contributing to the pathogenesis of diverse CVDs, such as congenital heart disease $(216,217)$, atherosclerosis $(218,223)$, myocardial fibrosis (219), and MI (220). We therefore studied the effect on post-MI EndMT of the impaired TGF $\beta 1$ production by MT1-MMP-deficient macrophages and the associated reduction in paracrine PSMAD2 signaling in ECs.

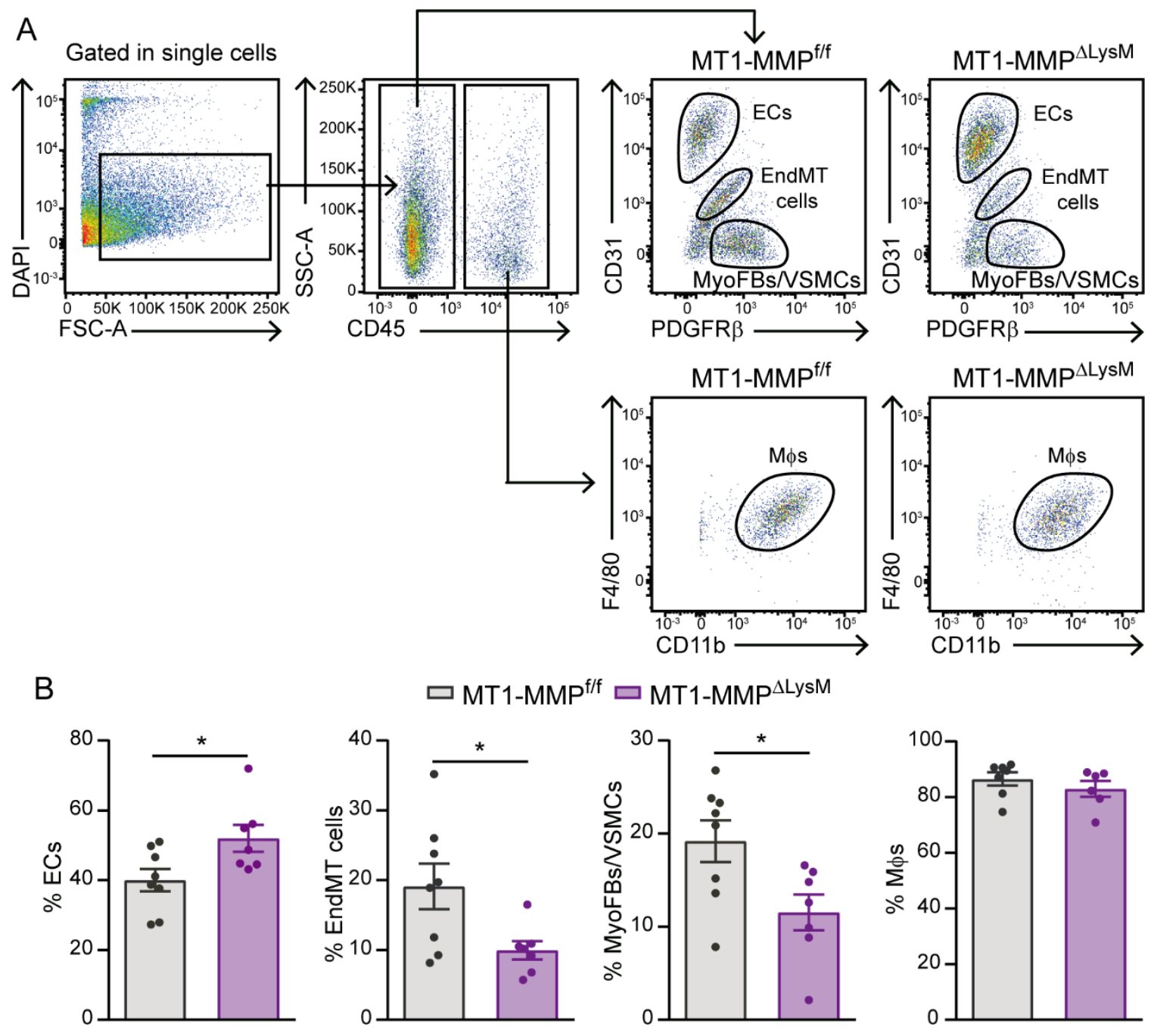

Figure 28. Mice with macrophage-deficiency of MT1-MMP had fewer MyoFBs and cells undergoing EndMT transition post-MI. (A) Flow cytometry gating strategy used to identify and quantify cardiac ECs, MyoFBs/VSMCs, cells undergoing EndMT, and macrophages in MT1-MMP//f mice (left) and MT1-MMP ${ }^{\Delta L y s M}$ mice (right) on day 7 after MI. (B) Percentages of ECs, cells undergoing EndMT, MyoFBs/VSMCs, and macrophages in cardiac tissue 7 days after MI. Data are means \pm SEM of 7-8 mice per genotype. Unpaired $t$-test. Significant differences are indicated as ${ }^{*} p<0.05$.

To further assess macrophage-mediated EndMT, we co-cultured purified mouse aortic

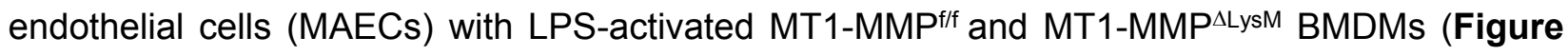


29). Immunofluorescence analysis with the endothelial marker CD31 and the mesenchymal marker SMA revealed morphological changes in MAECs after co-culture with MT1-MMPf/f BMDMs, with cells progressively losing their cobblestone appearance and adopting a dispersed, spindle-shaped morphology (Figure 29A). Moreover, MAECs co-cultured with MT1-MMPf/f BMDMs significantly decreased CD31 expression and acquired SMA expression, indicating the acquisition of molecular traits of a mesenchymal phenotype (Figure 29A, B). This phenotype was similar to the effects of recombinant TGF $\beta 1$ stimulation (Figure 29A, B). In contrast, coculture of MAECs with MT1-MMP ${ }^{\Delta L y S M} B M D M s$ led neither to the loss of endothelial features nor to the acquisition of mesenchymal markers (Figure 29A, B).

Altered expression of endothelial and mesenchymal markers in the co-cultures was confirmed by qPCR. In accordance with the immunofluorescence data, the co-culture of MAECs with MT1-MMP/f BMDMs caused the downregulation of EC-related genes (Pecam, Kdr, and Col4a2) and the upregulation of mesenchymal genes (Tagln and Acta2) and the direct TGF $\beta 1$ target Pai1. A similar phenotype was induced by TGF $\beta 1$-treatment. In contrast, these changes toward a mesenchymal phenotype in MAECs were not triggered by co-culture with MT1-MMP ${ }^{\Delta}$ LysM BMDMs (Figure 29C).

To confirm macrophage MT1-MMP-dependent induction of EndMT in vivo post-MI, we first investigated TGF $\beta 1$ processing in MT1-MMP/f and MT1-MMP ${ }^{\Delta L y s M}$ cardiac macrophages. LAP and TGF $\beta 1$ were both significantly increased on the surface of MT1-MMP ${ }^{\triangle L y s M}$ cardiac macrophages after $\mathrm{MI}$, indicating the retention of latent TGF 1 (Figure 30A). We then sorted cardiac macrophages from MT1-MMP/f and MT1-MMP ${ }^{\Delta L y s M}$ mice at 7 days post-MI and cocultured them with luciferase-transfected HEK293 cells. As with BMDMs, post-MI WT cardiac macrophages produced detectable levels of active TGF $\beta 1$, whereas the deletion of macrophage MT1-MMP abrogated TGF $\beta 1$ activation (Figure 30B). In MAEC co-culture experiments, MT1$\mathrm{MMP}^{\mathrm{f} / \mathrm{f}}$ post-MI cardiac macrophages induced EndMT in MAECs, downregulating CD31 expression and increasing SMA expression. In contrast, no transition to a mesenchymal phenotype was evident in MAECs co-cultured with MT1-MMP-deficient post-MI cardiac macrophages (Figure 30C, D). Taken together, the in vivo and in vitro data indicated that macrophages induce post-MI EndMT in a MT1-MMP-dependent mechanism. 
A

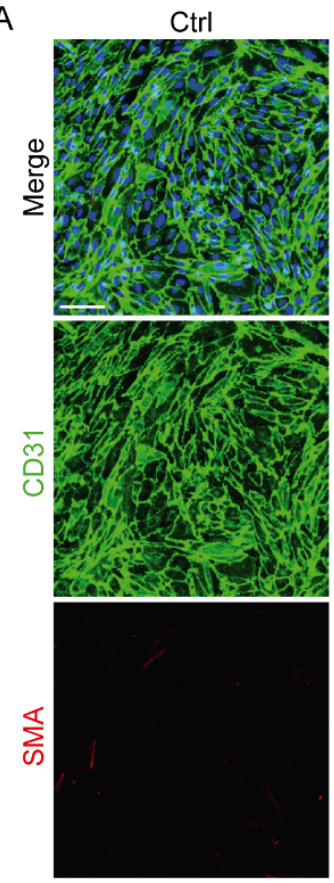

C
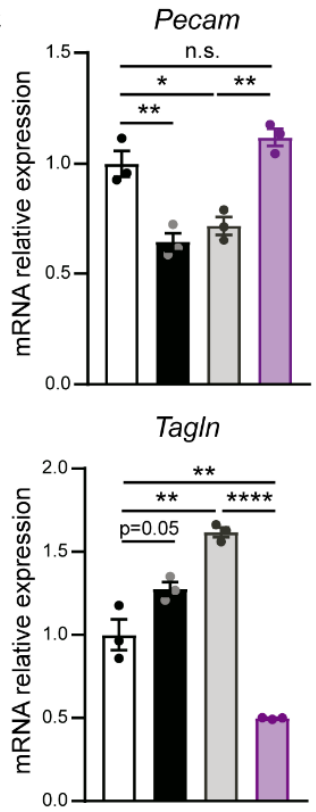

TGF $\beta 1$
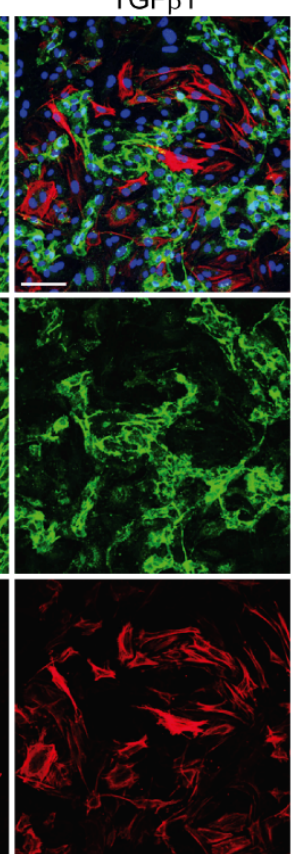

Pecam
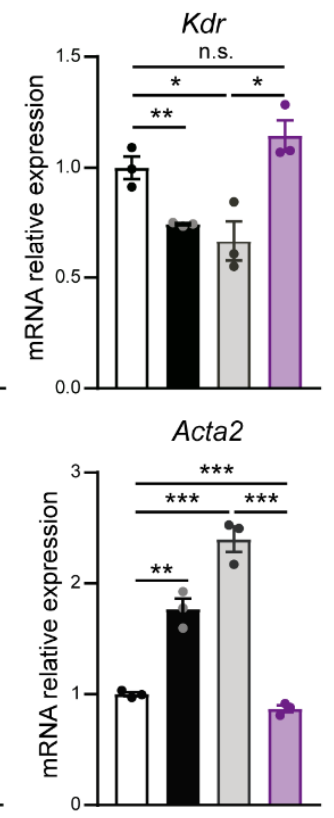
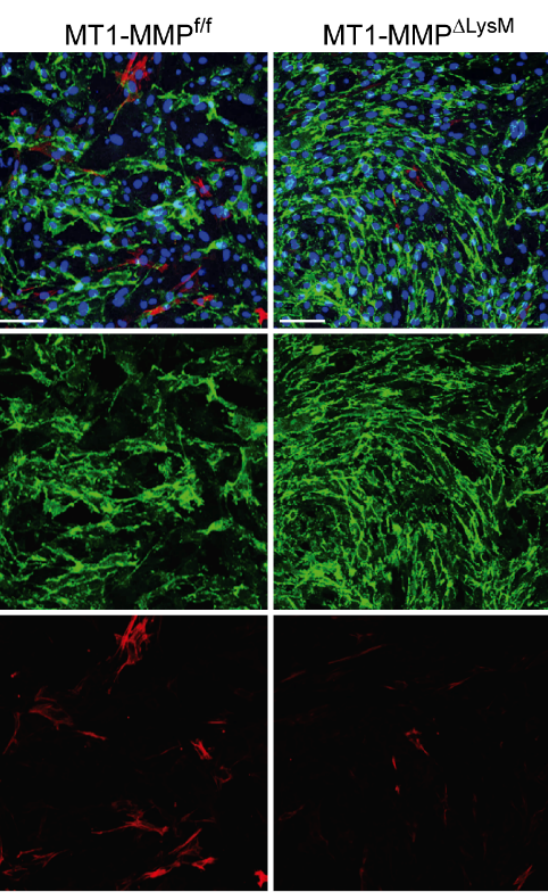

Col4a2
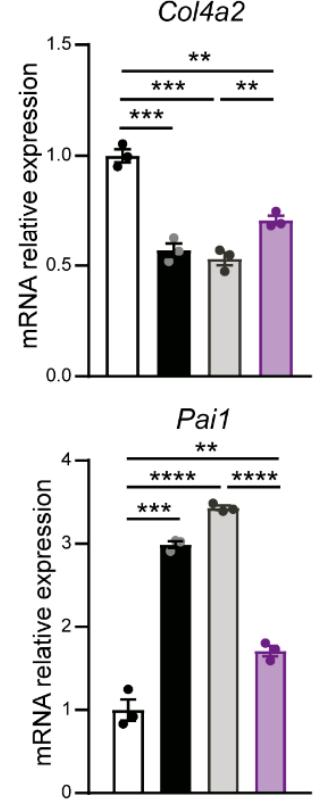

B $\square$ Ctrl

$\boldsymbol{\square}+$ TGF $\beta 1$

$\square+\mathrm{MT} 1-\mathrm{MMP}^{\mathrm{f} / \mathrm{f}} \mathrm{BMDMs}$

$\square+$ MT1-MMP ${ }^{\Delta \text { LysM }}$ BMDMs
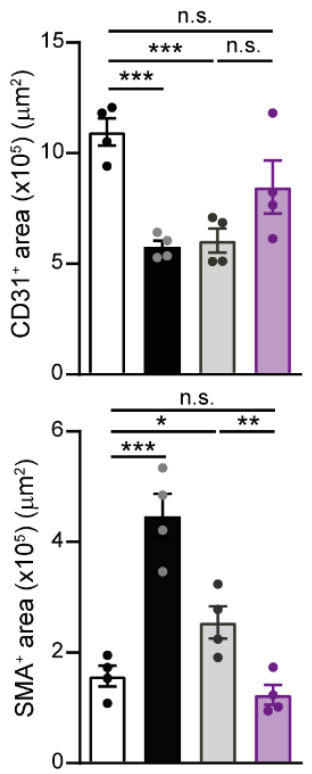

$\square$ Ctrl

a TGF $\beta 1$

口+ MT1-MMP ${ }^{\mathrm{f} / \mathrm{f}} \mathrm{BMDMs}$

$\square+\mathrm{MT} 1-\mathrm{MMP}^{\Delta \mathrm{LysM}^{\mathrm{B}} \mathrm{BMDMs}}$

Figure 29. MT1-MMP is required for macrophage-mediated induction of EndMT in vitro. (A) Representative immunofluorescence staining of CD31 (green) and SMA (red) in in vitro co-cultures of MAECs and LPS-activated MT1-MMPf/f or MT1-MMP ${ }^{\triangle L y s M}$ BMDMs. Nuclei are stained with DAPI (blue). MAECs were also treated with TGF $\beta 1(10 \mathrm{ng} / \mathrm{ml})$ as an EndMT positive control. (B) CD $31^{+}$area $\left(\mu \mathrm{m}^{2}\right)$ and $\mathrm{SMA}^{+}$area $\left(\mu \mathrm{m}^{2}\right)$ in the different conditions. Data are means \pm SEM of four independent experiments carried out with three technical replicates. Unpaired $t$-test. Significant differences are indicated as ${ }^{*} p<0.05,{ }^{* *} p<$ 0.01 , and ${ }^{* * *} p<0.001$. (C) qPCR analysis of endothelial and myofibroblast markers and TGF $\beta 1$ target genes in in vitro co-cultures of MAECs and LPS-activated MT1-MMPf/f or MT1-MMP ${ }^{\Delta L y S M}$ BMDMs. Data are means \pm SEM of a representative experiment of three performed with three technical replicates per condition. Unpaired $t$-test. Significant differences are indicated as ${ }^{*} p<0.05$, ${ }^{* *} p<0.01,{ }^{* * *} p<0.001$, and ${ }^{* * * *} p<0.0001$. 
A

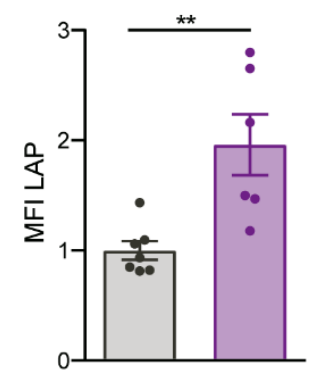

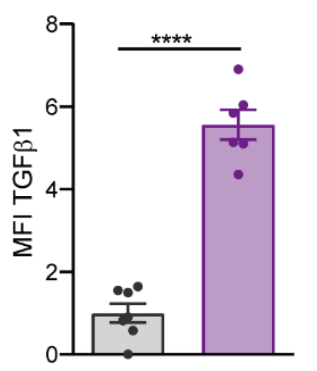

$\square \mathrm{MT1}-\mathrm{MMP} \mathrm{f}^{\mathrm{f} / \mathrm{f}}$

$\square \mathrm{MT1}$ 1-MMP ${ }^{\Delta \mathrm{LysM}}$
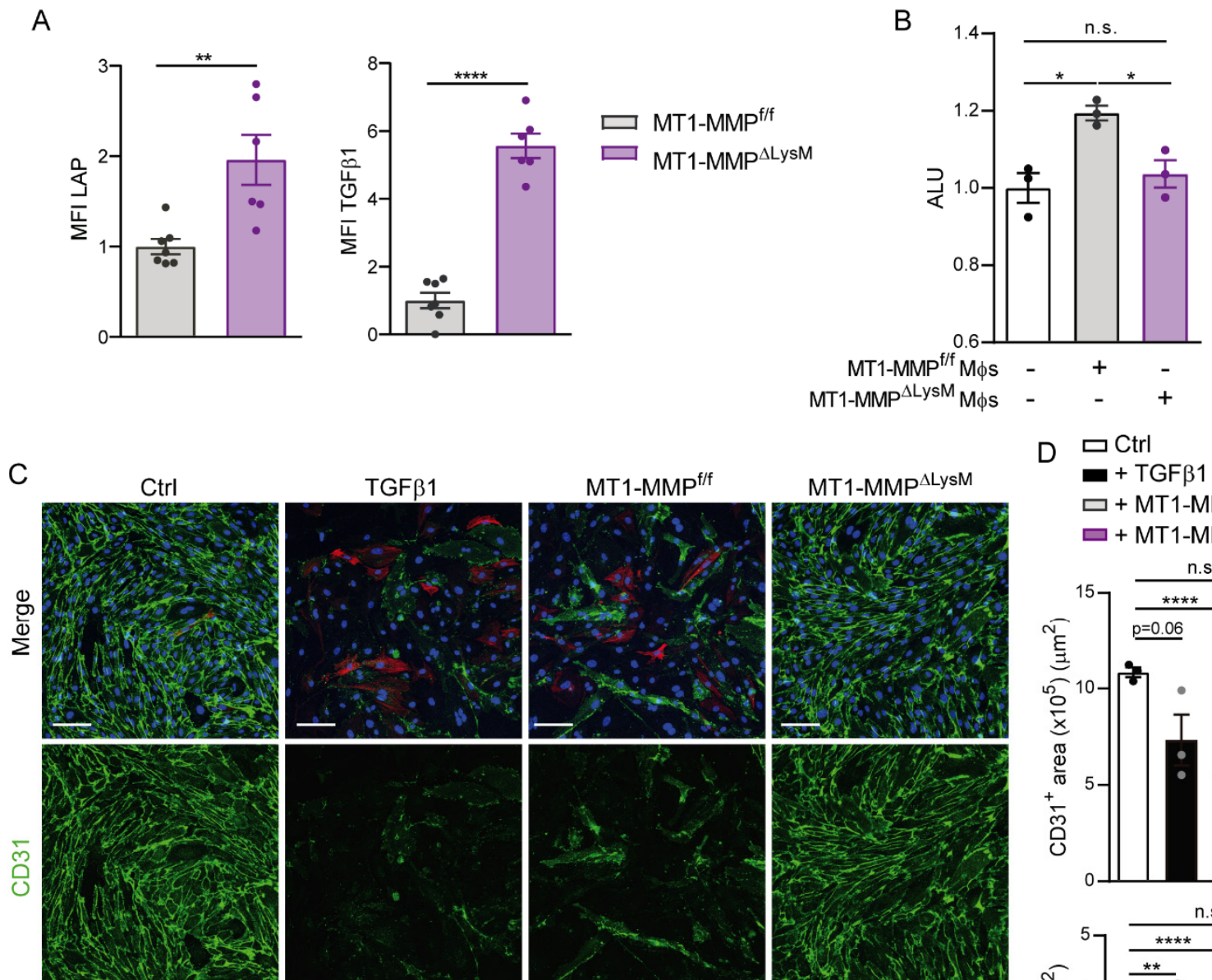
D $\square$ Ctrl
a + TGF $\beta 1$
$\square+\mathrm{MT} 1-\mathrm{MMP}^{\mathrm{f} / \mathrm{f}} \mathrm{M} \phi \mathrm{s}$
$\square+\mathrm{MT} 1-\mathrm{MMP}^{\Delta \mathrm{LysM}} \mathrm{M} \phi \mathrm{s}$
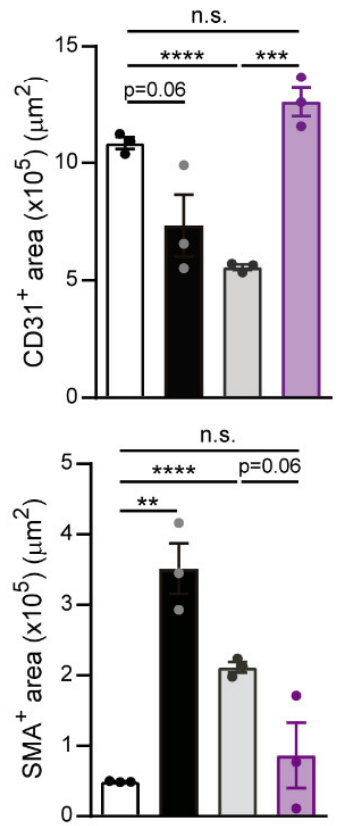

Figure 30. Post-MI cardiac macrophages induce EndMT through MT1-MMP-mediated TGF $\beta 1$ activation. (A) Standardized MFI of LAP and TGF $\beta 1$ staining in MT1-MMP//f and MT1-MMP ${ }^{\triangle L y s M}$ cardiac macrophages on day 7 after MI. Data are means \pm SEM of 6-7 mice per group. Unpaired $t$-test. Significant differences are indicated as ${ }^{* *} p<0.01$, and ${ }^{* * *} p<0.0001$. (B) Luciferase activity (ALU) in transfected HEK293 cells co-cultured with macrophages from 7-day-post-MI MT1-MMP/f or MT1-MMP $^{\Delta L y s M}$ hearts. Data are means \pm SEM of three independent experiments performed with four technical replicates per condition. One-way ANOVA followed by Tukey's multiple comparisons test. Significant differences are indicated as * $p<0.05$. (C) Representative immunofluorescence staining of CD31 (green) and SMA (red) in in vitro cocultures of MAECs and cardiac macrophages from MT1-MMP/f or MT1-MMP ${ }^{\Delta L y s M}$ 7-day-post-MI hearts. Nuclei are stained with DAPI (blue). (D) CD31+ area $\left(\mu \mathrm{m}^{2}\right)$ and $S M A^{+}$area $\left(\mu \mathrm{m}^{2}\right)$ in the different conditions. Data are means \pm SEM of a representative experiment of three performed with three technical replicates per condition. Unpaired $t$-test. Significant differences are indicated as ${ }^{* *} p<0.01,{ }^{* * *} p<0.001$, and ${ }^{* * * *} p$ $<0.0001$. 

DISCUSSION 

MI results in loss of cardiomyocytes, adverse structural remodeling, and LV dilation and dysfunction, eventually causing heart failure. Trying to overcome the inability of adult cardiac muscle to regenerate, stem cell therapy using multiple cell types has been tested in clinical trials $(263,264)$. Nevertheless, its efficacy has distinct limitations, such as low cardiac engraftment of cells, little cardiomyogenic potential of BM stem cells as well as the necessity to improve therapeutic delivery methods (265-267). This overview has led to clinicians and basic researchers to work together in the pursuit of alternative therapeutic pathways aiming to improve the intrinsic healing features of the heart. Since appropriate cardiac repair requires a balanced inflammatory response to avoid adverse cardiac remodeling after $\mathrm{MI}$, macrophages have emerged as likely candidates for investigation and therapeutic intervention $(2,65,268)$.

In this study, we first did an extensive analysis of the central role of macrophages in cardiac healing comparing two models of injury (cryoinjury and LAD-ligation) regarding the functional cardiac outcome, tissue remodeling, and vasculature alterations. Remarkably, whereas LADligation severely impacted LV function and geometry $(49,269)$, cryoinjury only affected LV function mildly without any signs of LV dilation, which are usually a consequence of adverse remodeling. From this very first finding, we aimed to elucidate the alternatively activated mechanisms of repair that may account for the better resolution of the damage and prevention of worsening in cardiac function in cryoinjury versus LAD-ligation.

Consistent with observations in patients subjected to cryoablation for treatment of arrhythmias, cryoinjury resulted in a firm scar with little disruption of surrounding myocardial anatomy $(270,271)$, while LAD-ligation led to an active remodeling of the ECM with live cardiomyocytes interspersed in the fibrotic scar. Moreover, the evolution of the initial damage is completely different in both models. Permanent occlusion of LAD coronary artery led to increasing infarct regions along time with the final deposition of a dense fibrotic scar that provoked LV wall thinning (272). In contrast, cryolesion in mice was characterized by initial hemorrhage and necrosis that persisted in the early reparative phase, although it was completely replaced by a reduced fibrotic scar at 28 days post-injury with LV wall thickness preservation, similarly to histological observations in a canine model of myocardial cryoinjury (224). In summary, the area of cryolesion decreased in the advanced post-injury stages, as previously suggested (224, 230), indicating a superior reparative capacity of the myocardium in response to this latter approach. These observations have led to the postulation of cryoinjury as model to study myocardial regeneration in mammals (230). Unfortunately, this seems to be a misleading conclusion based on the healing properties of the model. It is true that adult mammalian heart progressively recovers when subjected to cryoinjury, however, it is a partial recovery and not a complete regeneration either in structure or function $(20,273)$. 
Alternative remodeling of vasculature was observed between models. Cryoinjury but not LAD-ligation increased the number of arterioles at late post-injury stage, as suggested in previous studies (230). Since macrophage depletion in cryoinjury has been associated with less SMA ${ }^{+}$ vascular structures (57), the increase in $\mathrm{SMA}^{+}$vessels we described may rely on macrophage activity. One possible mechanism is increased nitric oxide production, which is essential for arteriogenesis (274), since higher levels of Nos2 were reported in macrophages found in cryoinjury versus LAD-ligation. However, further research will be necessary to define the mechanism.

Here, we described that following tissue injury the cardiac lymphatics underwent dramatic vessel growth $(275,276)$, with augmented development in cryoinjured hearts. This enlarged lymphatic growth correlated with significant improvement of LV function in cryoinjury versus LADligation, possibly indicating a direct association between lymphangiogenesis and post-injury cardiac function (275-277). The lymphatic system regulates interstitial tissue fluid balance, and lymphangiogenesis has been implicated in inflammatory limitation and edema resolution, by draining excessive proteins and fluids from the tissue $(275,277-280)$. Moreover, stimulation of cardiac lymphangiogenesis following $\mathrm{MI}$ results in attenuated cardiac dysfunction due to reduced myocardial edema and fibrosis (275), further supporting our hypothesis.

Crosstalk of macrophages and ECs is important for vascular network formation in developing organs as well as in neonatal cardiac regeneration (45) and adult cardiac repair (57). In line with previous studies $(20,32,34)$, we found that CRMs highly express LYVE1, suggesting a possible role in blood vessel development in the healthy heart (281). After injury, LYVE1 expression dramatically declined in inflammatory macrophages and start to recover in reparative macrophages until almost complete restoration on 28 days post-injury. This timeline in LYVE expression correlates with lymph vessel growth in injured hearts, probably indicating a role of macrophage LYVE1 in this process $(282,283)$. However, other mechanisms may be involved in post-injury lymphangiogenesis, since LYVE1 expression in macrophages does not account for the differences observed in lymph vessel growth between models.

In agreement with previous reports $(51,60)$, we identified distinct post-injury macrophage populations. Whereas Ly6Clow macrophages represent most of the CRM pool, they are rapidly overcome by blood monocyte-derived Ly6C ${ }^{\text {high }}$ macrophages in the inflammatory phase after injury, producing IL6, NOS2, and COX2. Later, Ly6Chigh inflammatory macrophages shift towards a Ly6C ${ }^{\text {low }}$ reparative phenotype that resolves inflammation and promotes angiogenesis and scar formation by secretion of MMPs. Interestingly, we identified massive mobilization of Ly6Chigh inflammatory macrophages and higher expression of pro-inflammatory genes (I/6 and Nos2) in these cells following cryoinjury versus LAD-ligation, indicating the great capacity of cryoinjury model to activate inflammation $(20,57,224)$. Consistent with our results, wound healing models 
are characterized by a robust innate immune response and macrophages are central players in these tissue repair responses (284).

In our characterization of macrophage gene expression profile, we found high levels of Mmp13 in CRMs, which dramatically decreased in macrophages from days 3 and 7 , and its expression started to recover at 28 days post-injury. This collagenase has been associated with the termination of fibrotic response in the liver (285), thus suggesting that CRMs might be endowed with anti-fibrotic functions which are lost in post-injury macrophages in favor of scar formation.

In addition, CRMs expressed high levels of the scavenger receptors Mrc1, Cd163, and Mertk, supporting the role of these cells in phagocytosis and debris clearance (40). MRC1 is a Ctype lectin that mediates scavenging of pro-inflammatory glycoproteins, such as lysosomal hydrolases, tissue plasminogen activator, and myeloperoxidase, once the initial threat has subsided (286). The scavenger receptor CD163 participates in the clearance of hemoglobin/haptoglobin complexes by macrophages, protecting tissues from free hemoglobinmediated oxidative damage (287). In line with our results, Dr. Ira Tabas' laboratory reported Mertk expression by CRMs. MerTK is a receptor tyrosine kinase that mediates efferocytosis and resolves inflammation in $\mathrm{Ml}$ and atherosclerosis, among other pathological settings, contributing to tissue repair (288-292). Consistent with these functions, Mrc1, Cd163 and Mertk are expressed at low levels during inflammation (day 3 ) and started recovering their expression in the resolution of inflammation (from day 7 to day 28), to ensure inflammatory agents are removed from the myocardium at the appropriate time $(34,293)$. Remarkably, post-injury macrophage expression of Mertk was significantly higher in cryoinjury than LAD-ligation. This finding suggests that, although cryoinjury mobilized augmented numbers of inflammatory macrophages, the wound healing activates a more effective clearance of pro-inflammatory mediators and subsequent resolution of inflammation than LAD-ligation does $(289,291,292)$.

In line with the resolution of inflammation, it is proposed that cardiac lymphatics may influence the extent, duration, and quality of the inflammatory response to myocardial injury (275, $276,294)$. Specifically, the expanded lymphatic network, draining the injury area, enables active trafficking of innate immune cells to regional mediastinal lymph nodes (294). Therefore, the increased lymph vessel growth reported in cryoinjury might also contribute to a more efficient resolution of inflammation.

Collectively, the distinct numbers and gene expression profile of post-injury macrophages between models may explain the differences observed in inflammation, its resolution, and scar formation. Despite the early peak in inflammation and increased expression of pro-inflammatory mediators, cryoinjury triggers a better resolution of the initial damage, characterized by milder 
ECM remodeling, and increased lymph and arteriole vessel growth, as well as higher expression of efferocytosis mediators (MerTK) than LAD-ligation (Figure 31).

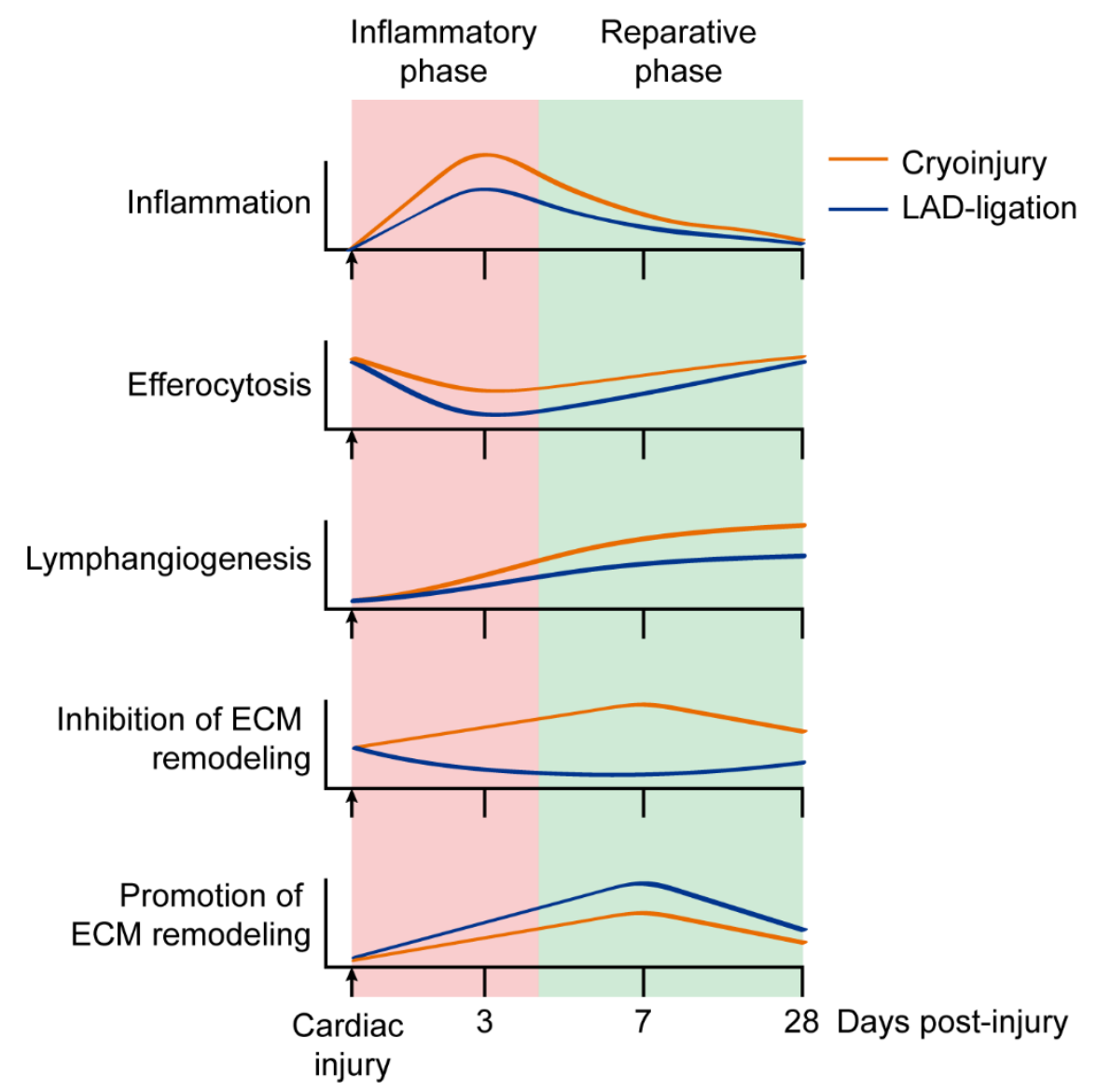

Cardiac outcome

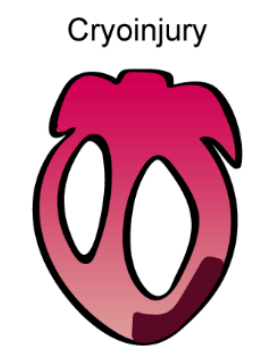

No LV dilation Mild LV dysfuntion

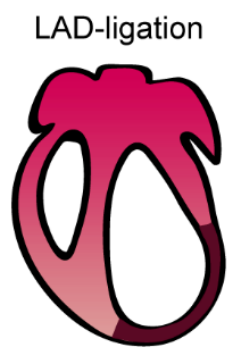

LV dilation Severe LV dysfuntion

Figure 31. Cryoinjury and LAD-ligation lead to disparate patterns of macrophage activation resulting in distinct cardiac healing responses. Summary of macrophage-mediated repair mechanisms activated in cardiac tissue after injury. Cryoinjury triggers enhanced inflammation, efferocytosis, and lymphangiogenesis while LAD-ligation promotes active ECM remodeling. Whereas cryoinjury-induced repair mechanisms lead to mild LV dysfunction with preserved LV structure, LAD-ligation causes severe LV dysfunction and dilation.

In terms of tissue remodeling, we described that both models induced ECM turnover and collagen deposition $(57,224,269)$, despite LAD-ligation led to significantly more robust ECM 
disruption and denser collagen deposition. Strikingly, post-cryoinjury macrophages massively expressed Timp3, an inhibitor of MMPs which are the main responsible of ECM turnover. In contrast, Timp3 levels were reduced immediately after LAD-ligation in Ly6C ${ }^{\text {high }}$ macrophages, in line with the general cardiac decline of Timp3 expression reported shortly post-MI in animal models and patients with heart failure (295-297). This finding suggests that post-cryoinjury macrophages tightly control MMP activity to avoid extreme ECM remodeling, as we reported histologically, ensuring a better preservation of LV structure and function. Our conclusion is supported by the literature, since overexpression of Timp3 in a mouse model of $\mathrm{Ml}$ exerts beneficial effects by suppressing early proteolysis and promoting angiogenesis (297).

Conversely, macrophages found after LAD-ligation displayed higher expression of some MMPs, such as Mmp14 and Mmp2, corresponding with strong tissue remodeling and collagen deposition when compared to cryoinjury. Although ECM remodeling and granulation tissue formation are prerequisites for tissue repair, excessive MMP activity after MI and subsequent ECM turnover can result in adverse remodeling and worsened cardiac dysfunction (110, 190, 297, 298). Thus, the significantly milder expression of Mmp14 and Mmp2, and higher Timp3 expression by macrophages after cryoinjury could prevent the adverse tissue remodeling and worsening in LV function observed in the model of LAD-ligation.

MT1-MMP (Mmp14) has been shown to be elevated in patients with CVD, contributing to heart disease $(158,159)$. Furthermore, animal studies have reported a beneficial effect of systemic MT1-MMP haplodeficiency (MT1-MMP ${ }^{+/-}$mice) in LV remodeling, cardiac function, and survival following $\mathrm{MI}(80,190,191)$. On the other hand, a mouse model with cardiomyocyte MT1-MMP overexpression resulted in severe dilated cardiomyopathy (190), further supporting the deleterious effect of dysregulated MT1-MMP activity post-MI. However, the myocyte-restricted nature of this study (191) precluded any direct assessment of the role of the protease in macrophages, although these immune cells are known to express MT1-MMP $(171,172,209)$. Nevertheless, the detrimental effect of myeloid-derived MT1-MMP has been demonstrated in other pathological contexts (198). Therefore, we hypothesized that macrophage-restricted MT1-MMP deletion might limit adverse remodeling and LV dilation and dysfunction after MI.

Although MT1-MMP ${ }^{\Delta L y S M}$ mice are phenotypically normal under homeostatic conditions, these animals were protected when challenged by acute $\mathrm{MI}$, similar to what has been reported for MT1-MMP ${ }^{+/-}$mice after $\mathrm{Ml}(80,191)$, and also in other pathological settings such as neointimal hyperplasia (183) or high-fat diet-induced obesity (299). MT1-MMP ${ }^{\Delta L y s M}$ mice had smaller infarcts and better LV contractility after MI than controls, as well as significantly improved preservation of systolic function and LV structure. This phenotype is likely caused by the lower myocardial fibrosis 
and ECM stiffness we catalogued in post-MI MT1-MMP ${ }^{\Delta L y s M}$ hearts, allowing the heart to work at less of a mechanical disadvantage. Excessive myocardial fibrosis and abnormalities in the ECM result in a significant decrease in myocardial compliance, and thus impairment of LV function (300). SHG detected altered ECM remodeling characterized by lower density and underdeveloped collagen fibers within the infarct of MT1-MMP ${ }^{\Delta L y s M}$ mice. This soft tissue fibrosis may arise from lower cellular collagenase activity in the absence of MT1-MMP $(128,190,191)$.

Previous studies attributed the detrimental role of MT1-MMP in post-MI cardiac remodeling to its collagenase activity in fibroblasts (FBs), disregarding its actions in macrophages (80, 190, 191). Our data obtained with the MT1-MMP $\triangle$ LysM model, and given the lack of MT1-MMP expression in neutrophils $(301,302)$, demonstrate the beneficial effect of macrophage-specific MT1-MMP deletion in preventing adverse LV remodeling after MI. Unlike transplant experiments (80), our macrophage-specific MT1-MMP KO model depleted the protease not only in monocytederived macrophages, but also in CRMs, which are maintained independently of BM-derived precursors (8). Additionally, after the initial post-MI boost in monocyte recruitment to the myocardium, cardiac macrophages regain self-renewal capacity and independence from circulating monocytes $(8,35,37)$. In the transplant model $(80)$ the apparent non-contribution of BM-derived MT1-MMP to post-MI fibrosis may also reflect the use of mice haplodeficient for MT1MMP, chosen because MT1-MMP--- mice die several weeks after birth $(128,129)$. Thus, while MT1-MMP was reduced in the haplodeficient mice, it was still produced (80). These considerations may explain the difference in the effect on cardiac function attributed to macrophage MT1-MMP between this earlier study and ours. In addition, myeloid cell-derived MT1-MMP has been implicated in detrimental tissue remodeling in other pathological contexts (198), supporting our findings in MI.

The favorable effect of macrophage-specific MT1-MMP deletion on cardiac repair also likely relies on better oxygenation of the infarcted myocardium due to the preservation of the microvasculature network in MT1-MMP $\triangle$ LysM mice. Notably, anti-angiogenic properties have been associated to MT1-MMP in a catalytic-independent fashion (303). Moreover, MT1-MMP blockade has been recently linked to reduced hypoxia in tumor environment (175). However, further investigations will be required to elucidate whether post-MI increased microvasculature network in MT1-MMP ${ }^{\triangle L y s M}$ versus control mice is a consequence of active angiogenic processes or better preservation of the preexistent vasculature.

MT1-MMP also plays a role in vessel wall architecture, promoting the migration and proliferation of VSMCs $(183,184)$. Accordingly, MT1-MMP ${ }^{\triangle L y s M}$ hearts exhibited attenuation of post-MI arteriole wall thickening. Following an arterial occlusion, remodeling of preexistent 
arterioles occurs by migration and proliferation of VSMCs, contributing to thickening of the arterial wall. Arteriole remodeling could lead to wall stiffness and luminal stenosis, and consequently impaired blood flow to the myocardium $(304,305)$. Hence, our results suggest that prevention of arteriole wall thickening contributed to the improved cardiac functional outcome following MI when macrophage MT1-MMP was absent.

Loss of collagenase activity in MT1-MMP ${ }^{\Delta L y s M}$ mice might be expected to lead to a dense scar, contrary to our findings. However, in addition to its collagenolytic activity (122), MT1-MMP proteolytically processes a diverse range of biologically active signaling molecules $(86,106,144$, 145); stimulation of collagen synthetic pathways by these molecules would explain the observed phenotype of post-MI MT1-MMP $\triangle$ LysM mice. Pro-TGF $\beta$ has been recognized as a target for MT1MMP-mediated cleavage in several contexts $(106,144,145,148-150,152,306)$. Our results provide evidence for MT1-MMP-mediated activation of latent TGF $\beta 1$ in cardiac macrophages after MI. Dampened processing and release of active TGF $\beta 1$ in MT1-MMP ${ }^{\triangle L y s M}$ mice was associated with a decrease in SMAD2-mediated signaling in the infarcted myocardium, providing a mechanism for the reduced pro-fibrotic response, attenuation of arteriole hyperplasia, and preservation of microvasculature network. Via TGF $\beta 1$ activation, macrophage MT1-MMP could thus have indirect downstream effects on the FB activation state and EC and VSMC proliferation (Figure 32). In accordance with our findings, it was reported that TGF $\beta$-producing inflammatory cells contribute to diastolic dysfunction in human heart failure with preserved ejection fraction by triggering the accumulation of ECM (307).

One possible effect of suppressed production of active TGF $\beta 1$ in post-MI MT1-MMP ${ }^{\Delta L y s M}$ mice is reduced collagen-fiber synthesis by MyoFBs (Figure 32). Previous studies identified MT1MMP as an inducer of fibrosis through its cleavage of latent-transforming growth factor betabinding protein 1 (LTBP1) and activation of TGF $\beta$-mediated SMAD2/3 signaling in the infarcted myocardium $(190,191)$. There is also abundant evidence that TGF $\beta$ directly activates FB differentiation to MyoFBs and collagen synthesis via SMAD-signaling pathways (Figure 6) (75, $76,308)$. The main role of MyoFBs is to produce structural ECM proteins; however, excessive ECM production and deposition can adversely affect cardiac structure and function (75). Consequently, numerous studies have demonstrated the ability of strategies targeting TGF $\beta 1$ (eg, neutralizing antibodies, gene therapy against TGF $\beta$ signaling, KO mice for SMAD signaling components) to prevent cardiac fibrosis and improve LV function after MI (256, 260, 309-312). Due to its multifaceted nature, TGF $\beta$ signaling needs to be orchestrated with temporal and spatial precision. Thus, although early inhibition of TGF $\beta$ after the ischemic event is associated with increased mortality, leukocyte infiltration, and chemokine expression, the later elimination of this growth factor results in improved survival and reduced tissue fibrosis (313). 


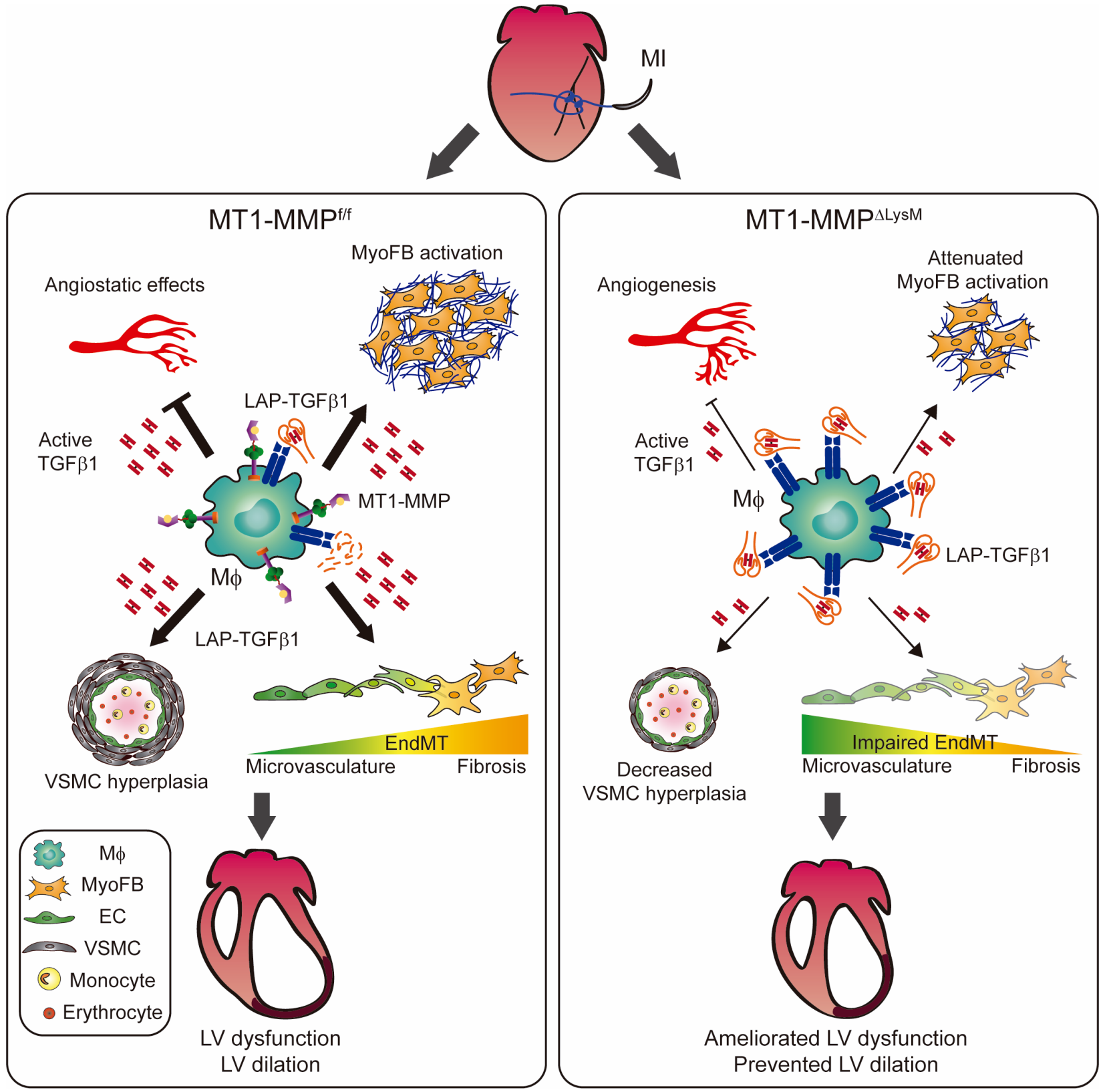

Figure 32. Macrophage MT1-MMP deletion preserves cardiac function after MI by impairing TGF $\beta 1$ signaling in the myocardium. MI triggers MT1-MMP production by macrophages, contributing to release of active TGF $\beta 1$ from SLC (LAP- TGF $\beta 1$ ) to the myocardium. Active TGF $\beta 1$ signals acting on ECs promote EndMT, contributing to adverse tissue remodeling. When macrophage MT1-MMP is absent, latent TGF $\beta 1$ accumulates, and the availability of active TGF $\beta 1$ in the myocardium decreases. In this scenario, the impairment of macrophage-mediated EndMT results in enhanced angiogenesis and reduced fibrosis, limiting LV remodeling and preserving cardiac function. $M \phi$ : macrophage.

Suppressed active TGF $\beta 1$ production could also underlie the preservation of the post-MI microvasculature network, through the loss of TGF $\beta 1$ angiostatic effects (Figure 32). Whether TGF $\beta$ actions on ECs are angiogenic or angiostatic depends on the context, the origin of the ECs, the combination of TGF $\beta$ receptors expressed on the cell surface, and the presence or absence 
of other mediators (314). Very limited information is available on the effects of TGF $\beta$ on vascular cells in the infarcted myocardium. Nevertheless, TGF $\beta 1$ has been proposed to inhibit EC proliferation and migration and to stimulate vascular maturation and pericyte coverage $(257,258$, 315), supporting our findings in post-MI macrophage-specific MT1-MMP KO mouse. Accordingly, the reduction in SMAD2 signaling in VSMCs and resultant attenuation of arteriole hyperplasia, may be explained by impairment of TFG $\beta 1$-mediated recruitment and differentiation of VSMCs (Figure 32) (261).

TGF $\beta$-mediated EndMT has been identified during cardiac fibrosis (219), contributing to collagen matrix deposition and disease. The concomitant loss of functional ECs may also lead to capillary rarefaction, thus causing tissue ischemia, a potent driver of fibrosis. This mechanism is not restricted to the heart and has been also proved to underlie stenosis in vein graft remodeling in atherosclerotic patients (316), idiopathic portal hypertension (317), and chronic kidney disease (318). Moreover, macrophages have been recently reported as partial inducers of EndMT in atherosclerosis (223). Our results showing changes in ECs, 'transitioning cells', and MyoFBs demonstrate a role of macrophage-derived MT1-MMP in TGF $\beta 1$-mediated EndMT after MI (Figure 32), contributing to the observed phenotype. A role of MT1-MMP in macrophage-mediated EndMT is further supported by the in vitro experiments. Our findings are in line with the role of MT1-MMP as an activator of EMT in other pathophysiological contexts such as development, cancer, and lung fibrosis $(149,152,188,189)$.

Based on our discoveries, we propose that macrophages activate EndMT through MT1MMP after ischemic injury, contributing to increased numbers and activity of MyoFBs during granulation tissue formation. These cells might then take part in fibrosis, giving rise to a dense fibrotic scar that compromises LV cardiac function after MI. Restraining macrophage-mediated TGF $\beta 1$ activation by MT1-MMP thus limits EndMT, favoring preservation of cardiac microvasculature, improving myocardial blood flow, and reducing tissue hypoxia and fibrotic scarring (Figure 32). These alterations in MT1-MMP ${ }^{\triangle L y s M}$ mice limited LV dilation and dysfunction, and suggest novel approaches to the promotion of cardiac recovery after MI. Therapeutic strategies would consist of manipulating macrophage MT1-MMP production in order to control EndMT, thus promoting angiogenesis and moderating scar formation. Interestingly, in an experimental rat model of $\mathrm{Ml}$, treatment with menstrual-blood-derived mesenchymal stem cells has been shown to protect endothelial function, reduce infarct size, decrease cardiac fibrosis, and downregulate TGF $\beta 1 /$ SMAD signaling, all through the comprehensive inhibition of EndMT (319).

Following this rationale, previous studies have pointed to the beneficial effect of pharmacological inhibition of MMPs on post-MI cardiac remodeling (82, 320, 321); however, implementation of clinically relevant therapies has proved difficult $(206,207,322,323)$. Selective 


\section{DISCUSSION}

MMP inhibition has been proposed to minimize the negative side effects of the use of non-selective inhibitors, such as musculoskeletal toxicity after treatment with marimastat in patients with metastatic cancer (206). A recent study reported that selective MT1-MMP inhibition rescued tissue damage and mortality in influenza-infected mice, demonstrating the potential of specific MT1-MMP inhibitors to ameliorate the detrimental effects of this protease on tissue remodeling (198). Accordingly, controlling dysregulated myocardial MT1-MMP activity in macrophages could be a suitable option for patients at risk of developing heart failure after MI. 
CONCLUSIONS 

1. LAD-ligation is a model of MI that severely disrupts myocardial integrity, leading to intense cardiac remodeling and subsequent cardiac dysfunction. Conversely, cryoinjury is a wound healing model that mildly affects the cardiac function and provokes a smaller fibrotic response.

2. Macrophage-mediated responses in the heart are divergent in these two models of cardiac injury. Cryoinjury results in enhanced Ly6Chigh macrophage infiltration and exacerbated production of pro-inflammatory mediators, whereas coronary ligation activates a profound ECM-remodeling response in cardiac macrophages.

3. Although cryoinjury triggers a heightened inflammation, macrophage-mediated healing response is more efficient compared to LAD-ligation. This is explained by increased lymphatic drainage of the tissue, improved efferocytosis, and ameliorated ECM remodeling and collagen deposition.

4. Macrophage production of MT1-MMP (Mmp14) actively contributes to adverse ECM remodeling following MI. Consequently, macrophage deletion of MT1-MMP has a beneficial effect in post-MI LV function due to reduced ECM stiffness.

5. Macrophage-derived MT1-MMP participates in post-MI vascular remodeling and stabilization. Accordingly, the absence of macrophage MT1-MMP improves myocardial blood flow by preservation of the microvasculature network and attenuation of Ml-induced arteriole hyperplasia, resulting in enhanced tissue oxygenation.

6. MT1-MMP activates TGF $\beta 1$ in macrophages in response to $\mathrm{MI}$, leading to paracrine SMAD2-meadiated signaling in endothelial cells, myofibroblasts and vascular smooth muscle cells.

7. Macrophage MT1-MMP-activated TGF $\beta 1$ triggers EndMT in vitro and in vivo following MI. The blockade of MT1-MMP-induced EndMT by macrophages promotes myocardial infarct healing through enhanced angiogenesis and myocardium oxygenation, as well as reduced myofibroblast numbers and fibrotic response. 

CONCLUSIONES 

1. La ligación de LAD es un modelo experimental de IM que afecta de forma severa a la integridad del miocardio, causando un intenso remodelado que provoca disfunción cardiaca. En cambio, la criolesión es un modelo de "cicatrización de la herida" que compromete levemente la función cardiaca y provoca una menor fibrosis.

2. La activación de los macrófagos cardiacos en respuesta al daño es diferente en ambos modelos. La criolesión provoca una marcada infiltración de macrófagos Ly6Chigh y una producción exacerbada de mediadores pro-inflamatorios; mientras que la ligación coronaria activa una profunda respuesta de remodelado de la matriz extracelular en los macrófagos.

3. Aunque la criolesión desencadena una inflamación más potente que la ligación, la respuesta reparadora de los macrófagos es más eficiente. Esto se debe a un mayor drenaje linfático del tejido, una mejora de la eferocitosis y una atenuación del remodelado del tejido y de la deposición de colágeno.

4. La proteasa MT1-MMP (Mmp14) producida por macrófagos participa activamente en el remodelado adverso de la matriz extracelular tras el IM. En consecuencia, la eliminación de MT1-MMP en macrófagos tiene un efecto beneficioso en la función cardiaca tras el IM, gracias a una disminución de la rigidez de la matriz extracelular.

5. La proteasa MT1-MMP producida por macrófagos interviene en el remodelado y estabilización de la vasculatura después del IM. De modo que su eliminación mejora el flujo sanguíneo al miocardio al preservar la microvasculatura y atenuar la hiperplasia en arteriolas, aumentando así la oxigenación del tejido.

6. MT1-MMP activa TGFß1 en macrófagos en respuesta al IM, provocando la señalización paracrina a través de SMAD2 en células endoteliales, miofibroblastos y células vasculares de músculo liso.

7. La activación de TGF $\beta 1$ por MT1-MMP en macrófagos desencadena la transición endotelial-mesenquimal (EndMT) in vitro e in vivo tras el IM. El bloqueo de la EndMT mediada por MT1-MMP de macrófagos favorece la reparación del corazón infartado gracias al incremento de la angiogénesis y oxigenación del miocardio, así como al menor número de miofibroblastos y fibrosis. 

BIBLIOGRAPHY 

1. Davies LC, Jenkins SJ, Allen JE, and Taylor PR. Tissue-resident macrophages. Nat Immunol. 2013;14(10):986-95.

2. Harel-Adar T, Ben Mordechai T, Amsalem Y, Feinberg MS, Leor J, and Cohen S. Modulation of cardiac macrophages by phosphatidylserine-presenting liposomes improves infarct repair. Proceedings of the National Academy of Sciences of the United States of America. 2011;108(5):1827-32.

3. Sica A, Erreni M, Allavena P, and Porta C. Macrophage polarization in pathology. Cell Mol Life Sci. 2015;72(21):4111-26.

4. Ginhoux F, and Guilliams M. Tissue-Resident Macrophage Ontogeny and Homeostasis. Immunity. 2016;44(3):439-49.

5. van Furth R, Cohn ZA, Hirsch JG, Humphrey JH, Spector WG, and Langevoort HL. The mononuclear phagocyte system: a new classification of macrophages, monocytes, and their precursor cells. Bull World Health Organ. 1972;46(6):845-52.

6. Ginhoux F, Greter M, Leboeuf M, Nandi S, See P, Gokhan S, Mehler MF, Conway SJ, Ng LG, Stanley ER, et al. Fate Mapping Analysis Reveals That Adult Microglia Derive from Primitive Macrophages. Science. 2010;330(6005):841-5.

7. Hashimoto D, Chow A, Noizat C, Teo P, Beasley MB, Leboeuf M, Becker CD, See P, Price $\mathrm{J}$, Lucas $\mathrm{D}$, et al. Tissue-resident macrophages self-maintain locally throughout adult life with minimal contribution from circulating monocytes. Immunity. 2013;38(4):792-804.

8. Epelman S, Lavine KJ, Beaudin AE, Sojka DK, Carrero JA, Calderon B, Brija T, Gautier EL, Ivanov S, Satpathy AT, et al. Embryonic and adult-derived resident cardiac macrophages are maintained through distinct mechanisms at steady state and during inflammation. Immunity. 2014;40(1):91-104.

9. Bajpai G, Schneider C, Wong N, Bredemeyer A, Hulsmans M, Nahrendorf M, Epelman S, Kreisel D, Liu Y, Itoh A, et al. The human heart contains distinct macrophage subsets with divergent origins and functions. Nat Med. 2018;24(8):1234-45.

10. Tamoutounour S, Guilliams M, Montanana Sanchis F, Liu H, Terhorst D, Malosse C, Pollet $\mathrm{E}$, Ardouin L, Luche $\mathrm{H}$, Sanchez $\mathrm{C}$, et al. Origins and functional specialization of macrophages and of conventional and monocyte-derived dendritic cells in mouse skin. Immunity. 2013;39(5):925-38.

11. Schulz C, Perdiguero EG, Chorro L, Szabo-Rogers H, Cagnard N, Kierdorf K, Prinz M, Wu B, Jacobsen SEW, Pollard JW, et al. A Lineage of Myeloid Cells Independent of Myb and Hematopoietic Stem Cells. Science. 2012;336(6077):86-90.

12. Yona S, Kim KW, Wolf Y, Mildner A, Varol D, Breker M, Strauss-Ayali D, Viukov S, Guilliams M, Misharin A, et al. Fate mapping reveals origins and dynamics of monocytes and tissue macrophages under homeostasis. Immunity. 2013;38(1):79-91.

13. Zigmond E, Varol C, Farache J, Elmaliah E, Satpathy AT, Friedlander G, Mack M, Shpigel $\mathrm{N}$, Boneca IG, Murphy KM, et al. Ly6C hi monocytes in the inflamed colon give rise to 
proinflammatory effector cells and migratory antigen-presenting cells. Immunity. 2012;37(6):1076-90.

14. Mantovani A, Biswas SK, Galdiero MR, Sica A, and Locati M. Macrophage plasticity and polarization in tissue repair and remodelling. The Journal of pathology. 2013;229(2):17685.

15. Mills CD, Kincaid K, Alt JM, Heilman MJ, and Hill AM. M-1/M-2 macrophages and the Th1/Th2 paradigm. J Immunol. 2000;164(12):6166-73.

16. Stein M, Keshav S, Harris N, and Gordon S. Interleukin 4 potently enhances murine macrophage mannose receptor activity: a marker of alternative immunologic macrophage activation. J Exp Med. 1992;176(1):287-92.

17. Nahrendorf M, and Swirski FK. Abandoning M1/M2 for a Network Model of Macrophage Function. Circ Res. 2016;119(3):414-7.

18. Mosser DM, and Edwards JP. Exploring the full spectrum of macrophage activation. Nat Rev Immunol. 2008;8(12):958-69.

19. Martinez FO, and Gordon S. The M1 and M2 paradigm of macrophage activation: time for reassessment. F1000Prime Rep. 1000;6(13):6-13.

20. Walter W, Alonso-Herranz L, Trappetti V, Crespo I, Ibberson M, Cedenilla M, Karaszewska A, Nunez V, Xenarios I, Arroyo AG, et al. Deciphering the Dynamic Transcriptional and Post-transcriptional Networks of Macrophages in the Healthy Heart and after Myocardial Injury. Cell reports. 2018;23(2):622-36.

21. Epelman S, Lavine KJ, and Randolph GJ. Origin and functions of tissue macrophages. Immunity. 2014;41(1):21-35.

22. Gautier EL, Shay T, Miller J, Greter M, Jakubzick C, Ivanov S, Helft J, Chow A, Elpek KG, Gordonov S, et al. Gene-expression profiles and transcriptional regulatory pathways that underlie the identity and diversity of mouse tissue macrophages. Nat Immunol. 2012;13(11):1118-28.

23. Hulsmans M, Clauss S, Xiao L, Aguirre AD, King KR, Hanley A, Hucker WJ, Wulfers EM, Seemann G, Courties G, et al. Macrophages Facilitate Electrical Conduction in the Heart. Cell. 2017;169(3):510-22.

24. Theurl I, Hilgendorf I, Nairz M, Tymoszuk P, Haschka D, Asshoff M, He S, Gerhardt LM, Holderried TA, Seifert M, et al. On-demand erythrocyte disposal and iron recycling requires transient macrophages in the liver. Nature medicine. 2016;22(8):945-51.

25. Bedoret D, Wallemacq H, Marichal T, Desmet C, Quesada Calvo F, Henry E, Closset R, Dewals B, Thielen C, Gustin P, et al. Lung interstitial macrophages alter dendritic cell functions to prevent airway allergy in mice. The Journal of clinical investigation. 2009;119(12):3723-38. 
26. Nguyen KD, Qiu Y, Cui X, Goh YP, Mwangi J, David T, Mukundan L, Brombacher F, Locksley RM, and Chawla A. Alternatively activated macrophages produce catecholamines to sustain adaptive thermogenesis. Nature. 2011;480(7375):104-8.

27. Dutta P, Hoyer FF, Grigoryeva LS, Sager HB, Leuschner F, Courties G, Borodovsky A, Novobrantseva T, Ruda VM, Fitzgerald K, et al. Macrophages retain hematopoietic stem cells in the spleen via VCAM-1. J Exp Med. 2015;212(4):497-512.

28. Mazzini E, Massimiliano L, Penna G, and Rescigno M. Oral tolerance can be established via gap junction transfer of fed antigens from CX3CR1(+) macrophages to CD103(+) dendritic cells. Immunity. 2014;40(2):248-61.

29. Paolicelli RC, Bolasco G, Pagani F, Maggi L, Scianni M, Panzanelli P, Giustetto M, Ferreira TA, Guiducci E, Dumas L, et al. Synaptic pruning by microglia is necessary for normal brain development. Science. 2011;333(6048):1456-8.

30. Murray PJ, and Wynn TA. Protective and pathogenic functions of macrophage subsets. Nat Rev Immunol. 2011;11(11):723-37.

31. Nag AC. Study of non-muscle cells of the adult mammalian heart: a fine structural analysis and distribution. Cytobios. 1980;28(109):41-61.

32. Pinto AR, Paolicelli R, Salimova E, Gospocic J, Slonimsky E, Bilbao-Cortes D, Godwin JW, and Rosenthal NA. An abundant tissue macrophage population in the adult murine heart with a distinct alternatively-activated macrophage profile. PLoS One. 2012;7(5):10.

33. King KR, Aguirre AD, Ye YX, Sun Y, Roh JD, Ng RP, Jr., Kohler RH, Arlauckas SP, Iwamoto $\mathrm{Y}$, Savol A, et al. IRF3 and type I interferons fuel a fatal response to myocardial infarction. Nat Med. 2017;23(12):1481-7.

34. Dick SA, Macklin JA, Nejat S, Momen A, Clemente-Casares X, Althagafi MG, Chen J, Kantores C, Hosseinzadeh S, Aronoff L, et al. Self-renewing resident cardiac macrophages limit adverse remodeling following myocardial infarction. Nat Immunol. 2019;20(1):29-39.

35. Heidt T, Courties G, Dutta P, Sager HB, Sebas M, Iwamoto Y, Sun Y, Da Silva N, Panizzi $P$, van der Laan AM, et al. Differential contribution of monocytes to heart macrophages in steady-state and after myocardial infarction. Circ Res. 2014;115(2):284-95.

36. Molawi K, Wolf Y, Kandalla PK, Favret J, Hagemeyer N, Frenzel K, Pinto AR, Klapproth K, Henri S, Malissen B, et al. Progressive replacement of embryo-derived cardiac macrophages with age. J Exp Med. 2014;211(11):2151-8.

37. Bajpai G, Bredemeyer A, Li W, Zaitsev K, Koenig AL, Lokshina I, Mohan J, Ivey B, Hsiao $\mathrm{HM}$, Weinheimer C, et al. Tissue Resident CCR2- and CCR2+ Cardiac Macrophages Differentially Orchestrate Monocyte Recruitment and Fate Specification Following Myocardial Injury. Circ Res. 2019;124(2):263-78.

38. Cohen HB, and Mosser DM. Cardiac macrophages: how to mend a broken heart. Immunity. 2014;40(1):3-5. 
39. Pinto AR, Godwin JW, and Rosenthal NA. Macrophages in cardiac homeostasis, injury responses and progenitor cell mobilisation. Stem Cell Res. 2014;13(3 Pt B):705-14.

40. Lavine KJ, Pinto AR, Epelman S, Kopecky BJ, Clemente-Casares X, Godwin J, Rosenthal $\mathrm{N}$, and Kovacic JC. The Macrophage in Cardiac Homeostasis and Disease: JACC Macrophage in CVD Series (Part 4). J Am Coll Cardiol. 2018;72(18):2213-30.

41. Swirski FK, and Nahrendorf M. Cardioimmunology: the immune system in cardiac homeostasis and disease. Nat Rev Immunol. 2018;18(12):733-44.

42. Leid J, Carrelha J, Boukarabila H, Epelman S, Jacobsen SE, and Lavine KJ. Primitive Embryonic Macrophages are Required for Coronary Development and Maturation. Circ Res. 2016;118(10):1498-511.

43. Rhinn $\mathrm{M}$, and Dolle $\mathrm{P}$. Retinoic acid signalling during development. Development. 2012;139(5):843-58.

44. Lavine KJ, Epelman S, Uchida K, Weber KJ, Nichols CG, Schilling JD, Ornitz DM, Randolph GJ, and Mann DL. Distinct macrophage lineages contribute to disparate patterns of cardiac recovery and remodeling in the neonatal and adult heart. Proceedings of the National Academy of Sciences. 2014;111(45):16029-34.

45. Aurora AB, Porrello ER, Tan W, Mahmoud AI, Hill JA, Bassel-Duby R, Sadek HA, and Olson EN. Macrophages are required for neonatal heart regeneration. The Journal of clinical investigation. 2014;124(3):1382-92.

46. Nabel EG, and Braunwald E. A Tale of Coronary Artery Disease and Myocardial Infarction. New England Journal of Medicine. 2012;366(1):54-63.

47. Benjamin EJ, Blaha MJ, Chiuve SE, Cushman M, Das SR, Deo R, de Ferranti SD, Floyd J, Fornage M, Gillespie C, et al. Heart Disease and Stroke Statistics-2017 Update: A Report From the American Heart Association. Circulation. 2017;135(10):e146-e603.

48. Weinberger T, and Schulz C. Myocardial infarction: a critical role of macrophages in cardiac remodeling. Front Physiol. 2015;6(107).

49. Frangogiannis NG. Pathophysiology of Myocardial Infarction. Comprehensive Physiology. 2015;5(4):1841-75.

50. Epelman S, Liu PP, and Mann DL. Role of innate and adaptive immune mechanisms in cardiac injury and repair. Nat Rev Immunol. 2015;15(2):117-29.

51. Nahrendorf M, Swirski FK, Aikawa E, Stangenberg L, Wurdinger T, Figueiredo JL, Libby $\mathrm{P}$, Weissleder $\mathrm{R}$, and Pittet MJ. The healing myocardium sequentially mobilizes two monocyte subsets with divergent and complementary functions. $J$ Exp Med. 2007;204(12):3037-47.

52. Jung K, Kim P, Leuschner F, Gorbatov R, Kim JK, Ueno T, Nahrendorf M, and Yun SH. Endoscopic time-lapse imaging of immune cells in infarcted mouse hearts. Circ Res. 2013;112(6):891-9. 
53. Anzai A, Anzai T, Nagai S, Maekawa Y, Naito K, Kaneko H, Sugano Y, Takahashi T, Abe $\mathrm{H}$, Mochizuki $\mathrm{S}$, et al. Regulatory role of dendritic cells in postinfarction healing and left ventricular remodeling. Circulation. 2012;125(10):1234-45.

54. Dobaczewski M, Xia Y, Bujak M, Gonzalez-Quesada C, and Frangogiannis NG. CCR5 signaling suppresses inflammation and reduces adverse remodeling of the infarcted heart, mediating recruitment of regulatory $\mathrm{T}$ cells. The American journal of pathology. 2010;176(5):2177-87.

55. Frangogiannis NG, Lindsey ML, Michael LH, Youker KA, Bressler RB, Mendoza LH, Spengler RN, Smith CW, and Entman ML. Resident cardiac mast cells degranulate and release preformed TNF-alpha, initiating the cytokine cascade in experimental canine myocardial ischemia/reperfusion. Circulation. 1998;98(7):699-710.

56. Panizzi P, Swirski FK, Figueiredo JL, Waterman P, Sosnovik DE, Aikawa E, Libby P, Pittet $\mathrm{M}$, Weissleder R, and Nahrendorf M. Impaired infarct healing in atherosclerotic mice with Ly-6C(hi) monocytosis. J Am Coll Cardiol. 2010;55(15):1629-38.

57. van Amerongen MJ, Harmsen MC, van Rooijen $\mathrm{N}$, Petersen $\mathrm{AH}$, and van Luyn $\mathrm{MJ}$. Macrophage depletion impairs wound healing and increases left ventricular remodeling after myocardial injury in mice. Am J Pathol. 2007;170(3):818-29.

58. Leuschner F, Rauch PJ, Ueno T, Gorbatov R, Marinelli B, Lee WW, Dutta P, Wei Y, Robbins C, Iwamoto $\mathrm{Y}$, et al. Rapid monocyte kinetics in acute myocardial infarction are sustained by extramedullary monocytopoiesis. J Exp Med. 2012;209(1):123-37.

59. Swirski FK, Nahrendorf M, Etzrodt M, Wildgruber M, Cortez-Retamozo V, Panizzi P, Figueiredo JL, Kohler RH, Chudnovskiy A, Waterman $\mathrm{P}$, et al. Identification of splenic reservoir monocytes and their deployment to inflammatory sites. Science. 2009;325(5940):612-6.

60. Hilgendorf I, Gerhardt LM, Tan TC, Winter C, Holderried TA, Chousterman BG, Iwamoto Y, Liao R, Zirlik A, Scherer-Crosbie M, et al. Ly-6Chigh monocytes depend on Nr4a1 to balance both inflammatory and reparative phases in the infarcted myocardium. Circ Res. 2014;114(10):1611-22.

61. Fuster JJ, MacLauchlan S, Zuriaga MA, Polackal MN, Ostriker AC, Chakraborty R, Wu CL, Sano S, Muralidharan S, Rius C, et al. Clonal hematopoiesis associated with TET2 deficiency accelerates atherosclerosis development in mice. Science. 2017;355(6327):842-7.

62. Sano S, Oshima K, Wang Y, MacLauchlan S, Katanasaka Y, Sano M, Zuriaga MA, Yoshiyama M, Goukassian D, Cooper MA, et al. Tet2-Mediated Clonal Hematopoiesis Accelerates Heart Failure Through a Mechanism Involving the IL-1beta/NLRP3 Inflammasome. J Am Coll Cardiol. 2018;71(8):875-86.

63. Krishnamurthy P, Rajasingh J, Lambers E, Qin G, Losordo DW, and Kishore R. IL-10 inhibits inflammation and attenuates left ventricular remodeling after myocardial infarction via activation of STAT3 and suppression of HuR. Circ Res. 2009;104(2):e9-18. 
64. Nahrendorf M, Pittet MJ, and Swirski FK. Monocytes: Protagonists of Infarct Inflammation and Repair After Myocardial Infarction. Circulation. 2010;121(22):2437-45.

65. Ridker PM, Everett BM, Thuren T, MacFadyen JG, Chang WH, Ballantyne C, Fonseca F, Nicolau J, Koenig W, Anker SD, et al. Antiinflammatory Therapy with Canakinumab for Atherosclerotic Disease. N Engl J Med. 2017;377(12):1119-31.

66. Porrello ER, Mahmoud AI, Simpson E, Hill JA, Richardson JA, Olson EN, and Sadek HA. Transient regenerative potential of the neonatal mouse heart. Science. 2011;331(6020):1078-80.

67. Tsujioka H, Imanishi T, Ikejima H, Kuroi A, Takarada S, Tanimoto T, Kitabata H, Okochi K, Arita $\mathrm{Y}$, Ishibashi $\mathrm{K}$, et al. Impact of heterogeneity of human peripheral blood monocyte subsets on myocardial salvage in patients with primary acute myocardial infarction. $J \mathrm{Am}$ Coll Cardiol. 2009;54(2):130-8.

68. Novak ML, and Koh TJ. Phenotypic transitions of macrophages orchestrate tissue repair. Am J Pathol. 2013;183(5):1352-63.

69. Fantin A, Vieira JM, Gestri G, Denti L, Schwarz Q, Prykhozhij S, Peri F, Wilson SW, and Ruhrberg $C$. Tissue macrophages act as cellular chaperones for vascular anastomosis downstream of VEGF-mediated endothelial tip cell induction. Blood. 2010;116(5):829-40.

70. Sunderkötter C, Steinbrink K, Goebeler M, Bhardwaj R, and Sorg C. Macrophages and angiogenesis. Journal of Leukocyte Biology. 1994;55(3):410-22.

71. Newby AC. Metalloproteinase production from macrophages - a perfect storm leading to atherosclerotic plaque rupture and myocardial infarction. Exp Physiol. 2016;101(11):132737.

72. Meschiari CA, Jung M, Iyer RP, Yabluchanskiy A, Toba H, Garrett MR, and Lindsey ML. Macrophage overexpression of matrix metalloproteinase-9 in aged mice improves diastolic physiology and cardiac wound healing after myocardial infarction. American journal of physiology Heart and circulatory physiology. 2018;314(2):H224-H35.

73. Zamilpa R, Ibarra J, de Castro Bras LE, Ramirez TA, Nguyen N, Halade GV, Zhang J, Dai $\mathrm{Q}$, Dayah T, Chiao YA, et al. Transgenic overexpression of matrix metalloproteinase-9 in macrophages attenuates the inflammatory response and improves left ventricular function post-myocardial infarction. J Mol Cell Cardiol. 2012;53(5):599-608.

74. Petrov VV, Fagard $\mathrm{RH}$, and Lijnen PJ. Stimulation of collagen production by transforming growth factor-beta1 during differentiation of cardiac fibroblasts to myofibroblasts. Hypertension (Dallas, Tex : 1979). 2002;39(2):258-63.

75. Weber KT, Sun Y, Bhattacharya SK, Ahokas RA, and Gerling IC. Myofibroblast-mediated mechanisms of pathological remodelling of the heart. Nat Rev Cardiol. 2013;10(1):15-26.

76. Bronnum H, Eskildsen T, Andersen DC, Schneider M, and Sheikh SP. IL-1beta suppresses TGF-beta-mediated myofibroblast differentiation in cardiac fibroblasts. Growth factors (Chur, Switzerland). 2013;31(3):81-9. 
77. Tao ZY, Cavasin MA, Yang F, Liu YH, and Yang XP. Temporal changes in matrix metalloproteinase expression and inflammatory response associated with cardiac rupture after myocardial infarction in mice. Life Sci. 2004;74(12):1561-72.

78. Chen W, and Frangogiannis NG. Fibroblasts in post-infarction inflammation and cardiac repair. Biochim Biophys Acta. 2013;4(945-53.

79. Konstam MA, Kramer DG, Patel AR, Maron MS, and Udelson JE. Left Ventricular Remodeling in Heart Failure. Current Concepts in Clinical Significance and Assessment. 2011;4(1):98-108.

80. Koenig GC, Rowe RG, Day SM, Sabeh F, Atkinson JJ, Cooke KR, and Weiss SJ. MT1MMP-dependent remodeling of cardiac extracellular matrix structure and function following myocardial infarction. The American journal of pathology. 2012;180(5):1863-78.

81. Ma Y, Halade GV, Zhang J, Ramirez TA, Levin D, Voorhees A, Jin YF, Han HC, Manicone $\mathrm{AM}$, and Lindsey ML. Matrix metalloproteinase-28 deletion exacerbates cardiac dysfunction and rupture after myocardial infarction in mice by inhibiting M2 macrophage activation. Circulation research. 2013;112(4):675-88.

82. Lindsey ML, Gannon J, Aikawa M, Schoen FJ, Rabkin E, Lopresti-Morrow L, Crawford J, Black S, Libby P, Mitchell PG, et al. Selective matrix metalloproteinase inhibition reduces left ventricular remodeling but does not inhibit angiogenesis after myocardial infarction. Circulation. 2002;105(6):753-8.

83. Lindsey ML. Assigning matrix metalloproteinase roles in ischaemic cardiac remodelling. Nat Rev Cardiol. 2018;15(8):471-9.

84. Matsumura S, Iwanaga S, Mochizuki S, Okamoto H, Ogawa S, and Okada Y. Targeted deletion or pharmacological inhibition of MMP-2 prevents cardiac rupture after myocardial infarction in mice. J Clin Invest. 2005;115(3):599-609.

85. Page-McCaw A, Ewald AJ, and Werb Z. Matrix metalloproteinases and the regulation of tissue remodelling. Nat Rev Mol Cell Biol. 2007;8(3):221-33.

86. Rodriguez D, Morrison CJ, and Overall CM. Matrix metalloproteinases: what do they not do? New substrates and biological roles identified by murine models and proteomics. Biochim Biophys Acta. 2010;1(39-54.

87. Itoh Y. Membrane-type matrix metalloproteinases: Their functions and regulations. Matrix Biol. 2015;44-46(207-23.

88. Sato H, Takino T, Okada Y, Cao J, Shinagawa A, Yamamoto E, and Seiki M. A matrix metalloproteinase expressed on the surface of invasive tumour cells. Nature. 1994;370(6484):61-5.

89. Zucker S, Pei D, Cao J, and Lopez-Otin C. Membrane type-matrix metalloproteinases (MTMMP). Curr Top Dev Biol. 2003;54(1-74.

90. Brinckerhoff CE, and Matrisian LM. Matrix metalloproteinases: a tail of a frog that became a prince. Nat Rev Mol Cell Biol. 2002;3(3):207-14. 
91. Overall CM. Molecular determinants of metalloproteinase substrate specificity: matrix metalloproteinase substrate binding domains, modules, and exosites. Mol Biotechnol. 2002;22(1):51-86.

92. Nakahara H, Howard L, Thompson EW, Sato H, Seiki M, Yeh Y, and Chen WT. Transmembrane/cytoplasmic domain-mediated membrane type 1-matrix metalloprotease docking to invadopodia is required for cell invasion. Proc Natl Acad Sci US A. 1997;94(15):7959-64.

93. Urena JM, Merlos-Suarez A, Baselga J, and Arribas J. The cytoplasmic carboxy-terminal amino acid determines the subcellular localization of proTGF-(alpha) and membrane type matrix metalloprotease (MT1-MMP). J Cell Sci. 1999;112 ( Pt 6)(773-84.

94. Koziol A, Martin-Alonso M, Clemente C, Gonzalo P, and Arroyo AG. Site-specific cellular functions of MT1-MMP. Eur J Cell Biol. 2012;91(11-12):889-95.

95. Pei D, and Weiss SJ. Furin-dependent intracellular activation of the human stromelysin-3 zymogen. Nature. 1995;375(6528):244-7.

96. Treadwell BV, Neidel J, Pavia M, Towle CA, Trice ME, and Mankin HJ. Purification and characterization of collagenase activator protein synthesized by articular cartilage. Arch Biochem Biophys. 1986;251(2):715-23.

97. Yana I, and Weiss SJ. Regulation of membrane type-1 matrix metalloproteinase activation by proprotein convertases. Mol Biol Cell. 2000;11(7):2387-401.

98. Sato H, Kinoshita T, Takino T, Nakayama K, and Seiki M. Activation of a recombinant membrane type 1-matrix metalloproteinase (MT1-MMP) by furin and its interaction with tissue inhibitor of metalloproteinases (TIMP)-2. FEBS Lett. 1996;393(1):101-4.

99. Haas TL, Stitelman D, Davis SJ, Apte SS, and Madri JA. Egr-1 mediates extracellular matrix-driven transcription of membrane type 1 matrix metalloproteinase in endothelium. $J$ Biol Chem. 1999;274(32):22679-85.

100. Gallardo-Vara E, Blanco FJ, Roque M, Friedman SL, Suzuki T, Botella LM, and Bernabeu C. Transcription factor KLF6 upregulates expression of metalloprotease MMP14 and subsequent release of soluble endoglin during vascular injury. Angiogenesis. 2016;19(2):155-71.

101. Gramolelli S, Cheng J, Martinez-Corral I, Vaha-Koskela M, Elbasani E, Kaivanto E, Rantanen V, Tuohinto K, Hautaniemi S, Bower M, et al. PROX1 is a transcriptional regulator of MMP14. Sci Rep. 2018;8(1):9531.

102. Han YP, Tuan TL, Wu H, Hughes M, and Garner WL. TNF-alpha stimulates activation of pro-MMP2 in human skin through NF-(kappa)B mediated induction of MT1-MMP. J Cell Sci. 2001;114(Pt 1):131-9.

103. Rajavashisth TB, Liao JK, Galis ZS, Tripathi S, Laufs U, Tripathi J, Chai NN, Xu XP, Jovinge S, Shah PK, et al. Inflammatory cytokines and oxidized low density lipoproteins 
increase endothelial cell expression of membrane type 1-matrix metalloproteinase. J Biol Chem. 1999;274(17):11924-9.

104. Tomita T, Fujii M, Tokumaru Y, Imanishi Y, Kanke M, Yamashita T, Ishiguro R, Kanzaki J, Kameyama K, and Otani Y. Granulocyte-macrophage colony-stimulating factor upregulates matrix metalloproteinase-2 (MMP-2) and membrane type-1 MMP (MT1-MMP) in human head and neck cancer cells. Cancer Lett. 2000;156(1):83-91.

105. Galvez BG, Genis L, Matias-Roman S, Oblander SA, Tryggvason K, Apte SS, and Arroyo AG. Membrane type 1-matrix metalloproteinase is regulated by chemokines monocytechemoattractant protein-1/ccl2 and interleukin-8/CXCL8 in endothelial cells during angiogenesis. J Biol Chem. 2005;280(2):1292-8.

106. Koziol A, Gonzalo P, Mota A, Pollan A, Lorenzo C, Colome N, Montaner D, Dopazo J, Arribas J, Canals $\mathrm{F}$, et al. The protease MT1-MMP drives a combinatorial proteolytic program in activated endothelial cells. Faseb j. 2012;26(11):4481-94.

107. Genis L, Galvez BG, Gonzalo P, and Arroyo AG. MT1-MMP: universal or particular player in angiogenesis? Cancer Metastasis Rev. 2006;25(1):77-86.

108. Masciantonio MG, Lee CKS, Arpino V, Mehta S, and Gill SE. The Balance Between Metalloproteinases and TIMPs: Critical Regulator of Microvascular Endothelial Cell Function in Health and Disease. Progress in molecular biology and translational science. 2017;147(101-31.

109. Sato $\mathrm{H}$, and Takino $\mathrm{T}$. Coordinate action of membrane-type matrix metalloproteinase-1 (MT1-MMP) and MMP-2 enhances pericellular proteolysis and invasion. Cancer Sci. 2010;101(4):843-7.

110. Kandalam V, Basu R, Abraham T, Wang X, Soloway PD, Jaworski DM, Oudit GY, and Kassiri Z. TIMP2 deficiency accelerates adverse post-myocardial infarction remodeling because of enhanced MT1-MMP activity despite lack of MMP2 activation. Circulation research. 2010;106(4):796-808.

111. Gonzalo P, Moreno V, Galvez BG, and Arroyo AG. MT1-MMP and integrins: Hand-to-hand in cell communication. Biofactors. 2010;36(4):248-54.

112. Galvez BG, Matias-Roman S, Yanez-Mo M, Sanchez-Madrid F, and Arroyo AG. ECM regulates MT1-MMP localization with beta1 or alphavbeta3 integrins at distinct cell compartments modulating its internalization and activity on human endothelial cells. $J$ Cell Biol. 2002;159(3):509-21.

113. Gonzalo P, and Arroyo AG. MT1-MMP: A novel component of the macrophage cell fusion machinery. Commun Integr Biol. 2010;3(3):256-9.

114. Seano G, Chiaverina G, Gagliardi PA, di Blasio L, Puliafito A, Bouvard C, Sessa R, Tarone $\mathrm{G}$, Sorokin L, Helley D, et al. Endothelial podosome rosettes regulate vascular branching in tumour angiogenesis. Nat Cell Biol. 2014;16(10):931-41, 1-8. 
115. Takino T, Watanabe $\mathrm{Y}$, Matsui M, Miyamori $\mathrm{H}$, Kudo T, Seiki M, and Sato $\mathrm{H}$. Membranetype 1 matrix metalloproteinase modulates focal adhesion stability and cell migration. Exp Cell Res. 2006;312(8):1381-9.

116. Wang $Y$, and McNiven MA. Invasive matrix degradation at focal adhesions occurs via protease recruitment by a FAK-p130Cas complex. J Cell Biol. 2012;196(3):375-85.

117. Hakulinen J, Sankkila L, Sugiyama N, Lehti K, and Keski-Oja J. Secretion of active membrane type 1 matrix metalloproteinase (MMP-14) into extracellular space in microvesicular exosomes. J Cell Biochem. 2008;105(5):1211-8.

118. Taraboletti G, D'Ascenzo S, Borsotti P, Giavazzi R, Pavan A, and Dolo V. Shedding of the matrix metalloproteinases MMP-2, MMP-9, and MT1-MMP as membrane vesicleassociated components by endothelial cells. Am J Pathol. 2002;160(2):673-80.

119. Galvez BG, Matias-Roman S, Yanez-Mo M, Vicente-Manzanares M, Sanchez-Madrid F, and Arroyo AG. Caveolae are a novel pathway for membrane-type 1 matrix metalloproteinase traffic in human endothelial cells. Mol Biol Cell. 2004;15(2):678-87.

120. Itoh Y, Takamura A, Ito N, Maru Y, Sato H, Suenaga N, Aoki T, and Seiki M. Homophilic complex formation of MT1-MMP facilitates proMMP-2 activation on the cell surface and promotes tumor cell invasion. EMBO J. 2001;20(17):4782-93.

121. Verma RP, and Hansch C. Matrix metalloproteinases (MMPs): chemical-biological functions and (Q)SARs. Bioorg Med Chem. 2007;15(6):2223-68.

122. Ohuchi E, Imai K, Fuji Y, Sato H, Seiki M, and Okada Y. Membrane type 1 matrix metalloproteinase digests interstitial collagens and other extracellular matrix macromolecules. J Biol Chem. 1997;272(4):2446-51.

123. Ohtake $\mathrm{Y}$, Tojo $\mathrm{H}$, and Seiki M. Multifunctional roles of MT1-MMP in myofiber formation and morphostatic maintenance of skeletal muscle. J Cell Sci. 2006;119(Pt 18):3822-32.

124. Koshikawa N, Minegishi T, Sharabi A, Quaranta V, and Seiki M. Membrane-type matrix metalloproteinase-1 (MT1-MMP) is a processing enzyme for human laminin gamma 2 chain. J Biol Chem. 2005;280(1):88-93.

125. Butler GS, Dean RA, Tam EM, and Overall CM. Pharmacoproteomics of a metalloproteinase hydroxamate inhibitor in breast cancer cells: dynamics of membrane type 1 matrix metalloproteinase-mediated membrane protein shedding. Mol Cell Biol. 2008;28(15):4896-914.

126. Hiraoka N, Allen E, Apel IJ, Gyetko MR, and Weiss SJ. Matrix metalloproteinases regulate neovascularization by acting as pericellular fibrinolysins. Cell. 1998;95(3):365-77.

127. Hotary KB, Yana I, Sabeh F, Li XY, Holmbeck K, Birkedal-Hansen H, Allen ED, Hiraoka N, and Weiss SJ. Matrix metalloproteinases (MMPs) regulate fibrin-invasive activity via MT1MMP-dependent and -independent processes. J Exp Med. 2002;195(3):295-308.

128. Holmbeck K, Bianco P, Caterina J, Yamada S, Kromer M, Kuznetsov SA, Mankani M, Robey PG, Poole AR, Pidoux I, et al. MT1-MMP-deficient mice develop dwarfism, 
osteopenia, arthritis, and connective tissue disease due to inadequate collagen turnover. Cell. 1999;99(1):81-92.

129. Zhou Z, Apte SS, Soininen R, Cao R, Baaklini GY, Rauser RW, Wang J, Cao Y, and Tryggvason K. Impaired endochondral ossification and angiogenesis in mice deficient in membrane-type matrix metalloproteinase I. Proceedings of the National Academy of Sciences of the United States of America. 2000;97(8):4052-7.

130. Irie K, Komori K, Seiki M, Tsuruga E, Sakakura Y, Kaku T, and Yajima T. Impaired alveolization in mice deficient in membrane-type matrix metalloproteinase 1 (MT1-MMP). Med Mol Morphol. 2005;38(1):43-6.

131. Holopainen JM, Moilanen JA, Sorsa T, Kivela-Rajamaki M, Tervahartiala T, Vesaluoma $\mathrm{MH}$, and Tervo TM. Activation of matrix metalloproteinase-8 by membrane type 1-MMP and their expression in human tears after photorefractive keratectomy. Invest Ophthalmol Vis Sci. 2003;44(6):2550-6.

132. Knauper V, Will H, Lopez-Otin C, Smith B, Atkinson SJ, Stanton H, Hembry RM, and Murphy G. Cellular mechanisms for human procollagenase-3 (MMP-13) activation. Evidence that MT1-MMP (MMP-14) and gelatinase a (MMP-2) are able to generate active enzyme. J Biol Chem. 1996;271(29):17124-31.

133. Chan KM, Wong HL, Jin G, Liu B, Cao R, Cao Y, Lehti K, Tryggvason K, and Zhou Z. MT1MMP inactivates ADAM9 to regulate FGFR2 signaling and calvarial osteogenesis. Dev Cell. 2012;22(6):1176-90.

134. Taniwaki K, Fukamachi H, Komori K, Ohtake Y, Nonaka T, Sakamoto T, Shiomi T, Okada $\mathrm{Y}$, Itoh $\mathrm{T}$, Itohara $\mathrm{S}$, et al. Stroma-derived matrix metalloproteinase (MMP)-2 promotes membrane type 1-MMP-dependent tumor growth in mice. Cancer Res. 2007;67(9):43119.

135. Kajita M, Itoh Y, Chiba T, Mori H, Okada A, Kinoh H, and Seiki M. Membrane-type 1 matrix metalloproteinase cleaves CD44 and promotes cell migration. J Cell Biol. 2001;153(5):893904.

136. Deryugina El, Bourdon MA, Jungwirth K, Smith JW, and Strongin AY. Functional activation of integrin alpha $V$ beta 3 in tumor cells expressing membrane-type 1 matrix metalloproteinase. Int J Cancer. 2000;86(1):15-23.

137. Egawa N, Koshikawa N, Tomari T, Nabeshima K, Isobe T, and Seiki M. Membrane type 1 matrix metalloproteinase (MT1-MMP/MMP-14) cleaves and releases a 22-kDa extracellular matrix metalloproteinase inducer (EMMPRIN) fragment from tumor cells. $J$ Biol Chem. 2006;281(49):37576-85.

138. Endo K, Takino T, Miyamori H, Kinsen H, Yoshizaki T, Furukawa M, and Sato H. Cleavage of syndecan-1 by membrane type matrix metalloproteinase-1 stimulates cell migration. $J$ Biol Chem. 2003;278(42):40764-70. 
139. Deryugina EI, Ratnikov BI, Postnova TI, Rozanov DV, and Strongin AY. Processing of integrin alpha(v) subunit by membrane type 1 matrix metalloproteinase stimulates migration of breast carcinoma cells on vitronectin and enhances tyrosine phosphorylation of focal adhesion kinase. J Biol Chem. 2002;277(12):9749-56.

140. Sithu SD, English WR, Olson P, Krubasik D, Baker AH, Murphy G, and D'Souza SE. Membrane-type 1-matrix metalloproteinase regulates intracellular adhesion molecule-1 (ICAM-1)-mediated monocyte transmigration. J Biol Chem. 2007;282(34):25010-9.

141. Wong HL, Jin G, Cao R, Zhang S, Cao Y, and Zhou Z. MT1-MMP sheds LYVE-1 on lymphatic endothelial cells and suppresses VEGF-C production to inhibit lymphangiogenesis. Nat Commun. 2016;7(10824.

142. Golubkov VS, Boyd S, Savinov AY, Chekanov AV, Osterman AL, Remacle A, Rozanov DV, Doxsey SJ, and Strongin AY. Membrane type-1 matrix metalloproteinase (MT1-MMP) exhibits an important intracellular cleavage function and causes chromosome instability. $J$ Biol Chem. 2005;280(26):25079-86.

143. Shofuda T, Shofuda K, Ferri N, Kenagy RD, Raines EW, and Clowes AW. Cleavage of focal adhesion kinase in vascular smooth muscle cells overexpressing membrane-type matrix metalloproteinases. Arterioscler Thromb Vasc Biol. 2004;24(5):839-44.

144. Karsdal MA, Larsen L, Engsig MT, Lou H, Ferreras M, Lochter A, Delaisse JM, and Foged NT. Matrix metalloproteinase-dependent activation of latent transforming growth factorbeta controls the conversion of osteoblasts into osteocytes by blocking osteoblast apoptosis. J Biol Chem. 2002;277(46):44061-7.

145. Tam EM, Morrison CJ, Wu YI, Stack MS, and Overall CM. Membrane protease proteomics: Isotope-coded affinity tag MS identification of undescribed MT1-matrix metalloproteinase substrates. Proceedings of the National Academy of Sciences of the United States of America. 2004;101(18):6917-22.

146. McQuibban GA, Butler GS, Gong JH, Bendall L, Power C, Clark-Lewis I, and Overall CM. Matrix metalloproteinase activity inactivates the CXC chemokine stromal cell-derived factor-1. J Biol Chem. 2001;276(47):43503-8.

147. McQuibban GA, Gong JH, Wong JP, Wallace JL, Clark-Lewis I, and Overall CM. Matrix metalloproteinase processing of monocyte chemoattractant proteins generates CC chemokine receptor antagonists with anti-inflammatory properties in vivo. Blood. 2002;100(4):1160-7.

148. Mu D, Cambier S, Fjellbirkeland L, Baron JL, Munger JS, Kawakatsu H, Sheppard D, Broaddus VC, and Nishimura SL. The integrin alpha(v)beta8 mediates epithelial homeostasis through MT1-MMP-dependent activation of TGF-beta1. J Cell Biol. 2002;157(3):493-507.

149. Xiong Y, Zhang J, Shi L, Ning Y, Zhu Y, Chen S, Yang M, Chen J, Zhou GW, and Li Q. NOGO-B promotes EMT in lung fibrosis via MMP14 mediates free TGF-beta1 formation. Oncotarget. 2017;8(41):71024-37. 
150. Kelly A, Gunaltay S, McEntee CP, Shuttleworth EE, Smedley C, Houston SA, Fenton TM, Levison S, Mann ER, and Travis MA. Human monocytes and macrophages regulate immune tolerance via integrin alphavbeta8-mediated TGFbeta activation. J Exp Med. 2018;215(11):2725-36.

151. Robertson IB, and Rifkin DB. Regulation of the Bioavailability of TGF-beta and TGF-betaRelated Proteins. Cold Spring Harb Perspect Biol. 2016;8(6).

152. Nguyen HL, Kadam P, Helkin A, Cao K, Wu S, Samara GJ, Zhang Q, Zucker S, and Cao J. MT1-MMP Activation of TGF-beta Signaling Enables Intercellular Activation of an Epithelial-mesenchymal Transition Program in Cancer. Curr Cancer Drug Targets. 2016;16(7):618-30.

153. Chen Q, Jin M, Yang F, Zhu J, Xiao Q, and Zhang L. Matrix metalloproteinases: inflammatory regulators of cell behaviors in vascular formation and remodeling. Mediators Inflamm. 2013;928315(10):12.

154. Hikita A, Yana I, Wakeyama H, Nakamura M, Kadono Y, Oshima Y, Nakamura K, Seiki M, and Tanaka S. Negative regulation of osteoclastogenesis by ectodomain shedding of receptor activator of NF-kappaB ligand. J Biol Chem. 2006;281(48):36846-55.

155. Imai K, Ohta S, Matsumoto T, Fujimoto N, Sato H, Seiki M, and Okada Y. Expression of membrane-type 1 matrix metalloproteinase and activation of progelatinase $A$ in human osteoarthritic cartilage. Am J Pathol. 1997;151(1):245-56.

156. Belien AT, Paganetti PA, and Schwab ME. Membrane-type 1 matrix metalloprotease (MT1MMP) enables invasive migration of glioma cells in central nervous system white matter. $J$ Cell Biol. 1999;144(2):373-84.

157. Awad AE, Kandalam V, Chakrabarti S, Wang X, Penninger JM, Davidge ST, Oudit GY, and Kassiri Z. Tumor necrosis factor induces matrix metalloproteinases in cardiomyocytes and cardiofibroblasts differentially via superoxide production in a PI3Kgamma-dependent manner. Am J Physiol Cell Physiol. 2010;298(3):9.

158. Spruill LS, Lowry AS, Stroud RE, Squires CE, Mains IM, Flack EC, Beck C, Ikonomidis JS, Crumbley AJ, McDermott PJ, et al. Membrane-type-1 matrix metalloproteinase transcription and translation in myocardial fibroblasts from patients with normal left ventricular function and from patients with cardiomyopathy. Am J Physiol Cell Physiol. 2007;293(4):1.

159. Spinale FG, Coker ML, Heung LJ, Bond BR, Gunasinghe HR, Etoh T, Goldberg AT, Zellner $\mathrm{JL}$, and Crumbley AJ. A matrix metalloproteinase induction/activation system exists in the human left ventricular myocardium and is upregulated in heart failure. Circulation. 2000;102(16):1944-9.

160. Kadono Y, Shibahara K, Namiki M, Watanabe Y, Seiki M, and Sato H. Membrane type 1matrix metalloproteinase is involved in the formation of hepatocyte growth factor/scatter factor-induced branching tubules in madin-darby canine kidney epithelial cells. Biochem Biophys Res Commun. 1998;251(3):681-7. 
161. Will $\mathrm{H}$, and Hinzmann B. cDNA sequence and mRNA tissue distribution of a novel human matrix metalloproteinase with a potential transmembrane segment. Eur $J$ Biochem. 1995;231(3):602-8.

162. Ries C, Egea V, Karow M, Kolb H, Jochum M, and Neth P. MMP-2, MT1-MMP, and TIMP2 are essential for the invasive capacity of human mesenchymal stem cells: differential regulation by inflammatory cytokines. Blood. 2007;109(9):4055-63.

163. Sato T, del Carmen Ovejero M, Hou P, Heegaard AM, Kumegawa M, Foged NT, and Delaisse JM. Identification of the membrane-type matrix metalloproteinase MT1-MMP in osteoclasts. J Cell Sci. 1997;110 ( Pt 5)(589-96.

164. Chun TH, Hotary KB, Sabeh F, Saltiel AR, Allen ED, and Weiss SJ. A pericellular collagenase directs the 3-dimensional development of white adipose tissue. Cell. 2006;125(3):577-91.

165. Esparza J, Vilardell C, Calvo J, Juan M, Vives J, Urbano-Marquez A, Yague J, and Cid MC. Fibronectin upregulates gelatinase $B$ (MMP-9) and induces coordinated expression of gelatinase A (MMP-2) and its activator MT1-MMP (MMP-14) by human T lymphocyte cell lines. A process repressed through RAS/MAP kinase signaling pathways. Blood. 1999;94(8):2754-66.

166. Jin G, Zhang F, Chan KM, Xavier Wong HL, Liu B, Cheah KS, Liu X, Mauch C, Liu D, and Zhou Z. MT1-MMP cleaves DIl1 to negatively regulate Notch signalling to maintain normal B-cell development. EMBO J. 2011;30(11):2281-93.

167. Seizer $\mathrm{P}$, and May AE. Platelets and matrix metalloproteinases. Thromb Haemost. 2013;110(5):903-9.

168. Shofuda K, Yasumitsu H, Nishihashi A, Miki K, and Miyazaki K. Expression of three membrane-type matrix metalloproteinases (MT-MMPs) in rat vascular smooth muscle cells and characterization of MT3-MMPs with and without transmembrane domain. The Journal of biological chemistry. 1997;272(15):9749-54.

169. Barnes RH, 2nd, Akama T, Ohman MK, Woo MS, Bahr J, Weiss SJ, Eitzman DT, and Chun TH. Membrane-Tethered Metalloproteinase Expressed by Vascular Smooth Muscle Cells Limits the Progression of Proliferative Atherosclerotic Lesions. J Am Heart Assoc. 2017;6(7).

170. Sakamoto T, and Seiki M. Cytoplasmic tail of MT1-MMP regulates macrophage motility independently from its protease activity. Genes Cells. 2009;14(5):617-26.

171. Gonzalo P, Guadamillas MC, Hernandez-Riquer MV, Pollan A, Grande-Garcia A, Bartolome RA, Vasanji A, Ambrogio C, Chiarle R, Teixido J, et al. MT1-MMP is required for myeloid cell fusion via regulation of Rac1 signaling. Dev Cell. 2010;18(1):77-89.

172. Shimizu-Hirota R, Xiong W, Baxter BT, Kunkel SL, Maillard I, Chen XW, Sabeh F, Liu R, $\mathrm{Li} X Y$, and Weiss SJ. MT1-MMP regulates the PI3Kdelta.Mi-2/NuRD-dependent control of macrophage immune function. Genes Dev. 2012;26(4):395-413. 
173. Gingras D, and Beliveau R. Emerging concepts in the regulation of membrane-type 1 matrix metalloproteinase activity. Biochim Biophys Acta. 2010;1(142-50.

174. Hotary K, Allen E, Punturieri A, Yana I, and Weiss SJ. Regulation of cell invasion and morphogenesis in a three-dimensional type I collagen matrix by membrane-type matrix metalloproteinases 1, 2, and 3. J Cell Biol. 2000;149(6):1309-23.

175. Ling B, Watt K, Banerjee S, Newsted D, Truesdell P, Adams J, Sidhu SS, and Craig AWB. A novel immunotherapy targeting MMP-14 limits hypoxia, immune suppression and metastasis in triple-negative breast cancer models. Oncotarget. 2017;8(35):58372-85.

176. Okada A, Tomasetto C, Lutz Y, Bellocq JP, Rio MC, and Basset P. Expression of matrix metalloproteinases during rat skin wound healing: evidence that membrane type-1 matrix metalloproteinase is a stromal activator of pro-gelatinase A. J Cell Biol. 1997;137(1):6777.

177. Snyman C, and Niesler CU. MMP-14 in skeletal muscle repair. J Muscle Res Cell Motil. 2015;36(3):215-25.

178. Chun TH, Sabeh F, Ota I, Murphy H, McDonagh KT, Holmbeck K, Birkedal-Hansen H, Allen ED, and Weiss SJ. MT1-MMP-dependent neovessel formation within the confines of the three-dimensional extracellular matrix. J Cell Biol. 2004;167(4):757-67.

179. Handsley MM, and Edwards DR. Metalloproteinases and their inhibitors in tumor angiogenesis. Int J Cancer. 2005;115(6):849-60.

180. Yana I, Sagara H, Takaki S, Takatsu K, Nakamura K, Nakao K, Katsuki M, Taniguchi S, Aoki T, Sato H, et al. Crosstalk between neovessels and mural cells directs the site-specific expression of MT1-MMP to endothelial tip cells. J Cell Sci. 2007;120(Pt 9):1607-14.

181. Kubota Y, Takubo K, Shimizu T, Ohno H, Kishi K, Shibuya M, Saya H, and Suda T. M-CSF inhibition selectively targets pathological angiogenesis and lymphangiogenesis. $J$ Exp Med. 2009;206(5):1089-102.

182. Stefater JA, 3rd, Lewkowich I, Rao S, Mariggi G, Carpenter AC, Burr AR, Fan J, Ajima R, Molkentin JD, Williams BO, et al. Regulation of angiogenesis by a non-canonical Wnt-Flt1 pathway in myeloid cells. Nature. 2011;474(7352):511-5.

183. Filippov S, Koenig GC, Chun TH, Hotary KB, Ota I, Bugge TH, Roberts JD, Fay WP, Birkedal-Hansen $\mathrm{H}$, Holmbeck K, et al. MT1-matrix metalloproteinase directs arterial wall invasion and neointima formation by vascular smooth muscle cells. $J$ Exp Med. 2005;202(5):663-71.

184. Lehti K, Allen E, Birkedal-Hansen H, Holmbeck K, Miyake Y, Chun TH, and Weiss SJ. An MT1-MMP-PDGF receptor-beta axis regulates mural cell investment of the microvasculature. Genes Dev. 2005;19(8):979-91.

185. Schuler F, and Sorokin LM. Expression of laminin isoforms in mouse myogenic cells in vitro and in vivo. J Cell Sci. 1995;108 ( Pt 12)(3795-805. 
186. Mylona E, Jones KA, Mills ST, and Pavlath GK. CD44 regulates myoblast migration and differentiation. J Cell Physiol. 2006;209(2):314-21.

187. Klose A, Zigrino P, and Mauch C. Monocyte/macrophage MMP-14 modulates cell infiltration and T-cell attraction in contact dermatitis but not in murine wound healing. The American journal of pathology. 2013;182(3):755-64.

188. Garmon T, Wittling M, and Nie S. MMP14 Regulates Cranial Neural Crest Epithelial-toMesenchymal Transition and Migration. Dev Dyn. 2018;247(9):1083-92.

189. Liu M, Qi Y, Zhao L, Chen D, Zhou Y, Zhou H, Lv Y, Zhang L, Jin S, Li S, et al. Matrix metalloproteinase-14 induces epithelial-to-mesenchymal transition in synovial sarcoma. Hum Pathol. 2018;80(201-9.

190. Spinale FG, Mukherjee R, Zavadzkas JA, Koval CN, Bouges S, Stroud RE, Dobrucki LW, and Sinusas AJ. Cardiac restricted overexpression of membrane type-1 matrix metalloproteinase causes adverse myocardial remodeling following myocardial infarction. The Journal of biological chemistry. 2010;285(39):30316-27.

191. Zavadzkas JA, Mukherjee R, Rivers WT, Patel RK, Meyer EC, Black LE, McKinney RA, Oelsen JM, Stroud RE, and Spinale FG. Direct regulation of membrane type 1 matrix metalloproteinase following myocardial infarction causes changes in survival, cardiac function, and remodeling. American journal of physiology Heart and circulatory physiology. 2011;301(4):H1656-66.

192. Rajavashisth TB, Xu XP, Jovinge S, Meisel S, Xu XO, Chai NN, Fishbein MC, Kaul S, Cercek B, Sharifi B, et al. Membrane type 1 matrix metalloproteinase expression in human atherosclerotic plaques: evidence for activation by proinflammatory mediators. Circulation. 1999;99(24):3103-9.

193. Hotary KB, Allen ED, Brooks PC, Datta NS, Long MW, and Weiss SJ. Membrane type I matrix metalloproteinase usurps tumor growth control imposed by the three-dimensional extracellular matrix. Cell. 2003;114(1):33-45.

194. Tsunezuka Y, Kinoh H, Takino T, Watanabe Y, Okada Y, Shinagawa A, Sato H, and Seiki M. Expression of membrane-type matrix metalloproteinase 1 (MT1-MMP) in tumor cells enhances pulmonary metastasis in an experimental metastasis assay. Cancer Res. 1996;56(24):5678-83.

195. Hillebrand LE, Wickberg SM, Gomez-Auli A, Follo M, Maurer J, Busch H, Boerries M, and Reinheckel T. MMP14 empowers tumor-initiating breast cancer cells under hypoxic nutrient-depleted conditions. Faseb j. 2019;33(3):4124-40.

196. Jones JA, Ruddy JM, Bouges S, Zavadzkas JA, Brinsa TA, Stroud RE, Mukherjee R, Spinale FG, and Ikonomidis JS. Alterations in membrane type-1 matrix metalloproteinase abundance after the induction of thoracic aortic aneurysm in a murine model. American journal of physiology Heart and circulatory physiology. 2010;299(1):23. 
197. Lehti K, Rose NF, Valavaara S, Weiss SJ, and Keski-Oja J. MT1-MMP promotes vascular smooth muscle dedifferentiation through LRP1 processing. J Cell Sci. 2009;122(Pt 1):12635.

198. Talmi-Frank D, Altboum Z, Solomonov I, Udi Y, Jaitin DA, Klepfish M, David E, Zhuravlev A, Keren-Shaul H, Winter DR, et al. Extracellular Matrix Proteolysis by MT1-MMP Contributes to Influenza-Related Tissue Damage and Mortality. Cell Host Microbe. 2016;20(4):458-70.

199. Sabeh F, Fox D, and Weiss SJ. Membrane-type I matrix metalloproteinase-dependent regulation of rheumatoid arthritis synoviocyte function. J Immunol. 2010;184(11):6396-406.

200. Kasurinen A, Tervahartiala T, Laitinen A, Kokkola A, Sorsa T, Bockelman C, and Haglund C. High serum MMP-14 predicts worse survival in gastric cancer. PLoS One. 2018;13(12).

201. Yao G, He P, Chen L, Hu X, Gu F, and Ye C. MT1-MMP in breast cancer: induction of VEGF-C correlates with metastasis and poor prognosis. Cancer Cell Int. 2013;13(1):14752867.

202. Li Y, Cai G, Yuan S, Jun Y, Li N, Wang L, Chen F, Ling R, and Yun J. The overexpression membrane type 1 matrix metalloproteinase is associated with the progression and prognosis in breast cancer. Am J Trans/ Res. 2015;7(1):120-7.

203. Sela-Passwell N, Kikkeri R, Dym O, Rozenberg H, Margalit R, Arad-Yellin R, Eisenstein M, Brenner O, Shoham T, Danon T, et al. Antibodies targeting the catalytic zinc complex of activated matrix metalloproteinases show therapeutic potential. Nat Med. 2011;18(1):143-7.

204. Sela-Passwell N, Trahtenherts A, Kruger A, and Sagi I. New opportunities in drug design of metalloproteinase inhibitors: combination between structure-function experimental approaches and systems biology. Expert opinion on drug discovery. 2011;6(5):527-42.

205. Morrison CJ, Butler GS, Rodriguez D, and Overall CM. Matrix metalloproteinase proteomics: substrates, targets, and therapy. Curr Opin Cell Biol. 2009;21(5):645-53.

206. Drummond AH, Beckett P, Brown PD, Bone EA, Davidson AH, Galloway WA, Gearing AJ, Huxley $\mathrm{P}$, Laber D, McCourt M, et al. Preclinical and clinical studies of MMP inhibitors in cancer. Ann N Y Acad Sci. 1999;878(228-35.

207. Levitt NC, Eskens FA, O'Byrne KJ, Propper DJ, Denis LJ, Owen SJ, Choi L, Foekens JA, Wilner S, Wood JM, et al. Phase I and pharmacological study of the oral matrix metalloproteinase inhibitor, MMI270 (CGS27023A), in patients with advanced solid cancer. Clin Cancer Res. 2001;7(7):1912-22.

208. Felkin LE, Birks EJ, George R, Wong S, Khaghani A, Yacoub MH, and Barton PJ. A quantitative gene expression profile of matrix metalloproteinases (MMPS) and their inhibitors (TIMPS) in the myocardium of patients with deteriorating heart failure requiring left ventricular assist device support. J Heart Lung Transplant. 2006;25(12):1413-9. 
209. Matias-Roman S, Galvez BG, Genis L, Yanez-Mo M, de la Rosa G, Sanchez-Mateos P, Sanchez-Madrid F, and Arroyo AG. Membrane type 1-matrix metalloproteinase is involved in migration of human monocytes and is regulated through their interaction with fibronectin or endothelium. Blood. 2005;105(10):3956-64.

210. Kovacic JC, Dimmeler S, Harvey RP, Finkel T, Aikawa E, Krenning G, and Baker AH. Endothelial to Mesenchymal Transition in Cardiovascular Disease: JACC State-of-the-Art Review. J Am Coll Cardiol. 2019;73(2):190-209.

211. Gong H, Lyu X, Wang Q, Hu M, and Zhang X. Endothelial to mesenchymal transition in the cardiovascular system. Life Sci. 2017;184(95-102.

212. Piera-Velazquez S, and Jimenez SA. Endothelial to Mesenchymal Transition: Role in Physiology and in the Pathogenesis of Human Diseases. Physiol Rev. 2019;99(2):1281324.

213. Armstrong EJ, and Bischoff J. Heart Valve Development. Circulation research. 2004;95(5):459-70.

214. Kisanuki YY, Hammer RE, Miyazaki J, Williams SC, Richardson JA, and Yanagisawa M. Tie2-Cre transgenic mice: a new model for endothelial cell-lineage analysis in vivo. Dev Biol. 2001;230(2):230-42.

215. Chen Q, Zhang H, Liu Y, Adams S, Eilken H, Stehling M, Corada M, Dejana E, Zhou B, and Adams RH. Endothelial cells are progenitors of cardiac pericytes and vascular smooth muscle cells. Nature Communications. 2016;7(12422.

216. Xu X, Friehs I, Hu TZ, Melnychenko I, Tampe B, Alnour F, lascone M, Kalluri R, Zeisberg M, Nido PJd, et al. Endocardial Fibroelastosis Is Caused by Aberrant Endothelial to Mesenchymal Transition. Circulation research. 2015;116(5):857-66.

217. Hofmann JJ, Briot A, Enciso J, Zovein AC, Ren S, Zhang ZW, Radtke F, Simons M, Wang $\mathrm{Y}$, and Iruela-Arispe ML. Endothelial deletion of murine $<\mathrm{em}>\mathrm{Jag} 1</ \mathrm{em}>$ leads to valve calcification and congenital heart defects associated with Alagille syndrome. Development. 2012;139(23):4449-60.

218. Evrard SM, Lecce L, Michelis KC, Nomura-Kitabayashi A, Pandey G, Purushothaman KR, d'Escamard V, Li JR, Hadri L, Fujitani K, et al. Endothelial to mesenchymal transition is common in atherosclerotic lesions and is associated with plaque instability. Nat Commun. $2016 ; 7(11853$.

219. Zeisberg EM, Tarnavski O, Zeisberg M, Dorfman AL, McMullen JR, Gustafsson E, Chandraker A, Yuan X, Pu WT, Roberts AB, et al. Endothelial-to-mesenchymal transition contributes to cardiac fibrosis. Nat Med. 2007;13(8):952-61.

220. Aisagbonhi O, Rai M, Ryzhov S, Atria N, Feoktistov I, and Hatzopoulos AK. Experimental myocardial infarction triggers canonical Wnt signaling and endothelial-to-mesenchymal transition. Dis Model Mech. 2011;4(4):469-83. 
221. Ma L, Lu M-F, Schwartz RJ, and Martin JF. <em>Bmp2</em> is essential for cardiac cushion epithelial-mesenchymal transition and myocardial patterning. Development. 2005;132(24):5601-11.

222. Kaneko K, Li X, Zhang X, Lamberti JJ, Jamieson SW, and Thistlethwaite PA. Endothelial expression of bone morphogenetic protein receptor type $1 \mathrm{a}$ is required for atrioventricular valve formation. Ann Thorac Surg. 2008;85(6):2090-8.

223. Helmke A, Casper J, Nordlohne J, David S, Haller H, Zeisberg EM, and von Vietinghoff S. Endothelial-to-mesenchymal transition shapes the atherosclerotic plaque and modulates macrophage function. FASEB J. 2019;33(2):2278-89.

224. Jensen JA, Kosek JC, Hunt TK, Goodson WH, 3rd, and Miller DC. Cardiac cryolesions as an experimental model of myocardial wound healing. Ann Surg. 1987;206(6):798-803.

225. Hulsmans M, Sam F, and Nahrendorf M. Monocyte and macrophage contributions to cardiac remodeling. J Mol Cell Cardiol. 2016;93(149-55.

226. Kolk MV, Meyberg D, Deuse T, Tang-Quan KR, Robbins RC, Reichenspurner H, and Schrepfer S. LAD-ligation: a murine model of myocardial infarction. Journal of visualized experiments : JoVE. 2009;14(32).

227. Clausen BE, Burkhardt C, Reith W, Renkawitz R, and Forster I. Conditional gene targeting in macrophages and granulocytes using LysMcre mice. Transgenic Res. 1999;8(4):26577.

228. Gutierrez-Fernandez A, Soria-Valles C, Osorio FG, Gutierrez-Abril J, Garabaya C, Aguirre A, Fueyo A, Fernandez-Garcia MS, Puente XS, and Lopez-Otin C. Loss of MT1-MMP causes cell senescence and nuclear defects which can be reversed by retinoic acid. Embo J. 2015;34(14):1875-88.

229. Paik DT, Rai M, Ryzhov S, Sanders LN, Aisagbonhi O, Funke MJ, Feoktistov I, and Hatzopoulos AK. Wnt10b Gain-of-Function Improves Cardiac Repair by Arteriole Formation and Attenuation of Fibrosis. Circ Res. 2015;117(9):804-16.

230. van Amerongen MJ, Harmsen MC, Petersen AH, Popa ER, and van Luyn MJ. Cryoinjury: a model of myocardial regeneration. Cardiovascular pathology : the official journal of the Society for Cardiovascular Pathology. 2008;17(1):23-31.

231. Inserte J, Aluja D, Barba I, Ruiz-Meana M, Miro E, Poncelas M, Vilardosa U, Castellano J, and Garcia-Dorado D. High-fat diet improves tolerance to myocardial ischemia by delaying normalization of intracellular PH at reperfusion. J Mol Cell Cardiol. 2019;133(164-73.

232. Cruz-Adalia A, Jimenez-Borreguero LJ, Ramirez-Huesca M, Chico-Calero I, Barreiro O, Lopez-Conesa E, Fresno M, Sanchez-Madrid F, and Martin P. CD69 limits the severity of cardiomyopathy after autoimmune myocarditis. Circulation. 2010;122(14):1396-404.

233. Ram R, Mickelsen DM, Theodoropoulos C, and Blaxall BC. New approaches in small animal echocardiography: imaging the sounds of silence. Am J Physiol Heart Circ Physiol. 2011;301(5):H1765-80. 
234. Gallego-Colon E, Villalba M, Tonkin J, Cruz F, Bernal JA, Jimenez-Borregureo LJ, Schneider MD, Lara-Pezzi E, and Rosenthal N. Intravenous delivery of adeno-associated virus 9-encoded IGF-1Ea propeptide improves post-infarct cardiac remodelling. NPJ Regenerative medicine. 2016;1(16001.

235. Abraham T, Carthy J, and McManus B. Collagen matrix remodeling in 3-dimensional cellular space resolved using second harmonic generation and multiphoton excitation fluorescence. J Struct Biol. 2010;169(1):36-44.

236. Mostaco-Guidolin LB, Ko AC, Wang F, Xiang B, Hewko M, Tian G, Major A, Shiomi M, and Sowa MG. Collagen morphology and texture analysis: from statistics to classification. Scientific reports. 2013;3(2190.

237. Pantazis P, Maloney J, Wu D, and Fraser SE. Second harmonic generating (SHG) nanoprobes for in vivo imaging. Proceedings of the National Academy of Sciences of the United States of America. 2010;107(33):14535-40.

238. Gkontra P, Norton KA, Zak MM, Clemente C, Aguero J, Ibanez B, Santos A, Popel AS, and Arroyo AG. Deciphering microvascular changes after myocardial infarction through 3D fully automated image analysis. Scientific reports. 2018;8(1):018-19758.

239. Zak MM, Gkontra P, Clemente C, Squadrito ML, Ferrarini A, Mota RA, Oliver E, Rocha S, Aguero J, Vazquez J, et al. Sequential Bone-Marrow Cell Delivery of VEGFA/S1P Improves Vascularization and Limits Adverse Cardiac Remodeling After Myocardial Infarction in Mice. Hum Gene Ther. 2019.

240. Buades A, Coll B, and Morel J-M. Proceedings of the 2005 IEEE Computer Society Conference on Computer Vision and Pattern Recognition (CVPR'05) - Volume 2 - Volume 02. IEEE Computer Society; 2005:60-5.

241. Otsu N. A Threshold Selection Method from Gray-Level Histograms. IEEE Trans Syst Man Cybern. 1979;9(1):62-6.

242. Alonso-Herranz L, Porcuna J, and Ricote M. Isolation and Purification of Tissue Resident Macrophages for the Analysis of Nuclear Receptor Activity. Methods in molecular biology (Clifton, NJ). 2019;1951(59-73.

243. Fogelstrand P, Feral CC, Zargham R, and Ginsberg MH. Dependence of proliferative vascular smooth muscle cells on CD98hc (4F2hc, SLC3A2). J Exp Med. 2009;206(11):2397-406.

244. Wrana JL, Attisano L, Carcamo J, Zentella A, Doody J, Laiho M, Wang XF, and Massague J. TGF beta signals through a heteromeric protein kinase receptor complex. Cell. 1992;71(6):1003-14.

245. Abe M, Harpel JG, Metz CN, Nunes I, Loskutoff DJ, and Rifkin DB. An assay for transforming growth factor-beta using cells transfected with a plasminogen activator inhibitor-1 promoter-luciferase construct. Anal Biochem. 1994;216(2):276-84. 
246. Martin-Alonso M, Garcia-Redondo AB, Guo D, Camafeita E, Martinez F, Alfranca A, Mendez-Barbero N, Pollan A, Sanchez-Camacho C, Denhardt DT, et al. Deficiency of MMP17/MT4-MMP proteolytic activity predisposes to aortic aneurysm in mice. Circ Res. 2015;117(2):e13-26.

247. Cox G, Kable E, Jones A, Fraser I, Manconi F, and Gorrell MD. 3-dimensional imaging of collagen using second harmonic generation. J Struct Biol. 2003;141(1):53-62.

248. Abram CL, Roberge GL, Hu Y, and Lowell CA. Comparative analysis of the efficiency and specificity of myeloid-Cre deleting strains using ROSA-EYFP reporter mice. J Immunol Methods. 2014;408(89-100.

249. Fraccarollo D, Thomas S, Scholz CJ, Hilfiker-Kleiner D, Galuppo P, and Bauersachs J. Macrophage Mineralocorticoid Receptor Is a Pleiotropic Modulator of Myocardial Infarct Healing. Hypertension. 2019;73(1):102-11.

250. Nagase H, Visse R, and Murphy G. Structure and function of matrix metalloproteinases and TIMPs. Cardiovasc Res. 2006;69(3):562-73.

251. Pries AR, and Secomb TW. Making microvascular networks work: angiogenesis, remodeling, and pruning. Physiol (Bethesda). 2014;29(6):446-55.

252. Cassot F, Lauwers F, Fouard C, Prohaska S, and Lauwers-Cances V. A novel threedimensional computer-assisted method for a quantitative study of microvascular networks of the human cerebral cortex. Microcirculation. 2006;13(1):1-18.

253. Loncaster JA, Harris AL, Davidson SE, Logue JP, Hunter RD, Wycoff CC, Pastorek J, Ratcliffe PJ, Stratford IJ, and West CM. Carbonic anhydrase (CA IX) expression, a potential new intrinsic marker of hypoxia: correlations with tumor oxygen measurements and prognosis in locally advanced carcinoma of the cervix. Cancer Res. 2001;61(17):63949.

254. Ambrosio MR, Di Serio C, Danza G, Rocca BJ, Ginori A, Prudovsky I, Marchionni N, Del Vecchio MT, and Tarantini F. Carbonic anhydrase IX is a marker of hypoxia and correlates with higher Gleason scores and ISUP grading in prostate cancer. Diagn Pathol. 2016;11(1):45.

255. Je KH, Ryu WS, Lee SK, Kim EJ, Kim JY, Jang HJ, Park JE, Nahrendorf M, Schellingerhout D, and Kim DE. Green-channel autofluorescence imaging: A novel and sensitive technique to delineate infarcts. J Neurosci Methods. 2017;279(22-32.

256. Khalil H, Kanisicak O, Prasad V, Correll RN, Fu X, Schips T, Vagnozzi RJ, Liu R, Huynh T, Lee SJ, et al. Fibroblast-specific TGF-beta-Smad2/3 signaling underlies cardiac fibrosis. J Clin Invest. 2017;127(10):3770-83.

257. Frangogiannis NG. The role of transforming growth factor (TGF)-beta in the infarcted myocardium. Journal of thoracic disease. 2017;9(Suppl 1):S52-s63.

258. Arnold TD, Niaudet C, Pang M-F, Siegenthaler J, Gaengel K, Jung B, Ferrero GM, Mukouyama Y-s, Fuxe J, Akhurst R, et al. Excessive vascular sprouting underlies cerebral 
hemorrhage in mice lacking $\alpha \mathrm{V} \beta 8$-TGF $\beta$ signaling in the brain. Development. 2014;141(23):4489-99.

259. Lawrence DA. Latent-TGF-beta: an overview. Mol Cell Biochem. 2001;219(1-2):163-70.

260. Dobaczewski M, Bujak M, Li N, Gonzalez-Quesada C, Mendoza LH, Wang XF, and Frangogiannis NG. Smad3 signaling critically regulates fibroblast phenotype and function in healing myocardial infarction. Circ Res. 2010;107(3):418-28.

261. Pepper MS. Transforming growth factor-beta: vasculogenesis, angiogenesis, and vessel wall integrity. Cytokine Growth Factor Rev. 1997;8(1):21-43.

262. Henderson NC, Arnold TD, Katamura Y, Giacomini MM, Rodriguez JD, McCarty JH, Pellicoro A, Raschperger E, Betsholtz C, Ruminski PG, et al. Targeting of alphav integrin identifies a core molecular pathway that regulates fibrosis in several organs. Nature medicine. 2013;19(12):1617-24.

263. Doppler SA, Deutsch MA, Lange R, and Krane M. Cardiac regeneration: current therapiesfuture concepts. J Thorac Dis. 2013;5(5):683-97.

264. Nguyen PK, Rhee J-W, and Wu JC. Adult Stem Cell Therapy and Heart Failure, 2000 to 2016: A Systematic ReviewAdult Stem Cell Therapy and Heart FailureAdult Stem Cell Therapy and Heart Failure. JAMA Cardiology. 2016;1(7):831-41.

265. Tongers J, Losordo DW, and Landmesser U. Stem and progenitor cell-based therapy in ischaemic heart disease: promise, uncertainties, and challenges. Eur Heart J. 2011;32(10):1197-206.

266. Hedman M, Hartikainen J, Syvanne M, Stjernvall J, Hedman A, Kivela A, Vanninen E, Mussalo $H$, Kauppila E, Simula $S$, et al. Safety and feasibility of catheter-based local intracoronary vascular endothelial growth factor gene transfer in the prevention of postangioplasty and in-stent restenosis and in the treatment of chronic myocardial ischemia: phase II results of the Kuopio Angiogenesis Trial (KAT). Circulation. 2003;107(21):2677-83.

267. Stewart DJ, Kutryk MJ, Fitchett D, Freeman M, Camack N, Su Y, Della Siega A, Bilodeau L, Burton JR, Proulx G, et al. VEGF gene therapy fails to improve perfusion of ischemic myocardium in patients with advanced coronary disease: results of the NORTHERN trial. Mol Ther. 2009;17(6):1109-15.

268. van den Akker F, Deddens JC, Doevendans PA, and Sluijter JP. Cardiac stem cell therapy to modulate inflammation upon myocardial infarction. Biochim Biophys Acta. 2013;2(58):5.

269. Yang F, Liu YH, Yang XP, Xu J, Kapke A, and Carretero OA. Myocardial infarction and cardiac remodelling in mice. Exp Physiol. 2002;87(5):547-55.

270. Klein GJ, Harrison L, Ideker RF, Smith WM, Kasell J, Wallace AG, and Gallagher JJ. Reaction of the myocardium to cryosurgery: electrophysiology and arrhythmogenic potential. Circulation. 1979;59(2):364-72. 
271. Watanabe H, Eguchi S, Miyamura H, Hayashi J, Aizawa Y, Wakiya Y, and Igarashi T. Histologic findings of long-term cryolesions in a patient with ventricular tachycardia. Cardiovasc Surg. 1996;4(3):409-11.

272. Shiraishi M, Shintani Y, Ishida H, Saba R, Yamaguchi A, Adachi H, Yashiro K, and Suzuki $\mathrm{K}$. Alternatively activated macrophages determine repair of the infarcted adult murine heart. The Journal of clinical investigation. 2016;126(6):2151-66.

273. van den Bos EJ, Mees BM, de Waard MC, de Crom R, and Duncker DJ. A novel model of cryoinjury-induced myocardial infarction in the mouse: a comparison with coronary artery ligation. American journal of physiology Heart and circulatory physiology. 2005;289(3):29.

274. Troidl K, Tribulova S, Cai WJ, Ruding I, Apfelbeck H, Schierling W, Troidl C, Schmitz-Rixen T, and Schaper W. Effects of endogenous nitric oxide and of DETA NONOate in arteriogenesis. J Cardiovasc Pharmacol. 2010;55(2):153-60.

275. Henri O, Pouehe C, Houssari M, Galas L, Nicol L, Edwards-Levy F, Henry JP, Dumesnil A, Boukhalfa I, Banquet S, et al. Selective Stimulation of Cardiac Lymphangiogenesis Reduces Myocardial Edema and Fibrosis Leading to Improved Cardiac Function Following Myocardial Infarction. Circulation. 2016;133(15):1484-97; discussion 97.

276. Shimizu Y, Polavarapu R, Eskla KL, Pantner Y, Nicholson CK, Ishii M, Brunnhoelzl D, Mauria R, Husain A, Naqvi N, et al. Impact of Lymphangiogenesis on Cardiac Remodeling After Ischemia and Reperfusion Injury. Journal of the American Heart Association. 2018;7(19):e009565.

277. Klotz L, Norman S, Vieira JM, Masters M, Rohling M, Dube KN, Bollini S, Matsuzaki F, Carr CA, and Riley PR. Cardiac lymphatics are heterogeneous in origin and respond to injury. Nature. 2015;522(7554):62-7.

278. Kataru RP, Jung K, Jang C, Yang H, Schwendener RA, Baik JE, Han SH, Alitalo K, and Koh GY. Critical role of $\mathrm{CD} 11 \mathrm{~b}+$ macrophages and VEGF in inflammatory lymphangiogenesis, antigen clearance, and inflammation resolution. Blood. 2009;113(22):5650-9.

279. Huggenberger R, Siddiqui SS, Brander D, Ullmann S, Zimmermann K, Antsiferova M, Werner S, Alitalo K, and Detmar M. An important role of lymphatic vessel activation in limiting acute inflammation. Blood. 2011;117(17):4667-78.

280. Ishikawa Y, Akishima-Fukasawa Y, Ito K, Akasaka Y, Tanaka M, Shimokawa R, KimuraMatsumoto M, Morita H, Sato S, Kamata I, et al. Lymphangiogenesis in myocardial remodelling after infarction. Histopathology. 2007;51(3):345-53.

281. Cho $\mathrm{CH}$, Koh YJ, Han J, Sung HK, Jong Lee H, Morisada T, Schwendener RA, Brekken RA, Kang G, Oike Y, et al. Angiogenic role of LYVE-1-positive macrophages in adipose tissue. Circ Res. 2007;100(4):e47-57.

282. Maruyama K, Asai J, li M, Thorne T, Losordo DW, and D'Amore PA. Decreased macrophage number and activation lead to reduced lymphatic vessel formation and 
contribute to impaired diabetic wound healing. The American journal of pathology. 2007;170(4):1178-91.

283. Attout T, Hoerauf A, Denece G, Debrah AY, Marfo-Debrekyei Y, Boussinesq M, Wanji S, Martinez V, Mand S, Adjei O, et al. Lymphatic vascularisation and involvement of Lyve-1+ macrophages in the human onchocerca nodule. PLoS One. 2009;4(12):0008234.

284. Godwin JW, Pinto AR, and Rosenthal NA. Macrophages are required for adult salamander limb regeneration. Proceedings of the National Academy of Sciences. 2013;110(23):941520.

285. Fallowfield JA, Mizuno M, Kendall TJ, Constandinou CM, Benyon RC, Duffield JS, and Iredale JP. Scar-associated macrophages are a major source of hepatic matrix metalloproteinase-13 and facilitate the resolution of murine hepatic fibrosis. $J$ Immunol. 2007;178(8):5288-95.

286. Gazi U, and Martinez-Pomares L. Influence of the mannose receptor in host immune responses. Immunobiology. 2009;214(7):554-61.

287. Yang H, Wang H, Levine YA, Gunasekaran MK, Wang Y, Addorisio M, Zhu S, Li W, Li J, de Kleijn DP, et al. Identification of CD163 as an antiinflammatory receptor for HMGB1haptoglobin complexes. JCI Insight. 2016;1(7):19.

288. DeBerge M, Yeap XY, Dehn S, Zhang S, Grigoryeva L, Misener S, Procissi D, Zhou X, Lee DC, Muller WA, et al. MerTK Cleavage on Resident Cardiac Macrophages Compromises Repair After Myocardial Ischemia Reperfusion Injury. Circulation research. 2017;121(8):930-40.

289. Cai B, Kasikara C, Doran AC, Ramakrishnan R, Birge RB, and Tabas I. MerTK signaling in macrophages promotes the synthesis of inflammation resolution mediators by suppressing CaMKII activity. Sci Signal. 2018;11(549).

290. Cai B, Thorp EB, Doran AC, Sansbury BE, Daemen MJ, Dorweiler B, Spite M, Fredman $\mathrm{G}$, and Tabas I. MerTK receptor cleavage promotes plaque necrosis and defective resolution in atherosclerosis. The Journal of clinical investigation. 2017;127(2):564-8.

291. Cai B, Thorp EB, Doran AC, Subramanian M, Sansbury BE, Lin CS, Spite M, Fredman G, and Tabas I. MerTK cleavage limits proresolving mediator biosynthesis and exacerbates tissue inflammation. Proceedings of the National Academy of Sciences of the United States of America. 2016;113(23):6526-31.

292. Triantafyllou E, Pop OT, Possamai LA, Wilhelm A, Liaskou E, Singanayagam A, Bernsmeier C, Khamri W, Petts G, Dargue R, et al. MerTK expressing hepatic macrophages promote the resolution of inflammation in acute liver failure. Gut. 2018;67(2):333-47.

293. Lee SJ, Evers S, Roeder D, Parlow AF, Risteli J, Risteli L, Lee YC, Feizi T, Langen H, and Nussenzweig MC. Mannose receptor-mediated regulation of serum glycoprotein homeostasis. Science. 2002;295(5561):1898-901. 
294. Vieira JM, Norman S, Villa del Campo C, Cahill TJ, Barnette DN, Gunadasa-Rohling M, Johnson LA, Greaves DR, Carr CA, Jackson DG, et al. The cardiac lymphatic system stimulates resolution of inflammation following myocardial infarction. The Journal of clinical investigation. 2018;128(8):3402-12.

295. Kandalam V, Basu R, Abraham T, Wang X, Awad A, Wang W, Lopaschuk GD, Maeda N, Oudit GY, and Kassiri Z. Early activation of matrix metalloproteinases underlies the exacerbated systolic and diastolic dysfunction in mice lacking TIMP3 following myocardial infarction. American journal of physiology Heart and circulatory physiology. 2010;299(4):30.

296. Li YY, Feldman AM, Sun Y, and McTiernan CF. Differential expression of tissue inhibitors of metalloproteinases in the failing human heart. Circulation. 1998;98(17):1728-34.

297. Takawale A, Zhang P, Azad A, Wang W, Wang X, Murray AG, and Kassiri Z. Myocardial overexpression of TIMP3 after myocardial infarction exerts beneficial effects by promoting angiogenesis and suppressing early proteolysis. American journal of physiology Heart and circulatory physiology. 2017;313(2):H224-H36.

298. Jayasankar V, Woo YJ, Bish LT, Pirolli TJ, Berry MF, Burdick J, Bhalla RC, Sharma RV, Gardner TJ, and Sweeney HL. Inhibition of matrix metalloproteinase activity by TIMP-1 gene transfer effectively treats ischemic cardiomyopathy. Circulation. 2004;110(11 Suppl 1):49.

299. Chun TH, Inoue M, Morisaki H, Yamanaka I, Miyamoto Y, Okamura T, Sato-Kusubata K, and Weiss SJ. Genetic link between obesity and MMP14-dependent adipogenic collagen turnover. Diabetes. 2010;59(10):2484-94.

300. Fujino M, Dosaka-Akita H, Kato M, Kinoshita I, Akie K, and Kawakami Y. Simultaneous use of the PCR-SSCP method and immunohistochemistry for increasing the detection efficacy of p53 abnormalities in human lung cancer. Am J Clin Pathol. 1995;104(3):31924.

301. Daseke MJ, 2nd, Valerio FM, Kalusche WJ, Ma Y, DeLeon-Pennell KY, and Lindsey ML. Neutrophil proteome shifts over the myocardial infarction time continuum. Basic Res Cardiol. 2019;114(5):37.

302. Chou J, Chan MF, and Werb Z. Metalloproteinases: a Functional Pathway for Myeloid Cells. Microbiology spectrum. 2016;4(2).

303. Azar DT, Casanova FH, Mimura T, Jain S, Zhou Z, Han KY, and Chang JH. Corneal epithelial MT1-MMP inhibits vascular endothelial cell proliferation and migration. Cornea. 2010;29(3):321-30.

304. Pasterkamp G, Wensing PJ, Post MJ, Hillen B, Mali WP, and Borst C. Paradoxical arterial wall shrinkage may contribute to luminal narrowing of human atherosclerotic femoral arteries. Circulation. 1995;91(5):1444-9. 
305. van Varik BJ, Rennenberg RJ, Reutelingsperger CP, Kroon AA, de Leeuw PW, and Schurgers LJ. Mechanisms of arterial remodeling: lessons from genetic diseases. Front Genet. 2012;3(290.

306. Tatti O, Vehvilainen P, Lehti K, and Keski-Oja J. MT1-MMP releases latent TGF-beta1 from endothelial cell extracellular matrix via proteolytic processing of LTBP-1. Exp Cell Res. 2008;314(13):2501-14.

307. Westermann D, Lindner D, Kasner M, Zietsch C, Savvatis K, Escher F, von Schlippenbach J, Skurk C, Steendijk P, Riad A, et al. Cardiac Inflammation Contributes to Changes in the Extracellular Matrix in Patients With Heart Failure and Normal Ejection Fraction. Circulation: Heart Failure. 2011;4(1):44-52.

308. Meyer-Ter-Vehn T, Gebhardt S, Sebald W, Buttmann M, Grehn F, Schlunck G, and Knaus P. p38 inhibitors prevent TGF-beta-induced myofibroblast transdifferentiation in human tenon fibroblasts. Invest Ophthalmol Vis Sci. 2006;47(4):1500-9.

309. Kuwahara F, Kai H, Tokuda K, Kai M, Takeshita A, Egashira K, and Imaizumi T. Transforming growth factor-beta function blocking prevents myocardial fibrosis and diastolic dysfunction in pressure-overloaded rats. Circulation. 2002;106(1):130-5.

310. Okada H, Takemura G, Kosai K, Li Y, Takahashi T, Esaki M, Yuge K, Miyata S, Maruyama $\mathrm{R}$, Mikami $\mathrm{A}$, et al. Postinfarction gene therapy against transforming growth factor-beta signal modulates infarct tissue dynamics and attenuates left ventricular remodeling and heart failure. Circulation. 2005;111(19):2430-7.

311. Bujak M, Ren G, Kweon HJ, Dobaczewski M, Reddy A, Taffet G, Wang XF, and Frangogiannis NG. Essential role of Smad3 in infarct healing and in the pathogenesis of cardiac remodeling. Circulation. 2007;116(19):2127-38.

312. Rainer PP, Hao S, Vanhoutte D, Lee DI, Koitabashi N, Molkentin JD, and Kass DA. Cardiomyocyte-specific transforming growth factor beta suppression blocks neutrophil infiltration, augments multiple cytoprotective cascades, and reduces early mortality after myocardial infarction. Circ Res. 2014;114(8):1246-57.

313. Ikeuchi M, Tsutsui $H$, Shiomi T, Matsusaka $H$, Matsushima S, Wen J, Kubota T, and Takeshita A. Inhibition of TGF-beta signaling exacerbates early cardiac dysfunction but prevents late remodeling after infarction. Cardiovasc Res. 2004;64(3):526-35.

314. Goumans MJ, and Ten Dijke P. TGF-beta Signaling in Control of Cardiovascular Function. Cold Spring Harb Perspect Biol. 2018;10(2).

315. Imaizumi N, Monnier Y, Hegi M, Mirimanoff RO, and Ruegg C. Radiotherapy suppresses angiogenesis in mice through TGF-betaRI/ALK5-dependent inhibition of endothelial cell sprouting. PLoS ONE. 2010;5(6):e11084.

316. Cooley BC, Nevado J, Mellad J, Yang D, St Hilaire C, Negro A, Fang F, Chen G, San H, Walts $A D$, et al. TGF-beta signaling mediates endothelial-to-mesenchymal transition (EndMT) during vein graft remodeling. Sci Trans/ Med. 2014;6(227):3006927. 
317. Kitao A, Sato Y, Sawada-Kitamura S, Harada K, Sasaki M, Morikawa H, Shiomi S, Honda $M$, Matsui $O$, and Nakanuma $Y$. Endothelial to mesenchymal transition via transforming growth factor-beta1/Smad activation is associated with portal venous stenosis in idiopathic portal hypertension. The American journal of pathology. 2009;175(2):616-26.

318. Xavier S, Vasko R, Matsumoto K, Zullo JA, Chen R, Maizel J, Chander PN, and Goligorsky MS. Curtailing endothelial TGF-beta signaling is sufficient to reduce endothelialmesenchymal transition and fibrosis in CKD. J Am Soc Nephrol. 2015;26(4):817-29.

319. Zhang Z, Wang JA, Xu Y, Jiang Z, Wu R, Wang L, Chen P, Hu X, and Yu H. Menstrual blood derived mesenchymal cells ameliorate cardiac fibrosis via inhibition of endothelial to mesenchymal transition in myocardial infarction. Int J Cardiol. 2013 Sep 30;168(2):17114. doi: 10.1016/j.jjcard.2013.03.126. Epub 2013 Apr 20.; 2013.

320. Creemers EE, Cleutjens JP, Smits JF, and Daemen MJ. Matrix metalloproteinase inhibition after myocardial infarction: a new approach to prevent heart failure? Circ Res. 2001;89(3):201-10.

321. Rohde LE, Ducharme A, Arroyo LH, Aikawa M, Sukhova GH, Lopez-Anaya A, McClure KF, Mitchell PG, Libby $P$, and Lee RT. Matrix metalloproteinase inhibition attenuates early left ventricular enlargement after experimental myocardial infarction in mice. Circulation. 1999;99(23):3063-70.

322. Hudson MP, Armstrong PW, Ruzyllo W, Brum J, Cusmano L, Krzeski P, Lyon R, Quinones $M$, Theroux $P$, Sydlowski $D$, et al. Effects of selective matrix metalloproteinase inhibitor (PG-116800) to prevent ventricular remodeling after myocardial infarction: results of the PREMIER (Prevention of Myocardial Infarction Early Remodeling) trial. J Am Coll Cardiol. 2006;48(1):15-20.

323. Spinale FG, and Villarreal F. Targeting matrix metalloproteinases in heart disease: lessons from endogenous inhibitors. Biochem Pharmacol. 2014;90(1):7-15. 



\section{APPENDIX:}

Supplementary data 

Minkowski-Based Metrics

Vascular Volume Density (\%)

Vascular Surface Area Density $\left(\times 10^{-3}\right)\left(\mu \mathrm{m}^{2} / \mu \mathrm{m}^{3}\right)$
MT1-MMPf/f

$12,65 \pm 0,36$

$21,24 \pm 2,5$
MT1-MMP ${ }^{\Delta L y s M}$

$13,26 \pm 0,34$ *

$23,13 \pm 1,92$

Graph-Based Metrics

Vascular Length Density $\left(\times 10^{-3}\right)\left(\mu \mathrm{m} / \mu \mathrm{m}^{3}\right)$

Vascular Surface Density $\left(\times 10^{-3}\right)\left(\mu \mathrm{m}^{2} / \mu \mathrm{m}^{3}\right)$

Vascular Volume Density $\left(\times 10^{-2}\right)\left(\mu \mathrm{m}^{3} / \mu \mathrm{m}^{3}\right)$

Vascular Segment length $(\mu \mathrm{m})$

Vascular Segment surface $\left(\mu \mathrm{m}^{2}\right)$

Vascular Segment volume $\left(\mu \mathrm{m}^{3}\right)$

Tortuosity $(\mu \mathrm{m} / \mu \mathrm{m})$

Vascular Segments $\left(\times 10^{5}\right)^{a}$

Vascular Segments ${ }^{b}$

Vessels of diameter $<=3(\mu \mathrm{m})(\%)$

Vessels of diameter between 3 and $6(\mu \mathrm{m})(\%)$

Vessels of diameter $>6(\mu \mathrm{m})(\%)$

Vessels of diameter $<=3(\mu \mathrm{m})\left(\times 10^{5}\right)^{a}$

Vessels of diameter between 3 and $6(\mu \mathrm{m})\left(\times 10^{5}\right)^{\mathrm{a}}$

Vessels of diameter $>6(\mu \mathrm{m})^{\mathrm{a}}$

Branching Nodes $\left(\times 10^{4}\right)^{a}$

Blind-ends/sprouts $\left(\times 10^{4}\right)^{a}$

Branching nodes $^{b}$

Blind-ends/sprouts ${ }^{\mathrm{b}}$

\begin{tabular}{|c|c|}
\hline $2,78 \pm 0,27$ & $3,39 \pm 0,36^{*}$ \\
\hline $14,15 \pm 0,95$ & $15,94 \pm 0,68{ }^{*}$ \\
\hline $0,644 \pm 0,058$ & $0,669 \pm 0,032$ \\
\hline $6,97 \pm 0,74$ & $6,2 \pm 0,18$ \\
\hline $36,41 \pm 5,52$ & $29,5 \pm 1,6$ \\
\hline $17 \pm 3,8$ & $12,54 \pm 1,53$ \\
\hline $1,61 \pm 0,02$ & $1,61 \pm 0,03$ \\
\hline $4,12 \pm 0,68$ & $5,48 \pm 0,53$ \\
\hline $144,17 \pm 14,15$ & $158,27 \pm 2,31$ \\
\hline $95,48 \pm 2,55$ & $96,97 \pm 1,85^{*}$ \\
\hline $4,51 \pm 2,52$ & $3,03 \pm 1,85$ \\
\hline $0,012 \pm 0,001$ & $0,028 \pm 0,001$ \\
\hline $3,97 \pm 0,71$ & $5,33 \pm 0,59 *$ \\
\hline $0,16 \pm 0,06$ & $0,15 \pm 0,09$ \\
\hline $32,81 \pm 0,0001$ & $73,36 \pm 0,0001$ \\
\hline $22,39 \pm 4,28$ & $30,43 \pm 2,51$ \\
\hline $6,06 \pm 0,92$ & $7,93 \pm 1,2$ \\
\hline $77,38 \pm 9,59$ & $87,31 \pm 2,14$ \\
\hline $24,09 \pm 4,07$ & $25,9 \pm 1,66$ \\
\hline
\end{tabular}

SMA-related metrics

\begin{tabular}{|c|c|c|}
\hline Vessels covered with SMA (\%) & $47,2 \pm 17,67$ & $53,54 \pm 12$ \\
\hline $\mathrm{SMA}^{+}$layer thikness $(\mu \mathrm{m})$ & $2,98 \pm 0,76$ & $2,72 \pm 0,43$ \\
\hline Damage index & $0,21 \pm 0,11$ & $0,19 \pm 0,09$ \\
\hline Myofibroblasts $\left(\times 10^{4}\right)^{a}$ & $2,51 \pm 1,18$ & $2,05 \pm 0,64$ \\
\hline Myofibroblasts $^{\mathrm{b}}$ & $8,9 \pm 3,8$ & $5,97 \pm 1,47$ \\
\hline Myofibroblasts $\left(\times 10^{5}\right)^{d}$ & $19,1 \pm 10$ & $15,3 \pm 4,7$ \\
\hline SMA+ perivascular cells $\left(\times 10^{4}\right)^{a}$ & $4,74 \pm 2,36$ & $5,25 \pm 1,59$ \\
\hline SMA+ perivascular cells ${ }^{b}$ & $16,16 \pm 7,31$ & $15,48 \pm 3,65$ \\
\hline SMA+ perivascular cells $\left(\times 10^{5}\right)^{d}$ & $36,3 \pm 19,3$ & $38,9 \pm 10,8$ \\
\hline
\end{tabular}

Efficiency in oxigen diffusion

\begin{tabular}{|l|c|c|}
\hline Maximal Extravascualr Distance $(\mu \mathrm{m})$ & $51,47 \pm 10,83$ & $45,47 \pm 7,11$ \\
\hline Median Extravascualr Distance $(\mu \mathrm{m})$ & $14,28 \pm 2,64$ & $13 \pm 1,38$ \\
\hline Capillary Density & $1201 \pm 298,12$ & $1720 \pm 368,61^{*}$ \\
\hline Intercapillary Distance & $8,09 \pm 0,51$ & $7,31 \pm 0,27^{*}$ \\
\hline Diffusion Distance & $10,84 \pm 0,51$ & $9,76 \pm 0,49^{*}$ \\
\hline
\end{tabular}

Additional cell-related metrics

\begin{tabular}{|l|c|c|}
\hline${\text { Endothelial cells }\left(\times 10^{4}\right)^{\mathrm{a}}}^{\mathrm{a}}$ & $6,2 \pm 1,05$ & $7,91 \pm 1,21$ \\
\hline Endothelial cells $^{\mathrm{b}}$ & $22,45 \pm 3,91$ & $23,16 \pm 1,34$ \\
\hline Endothelial cells $\left(\times 10^{5}\right)^{\mathrm{d}}$ & $46,6 \pm 8,1$ & $58,8 \pm 7,7^{*}$ \\
\hline
\end{tabular}


Supplementary Table 1. Quantitative analysis of microvasculature parameters in the infarcted cardiac tissue from MT1-MMP//f and MT1-MMP ${ }^{\Delta L y s M}$ mice on day 7 after MI. Capillaries correspond to CD31 ${ }^{+} \mathrm{SMA}^{-}$vessels of diameter $<3 \mu \mathrm{m}$. Data are means \pm SEM of 5-6 mice per genotype. Unpaired $t$-test. Significant differences are indicated as ${ }^{*} p<0.05$. ${ }^{\text {a }}$ per $\mathrm{mm}^{3}$ of tissue, ${ }^{\mathrm{b}}$ per $\mathrm{mm}$ vessel length, ${ }^{\mathrm{c}}$ per $\mathrm{mm}^{2}$ of tissue, ${ }^{d}$ per $\mathrm{mm}^{3}$ vessel volume.

Supplementary Video 1. Parasternal 2D long axis echocardiography view of baseline (Day 0 ) mouse that afterwards underwent cryoinjury.

Supplementary Video 2. Parasternal 2D long axis echocardiography view of cryoinjured mouse at 28 days post-injury.

Supplementary Video 3. Parasternal 2D long axis echocardiography view of baseline (Day 0 ) mouse that afterwards underwent LAD-ligation.

Supplementary Video 4. Parasternal 2D long axis echocardiography view of mouse subjected to LADligation at 28 days post-injury.

Supplemental Video 5. Parasternal 2D long axis echocardiography view of MT1-MMP/f/f or MT1-MMP ${ }^{\Delta L y s M}$ hearts at baseline (Day 0 ) and at 28 days post-MI induced by LAD-ligation. 
APPENDIX: Publications 

During the research period, the $\mathrm{PhD}$ candidate has contributed to the following publications:

1. Alonso-Herranz L, Sahún-Español A, Gonzalo $P$, Gkontra $P$, Núñez V, Cedenilla $M$, Villalba-Orero M, Inserte J, García-Dorado D, Arroyo AG, and Ricote M. Macrophage MT1MMP promotes TGF $\beta 1$-mediated endothelial to mesenchymal transition after myocardial infarction. Manuscript submitted.

2. Blanco-Domínguez R., Sanchez R., Linillos-Pradillo B., de la Fuente H., JiménezBorreguero L.J, Tsilingiri, Martín M.L., Matesanz A., García-Fernández I., Relaño M., Alonso-Herranz L., Moreno G., Martín-Asenjo R., García-Guimaraes M., Martínez-León A., Ricote M., Bueno H., Fernández-Friera L., Alfonso F., Ibañez B., Sanchez-Madrid F. Circulating hsa-miR-Chr8:96 biomarker discriminates acute myocarditis and myocardial infarction. Manuscript under revision.

3. Alonso-Herranz L.*, Porcuna J.*, and Ricote M. Isolation and Purification of Tissue Resident Macrophages for the Analysis of Nuclear Receptor Activity. Methods in Molecular Biology (Clifton, N.J.). 2019 Mar; 1951: 59-73. *These authors have contributed equally to this work.

4. Walter W.*, Alonso-Herranz L.*, Trappetti V., Crespo I., Ibberson M., Cedenilla M., Karaszewska A., Núñez V., Xenarios I., Arroyo A.G., Sanchez-Cabo F., Ricote M. Deciphering the dynamic transcriptional and post-transcriptional networks of cardiac macrophages in the healthy heart and after myocardial injury. Cell Reports. 2018 Apr 10;23(2):622-636. *These authors have contributed equally to this work.

5. Clemente C., Rius C., Alonso-Herranz L., Martín-Alonso M., Pollán A., Camafeita E., Martínez F., Mota R.A., Núñez V., Rodríguez C., Seiki M., Martínez-González J., Andrés V., Ricote M., and Arroyo A.G. MT4-MMP deficiency increases patrolling monocyte recruitment to early lesions and accelerates atherosclerosis. Nat Commun. 2018 Mar $2 ; 9(1): 910$. 



\title{
Isolation and Purification of Tissue Resident Macrophages for the Analysis of Nuclear Receptor Activity
}

\author{
Laura Alonso-Herranz, Jesús Porcuna, and Mercedes Ricote
}

\begin{abstract}
Tissue resident macrophages (TRMs) are multifunctional immune cells present in all tissues, contributing to the correct development, homeostasis, and protection against pathogens and injury. TRMs are morphologically and functionally heterogeneous, as a result of both the diversity of tissue environments in which they reside and their complex origin. Furthermore, some specific TRM populations are controlled by nuclear receptors. A widely used method for studying the role of nuclear receptors in immune cells is flow cytometry. Although flow cytometry is extensively used in tissues such as the peripheral blood, lymph nodes, peritoneal cavity, and bone marrow, there is a need for protocols for the study TRMs in solid tissues.

In this chapter, we describe a comprehensive protocol for obtaining single-cell suspensions of resident macrophages from the pleural cavity, heart, lung, spleen, and kidney, and we present detailed gating strategies for the study of nuclear receptor activity in different TRM subsets within these tissues.
\end{abstract}

Key words Tissue macrophages, Heart, Pleural cavity, Kidney, Spleen, Lung, Nuclear receptors, Flow cytometry

1 Introduction

The term macrophage was first coined by Élie Metchnikoff in 1892 to identify cells involved in the phagocytosis process during inflammation. Macrophages are immune cells that play roles in many specific processes in order to maintain tissue homeostasis [1]. Tissue resident macrophages (TRM) are multifunctional, specialized, and heterogeneous cells found in most mammalian tissues. They act as sentinel cells or as an immune barrier against pathogens, protecting against homeostatic imbalance and tissue damage. However, TRMs have many other functions required not only in adulthood but also during development; moreover, many of these functions vary from one tissue to another $[2,3]$. Macrophages were for many years

Laura Alonso-Herranz and Jesús Porcuna contributed equally to this work.

Matthew C. Gage and Inés Pineda-Torra (eds.), Lipid-Activated Nuclear Receptors: Methods and Protocols, Methods in Molecular Biology, vol. 1951, https://doi.org/10.1007/978-1-4939-9130-3_5,

(C) Springer Science+Business Media, LLC, part of Springer Nature 2019 
thought to always originate from adult bone marrow; however, lately it has become evident that most adult TRMs originate during embryonic development and not from circulating monocytes $[2,4-6]$. The contribution of circulating monocytes to TRM populations is restricted to a few specific tissues, including the gut, the skin, and the heart, or during inflammation and injury $[4,7,8]$. In adulthood, most TRMs are replaced by local selfrenewal independently of bone marrow-derived precursors $[4,9$, $10]$.

Some TRM subtypes are regulated by specific types of nuclear receptors (NRs) [11-14]. NRs are ligand-dependent TFs that regulate diverse aspects of development and homeostasis [15-17]. Important NRs involved in TRM regulation include LXR $\alpha$ in marginal zone splenic macrophages [11], PPAR $\gamma$ in alveolar macrophages [13], and RAR in peritoneal macrophages [12]. The complex transcriptional control of TMR subsets creates a need for powerful tools allowing scientists to distinguish among the many different populations.

Flow cytometry is a powerful and established tool in the study of the immune system (e.g., immunophenotyping of peripheral blood cells, analysis of apoptosis, and detection of cytokines) $[18,19]$. Flow cytometry is based on the light scattering properties of the cells under investigation. Light scattering at different angles can distinguish differences in size and internal complexity; in addition, light emitted from fluorescently labeled antibodies can identify a great variety of cell surface and cytoplasmic antigens [20]. These properties make flow cytometry a powerful tool for the rapid and detailed analysis of complex populations. State-ofthe-art flow cytometers are able to analyze up to millions of cells, recognizing and differentiating, depending on the system, more than ten fluorochromes, and thus allowing the precise identification of several populations in a single sample. Flow cytometry techniques are improving continually. Moreover, the combination of time-of-flight flow cytometry (CyTOF) detectors and sophisticated algorithms ( $\mathrm{tSNE})$ is helping researchers to identify new subsets within already known TRM populations, ensuring an unbiased study of the cells.

In this chapter, we describe how to harvest, digest (if needed), and prepare single-cell suspensions of purified TRM samples from the pleural cavity, heart, lung, spleen, and kidney. These protocols generate high yields of leukocytes, and specifically macrophages, from the indicated tissues. Furthermore, the staining antibodies we propose here are optimized to give excellent fluorescence resolution, allowing the identification of diverse TRM subsets within each tissue.

The protocol described here is intended for the study of the contribution of NRs to TRM development, identity, and function. The protocol can be used to characterize TRMs from wild-type and 
NR knockout mice in order to analyze the role of the NR under study. This protocol can also be used to obtain pure TRM populations by cell sorting for further analysis, such as genome-wide studies (RNA-Seq, ATAC-Seq, ChIP-Seq, GRO-seq), qPCR, and ligand-based activation of NRs in cell culture.

\section{Materials}

1. Adult (8-12 weeks old) C57BL/6 mice.

2. Collagenase type IV from Clostridium histolyticum.

3. Hybridization oven with rocker.

4. $70 \%$ ethanol in distilled water.

5. Sterile surgical tools: tweezers and scissors.

6. $\mathrm{I} \times \mathrm{PBS}$, cold (around $4^{\circ} \mathrm{C}$ ).

7. 1,2 , and $10 \mathrm{~mL}$ syringes.

8. 18, 21, and $25 \mathrm{G}$ needles.

9. $1.5,15$, and $50 \mathrm{~mL}$ polypropylene conical test tubes.

10. $\mathrm{CO}_{2}$ chamber.

11. $1.5 \mathrm{~mL}$ test tubes.

12. Red blood cell lysis buffer: $4.13 \mathrm{~g} \mathrm{NH}_{4} \mathrm{Cl}, 0.5 \mathrm{~g} \mathrm{KHCO}_{3}$, $100 \mu \mathrm{L}$ EDTA, $500 \mathrm{~mL}$ distilled $\mathrm{H}_{2} \mathrm{O}$.

13. Portable electric pipette controller.

14. Sterile 10, 200, and 1000 plastic tips.

15. Compensation beads.

16. Pipettes.

17. $10 \mathrm{~mL}$ glass pipettes.

18. Vortex.

19. Precision balance.

20. Neubauer chamber.

21. Trypan blue.

22. Centrifuge.

23. Bright-field microscope.

24. Aluminum foil.

25. Tape.

26. FACS buffer: $1 \times$ PBS, $1 \%$ inactive fetal bovine serum $(\mathrm{FBS})$, and $5 \mathrm{mM}$ EDTA.

27. Heart and kidney digestion buffer: $1 \times$ PBS with $100 \mu \mathrm{g} / \mathrm{mL}$ collagenase IV.

28. Lung digestion buffer: $1 \times$ PBS with $10 \mu \mathrm{g} / \mathrm{mL}$ collagenase IV.

29. Cytometer tubes. 


\section{Table 1}

Proposed panel of antibodies for the gating strategies described in Figs. 1-5. For each antibody, we indicate the clone we use and the concentration. Note that the concentration needs to be adjusted according to the fluorescence intensity of the fluorochrome selected for each clone

\begin{tabular}{llll}
\hline & Antibody & Clone & Concentration $(\mu \mathbf{g} / \mathbf{m L})$ \\
\hline Pleural macrophages & CD45-APC-Cy7 & $30-\mathrm{F} 11$ & 2 \\
& B220-PerCPCy5.5 & RA3-6B2 & 2 \\
& CD11b-AF647 & M1/70 & 2 \\
& CD115-PE & AFS98 & 2 \\
& F4/80-PECy7 & BM8 & 2 \\
& MHCII-BV605 & M5/114.15.2 & 0.67 \\
\hline \multirow{5}{*}{ Cardiac macrophages } & CD45-PerCPCy5.5 & $30-$ F11 & 2 \\
& CD11b-PECy7 & M1/70 & 2 \\
& F4/80-PE & BM8 & 6 \\
& Ly6C-APC & AL-21 & 4 \\
& MHCII-BV605 & M5/114.15.2 & 0.67 \\
& CCR2-APC & 475,301 & 5 \\
\hline \multirow{2}{*}{ Alveolar macrophages } & CD45-PerCPCy5.5 & $30-F 11$ & 2 \\
& CD11b-PECy7 & M1/70 & 2 \\
& CD11c-FITC & N418 & 5 \\
& SiglecF-PE & E50-2440 & 4 \\
\hline \multirow{2}{*}{ Splenic macrophages } & CD45-APC-Cy7 & $30-F 11$ & 2 \\
& CD11b-AF647 & Ml/70 & 2 \\
& F4/80-PECy7 & BM8 & 2 \\
& MHCII-BV605 & M5/114.15.2 & 0.67 \\
\hline Kidney macrophages & CD45-APC-Cy7 & $30-F 12$ & 2 \\
& CD11b-AF647 & M1/71 & 2 \\
& F4/80-PECy7 & BM9 & 2 \\
& Tim 4-PE & RMT4-54 & 2 \\
\hline
\end{tabular}

30. Round-bottom 96-well plate.

31. Antibodies for flow cytometry (see Table 1).

32. 70 and $100 \mu \mathrm{m}$ nylon cell strainers.

33. $70 \mu \mathrm{m}$ conical filters.

34. Flow cytometer/cell sorter.

\section{Methods}
3.1 Setting Up Tools
1. Set up the hybridization oven at $37^{\circ} \mathrm{C}$. and Reagents in the Lab
2. Set up the centrifuge at $4^{\circ} \mathrm{C}$.
3. Thaw collagenase type IV from $-20{ }^{\circ} \mathrm{C}$ to $4{ }^{\circ} \mathrm{C}$.
4. Remove the red blood cell lysis buffer from the fridge, and place it at room temperature. 
3.2 Mouse Sacrifice and Tissue Harvesting
1. Euthanize mice according to the relevant regulatory laws for animal experimentation.

2. Place the mouse on its back. Clean the chest and abdomen by soaking all the fur with $70 \%$ ethanol.

3. Using tweezers and scissors, open the animal (see Note 1). First, make a small incision in the skin with the scissors. With the scissors near-closed, introduce them under the skin, and then open them up. Remove the scissors, and repeat this process until you have completely separated the skin from the peritoneum and ribs. After this, gently pull the fur back to expose the inner skin lining the peritoneal cavity and chest ( see Note 2).

4. Cap a $2 \mathrm{~mL}$ syringe with a $25 \mathrm{G}$ needle, and insert the needle between the fifth and sixth rib of the mouse (see Note 3 ). Introduce $2 \mathrm{~mL}$ of cold $1 \times$ PBS into the pleural cavity.

5. Using a $2 \mathrm{~mL}$ syringe capped with a $20 \mathrm{G}$ needle, recover as much pleural lavage as possible. We suggest injecting the needle through the diaphragm. It is extremely important not to damage the lungs.

6. Transfer the pleural lavage into a $15 \mathrm{~mL}$ test tube, and fill it to $10 \mathrm{~mL}$ with cold $\mathrm{l} \times$ PBS.

7. Use the scissors to open the chest under the sternum, and cut the ribs to expose the heart. Cut the right atrium, and, using a $10 \mathrm{~mL}$ syringe capped with a $25 \mathrm{G}$ needle, gently perfuse the animal through the apex with $20 \mathrm{~mL}$ of cold $1 \times$ PBS $($ see Note 4).

8. Repeat step 7, but this time perfuse through the right ventricle.

9. Dissect the atria from the ventricles and discard.

10. Transfer the ventricles to $1.5 \mathrm{~mL}$ tubes containing $1 \mathrm{~mL}$ cold $1 \times$ PBS.

11. Collect the lungs. Transfer the multilobular part to $1.5 \mathrm{~mL}$ tubes with cold $1 \times$ PBS.

12. Cut the splenic vessels and remove the spleen with the help of tweezers.

13. Transfer the spleen to a $1.5 \mathrm{~mL}$ tube with cold $1 \times$ PBS.

14. Next, cut the renal vessels, and harvest the kidneys in cold $1 \times$ PBS in $1.5 \mathrm{~mL}$ tubes.

15. Weigh the solid tissues on a precision balance (see Note 5). 


\subsection{Preparation of Single-Cell \\ Suspension from the Pleural Cavity (For Pleural Resident Macrophages)}

\subsection{Preparation of Single-Cell Suspension from Cardiac Tissue (For Cardiac Resident Macrophages)}

1. Transfer the pleural lavage to a $15 \mathrm{~mL}$ test tube, and fill up to $10 \mathrm{~mL}$ with cold $\mathrm{l} \times$ PBS.

2. Centrifuge for $5 \mathrm{~min}$ at $500 \times g$ and discard the supernatant.

3 . If blood is visible, resuspend the pellet with a vortex in $300 \mu \mathrm{L}$ of red blood cell lysis buffer for $3 \mathrm{~min}$. Then wash with $30 \mathrm{~mL}$ of $1 \times$ PBS (see Notes 6 and 7).

4. Centrifuge for $5 \mathrm{~min}$ at $500 \times g$ and discard the supernatant. Keep samples on ice until ready to proceed to Subheading 3.8.

1. Place the heart in one $1.5 \mathrm{~mL}$ tube with $1 \mathrm{~mL}$ of digestion buffer (see Note 8).

2. Finely chop the heart into small pieces with small sterile scissors (see Notes 9-11).

3. To digest the heart, place the sample in the hybridization oven, and incubate at $37^{\circ} \mathrm{C}$ for $45 \mathrm{~min}$ with gentle shaking (30 rpm). Hold the samples in place by sticking them to the oven surface with tape (see Note 11).

4. Mechanically homogenize the digested tissue with up and down motions through a $1 \mathrm{~mL}$ syringe capped with an $18 \mathrm{G}$ needle. Work on ice from this point on (see Note 12).

5. To remove the tissue stroma, transfer the digested sample to a $50 \mathrm{~mL}$ tube through a $100 \mu \mathrm{m}$ nylon cell strainer. Gently press the digested tissue against the cell strainer, and wash it with about $30 \mathrm{~mL}$ of $1 \times$ PBS ( see Note 13 ).

6. Centrifuge for $10 \mathrm{~min}$ at $500 \times g$ at $4{ }^{\circ} \mathrm{C}$ and discard the supernatant.

7. To eliminate erythrocytes, resuspend the pellet by vortexing in $600 \mu \mathrm{L}$ of red blood cell lysis buffer. Incubate for $3 \mathrm{~min}$ at room temperature (see Note 14).

8. Wash with $10 \mathrm{~mL} \mathrm{FACS}$ buffer, centrifuge for $5 \mathrm{~min}$ at $500 \times \mathfrak{g}$ at $4{ }^{\circ} \mathrm{C}$, and discard the supernatant. Keep samples on ice until ready to proceed to Subheading 3.8 .

1. Place the lung sample in one $1.5 \mathrm{~mL}$ tube with $1 \mathrm{~mL}$ of lung digestion buffer (see Note 8 ).

2. Finely chop the lung sample into small pieces with small sterile scissors ( see Notes 9-11).

3. To digest the lung tissue, place the sample in the hybridization oven, and incubate at $37^{\circ} \mathrm{C}$ for $30 \mathrm{~min}$ with gentle shaking $(30 \mathrm{rpm})$. Hold the samples in place by sticking them to the oven surface with tape (see Note 11).

4. Mechanically homogenize the digested tissue with up and down motions through a $1 \mathrm{~mL}$ syringe capped with an $18 \mathrm{G}$ needle. Work on ice from this point on (see Note 12). 
5. To remove the tissue stroma, transfer the digested sample to a $50 \mathrm{~mL}$ tube through a $70 \mu \mathrm{m}$ nylon cell strainer. Gently press the digested tissue against the cell strainer, and wash it with about $30 \mathrm{~mL}$ of $1 \times$ PBS (see Note 13 ).

6. Centrifuge for $5 \mathrm{~min}$ at $500 \times g$ at $4{ }^{\circ} \mathrm{C}$ and discard the supernatant.

7. To eliminate erythrocytes, resuspend the pellet by vortexing in $500 \mu \mathrm{L}$ of red blood cell lysis buffer. Incubate for $3 \mathrm{~min}$ at room temperature (see Note 14).

8. Wash with $10 \mathrm{~mL} \mathrm{FAC} \mathrm{buffer,} \mathrm{centrifuge} \mathrm{for} 5 \mathrm{~min}$ at $500 \times g$ at $4{ }^{\circ} \mathrm{C}$, and discard the supernatant. Keep samples on ice until ready to proceed to Subheading 3.8.

3.6 Preparation

of Single-Cell

Suspension from the Spleen (For Spleen Resident Macrophages)

\subsection{Preparation} of Single-Cell Suspension from the Kidney (For Kidney Resident Macrophages)
1. Place the spleen on a pre-wetted (with $1 \times$ PBS) $100 \mu$ m nylon filter over an open $50 \mathrm{~mL}$ tube. Squeeze the spleen against the filter with the plunger of a $2 \mathrm{~mL}$ syringe.

2. Pass $50 \mathrm{~mL}$ of $1 \times$ PBS through the filter.

3. Centrifuge for $5 \mathrm{~min}$ at $500 \times g$ at $4{ }^{\circ} \mathrm{C}$ and discard the supernatant.

4. Resuspend the pellet by vortexing in $500 \mu \mathrm{L}$ of red blood cell lysis buffer for $5 \mathrm{~min}$ at room temperature. Then wash with $30 \mathrm{~mL}$ of $1 \times$ PBS.

5. Centrifuge for $5 \mathrm{~min}$ at $500 \times \mathfrak{g}$ and discard the supernatant. Keep samples on ice until ready to proceed to Subheading 3.8.

1. Cut the kidney into two halves with sterile scissors.

2. Select the half to be processed, and weigh it in the precision balance (see Note 15).

3. Finely mince the tissue in $500 \mu \mathrm{L}$ digestion buffer in a $1.5 \mathrm{~mL}$ tube. Ensure that no visible tissue pieces remain (see Notes 9-11).

4. To digest the half kidney, place it in the hybridization oven, and incubate at $37{ }^{\circ} \mathrm{C}$ for $45 \mathrm{~min}$ with gentle shaking $(30 \mathrm{rpm})$. Hold the samples in place by sticking them to the oven surface with tape (see Note 16).

5. Transfer the digested tissue to a $50 \mathrm{~mL}$ test tube through a $100 \mu \mathrm{m}$ nylon cell strainer. Ensure you recover all the sample by washing the digestion tube with up to $30 \mathrm{~mL}$ of $1 \times$ PBS.

6. Centrifuge for $5 \mathrm{~min}$ at $500 \times g$ and discard the supernatant

7. Resuspend the pellet by vortexing in $500 \mu \mathrm{L}$ of red blood cell lysis buffer for $3 \mathrm{~min}$ at room temperature. Wash with $30 \mathrm{~mL}$ of $1 \times$ PBS.

8. Centrifuge for $5 \mathrm{~min}$ at $500 \times g$ and discard the supernatant. Keep samples on ice until ready to proceed to Subheading 3.8. 
3.8 Staining of TRMs for Flow Cytometry

3.8.1 Cell Counting

3.8.2 Staining of Pleural, Cardiac, Alveolar, Spleen, and Kidney Resident Macrophages for Flow Cytometry
The following steps are the same for all five tissues.

1. Mix $10 \mu \mathrm{L}$ of the cell suspension with $10 \mu \mathrm{L}$ Trypan blue.

2. Count the viable cells in a Neubauer chamber under a brightfield microscope fitted with a $10 \times$ objective.

3. Centrifuge the cell suspension for $5 \mathrm{~min}$ at $500 \times g$ and discard the supernatant.

You will need to use the entire cell suspension for the pleural cavity and heart. For spleen resident macrophages, use $5 \times 10^{6}$ cells; for alveolar macrophages, use $1 / 7$ of the sample; and for kidney resident macrophages, use $2 / 5$ of the sample.

1. Block the cells by adding $100 \mu \mathrm{L}$ of anti-CD16/CD32 Ab (1:100) in FACS buffer per sample.

2. Incubate for 10 to $15 \mathrm{~min}$ at $4{ }^{\circ} \mathrm{C}$.

3. For staining, transfer the samples to a round-bottom 96-well plate or cytometer tubes (see Notes 17 and 18).

4. Wash with FACS buffer: $200 \mu \mathrm{L}$ for 96 -well plate or $1 \mathrm{~mL}$ for cytometer tubes.

5. Centrifuge for $5 \mathrm{~min}$ at $500 \times g$ at $4{ }^{\circ} \mathrm{C}$, and discard the supernatant.

6. Use compensation beads to establish the cytometer settings according to your staining panel. Put one drop of compensation beads in empty wells of the p96-well plate or in fresh cytometer tubes (one for each fluorochrome used). Add one tested antibody to one well or tube containing compensation beads; the antibody should have the same concentration you will use in the staining panel. From this point, the compensation beads and experimental samples must follow the same steps of incubation, washing, and centrifugation.

7. Add $50 \mu \mathrm{L}$ (96-well plate) or $100 \mu \mathrm{L}$ (cytometer tube) of antibody mix per sample. Incubate for $30 \mathrm{~min}$ at $4{ }^{\circ} \mathrm{C}$ with gentle shacking $(30 \mathrm{rpm})$. Protect samples from light with aluminum foil (see Notes 19 and 20 ).

8. Propose antibody panels (see Table 1).

9. Transfer samples stained in 96-well plates to cytometer tubes. Wash with $1 \mathrm{~mL}$ FACS buffer, and centrifuge for $5 \mathrm{~min}$ at $500 \times g$ at $4{ }^{\circ} \mathrm{C}$, and discard the supernatant.

10. Resuspend in 200-300 $\mu$ L FACS buffer.

11. Filter the samples through $70 \mu \mathrm{m}$ conical filters, and transfer them to fresh cytometer tubes.

12. Place the samples on ice and go to the cytometer. 
3.8.3 At the Cytometer/ Cell Sorter

3.8.4 Flow Cytometry Analysis of Pleural Resident Macrophages
1. Use a small fraction of one stained sample to adjust the voltage settings. Remember to do this for each tissue analyzed.

2. Run the compensation beads to create the compensation matrix. Remember to do this for every antibody panel.

3. Run the negative and fluorescence minus one (FMO) controls to create the layout of the gating strategy for every tissue.

4. Run your stained samples, and acquire the data using the specifications of your particular cytometer.

5. Export the data for later analysis with the software of your choice.

Within the single viable cell population, we gate leukocytes (CD45 ${ }^{+}$ cells). We then exclude B cells by gating only B220- cells (see Note 21). Macrophages are gated within the $\mathrm{CD}^{1} 1 \mathrm{~b}^{+}$population. We can then differentiate two macrophage populations based on their levels of F4/80 and MHCII expression: large pleural macrophages (LPMs) are $\mathrm{F} 4 / 80^{\text {high }} \mathrm{MHCII}^{-/ \text {low }}$ cells, and small pleural macrophages (SPMs) are defined as F4/80-/low $\mathrm{MHCII}^{\text {high }}$ cells (see Fig. 1).

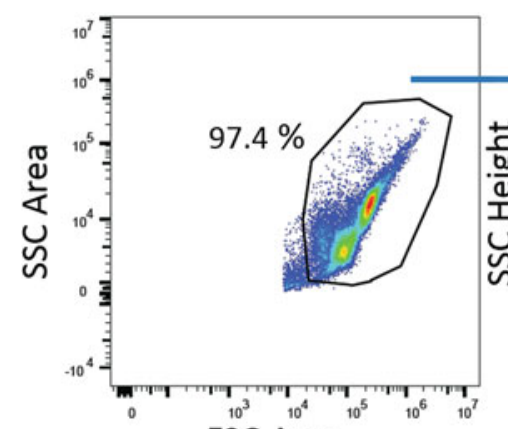

FSC Area

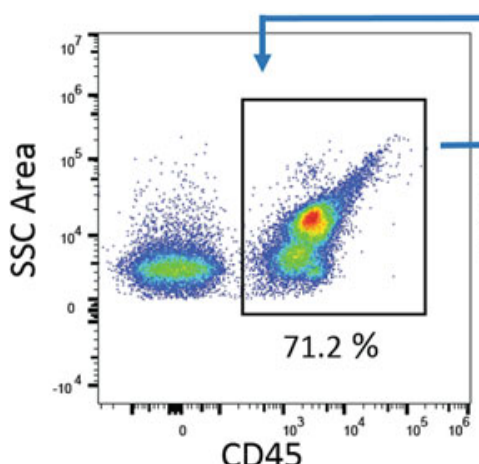

CD45

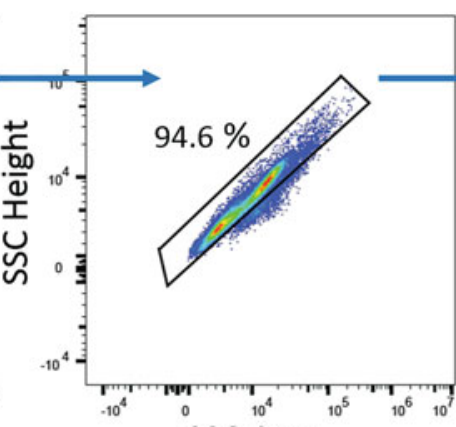

SSC Area

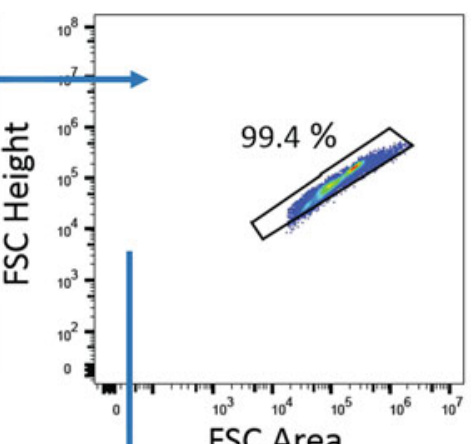

FSC Area

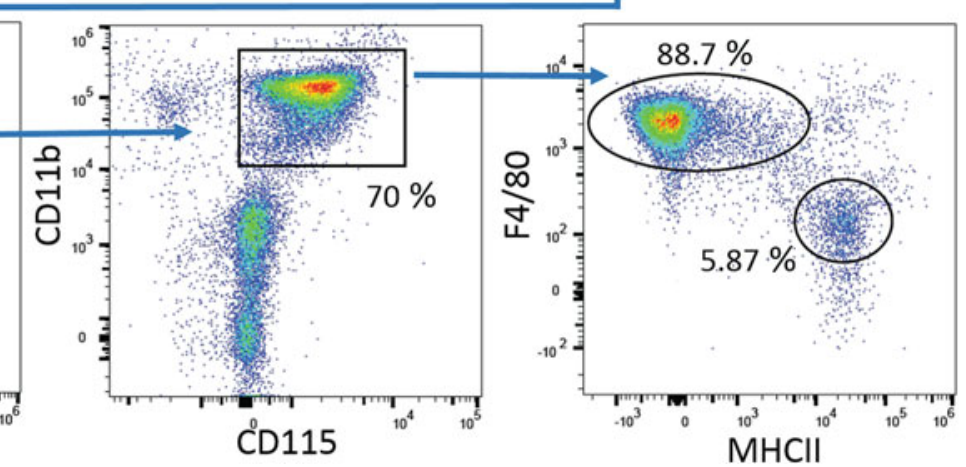

Fig. 1 Example gating strategy for pleural resident macrophages 

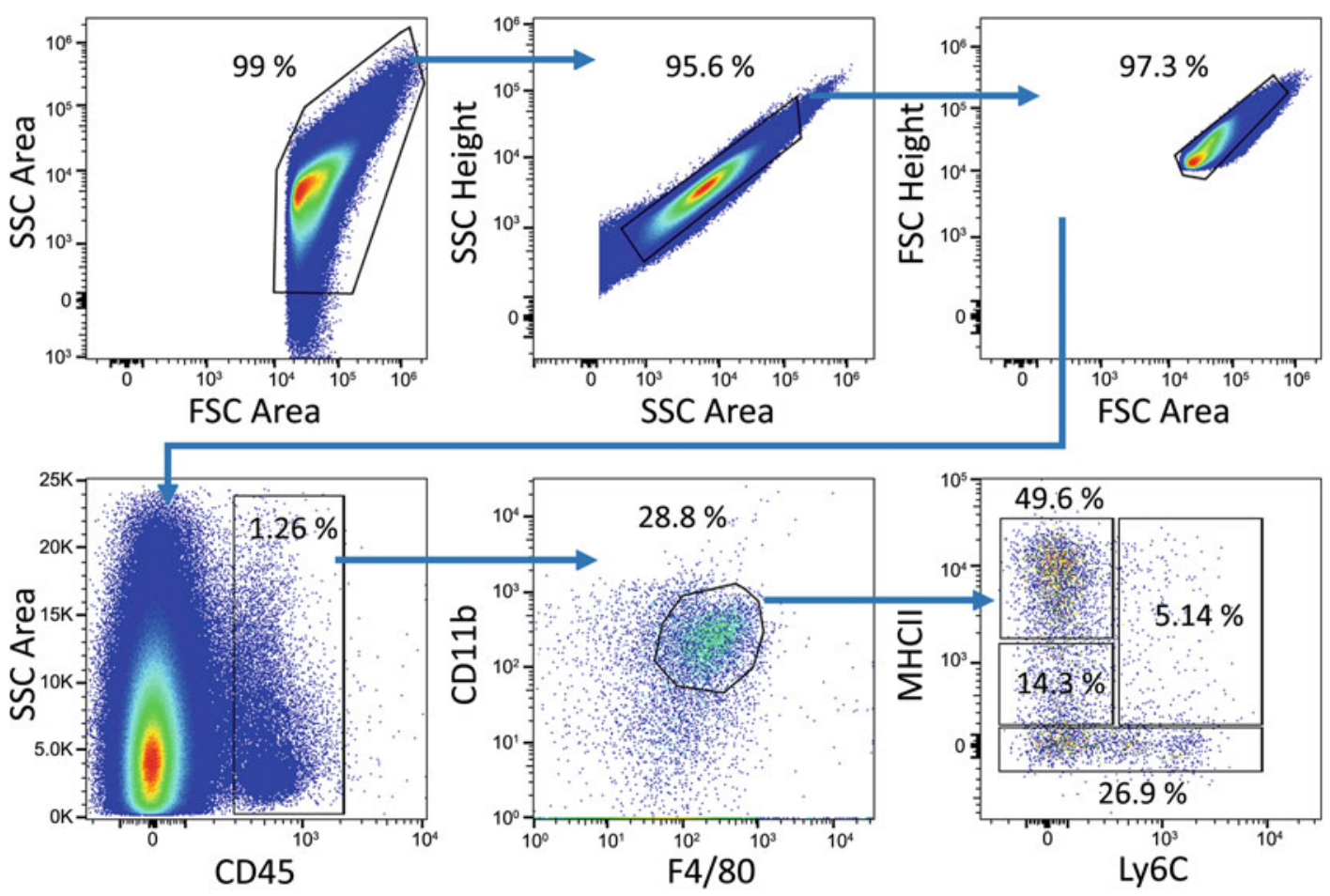

Fig. 2 Example gating strategy for cardiac resident macrophages

3.8.5 Flow Cytometry Analysis of Cardiac Resident Macrophages

3.8.6 Flow Cytometry Analysis of Alveolar Macrophages

3.8.7 Flow Cytometry Analysis of Spleen Resident Macrophages

\subsubsection{Flow Cytometry} Analysis of Kidney Resident Macrophages
Within the single viable cell population, we gate leukocytes $\left(\mathrm{CD} 45^{+}\right.$ cells). We then select macrophages $\left(\mathrm{CDI} \mathrm{b}^{+} \mathrm{F} 4 / 80^{+}\right.$cells $)$and differentiate two cardiac macrophage populations based on their level of MHCII expression: MHCII ${ }^{\text {high }} \mathrm{Ly} 6 \mathrm{C}^{\text {low }}$ macrophages and MHCII ${ }^{\text {low }}$ Ly6C ${ }^{\text {low }}$ macrophages (see Fig. 2). We can also identify monocytes as Ly6C ${ }^{\text {hi }}$ cells.

Within the single viable cell population, we gate leukocytes $\left(\mathrm{CD} 45^{+}\right.$ cells). We then select $\mathrm{Ly}_{6 \mathrm{G}^{-}} / \mathrm{CD} 1 \mathrm{lb}^{+}$cells to exclude neutrophils. Alveolar macrophages are distinguished as $\mathrm{CDl}_{1} \mathrm{c}^{\text {high }}$ SiglecF $\mathrm{F}^{\text {high }}$ cells (see Fig. 3).

Within the single viable cell population, we gate leukocytes $\left(\mathrm{CD} 45^{+}\right.$ cells). We then select myeloid cells as $\mathrm{CDI}^{1} \mathrm{~b}^{+}$cells. Two macrophage subsets can be differentiated according to the expression of F4/80 and Tim-4: Tim $4^{+}$macrophages and red pulp macrophages that are $\mathrm{F} 4 / 80^{+}$(see Fig. 4 ).

Within the single viable cell population, we gate leukocytes $\left(\mathrm{CD} 45^{+}\right.$ cells). We can then differentiate two myeloid subsets according to the expression levels of CDllb and F4/80: $\mathrm{CD}_{11 b^{\text {low }}} \mathrm{F} 480^{\text {high }}$ (kidney resident macrophages) and $\mathrm{CDl} 1 \mathrm{~b}^{\text {high }} \mathrm{F} 480^{\text {low }}$ (see Fig. 5 ). 

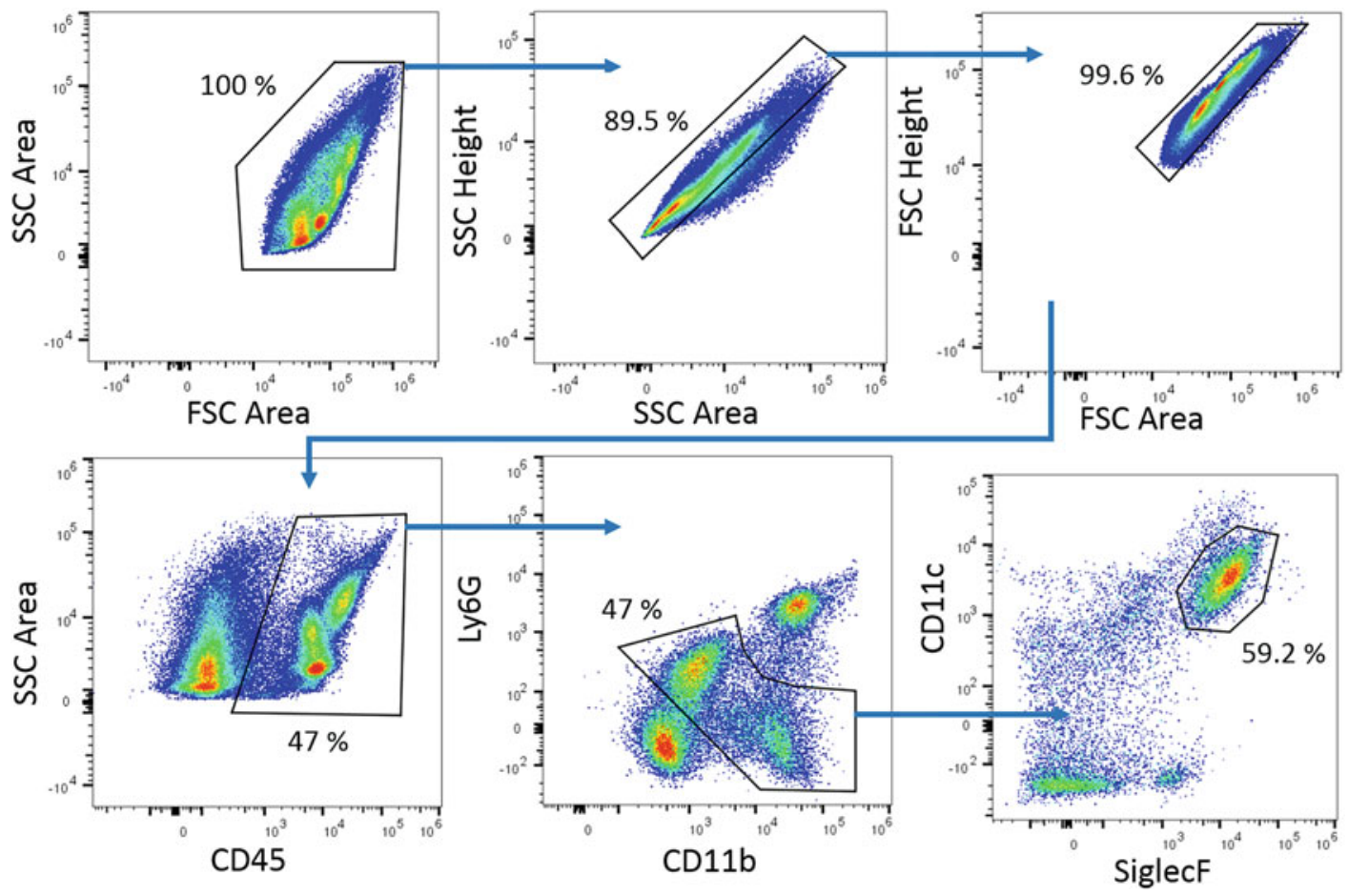

Fig. 3 Example gating strategy for alveolar macrophages

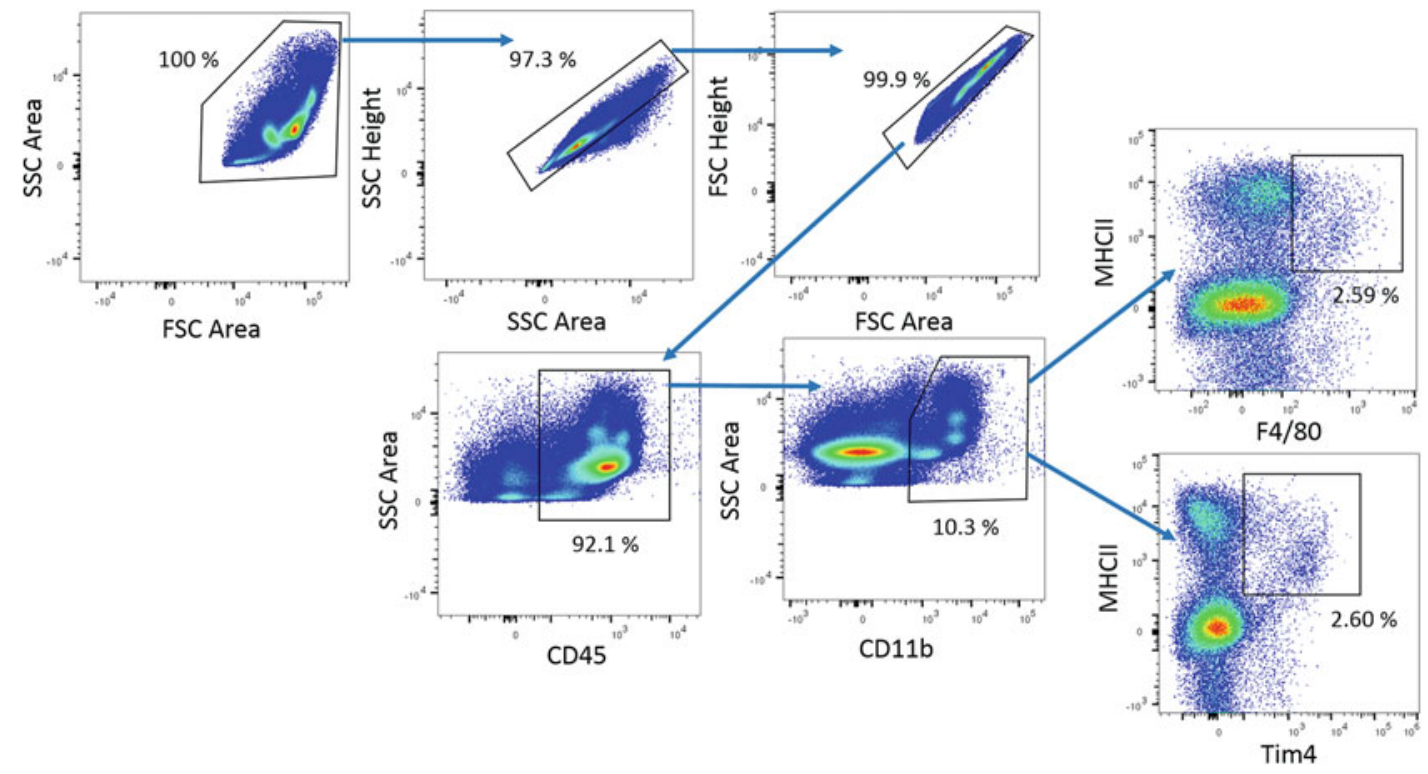

Fig. 4 Example gating strategy for spleen resident macrophages 


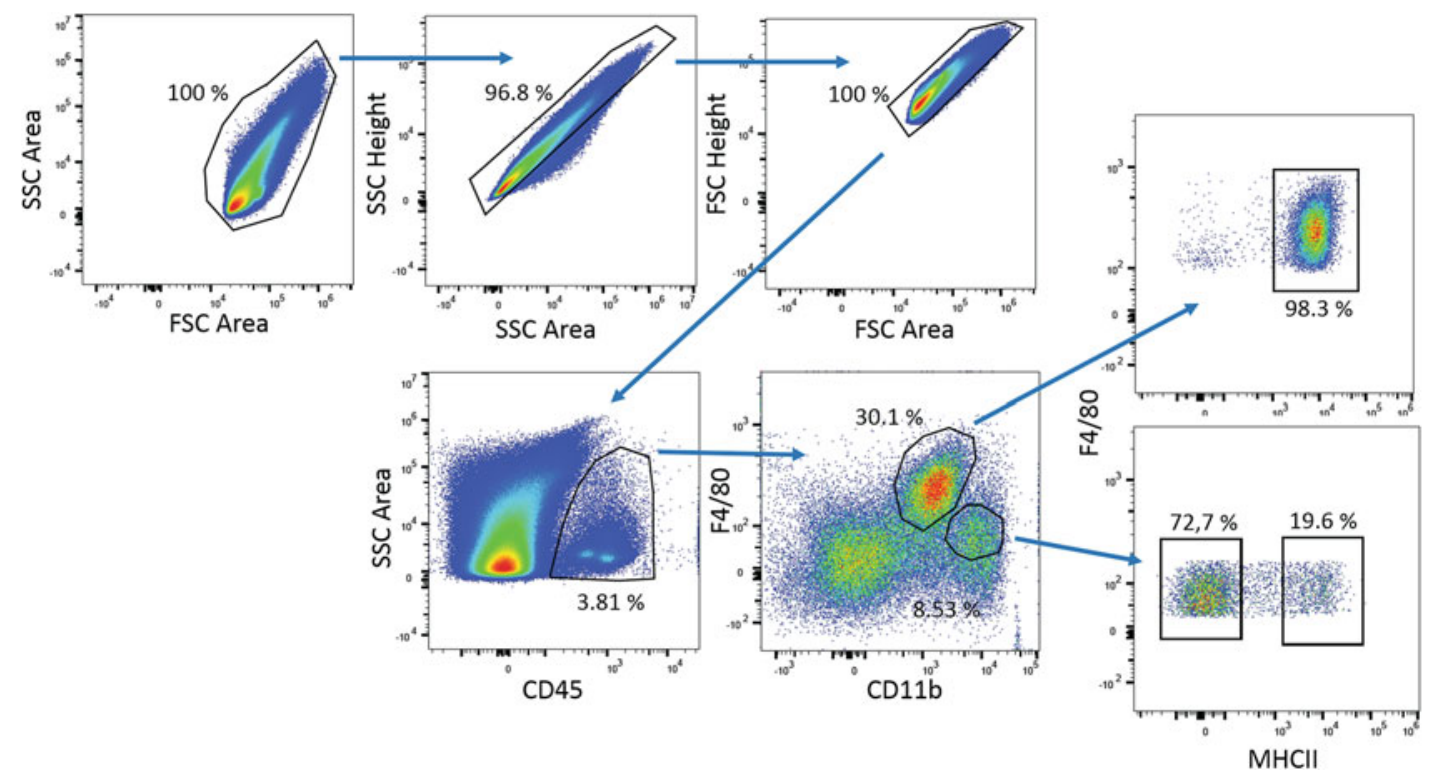

Fig. 5 Example gating strategy for kidney resident macrophages

\section{Notes}

1. We recommend use blunt-ended scissors.

2. If you also intend to do a peritoneal lavage, be careful not to break the peritoneum.

3 . It is extremely important to introduce only the needle tip; otherwise, the lungs can be damaged, and the pleural lavage will be contaminated with red blood cells and circulating monocytes. A sign that the pleural inflation is proceeding well is movement of the liver toward the intestine.

4. It is important to perfuse the mouse well in order to eliminate erythrocytes and circulating cells as much as possible. This avoids having a mix of TRMs and circulating myeloid cells during the flow cytometry analysis.

5. Weighing the tissues allows calculation of TRM abundance (TRMs/mg of tissue).

6. Sometimes, blood may be visible due to the injection or inflation. We recommend lysing red blood cells to ensure correct labeling in subsequent steps.

7. If the lungs are damaged during lavage, we strongly recommend discarding the sample because of the risk of contamination by circulating leukocytes.

8. We strongly recommend that you fine-tune the conditions for your own lab, varying digestion times by 10 min among tests, 
trying different collagenase concentrations, and even using digestion buffers different from those proposed here, for example, Hanks' balanced salt solution with $\mathrm{Ca}^{2+}$. Be careful with collagenase incubation times; exposures longer than $1 \mathrm{~h}$ will dramatically decrease the yield of viable cells.

9. Tissue pieces must be small enough to pass through an $18 \mathrm{G}$ needle.

10. If you have more than one sample, keep the already minced tissues on ice while mincing the rest.

11. Thorough mincing with shaking is very important to ensure proper cell extraction.

12. The combination of enzyme digestion and mechanical tissue disruption improves TRM yield during digestion and isolation.

13. We recommend the use of the soft end of a $2 \mathrm{~mL}$ syringe plunger to squeeze the sample residues.

14. Although the mouse is perfused through the heart, erythrocyte lysis is required afterward to eliminate residual red blood cells. Note that before the lysis, the pellet is still red, and after the lysis it should be completely white.

15. Maintain the other half in $1 \times$ PBS on ice; you many need it in case something goes wrong.

16. We strongly recommend shaking the tissue by hand every $5 \mathrm{~min}$ to increase the cell yield.

17. When several stainings are required, we recommend dividing the sample among different wells or tubes. Nevertheless, avoid this practice when studying rare populations.

18. When testing a new antibody, it is advisable to use fractions of the cell sample for a negative control $(50,000$ cells $)$ and a fluorescence minus one (FMO) control (50,000 cells). We recommend that these fractions are taken from the sample with the highest cell number. In the negative control, cells are not labeled with antibody, which allows the negative and the positive populations to be discerned. In the FMO control, the sample is stained with all the antibodies except the one being measured, revealing false-positive signals due to the effect of the other fluorochromes. In both controls, the cells must be processed with the same protocol as the experimental samples.

19. You can adjust the incubation time to your needs (minimum 15 min, maximum $2 \mathrm{~h}$ ).

20. It is very important to protect antibodies from light in order to prevent bleaching of conjugated fluorochromes.

21. Macrophages are highly autofluorescent; as a result, the population of $\mathrm{F} 4 / 80^{+}$cells in the $\mathrm{B} 220^{-}$gate seems to be partly $\mathrm{B} 220^{+}$. 
Acknowledgment

We thank Simon Bartlett for English editing. This work was supported by grants from the Spanish Ministry of Economy and Competitiveness (SAF2015-64287R, SAF2017-90604-REDT), Fundació Marató TV3 (121931), and the Community of Madrid (B2017/BMD-3684) to M.R. L.A-H. is funded by a fellowship from Obra Social "La Caixa". The CNIC is supported by the MEIC and the Pro CNIC Foundation and is a Severo Ochoa Center of Excellence awardee (MEIC award SEV-2015-0505).

\section{References}

1. Varol C, Mildner A, Jung S (2015) Macrophages: development and tissue specialization. Annu Rev Immunol 33:643-675

2. Davies LC, Jenkins SJ, Allen JE, Taylor PR (2013) Tissue-resident macrophages. Nat Immunol 14:986-995

3. Gautier EL, Shay T, Miller J, Greter M, Jakubzick C, Ivanov S, Helft J, Chow A, Elpek KG, Gordonov S, Mazloom AR, Ma'ayan A, Chua WJ, Hansen TH, Turley SJ, Merad M, Randolph GJ (2012) Geneexpression profiles and transcriptional regulatory pathways that underlie the identity and diversity of mouse tissue macrophages. Nat Immunol 13:1118-1128

4. Ginhoux F, Guilliams M (2016) Tissueresident macrophage ontogeny and homeostasis. Immunity 44:439-449

5. Gomez Perdiguero E, Klapproth K, Schulz C, Busch K, Azzoni E, Crozet L, Garner H, Trouillet C, de Bruijn MF, Geissmann F, Rodewald HR (2015) Tissue-resident macrophages originate from yolk-sac-derived erythromyeloid progenitors. Nature 518:547-551

6. Ginhoux F, Greter M, Leboeuf M, Nandi S, See P, Gokhan S, Mehler MF, Conway SJ, Ng LG, Stanley ER, Samokhvalov IM, Merad M (2010) Fate mapping analysis reveals that adult microglia derive from primitive macrophages. Science 330:841-845

7. Epelman S, Lavine KJ, Beaudin AE, Sojka DK, Carrero JA, Calderon B, Brija T, Gautier EL, Ivanov S, Satpathy AT, Schilling JD, Schwendener R, Sergin I, Razani B, Forsberg EC, Yokoyama WM, Unanue ER, Colonna M, Randolph GJ, Mann DL (2014) Embryonic and adult-derived resident cardiac macrophages are maintained through distinct mechanisms at steady state and during inflammation. Immunity 40:91-104

8. Lavine KJ, Epelman S, Uchida K, Weber KJ, Nichols CG, Schilling JD, Ornitz DM,
Randolph GJ, Mann DL (2014) Distinct macrophage lineages contribute to disparate patterns of cardiac recovery and remodeling in the neonatal and adult heart. Proc Natl Acad Sci U S A 111:16029-16034

9. Guilliams M, Scott CL (2017) Does niche competition determine the origin of tissueresident macrophages? Nat Rev Immunol $17: 451-460$

10. Hashimoto D, Chow A, Noizat C, Teo P, Beasley MB, Leboeuf M, Becker CD, See P, Price J, Lucas D, Greter M, Mortha A, Boyer SW, Forsberg EC, Tanaka M, van Rooijen N, García-Sastre A, Stanley ER, Ginhoux F, Frenette PS, Merad M (2013) Tissue resident macrophages self-maintain locally throughout adult life with minimal contribution from circulating monocytes. Immunity 38:792-804. https:// doi.org/10.1016/j.immuni.2013.04.004

11. N AG, Guillen JA, Gallardo G, Diaz M, de la Rosa JV, Hernandez IH, Casanova-Acebes M, Lopez F, Tabraue C, Beceiro S, Hong C, Lara PC, Andujar M, Arai S, Miyazaki T, Li S, Corbi AL, Tontonoz P, Hidalgo A, Castrillo A (2013) The nuclear receptor LXRalpha controls the functional specialization of splenic macrophages. Nat Immunol 14:831-839

12. Okabe Y, Medzhitov R (2014) Tissue-specific signals control reversible program of localization and functional polarization of macrophages. Cell 157:832-844

13. Schneider C, Nobs SP, Kurrer M, Rehrauer H, Thiele C, Kopf M (2014) Induction of the nuclear receptor PPAR-gamma by the cytokine GM-CSF is critical for the differentiation of fetal monocytes into alveolar macrophages. Nat Immunol 15:1026-1037

14. Lavin Y, Winter D, Blecher-Gonen R, David E, Keren-Shaul H, Merad M, Jung S, Amit I (2014) Tissue-resident macrophage enhancer landscapes are shaped by the local microenvironment. Cell 159:1312-1326 
15. Roszer T, Menendez-Gutierrez MP, Cedenilla M, Ricote M (2013) Retinoid X receptors in macrophage biology. Trends Endocrinol Metab 24:460-468

16. Valledor AF, Ricote M (2004) Nuclear receptor signaling in macrophages. Biochem Pharmacol 67:201-212

17. Rosenfeld MG, VV L, Glass CK (2006) Sensors and signals: a coactivator/corepressor/epigenetic code for integrating signal-dependent programs of transcriptional response. Genes Dev 20:1405-1428

18. Herzenberg LA, Tung J, Moore WA, Herzenberg LA, Parks DR (2006) Interpreting flow cytometry data: a guide for the perplexed. Nat Immunol 7:681

19. Walter W, Alonso-Herranz L, Trappetti V, Crespo I, Ibberson M, Cedenilla M, Karaszewska A, Nunez V, Xenarios I, Arroyo AG, Sanchez-Cabo F, Ricote M (2018) Deciphering the dynamic transcriptional and posttranscriptional networks of macrophages in the healthy heart and after myocardial injury. Cell Rep 23:622-636

20. Adan A, Alizada G, Kiraz Y, Baran Y, Nalbant A (2017) Flow cytometry: basic principles and applications. Crit Rev Biotechnol 37:163-176 



\section{Cell Reports}

\section{Deciphering the Dynamic Transcriptional and Post- transcriptional Networks of Macrophages in the Healthy Heart and after Myocardial Injury}

\section{Graphical Abstract}

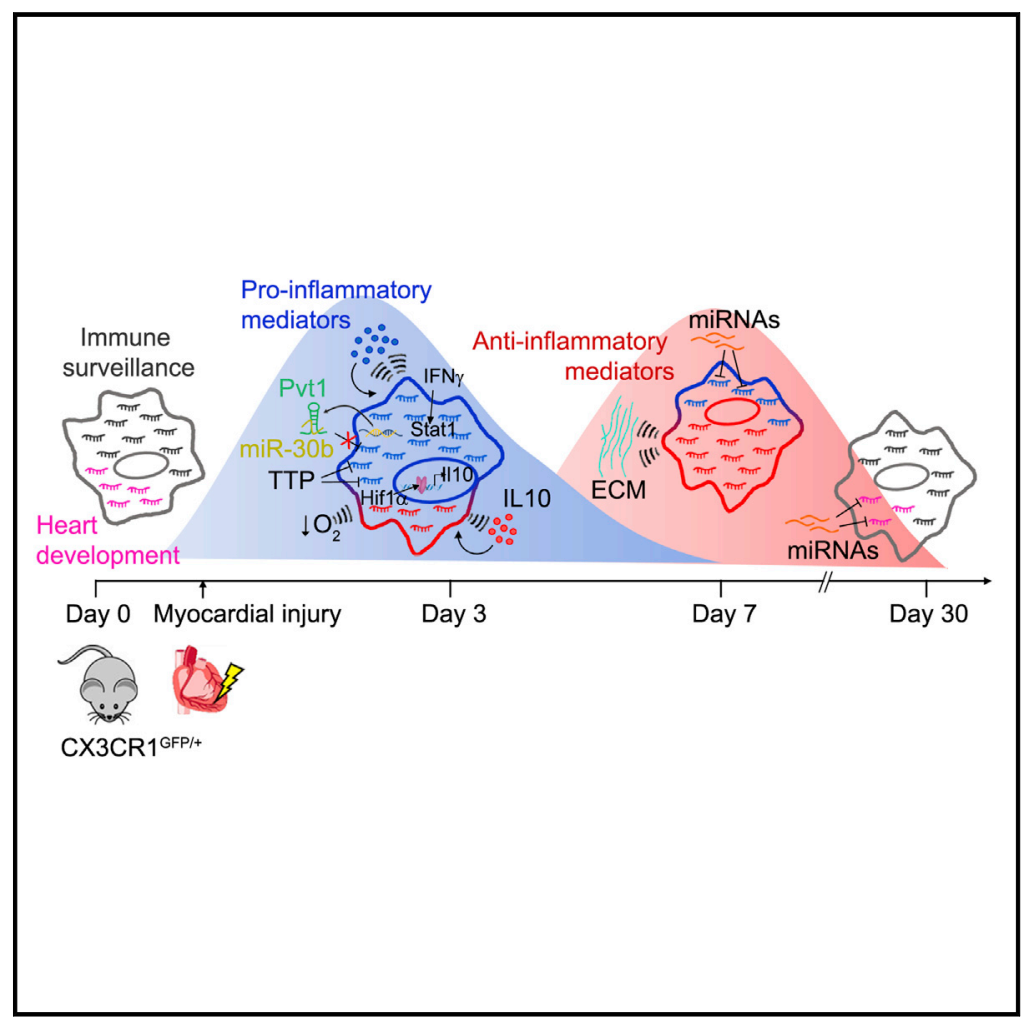

Highlights

- A comprehensive resource of the mouse cardiac macrophage transcriptional profile

- Macrophages involved in cardiac repair do not align to canonical M1/M2 programs

- Endogenous and exogenous feedback loops regulate phenotype transition after injury

- Identified markers might serve as targets for specific therapeutic intervention

\section{Authors}

Wencke Walter, Laura Alonso-Herranz, Verdiana Trappetti, ..., Alicia G. Arroyo, Fátima Sánchez-Cabo, Mercedes Ricote

\section{Correspondence}

fscabo@cnic.es (F.S.-C.), mricote@cnic.es (M.R.)

\section{In Brief}

Walter et al. generate a whole transcriptome dataset (mRNA, miRNA, and lincRNA) of macrophages in the healthy heart and after myocardial injury. This study reveals that post-injury macrophages simultaneously activate pro- and anti-inflammatory programs. Furthermore, they identified transcriptional and post-transcriptional mechanisms regulating myocardial injury-induced inflammation.

\section{Data and Software Availability} GSE97147 


\title{
Deciphering the Dynamic Transcriptional and Post-transcriptional Networks of Macrophages in the Healthy Heart and after Myocardial Injury
}

\author{
Wencke Walter, ${ }^{1,5}$ Laura Alonso-Herranz, ${ }^{1,5}$ Verdiana Trappetti, ${ }^{1}$ Isaac Crespo, ${ }^{2}$ Mark Ibberson, ${ }^{2}$ Marta Cedenilla, ${ }^{1}$ \\ Anna Karaszewska, ${ }^{1}$ Vanessa Núñez, ${ }^{1}$ Ioannis Xenarios, ${ }^{2}$ Alicia G. Arroyo, ${ }^{3}$ Fátima Sánchez-Cabo, ${ }^{4, *}$ \\ and Mercedes Ricote ${ }^{1,6, *}$ \\ ${ }^{1}$ Myocardial Pathophysiology Area, Centro Nacional de Investigaciones Cardiovasculares Carlos III (CNIC), 28029 Madrid, Spain \\ ${ }^{2}$ Vital-IT, SIB Swiss Institute of Bioinformatics, University of Lausanne, 1015 Lausanne, Switzerland \\ ${ }^{3}$ Vascular Pathophysiology Area, Centro Nacional de Investigaciones Cardiovasculares Carlos III (CNIC), 28029 Madrid, Spain \\ ${ }^{4}$ Bioinformatics Unit, Centro Nacional de Investigaciones Cardiovasculares Carlos III (CNIC), 28029 Madrid, Spain \\ ${ }^{5}$ These authors contributed equally to this work \\ ${ }^{6}$ Lead Contact \\ *Correspondence: fscabo@cnic.es (F.S.-C.), mricote@cnic.es (M.R.) \\ https://doi.org/10.1016/j.celrep.2018.03.029
}

\section{SUMMARY}

Macrophage plasticity has been studied in vitro, but transcriptional regulation upon injury is poorly understood. We generated a valuable dataset that captures transcriptional changes in the healthy heart and after myocardial injury, revealing a dynamic transcriptional landscape of macrophage activation. Partial deconvolution suggested that post-injury macrophages exhibit overlapping activation of pro-inflammatory and anti-inflammatory programs rather than aligning to canonical M1/M2 programs. Furthermore, simulated dynamics and experimental validation of a regulatory core of the underlying gene-regulatory network revealed a negative-feedback loop that limits initial inflammation via hypoxia-mediated upregulation of I110. Our results also highlight the prominence of post-transcriptional regulation (miRNAs, mRNA decay, and lincRNAs) in attenuating the myocardial injury-induced inflammatory response. We also identified a cardiac-macrophage-specific gene signature (e.g., Egfr and Lifr) and time-specific markers for macrophage populations (e.g., Lyve1, Cd40, and Mrc1). Altogether, these data provide a core resource for deciphering the transcriptional network in cardiac macrophages in vivo.

\section{INTRODUCTION}

Macrophages $(\mathrm{M} \varphi s)$ are multifunctional cells of the innate immune system that reside in all tissues, contributing to their development, homeostasis, and protection against pathogens and injury (Davies et al., 2013; Gautier et al., 2012). M $\varphi$ s are morphologically and functionally heterogeneous, a reflection of the diversity of tissue environments in which they reside. They are very plastic cells that continuously shift their functional phenotype to new states in response to microenvironmental changes (Sica et al., 2015). In addition to maintaining tissue homeostasis and responding to invading pathogens, $M \varphi s$ contribute to numerous pathological processes, making them potentially attractive targets for therapeutic intervention (HarelAdar et al., 2011; Sica et al., 2015). Such interventions will, however, require detailed understanding of $\mathrm{M} \varphi$ molecular biology in different tissues and disease contexts.

Extensive research into $\mathrm{M} \varphi$ activation using in vitro models has led to $M \varphi s$ being classified according to a bipolar model. $\mathrm{M} 1$ or classically activated $\mathrm{M} \varphi \mathrm{s}$ are elicited by pro-inflammatory signals such as lipopolysaccharide (LPS) and interferon- $\gamma$ (IFN- $\gamma$ ), whereas anti-inflammatory signals such as interleukin-4 (IL-4) and IL-13, lead to $M 2$ or alternatively activated $M \varphi s$ (Sica et al., 2015). Growing evidence indicates that this in vitro model is an oversimplification and has limited ability to explain the broad variety of phenotypes encountered in vivo (Varga et al., 2016). Recent studies have aimed to characterize the molecular signature of M $\varphi$ s in resting tissues (Gautier et al., 2012; Gosselin et al., 2014; Lavin et al., 2014). However, very little is known about $\mathrm{M} \varphi$ transcriptional and post-transcriptional activation during inflammation and the subsequent healing response in vivo.

Following myocardial injury, inflammatory monocytes are recruited from the bone marrow and spleen and enter the damaged tissue to give rise to $\mathrm{M} \varphi$ s (Heidt et al., 2014; Hilgendorf et al., 2014; Nahrendorf et al., 2007; Swirski et al., 2009). These recruited $\mathrm{M} \varphi$ s clear necrotic cellular debris and damaged extracellular matrix (ECM) from the tissue and attract other immune cells through the secretion of pro-inflammatory cytokines and chemokines such as tumor necrosis factor $\alpha$ (TNF- $\alpha$ ), IL-1 $1 \beta$, and IL-6. However, due to their high plasticity, $M \varphi s$ not only are able to initiate the inflammatory response but also play a critical role in resolving inflammation, and at later post-injury stages have the capacity to dampen inflammation and promote ECM reconstruction, cell proliferation, and angiogenesis (Hilgendorf et al., 2014; Nahrendorf et al., 2007). These M $\varphi$ s are characterized by the secretion of anti-inflammatory and profibrotic factors such as IL-10 and transforming growth factor $\beta$ (TGF- $\beta$ ), which promote tissue repair. These opposing functions are most likely carried out by distinct $M \varphi$ populations. However, the exact 
identities of these $M \varphi s$ remain undefined, and it is not well understood how this transition from pro-inflammatory to antiinflammatory activities is orchestrated in vivo.

Recent advances in omics technologies have opened up the possibility to address these questions and to elucidate transcriptional programs and the spatiotemporal properties of the underlying multifaceted regulatory networks. Recent studies addressed the transcriptional regulation in cardiac M $\varphi s$ (Epelman et al., 2014; Pinto et al., 2012; Yan et al., 2017), but while these studies were focused on the healthy heart, our work fills the void of an integrative study that deciphers the different levels of transcriptional regulation in cardiac homeostasis and after injury. Here, we used a systems biology approach to gain understanding of $\mathrm{M} \varphi \mathrm{s}$ in the healthy and post-injury heart by combining mathematical modeling and computational biology with experimental data. Our study focused not only on the response to injury of protein-coding RNAs (mRNAs) but also on microRNA (miRNA) and long intergenic noncoding RNA (lincRNA) profiles, in order to better define the different modes of $\mathrm{M} \varphi$ activation in cardiac repair. Furthermore, we collected published data on gene-regulatory interactions to create a prior knowledge network (PKN) and used Boolean logic to identify stable states within it based on our gene expression data (Albert, 2007; Garg et al., 2009; Rodriguez et al., 2015).

Hypotheses derived from the inferred model were validated by in vitro experiments and revealed a negative-feedback loop that potentially contributes to the observed switch between the proand anti-inflammatory responses post-injury. This dataset provides a valuable resource for extending knowledge of $\mathrm{M} \varphi$ biology and expanding the growing collection of molecular signatures of immune-related cells in different contexts and tissues.

\section{RESULTS}

$\mathrm{CX}_{3} \mathrm{CR}^{\mathrm{GFP} /+}$ Mice as a Model for Analyzing M $\varphi s$ in the Healthy and Injured Heart

Cryoinjury was induced in $\mathrm{CX}_{3} \mathrm{CR} 1^{\mathrm{GFP} /+}$ knockin mice (Jung et al., 2000), in which M $\varphi$ s can be tracked (Heidt et al., 2014; Hulsmans et al., 2017; Pinto et al., 2012; Varga et al., 2016). An extensive inflammatory response was observed in the early post-injury stage, followed by the deposition of a fibrotic scar at later post-injury stages (Figure S1A), and resulting in cardiac dysfunction (Figures S1B and S1C). To study $M \varphi$ responses, we isolated $\mathrm{GFP}^{+}$cells at steady state and different post-injury stages, applying a widely used fluorescence-activated cell sorting (FACS) gating strategy (Heidt et al., 2014; Pinto et al., 2012; Varga et al., 2016) (Figures S2A and S2B). The diversity of $M \varphi$ subsets in the myocardium has been reported (Epelman et al., 2014). However, our goal was to gain an unbiased picture of the transcriptional regulation and function of the total $\mathrm{M} \varphi$ population in cardiac healing. Cell quantification (Figure S2C) clearly shows the predominance of the $\mathrm{Ly} 6 \mathrm{C}^{\text {low }} / \mathrm{CX}_{3} \mathrm{CR} 1^{\text {high }}$ population at 0 days, contrasting an increase in the $\mathrm{Ly} 6 \mathrm{C}^{\text {high }} / \mathrm{CX}_{3} \mathrm{CR} 1^{\text {low }}$ population at 3 days post-injury, corresponding to the recruitment of monocyte-derived M $\varphi$ s (Heidt et al., 2014). At 7 and 30 days, the most abundant population is $\mathrm{Ly} 6 \mathrm{C}^{\text {low }} / \mathrm{CX}_{3} \mathrm{CR} 1^{\text {high }}$ cells. Hence, $\mathrm{Ly} 6 \mathrm{C}^{\text {low }} / \mathrm{CX}_{3} \mathrm{CR} 1^{\text {high }}$ cells were taken to assess the characteristics of cardiac-resident $\mathrm{M} \varphi s$ (CRMs) (day 0$)$ and in the reparative phase ( 7 and 30 days post-injury), whereas Ly $6 \mathrm{C}^{\text {high }} / \mathrm{CX}_{3} \mathrm{CR} 1^{\text {low }}$ cells were selected to characterize $\mathrm{M} \varphi \mathrm{s}$ in the inflammatory phase (3 days post-injury) (Varga et al., 2016). Our cell populations were distinguished from monocytes by the expression of the core $\mathrm{M} \varphi$ signature marker CD64 (Gautier et al., 2012) and the classical $M \varphi$ markers F4/80 and CD68 at all stages by flow cytometry (Figure S2D) and by confocal fluorescence microscopy (Figure S2E). To elucidate the dynamic transcriptional landscape of in vivo $\mathrm{M} \varphi \mathrm{s}$, we purified $\mathrm{M} \varphi$ populations from single-cell suspensions of digested hearts at different post-injury stages by FACS (Figures S2A and S2B). Global gene expression profiles of purified cells were obtained by RNAsequencing (RNA-seq) and miRNA profiling.

\section{Cardiac M $\varphi$ s Display a Unique and Tissue-Specific Gene Signature}

$\mathrm{M} \varphi s$ reside in nearly all tissues of the body and have been shown to differ in their ontological origin, epigenetic imprinting, and gene expression (Gautier et al., 2012; Gosselin et al., 2014; Lavin et al., 2014). We aimed to extend these findings to CRMs by comparing them with two published databases (GEO: GSE15907 and GSE63340) of tissue-resident M $\varphi$ s (TRMs) (Gautier et al., 2012; Lavin et al., 2014). Principal-component analysis (PCA) and pairwise correlation analysis of the samples supported previous findings indicating that TRMs can be distinguished by their gene expression (Figures $1 \mathrm{~A}$ and $\mathrm{S} 3 \mathrm{~A}$ ). To explore this heterogeneity in more detail, we used $k$-means clustering ( $k=15$; Figure S3B; Table S1) to identify sets of tissue-specific co-expressed genes. The clustering revealed a previously undescribed set of cardiac$\mathrm{M} \varphi$-specific genes (Figure S3B, cluster XII). Although we applied batch correction (Supplemental Experimental Procedures), comparisons among different datasets could be affected by limitations. We therefore qPCR-validated the cardiac-specific expression of some of the identified genes (Lifr, Egfr, Myh6, II1rl1, Osmr, and Steap4) (Figures 1B, S3C, S3D, and S4A). Expression of leukemia inhibitory factor receptor (LIFR) and epidermal growth factor receptor (EGFR) on the CRM surface was confirmed by flow cytometry (Figure 1B).

\section{M $\varphi$ s from the Healthy and Injured Hearts Have Different} Transcriptional Signatures

PCA of the global transcriptional profiles of all samples revealed clear separation between the different post-injury stages (Figure S4B). Unsupervised k-means clustering ( $k=6$; Figure $1 \mathrm{C})$ of 4,988 differentially expressed genes (DEGs) (Figure S4C; Tables S2 and S3) revealed three clusters with time-pointspecific gene signatures. Cluster I included genes specifically expressed in CRMs, such as cardiomyocyte structural genes (e.g., Myl2, Myh6, Tnnt2), and was enriched in heart development and myofibril assembly related genes (Figures $1 \mathrm{C}$ and 1D; Table S2). This cluster was also enriched for cell adhesion genes (e. g. Lyve-1, Cd36), possibly indicating close interactions between $\mathrm{M} \varphi \mathrm{s}$ and other cardiac cells in the healthy heart. Cluster II contained genes specifically expressed in $\mathrm{M} \varphi \mathrm{s}$ isolated at day 3. These genes were enriched for immune response (e.g., Cd274, Stat1, Ccl2), programmed cell death (e.g., Tnfrsf21, Xaf1, Itpr1), apoptotic signaling (e.g., Cd40, Casp8, Spp1), and regulation of reactive oxygen species (ROS) metabolic 
A

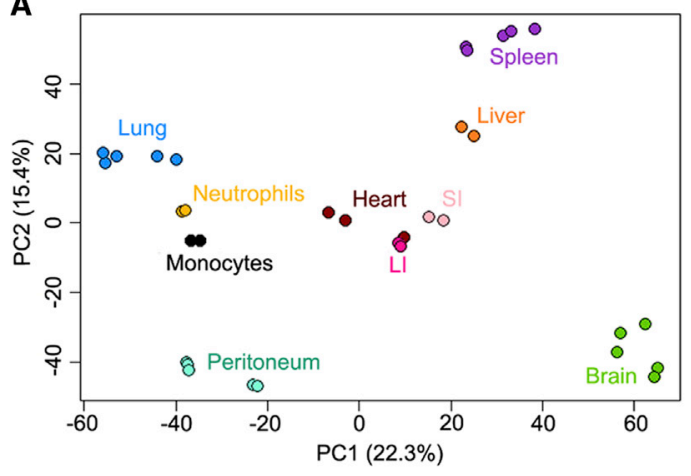

B
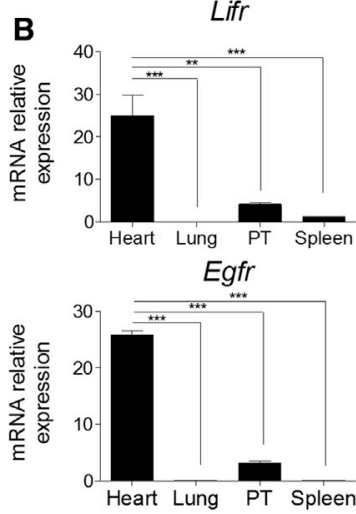

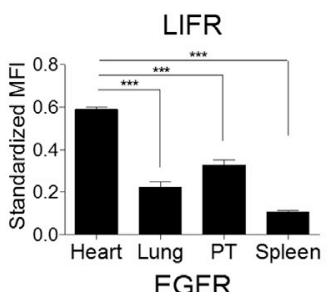

EGFR

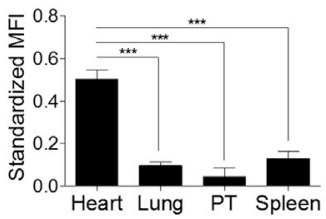

\section{C}

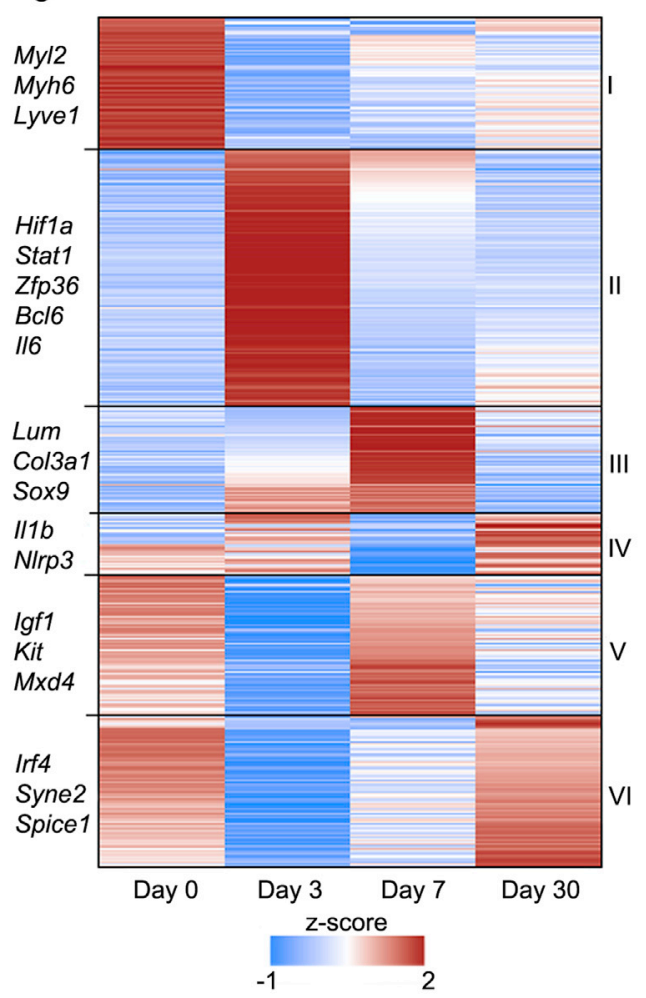

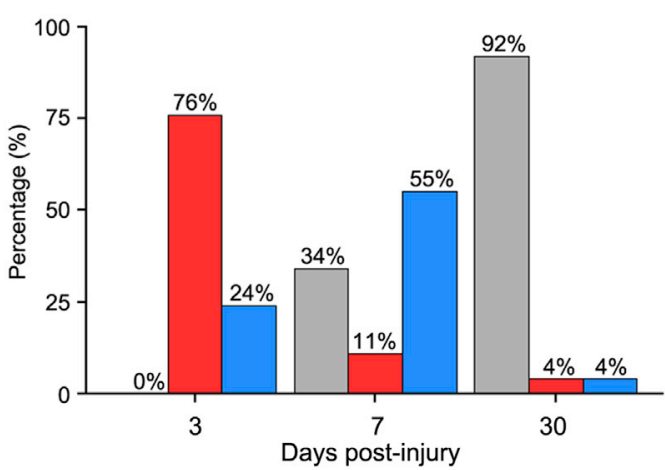

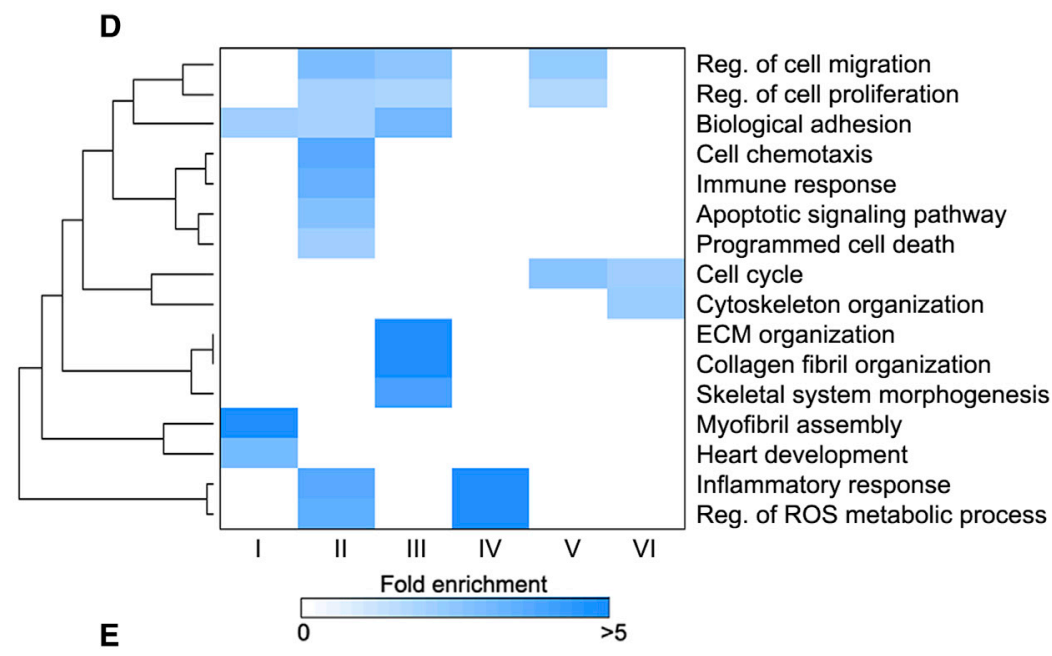

Reg. of cell migration Reg. of cell proliferation Biological adhesion Cell chemotaxis Immune response Apoptotic signaling pathway Programmed cell death Cell cycle Cytoskeleton organization ECM organization Collagen fibril organization Skeletal system morphogenesis Myofibril assembly Heart development Inflammatory response Reg. of ROS metabolic process

M0-gene signature M1-gene signature M2-gene signature

Figure 1. Transcriptional and Functional Characterization of $\mathrm{M} \varphi \mathrm{s}$ in the Healthy Heart and after Injury

(A) PCA of tissue-resident $M \varphi s$, comparing the transcriptional profile of heart $M \varphi s$ with published expression sets of other tissue-resident $M \varphi S$ (GSE15907, GSE63340).

(B) qPCR and flow cytometry validation of surface markers specific for CRMs. Data are shown as mean or median \pm SEM of three independent experiments; ${ }^{* *} p<0.01,{ }^{* * *} p<0.001$ (one-way ANOVA followed by Tukey test).

(C) K-means clustering $(\mathrm{k}=6)$ of the 4,988 DEGs in at least one time point compared with control.

(D) $\mathrm{HC}$ of significantly enriched PANTHER biological processes (Benjamini-Hochberg adjusted $\mathrm{p}[\mathrm{B}-\mathrm{H}$ adj-p] $<0.01$; fold enrichment $>2$ ).

(E) CellMix-estimated frequency of M0, M1, and M2 gene signatures (using published expression database GSE53321 of in vitro BMDM treated with various stimuli) in in vivo samples at different post-injury stages.

See also Figures S1-S4 and Tables S1 and S2.

processes (e.g., Ptegs2, Xdh, Acod1) (Figures 1C and 1D; Table S2). The upregulation at 3 days post-injury of Hif1a and its target genes Vegfa, Glut1, and Pgk1 may indicate a hypoxic environment (Figure 1C; Table S2). Interestingly, 20\% of these genes (e.g., Stat1, Zfp36, II6) are potential targets of IFN- $\gamma$ (Rusinova et al., 2013). Genes specifically expressed in M $\varphi s$ 
isolated at 7 days post-injury (cluster III) were associated with ECM and collagen fibril organization (e.g., Lum, Co/3a1), indicating an active role in tissue remodeling (Figures $1 \mathrm{C}$ and 1D; Table S2). The enrichment of cell proliferation regulators in the same cluster (e.g., Sox9, Sox4, Figures 1C and 1D; Table S2) is in accordance with previous findings in $\mathrm{M} \varphi$ s isolated after skeletal muscle injury (Varga et al., 2016). Cluster IV contained relevant immune related genes characterized by downregulation of their expression at day 7 (e.g., I/1b, Cxc/2, NIrp3; Figures $1 \mathrm{C}$ and 1D; Table S2).

K-means clustering also revealed a shared transcriptional signature between $\mathrm{CRMs}$ and $\mathrm{M} \varphi \mathrm{s}$ isolated at day 7 (cluster V), and $\mathrm{CRMs}$ and $\mathrm{M} \varphi \mathrm{s}$ at day 30 (cluster VI). Enrichment of cluster $\mathrm{V}$ for genes involved in cell cycle and cell proliferation processes (e.g., Igf1, Kit, Mxd4; Figures 1C and 1D; Table S2) would confirm the self-renewal potential of CRMs (Epelman et al., 2014) and the proliferative capacity of $\mathrm{M} \varphi \mathrm{s}$ involved in tissue repair (Hilgendorf et al., 2014; Varga et al., 2016). On the other hand, genes with elevated expression on day 0 and day 30 (cluster $\mathrm{VI}$ ) were mainly involved in cell-cycle processes (e.g., Spice1, Nuf2) and cytoskeleton organization (e.g., Syne2), indicating restoration of homeostasis at 30 days post-injury (Figures $1 \mathrm{C}$ and 1D; Table S2).

The Transcriptional Profiles of Post-injury M $\varphi$ s Are a Mix of the Gene Signatures of Described In Vitro Phenotypes Examination of genes in cluster II (3 days post-injury M $\varphi s$ ) revealed simultaneous expression of $\mathrm{M} 1$ markers (e.g., Ccr2, Stat1, I/6, Cxc/10) and M2 markers (e.g., Arg1, Msr1, Stat3, Tgfb1) (Table S2). Similar mixed expression of M1 genes (e.g., Ccr7, Ccl8) and M2 genes (e.g., Trem2, Clec2i) occurred in cluster III (7 days post-injury M $\varphi s$ ) (Table S2). These results suggest that in vivo $\mathrm{M} \varphi \mathrm{s}$ are transcriptional hybrids of the phenotypes described in vitro.

In order to test this hypothesis computationally, partial deconvolution was used to evaluate the M1 and M2 phenotype contribution to the in vivo samples. Partial deconvolution has become a useful tool for estimating cell-type frequencies within heterogeneous gene expression samples (Shen-Orr et al., 2010). The gene expression profile of CRMs (M0), BMDMs activated with LPS plus IFN- $\gamma$ (M1), and BMDMs activated with IL-4 plus IL-13 (M2), taken from published in vitro database GSE53321 (Li et al., 2015), were used as reference profiles to estimate the contributions of the $\mathrm{M0}, \mathrm{M} 1$, and $\mathrm{M} 2$ gene signatures to the post-injury $\mathrm{M} \varphi$ population in vivo using partial deconvolution (Shen-Orr et al., 2010) (see Experimental Procedures for further detail). The estimated frequencies of the M0, M1, and M2 gene signature within post-injury $\mathrm{M} \varphi \mathrm{s}$ are shown in Figure $1 \mathrm{E}$. The transcriptional profile of $\mathrm{M} \varphi \mathrm{s}$ isolated at 3 days post-injury was driven by $\mathrm{M} 1$ associated genes (76\% M1) but already included anti-inflammatory genes (24\% M2). The profile retained no gene expression pattern reminiscent of CRMs (0\%). Gene expression at 7 days post-injury was mainly characterized by $\mathrm{M} 2$-associated genes $(55 \%)$ but retained transcriptional traces of a M1 gene signature (11\%). This result suggests a transition from pro-inflammatory to anti-inflammatory further continuing to resting $M \varphi$, as indicated by the contribution of the M0 profile. The latest post-injury stage was completely dominated by the M0 gene signature (92\%). Altogether, these results reveal that post-injury cardiac $M \varphi s$ cannot be defined as canonical M1 or M2 Mps. Instead, we report dynamic transcriptional changes in $\mathrm{M} \varphi s$ during tissue repair.

\section{The Signaling Receptome and Secretome Program of Cardiac M $\varphi s$ Depends on the Activation State}

The secretome and receptome were identified within each cluster (Table S3; Supplemental Experimental Procedures). Interestingly, the highest relative abundance of genes encoding for the secretome occurred on day 7 and was nearly double the relative abundance of the receptome (cluster III, Figure 2A), indicating an increased heterotypic paracrine signaling potential. Functional analysis associated the identified secretome with regulation of angiogenesis and blood vessel development, and ECM and collagen fibril organization-related processes (Figure S5A), suggesting a key role of $\mathrm{M} \varphi \mathrm{s}$ in cell signaling through the secretion of angiogenic factors (e.g., Hgf, Figf, Srpx2) and ECM components (e.g., Col3a1, Lox, Postn) during the reparative post-injury phase (Figure 2B; Table S3). The secretome and receptome components expressed by $\mathrm{M} \varphi s$ during the inflammatory phase (cluster II, day 3) were consistently associated with the immune response (e.g., Cd40, Cd44, Cxc/10), leukocyte migration and leukocyte chemotaxis (e.g., Ccl7, Cc/12, Cxc/3), and blood vessel development (e.g., Angpt2, Mmp19, Vegfa) (Figures 2B, 2D, and S5A; Table S3). In addition, we found numerous potential secretome-receptome interactions (e.g., Cc/12-Cxcr4, Cxc/3-Cxcr2, Ccl7-Ccr5) (Figure 2C; Table S3), suggesting that $\mathrm{M} \varphi \mathrm{s}$ sustain the inflammatory response through homotypic paracrine signaling. At 3 days post-injury, M $\varphi$ s expressed Ccl2 (Figure 2B), suggesting recent infiltration by circulating monocytes and promotion of further monocyte recruitment to the inflammation site (Sica et al., 2015). CRMs (cluster I) expressed secretome components associated with angiogenesis regulation (e.g., Mmp9, $\mathrm{Cx} 3 \mathrm{c} / 1$ ) (Figure 2B), and this finding was supported by the receptome components identified (e.g., Lyve-1, Esam) (Figures 2B and 2D; Table S3). In addition, leukocyte chemotaxis and immune response processes were enriched (Figure S5A), supporting the role of CRMs in immune surveillance. The secretome of CRMs and 7 days post-injury M $\varphi$ s (cluster $V$ ) was associated with biological adhesion (e.g., Nid1, Lama5, Lamb2) and ECM and collagen-related processes (e.g., Mmp11, Col4a1, Dpt) (Figure S5A; Table S3), indicating a fundamental role of these $\mathrm{M} \varphi \mathrm{S}$ in the maintenance of tissue integrity. Secretome and receptome components with elevated expression on days 0 and 30 included anti-inflammatory genes (e.g., Ccl17, Ccl22, Mrc1, Cd86), supporting the immune quiescent phenotype of CRMs (Figures $2 \mathrm{~B}$ and 2D; Table S3). The low number of potential homotypic signaling pairs in the healthy heart and at 30 days post-injury (Figure 2C; Table S3) suggests that the receptome has a primarily immune surveillance function. Additionally, specific surface markers (Lyve1, Cd36, Cd40, Cd274, Cd86, and Mrc1) were validated by $\mathrm{qPCR}$ and flow cytometry for the different $\mathrm{M} \varphi$ populations at each stage (Figure 2D). Cells were isolated using the gating strategy shown in Figures S5B and S5C.

The Complex Regulatory Network of In Vivo Cardiac M $\varphi s$ Sequence-based motif enrichment analysis (Supplemental Experimental Procedures) of genes in each cluster (Figure 3A) 
A

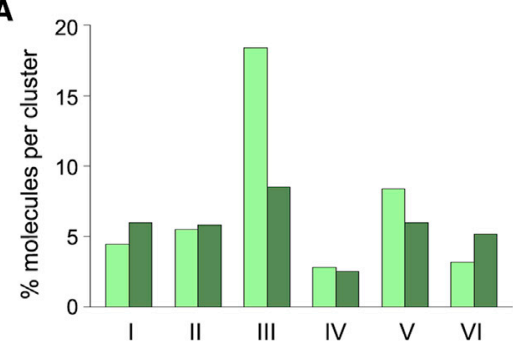

C
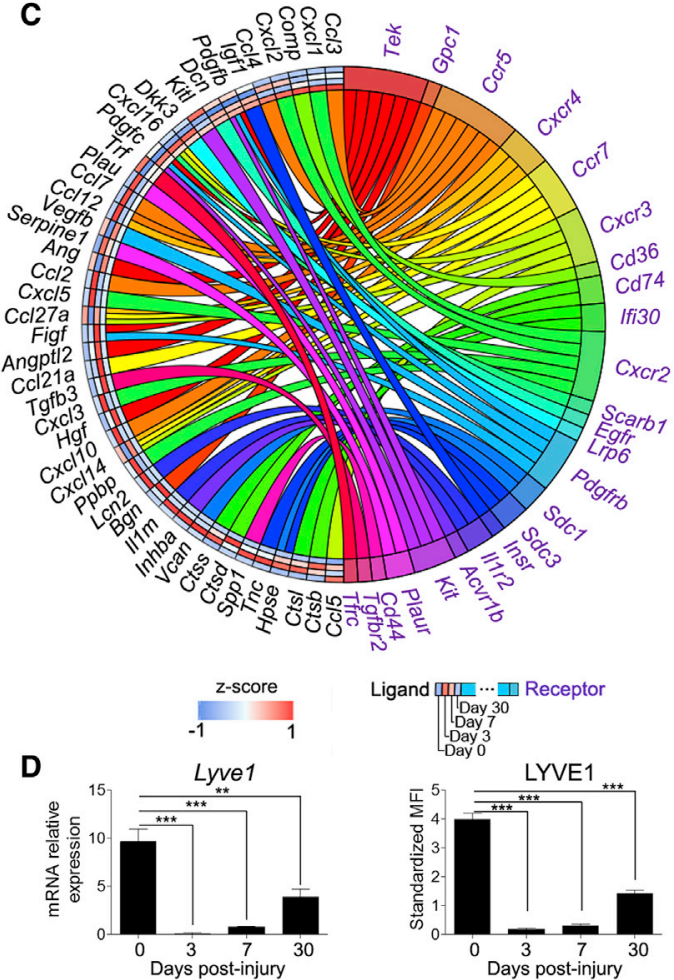

Cd40
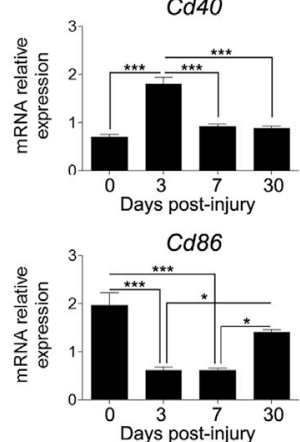

Ligand $\mathrm{mII} \cdots$... Receptor

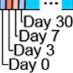

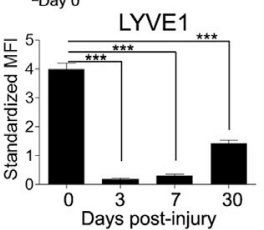

CD40
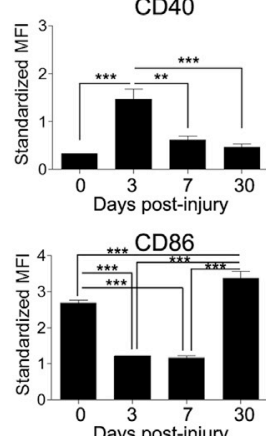
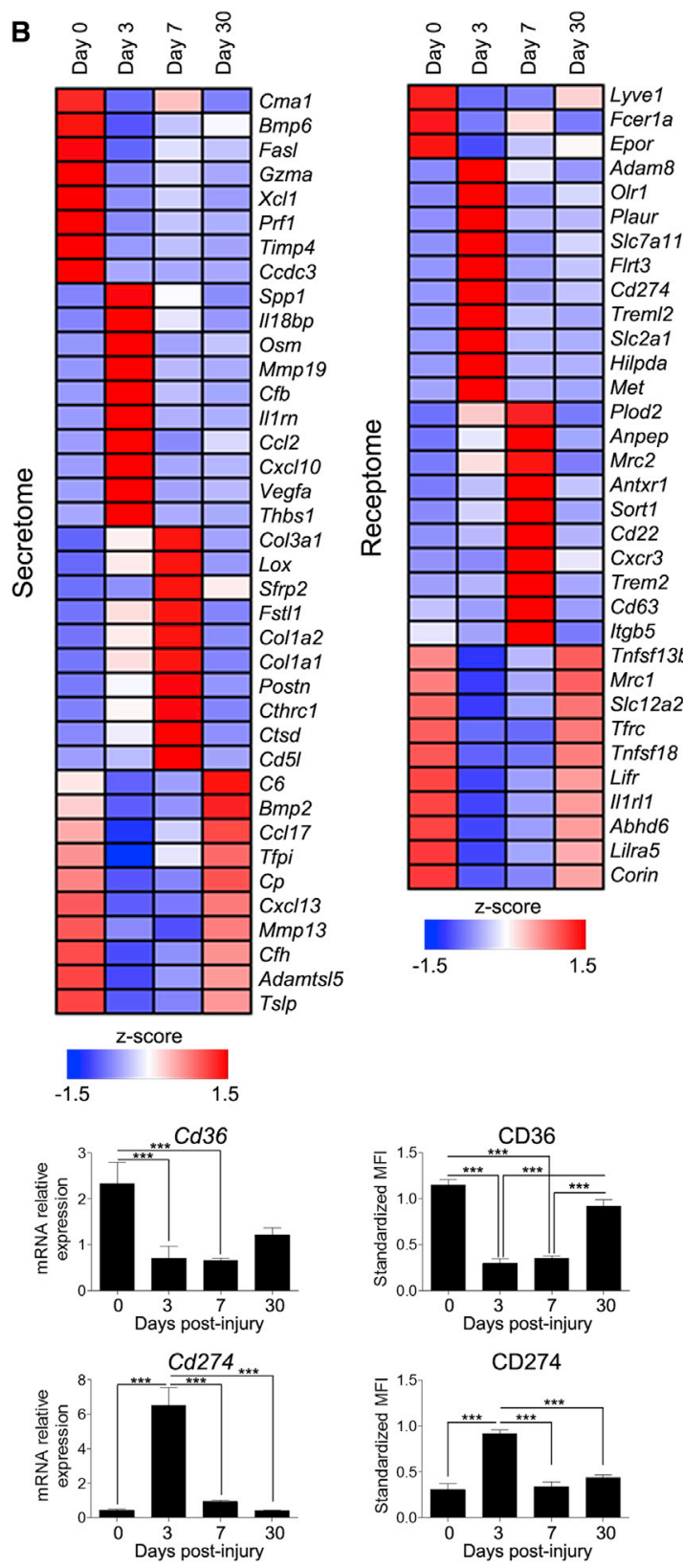

CD274
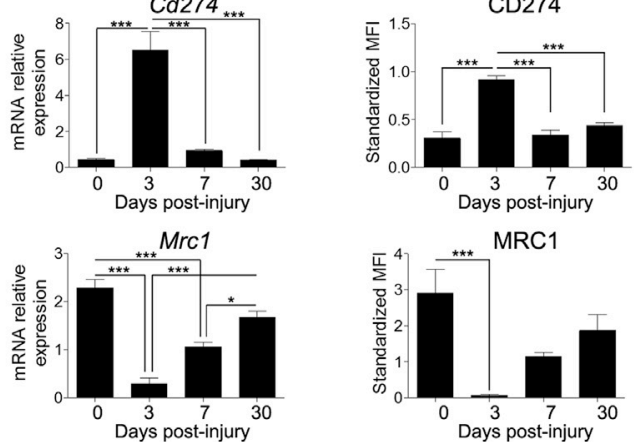

Figure 2. Transcriptional Profile of the Cardiac $\mathrm{M}_{\varphi}$ Secretome and Receptome

(A) Relative abundance of secretome and receptome components per cluster.

(B) Secretome and receptome heatmap for clusters I, II, III, and VI. Molecules with logFC > 1 in all relevant contrasts were kept, ranked by significance, and a maximum of 10 per cluster selected.

(C) Chord diagram of secretome (black)-receptome (purple) interactions. Squares alongside secretome gene symbols indicate the $z$ scores 0,3 , 7 , and 30 days post-injury.

(D) qPCR and flow cytometry validation of selected surface markers. Data are shown as mean or median $\pm \mathrm{SEM}$ of three independent experiments; ${ }^{*} \mathrm{p}<0.05$, ${ }^{* *} p<0.01,{ }^{* \star *} p<0.001$ (one-way ANOVA followed by Tukey test).

See also Figure S5 and Table S3. 
A

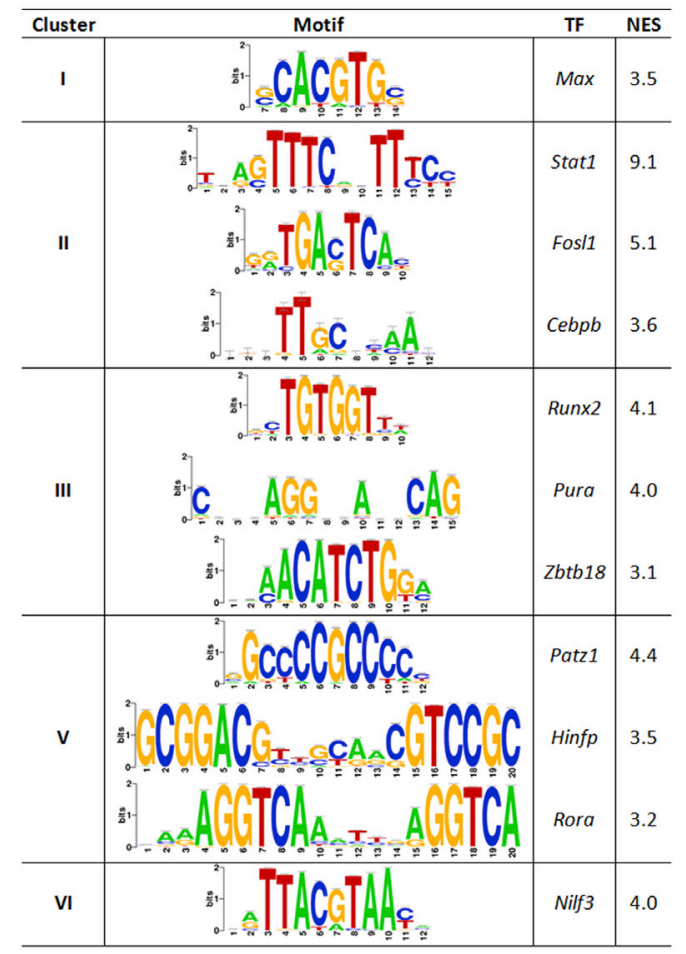

C

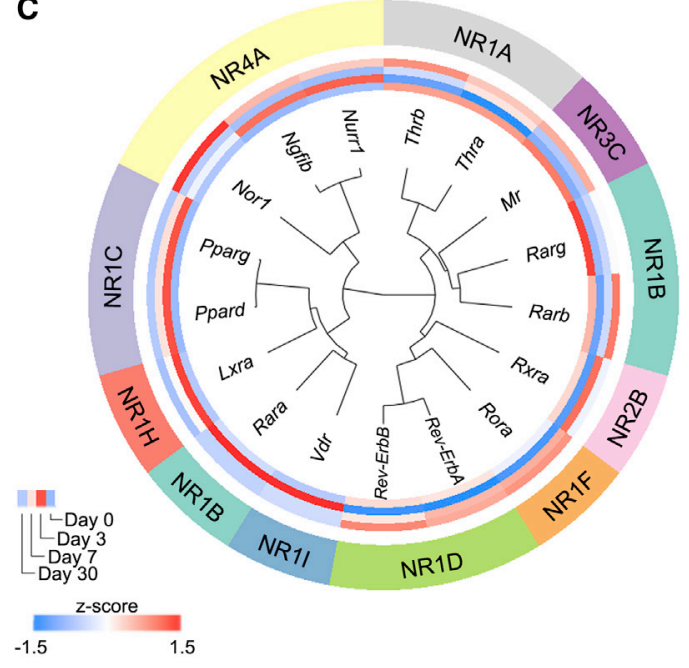

B

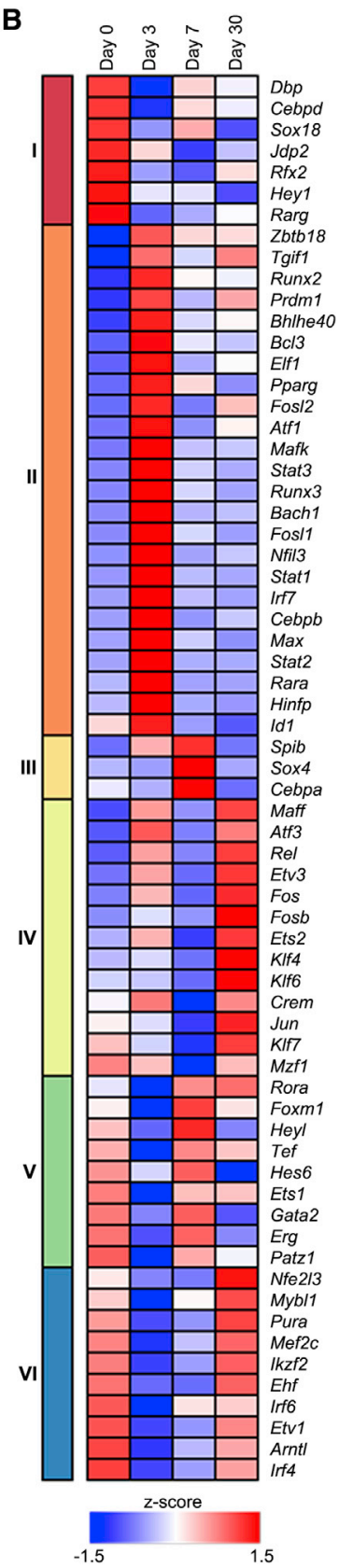

Figure 3. Sequence-Based Motif Enrichment Analysis of Genes in Each Cluster Identified DE TFs with Heterogeneous Expression Profiles

(A) Motifs enriched in the promoter region of clustered genes (Figure 1C). For each cluster, the motifs are shown with the highest normalized enrichment score up to a maximum of 3 . The selected motifs are linked to their corresponding TF. Only TFs that changed across conditions were considered.

(B) Expression z scores of each DE TF linked to the enriched motifs. Profiles were grouped according to cluster.

(C) GOCluster of DE nuclear receptors clustered by family. The inner ring represents the $z$-score profile (see legend).

(Glass and Saijo, 2010), consistent with the pro-inflammatory function of these M $\varphi$ s (Figure 3C).

Following the workflow depicted in Figure S6A, a PKN (Rodriguez et al., 2015) was built based on the 251 DEGs included in the top ten most enriched pathways (Figure S6B; Experimental Procedures). IL-6 and type II IFN signaling pathways were enriched 3 days post-injury. Focal adhesion PI3K-Akt-mTOR and TGF- $\beta$ signaling pathways were enriched at 7 and 30 days postinjury, respectively. The PKN was further extended with experimentally validated interactions and the subnetworks with significant temporal changes in expression were identified (Ideker et al., 2002).

Network structure analysis of the most significant subnetwork revealed a strongly connected component (SCC) (Albert, 2007) consisting of 21 genes (Figure 4A). Within the SCC, each gene is connected to every other through a directed path, and changes in the state of one gene can thus affect the other genes in the SCC (Albert, 2007). We therefore analyzed the core network stability. A Boolean dynamical model with an asynchronous updating scheme was used to compute network stable states (Garg et al., 2009). Despite training the network with a time series of four time points, computation of SCC stability revealed only three stable states. This result is consistent with the finding of only three time point-specific clusters and the high similarity of the global transcriptional profiles on days 0 and 30 post-injury (Figure 1C). We identified one stable state with all nodes "off," indicating a non-activated or deactivated state that may be associated with CRMs and $M \varphi s$ isolated on post-injury day 30 (Figure S6C). Another stable state was found for the onset of Prdm1, Bc/6, Stat3, and Eomes (Figure S6C). $\operatorname{Prdm} 1$ is a known transcriptional repressor that in mouse $\mathrm{M} \varphi \mathrm{s}$ 
A
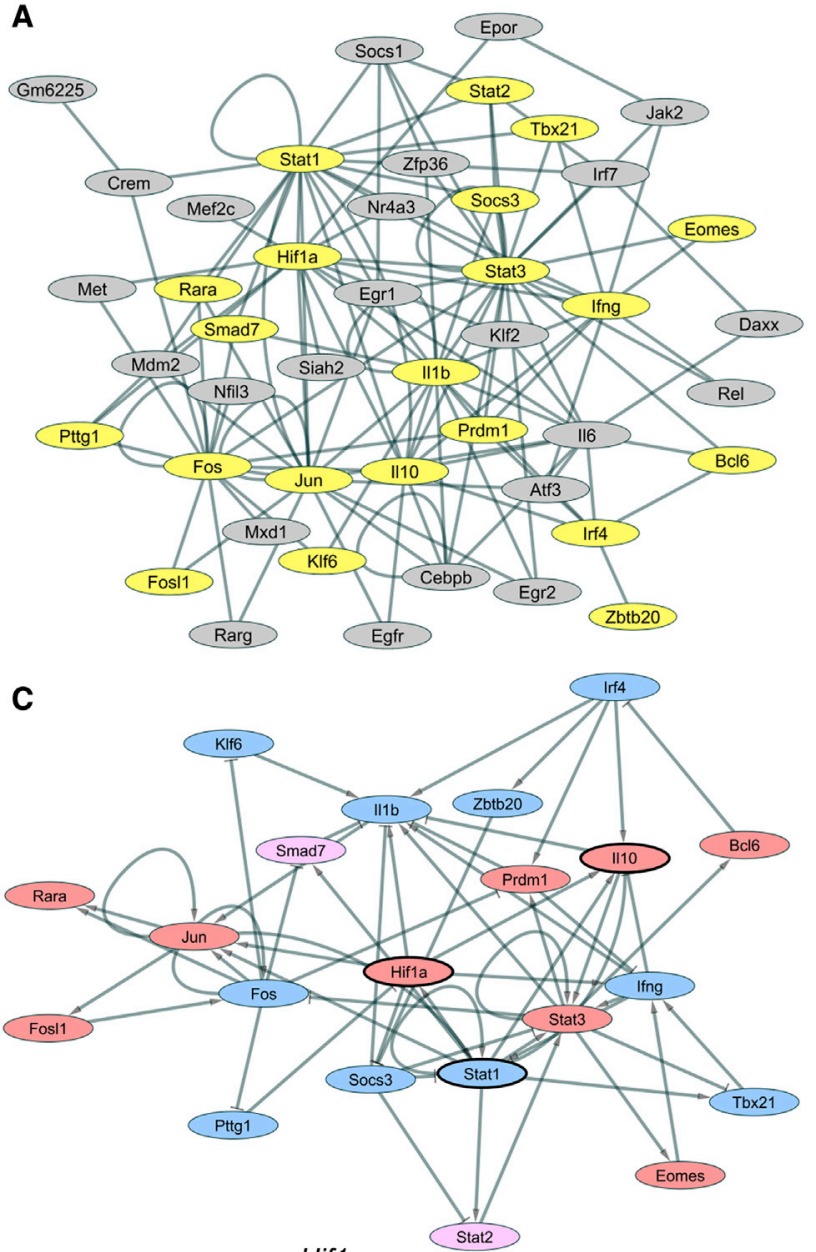

E
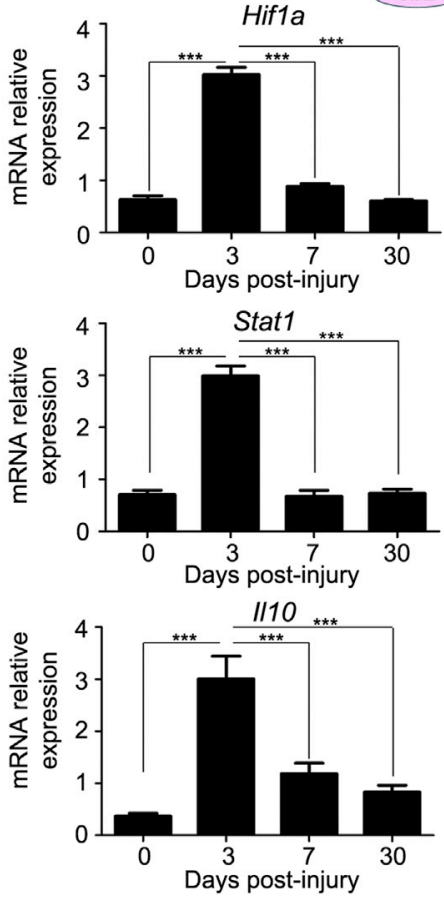

B
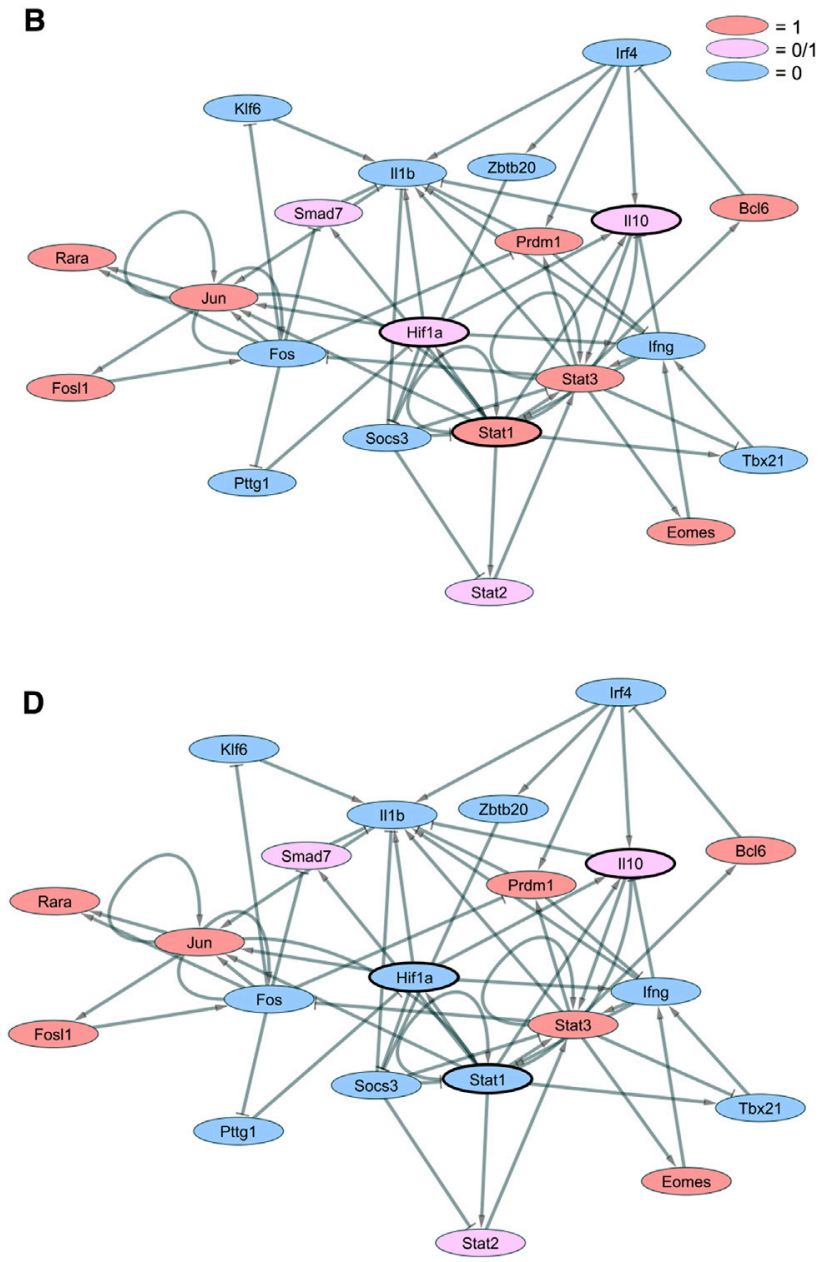

$\mathbf{F}$

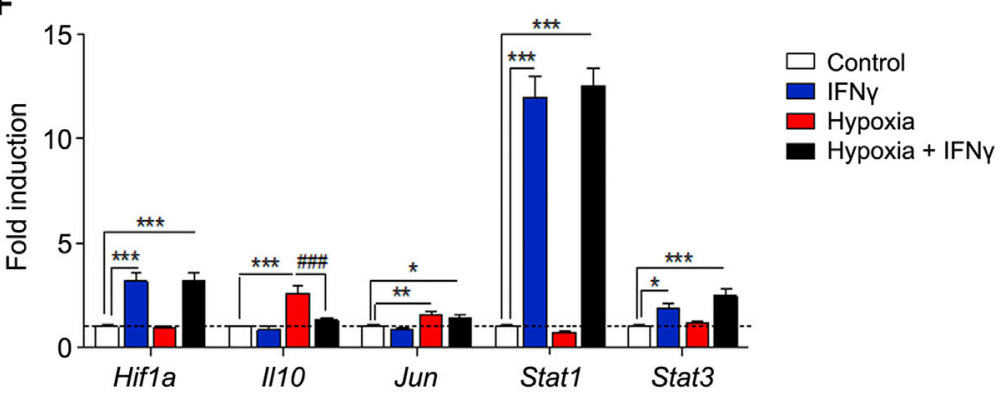


becomes activated in response to cellular stress (Tooze et al., 2006). Bc/6 negatively regulates $M \varphi$ proliferation by inhibiting II6 autocrine signaling (Yu et al., 2005), and Eomes has been associated with cell differentiation (Pearce et al., 2003). The transcription of all three genes is regulated by Stat3, which can trigger a pro-inflammatory or anti-inflammatory program depending on the strength and duration of its activation (Braun et al., 2013). The onset of these factors indicates a more repressive, anti-inflammatory state and may be associated with $\mathrm{M} \varphi s$ on post-injury day 7 . The third stable state was mainly characterized by oscillation in the activation of Hif1a, Stat1, and I/10 (Figures 4B-4D). Whereas Hif1a and Stat1 are associated with a pro-inflammatory program (Sica et al., 2015; Takeda et al., 2010), //10 is a powerful anti-inflammatory mediator that plays a fundamental role in the transition from the inflammatory to the resolution phase of the immune response (Lambert et al., 2008). The upregulated genes suggest an activation of both the pro-inflammatory and the anti-inflammatory programs, linking this stable state to $M \varphi s$ isolated on day 3 post-injury, a conclusion supported by qPCR expression profiles (Figure 4E).

The oscillatory pattern of this stable state suggests that the regulation of $/ / 10$ is tightly intertwined with the expression of Hif1a and Stat1, whereas a positive regulatory effect of Hif1a on I/10 expression seems to be diminished by the presence of Stat1, as indicated by the changes in the node states (Figures 4B-4D). Hif1a is the main mediator of the hypoxic response, and hypoxic conditions can positively alter //10 expression (Cai et al., 2013), whereas IFN- $\gamma$ has a negative effect on //10 expression through suppression of CREB and AP-1 activity (Hu et al., 2006). Based on this result, we hypothesized that hypoxia, but not IFN- $\gamma$, leads to the induction of $/ / 10$.

To test this hypothesis in vitro, we conducted qPCR to assess the expression of a panel of cycle attractor genes (Figures $4 \mathrm{~F}$, S6D, and S6E). In agreement with a previous report (Takeda et al., 2010), we observed strong upregulation of Hif1a by IFN- $\gamma$ and combined treatment with IFN- $\gamma$ and hypoxia, whereas hypoxic conditions alone did not upregulate Hif1a mRNA (Figure 4F). However, Hif1a expression is regulated at the post-mRNA level (Kaelin and Ratcliffe, 2008), and upregulation of Hif1a target genes confirmed its activation by hypoxia (Figure S6D). We also detected increased $/ / 10$ expression in hypoxic conditions but not in response to IFN- $\gamma$ or combined treatment with IFN- $\gamma$ and hypoxia, confirming our hypothesis. Combined treatment with IFN- $\gamma$ and hypoxia also induced the expression of $c$-Jun, whereas expression of Stat1 and Stat3 was exclusively altered by IFN- $\gamma$ and did not change in hypoxic conditions (Figure 4F).

\section{The Cardiac $\mathbf{M} \varphi$ miRnome in the Healthy and Injured} Heart

Following the workflow shown in Figure S7A, we studied the miRnome of cardiac M $\varphi s$ in the healthy heart and after injury. PCA of the global transcriptional profiles revealed well-separated miRNA expression signatures at the different post-injury stages (Figure S7B). Comparison of each post-injury stage with the control sample and all other stages identified 255 nonredundant miRNAs DE in at least one comparison (Figure S7C; Table S4). Hierarchical clustering (HC) of the DE miRNAs revealed heterogeneous expression profiles, indicating activity of the same miRNA during different phases of cardiac repair (Figure S7D).

Next, we constructed a global miRNA-mRNA interaction network of all DEGs and associated DE miRNAs (Figure $5 \mathrm{~A}$, Table S5; Supplemental Experimental Procedures) and identified three main subnetworks (S1, S2, S3; Table S5). Posttranscriptional regulation of genes in subnetwork $S 1$ is controlled by miRNAs (e.g., mmu-miR-328, mmu-miR-125a, and mmumiR-99b; Figure S7E; Table S5) that downregulated genes in CRMs and in M $\varphi s$ at 7 and 30 days post-injury. $\$ 1$ genes were associated with the inflammatory response and chemokine production (Figure 5B), suggesting miRNA regulation of inflammatory processes and resolution of inflammation at day 7, further supported by the downregulation of inflammatory-related genes in cluster IV (Figures 1C and 1D; Table S2) at day 7, and restoration of homeostasis at 30 days post-injury. The second subnetwork (S2; Table S5) is controlled by miRNAs upregulated at day 3 and downregulated in CRMs. Expression of these miRNAs at day 3 (e.g., mmu-miR-504 and mmu-miR-181d; Figure S7E; Table S5) downregulates cell-cycle genes (Figure 5B). In addition, the downregulation of miRNAs involved in heart development in the healthy heart (e.g., mmu-miR-1a, mmu-miR-126a, and mmumiR-342-5p; Figure S7E; Table S5) allows the upregulation of genes related to this process and to cardiac muscle contraction in CRMs (Figure 5B). The third subnetwork (S3) was controlled by miRNAs downregulated at day 7 and upregulated in CRMs (e.g., mmu-miR-484 and mmu-miR-345; Figure S7E; Table S5). Consistently with the functional analysis of genes in cluster III (Figure 1D), these miRNAs control genes predominantly related to ECM and collagen fibril organization (Figure 5B).

To further define the role of miRNAs in $\mathrm{M} \varphi$ polarization, we focused on the comparison between 7 and 3 days post-injury (Table S4). miRNAs upregulated at day 3 (e.g., mmu-miR-301a, mmu-miR-425, and mmu-miR-155) supported the inflammatory response by potentially suppressing processes linked to cell surface receptor signaling pathway, tissue development,

Figure 4. Simulated Dynamics of Gene-Regulatory Network Reveals a Negative-Feedback Loop That Limits Initial Inflammation via HypoxiaMediated Upregulation of II10

(A) Most significant active subnetwork. Nodes of the SCC of the module are highlighted in yellow.

(B-D) State 1 (B), 2 (C), and 3 (D) of the cycle attractor of the SCC network. Blue nodes are switched off, red nodes are on, and pink nodes oscillate between on/off states.

(E) mRNA expression levels of Hif1a, Stat1, and I/10 were analyzed by qPCR in cardiac M $\varphi$ s isolated at the indicated post-injury stages. Data are shown as mean \pm SEM of three independent experiments; ${ }^{* \star *} \mathrm{p}<0.001$ (one-way ANOVA followed by Tukey test).

(F) mRNA expression of selected genes from the cycle attractor were tested by qPCR in in vitro peritoneal M $\varphi s$ cultured for 24 hr in normoxia or hypoxia with or without IFN- $\gamma$ treatment. Results are expressed as fold induction compared with control (normoxia). Data are mean \pm SEM of three independent experiments; ${ }^{*} \mathrm{p}<0.05,{ }^{* \star} \mathrm{p}<0.01,{ }^{\star \star \star} \mathrm{p}<0.001$ versus control; ${ }^{\# \# \#} \mathrm{p}<0.001$ for hypoxia versus hypoxia plus IFN- $\gamma$ (one-way ANOVA followed by Tukey test).

See also Figure $\mathrm{S} 6$. 

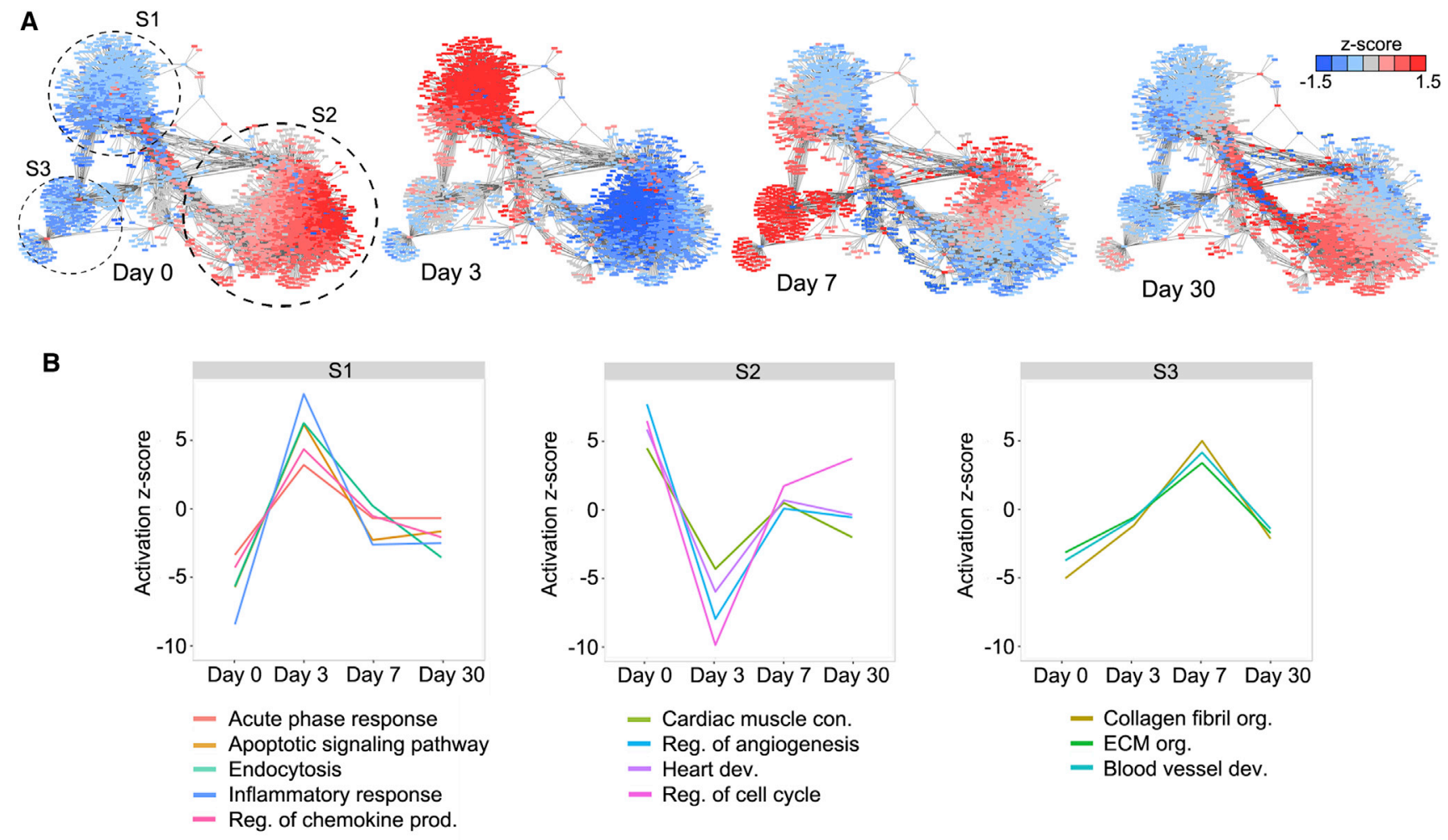

C
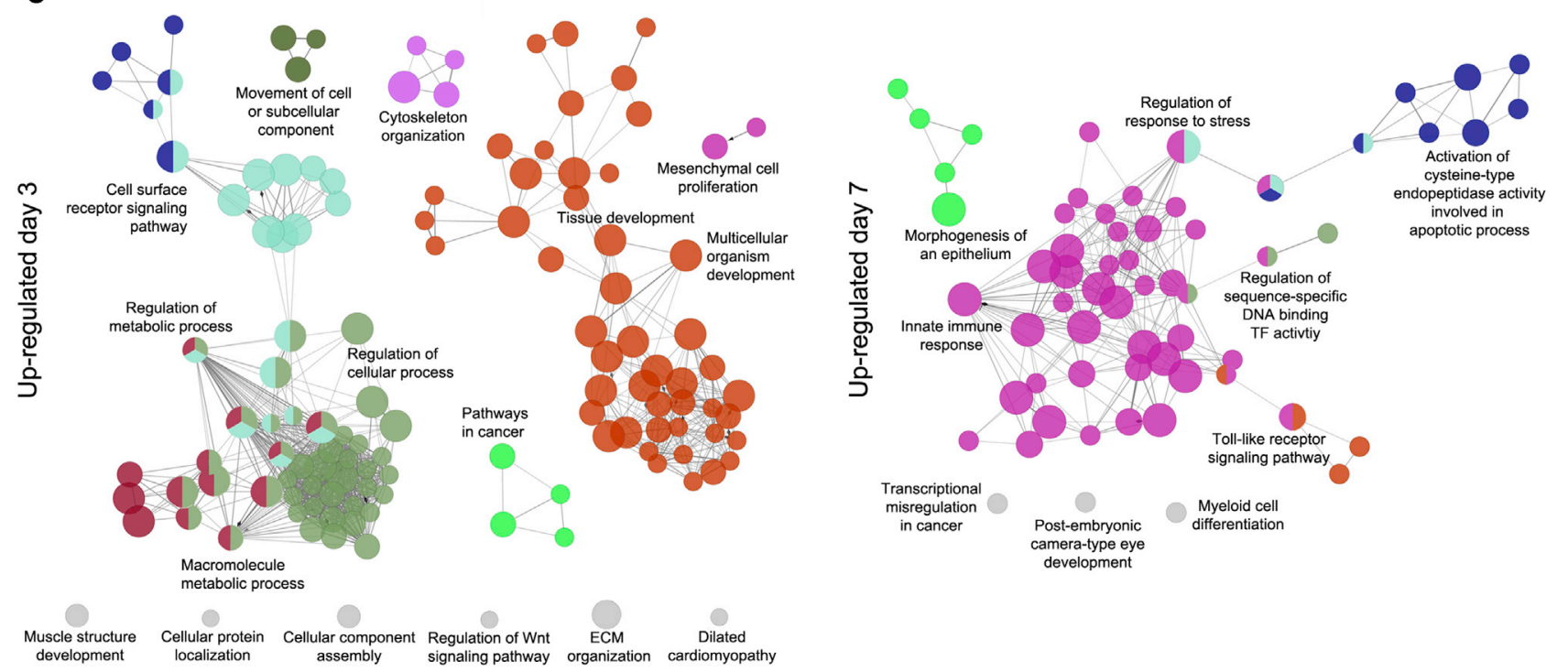

Figure 5. Analysis of the Cardiac $\mathrm{M} \varphi$ miRnome in Healthy and Injured Hearts

(A) Global mRNA-miRNA interaction network. S1, S2, and S3 denote the three network clusters.

(B) Enriched biological processes associated with genes in the identified subnetworks.

(C) ClueGO network connecting the most significant functional terms (biological process or KEGG pathway) for the targets of those miRNAs significantly upregulated on day 3 (left) and on day 7 (right) post-injury. Colors represent different groups. For each group the most significant term is displayed. Con, contraction; dev, development; org, organization; prod, production; reg, regulation.

See also Figure S7 and Tables S4 and S5. 


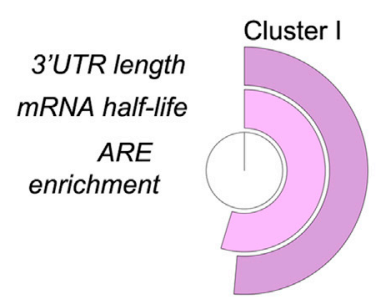

Myofibril assembly Immune response

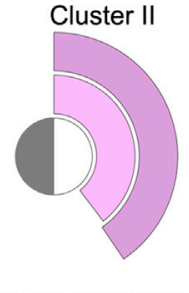

Figure 6. Analysis of mRNA Stability of Cardiac M $\varphi s$
Outer circle corresponds to median mRNA $3^{\prime}-$ UTR length. Midde

circle displays median mRNA half-life. Both values were normalized. Inner circle represents enrichment.

metabolism, and mesenchymal cell proliferation (Figure 5C). At 7 days post-injury, upregulated miRNAs (e.g., mmu-miR-125a, mmu-miR-146a, and mmu-miR-34a) might have contributed to resolution of inflammation by downregulating immune responserelated genes (Figures $1 \mathrm{C}$ and 1D), facilitating the critical transition to an anti-inflammatory phenotype (Figure 5C). In addition, we found miRNAs potentially mediating silencing of apoptotic signaling pathways at day 7 (e.g., mmu-miR-133a, mmu-miR-146a, and mmu-miR-99a), consistent with the upregulation of cell proliferation genes at this stage (Figure 1D).

\section{Specific Destabilization of Inflammatory mRNAs by the Activity of RNA-Binding Proteins}

Other important players in post-transcriptional regulation are RNA-binding proteins (RBPs). To determine the possible regulatory effects of RBPs and miRNAs, we calculated the median length of $3^{\prime}$-UTRs per cluster (Figure 6). Median $3^{\prime}$-UTR length was highest for genes downregulated on days 3 (cluster VI) and 7 (cluster IV).

One upregulated RBP at 3 days post-injury was tristetraprolin (TTP) (symbol = Zfp36) (Figure 1C), which has been reported to destabilize a third of inflammation-induced unstable mRNAs in M $\varphi$ s in vitro (Kratochvill et al., 2011). TTP binds to an AU-rich element (ARE) in the $3^{\prime}$-UTR of its target mRNAs. Testing of the k-means clusters for enrichment of AU-pentamers ("AUUUA") and AU-heptamers ("UAUUUAU") revealed significant upregulation of ARE-rich genes at 3 days post-injury (Figure 6), which, in combination with TTP upregulation (Figure 1C), indicates increased likelihood of TTP-directed regulation. We also found an enrichment of ARE-rich genes among the genes upregulated in the healthy heart and at 30 days post-injury (Figure 6). These genes were enriched for cell-cycle-related processes (Figure 1D), which is in line with the finding that many cell-cycle regulators are encoded by ARE-containing mRNAs (Barreau et al., 2006).

We next used mRNA degradation rates (Sharova et al., 2009) to calculate the median mRNA half-life of co-expressed genes. For all clusters, the median mRNA half-life anti-correlated with the median $3^{\prime}$-UTR length per cluster (spearman correlation coefficient $=-0.82$ ), indicating increased post-transcriptional regulation. In accordance with the results from the AU-motif enrichment analysis, the mRNAs in clusters II and VI had a half-life below the reported overall median of $7.1 \mathrm{hr}$. Genes downregulated 7 days post-injury (cluster IV) were not enriched for AU elements but had the shortest median mRNA half-life among all clusters $(4.7 \mathrm{hr})$. This cluster was enriched for regulation of transcription (Table S2), which have been linked to unstable mRNAs (Sharova et al., 2009). Consistent with their shorter $3^{\prime}$-UTRs and lack of ARE enrichment (Figure 6), mRNAs from cluster III (day 7 post-injury) had a long median half-life (9.6 hr). This cluster was enriched for ECM organization and collagen fibril organization (Figures 1D and 6), structural processes associated with stable mRNAs.

\section{Long Non-coding RNA Expression in Cardiac M $\mathrm{\varphi s}$}

Ensembl biotype information was used to classify DEGs as lincRNAs (Figure 7A; Table S6). lincRNAs and mRNA 3'-UTRs showed highly similar structural features (Figure 7B), but lincRNAs tended to have lower expression than mRNAs (Figure S7F).

We found that cluster IV had the highest relative abundance of lincRNAs (15.5\%), including Malat1 (Figures 7A and 7C), a lincRNA known to be induced by hypoxia and to play an important role in cardiovascular disease (CVD) (Skroblin and Mayr, 2014). In particular, Malat1 has been reported to be increased in blood samples of $\mathrm{Ml}$ patients versus healthy volunteers (Vausort et al., 2014). Within the same cluster, we found Mir17hg (Figure 7C), which encodes the miRNA 17-92 cluster. These miRNAs are associated with cell cycle and cell proliferation (Mogilyansky and Rigoutsos, 2013), indicating a potential role of Mir17hg in the regulation of $\mathrm{M} \varphi$ proliferation. We found upregulation of Neat1 at 3 days post-injury (cluster II, Figure 7C), which has been associated with the innate immune response (Imamura et al., 2014). This result agrees with the functional enrichment analysis of protein-coding genes linked to lincRNAs, showing that differential expression between days 0 and 3 was associated with processes related to antigen and leukocyte activation (Figure 7D). Pvt1, which has been proposed to function as a competing endogenous RNA (ceRNA) for MYC protein, preventing its degradation (Colombo et al., 2015), showed elevated expression in CRMs and at 30 days post-injury (Table S6).

Identification of all possible mRNA-lincRNA-miRNA triangles (Supplemental Experimental Procedures) revealed four different types of interaction (Figure 7E). The most abundant was characterized by positively correlated expression of all RNAs, among which we identified several triangles involving Neat1 and Pvt1 
A

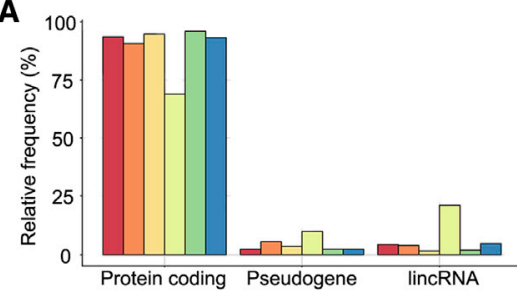

C
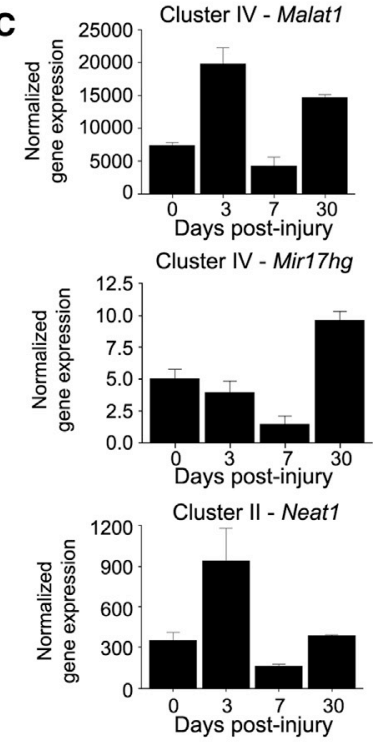

E

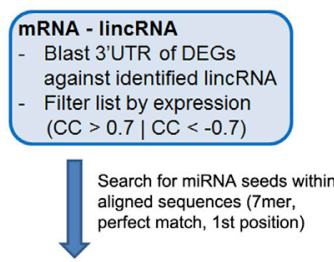

mRNA - lincRNA - miRNA - Filter list by expression $(\mathrm{CC}>0.7 \mid \mathrm{CC}<-0.7)$

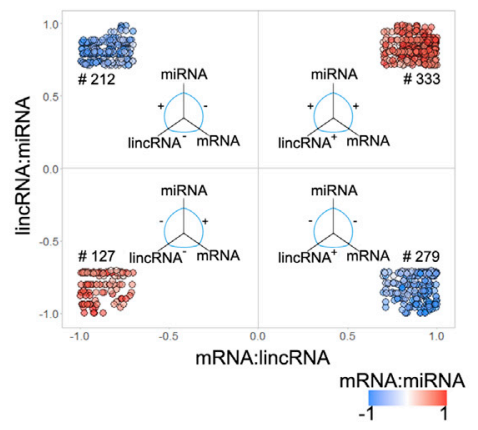

B
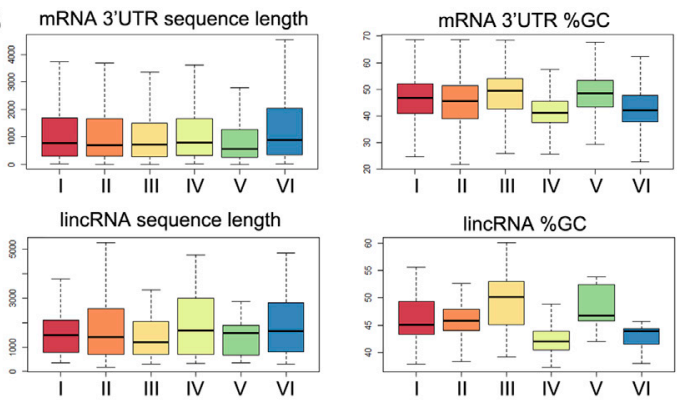

lincRNA \%GC

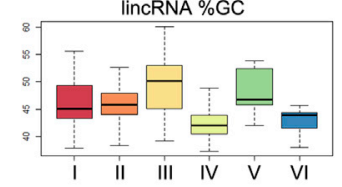

D

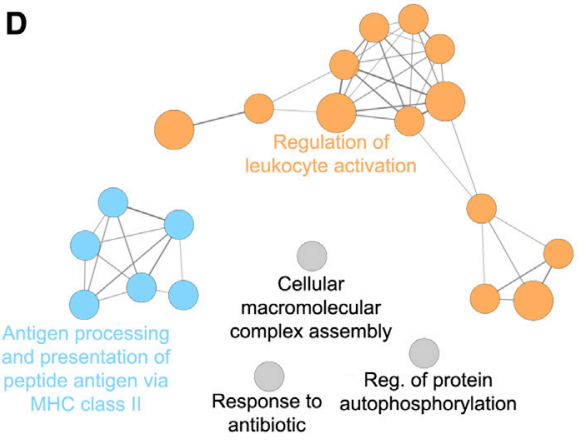

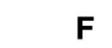

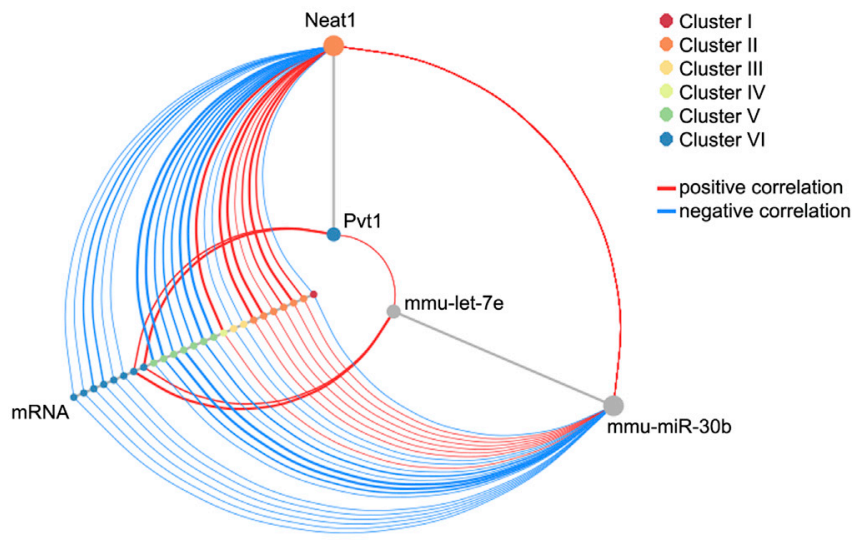

Figure 7. Analysis of lincRNAs in Cardiac $M \varphi s$

(A) Relative frequency of transcript biotypes per cluster.

(B) Structural similarities between mRNA $3^{\prime}$-UTR and lincRNA sequences.

(C) Normalized expression levels of selected lincRNAs measured by RNA-seq.

(D) ClueGO network connecting the most significant functional terms (biological process and KEGG pathway) for nearest genes of DE lincRNAs on day 3 versus day 0.

(E) Correlation of mRNA, lincRNA, and miRNA expression.

(F) Hive plot presentation of mRNA-lincRNA-miRNA triangle for the lincRNAs Neat1 and Pvt1. Nodes representing lincRNAs and mRNAs are colored according to clusters. Red lines indicate positive correlation; blue lines indicate negative correlation.

See also Figure S7 and Table S6. 
(Figure 7F). The identified mRNA-lincRNA-miRNA triangles including Neat1 were linked through miR-30b, a miRNA associated with immune suppression (Gaziel-Sovran et al., 2011). The positive correlation between Neat1, miR-30b, and other immune response-related mRNAs may indicate that Neat1 indirectly supports pro-inflammatory reactions as an additional binding partner for miR-30b, impairing the repressive effect of the miRNA.

\section{DISCUSSION}

In recent years, notable advances have been made in elucidating the origin of TRMs and their organ-specific gene and epigenetic signatures under steady-state conditions (Epelman et al., 2014; Fujiu et al., 2017; Ginhoux and Guilliams, 2016; Gosselin et al., 2014). However, $M \varphi$ activation after tissue injury in vivo remains poorly understood, mainly due to the lack of omics experiments with enough replication to achieve consistent conclusions (Yan et al., 2017). To address this issue, we have generated a global transcriptional dataset of mouse cardiac $M \varphi s$ that captures the transcriptional changes (mRNA, miRNA, and lincRNA) of M $\varphi s$ in the healthy heart and at various post-injury stages, providing an important resource for improving understanding of how $\mathrm{M} \varphi \mathrm{s}$ integrate, process, and respond to signals from their local environment.

We first characterized the unique gene signature of CRMs. A previous comparison of $\mathrm{M} \varphi$ transcriptional profiles in heart, spleen, and brain identified a set of 35 heart-specific $M \varphi$ genes (Pinto et al., 2012). However, our integrated analysis of mouse TRMs shows that although several genes of this signature are indeed specifically expressed in the heart, around $20 \%$ are expressed in both heart and intestine. The similar transcriptional profiles of mouse CRMs and intestinal $M \varphi s$ possibly reflects a contribution to these populations from monocyte influx (Ginhoux and Guilliams, 2016). Cardiac-specific genes identified in our analysis include Egfr, Lifr, Osmr, and I/1rl1, which encode receptors involved in $\mathrm{M} \varphi$ proliferation (Lamb et al., 2004), migration and chemotaxis (Sugiura et al., 2000), angiogenesis (Zhang et al., 2015), and the suppression of immune activity (Sweet et al., 2001). Remarkably, CRMs also showed specific expression of typical cardiomyocyte markers (Myh6 and Tnnt2). Interestingly, Myh6 expression has been reported in cardiac monocytes (Meyer et al., 2017). This finding could be a result of the environment instruction, as described for the microglia (Gosselin et al., 2017), but could also reflect the phagocytosis of dead cardiomyocytes by CRMs (Wan et al., 2013) to maintain cardiac homeostasis.

In line with previous reports (Hilgendorf et al., 2014; Nahrendorf et al., 2007), we identified distinct post-injury $M \varphi$ populations. The high plasticity of $M \varphi s$ makes it difficult to identify population-specific surface markers, an essential requirement for targeted therapy. In line with Pinto et al. (2012), we found that CRMs highly express the hyaluronan receptor LYVE-1, suggesting a possible role in blood vessel development in the healthy heart (Cho et al., 2007). Since hyaluronan plays an important role in tissue integrity and cardiac-valve formation (Rodgers et al., 2006), LYVE-1 expression might indicate involvement of CRMs in these processes. We also found that CRMs express CD36, a scavenger receptor that mediates apoptotic cell intake to preserve cardiac homeostasis (Driscoll et al., 2013). M $\varphi$ s at 3 days post-injury were characterized by CD40 and CD274 expression, indicating further amplification of the inflammatory response by $T$ cell activation via CD40:CD154 interactions (Suttles and Stout, 2009) and subsequent modulation of T cell responses (Sharpe et al., 2007). MRC1 was highly expressed in CRMs in the healthy heart and was then downregulated during the inflammatory phase, recovering its expression from 7 days post-injury. By 30 days post-injury, its expression returned to the level in CRMs, suggesting MRC1 as a possible marker of homeostasis restoration in post-injury $\mathrm{M} \varphi \mathrm{s}$.

Our RNA-seq analysis reveals massive changes in the cardiac $\mathrm{M} \varphi$ transcriptome at 3 days post-injury, likely due to the large influx of monocyte-derived Ly $6 \mathrm{C}^{\text {high }} / \mathrm{CX} 3 \mathrm{CR} 1^{\text {low }} \mathrm{M} \varphi \mathrm{s}$ (Heidt et al., 2014; Hilgendorf et al., 2014). These changes were associated with an immune response primarily triggered by IFN- $\gamma$ and STAT1 signaling. However, Ifn $\gamma$ was not upregulated in post-injury $\mathrm{M} \varphi \mathrm{s}$, suggesting its production by other cell types such as T cells and natural killer (NK) cells (Knorr et al., 2014). Our data further suggest that $\mathrm{M} \varphi \mathrm{s}$ sustain their activation at this post-injury stage by secreting pro-inflammatory cytokines, with the potential for autocrine signaling. During the reparative phase, $\mathrm{M} \varphi \mathrm{s}$ were characterized by an extensive secretome mainly composed of angiogenic and ECM-related components, indicating the pivotal role of $\mathrm{M} \varphi s$ in angiogenesis and tissue remodeling (Lambert et al., 2008). The high similarity in gene expression between CRMs and 30-day post-injury M $\varphi$ s indicates progressive deactivation after the inflammatory phase and a restoration of homeostasis. However, functional analysis revealed a lack of heart development reactivation at 30 days post-injury, possibly reflecting the prolonged miRNA-mediated suppression of involved genes. Our data provide the basis for future studies aimed at defining the differences between naive resident $\mathrm{M} \varphi \mathrm{s}$ and the long-lived monocyte-derived cells that replace them after tissue injury.

In vitro studies of $\mathrm{M} \varphi$ plasticity have produced an oversimplified binary M1/M2 classification (Sica et al., 2015) that has limited ability to explain the plethora of phenotypes observed in vivo (Novak et al., 2014; Varga et al., 2016). Partial deconvolution revealed that $\mathrm{M} \varphi s$ involved in cardiac repair are hybrids of the phenotypes described in vitro, characterized by mixed expression of M1/M2 polarization programs. This finding is consistent with the idea that activated $M \varphi s$ occur as a continuum rather than as discrete entities (Novak et al., 2014; Varga et al., 2016). This could reflect heterogeneity within the population or co-expression of M1/M2 markers by the same cell. Further studies at single-cell level would be required to address this issue. Our analysis further indicates that post-injury $\mathrm{M} \varphi \mathrm{s}$ dynamically shift their phenotype to orchestrate cardiac repair. A detailed understanding of this phenotypic transition is essential for developing timed interventions to improve cardiac healing (Harel-Adar et al., 2011).

$\mathrm{M} \varphi$ deactivation after sterile tissue injury is orchestrated by extrinsic and intrinsic control mechanisms, with IL-10 being the dominant mediator of the anti-inflammatory program in $\mathrm{M} \varphi \mathrm{s}$ (Lambert et al., 2008). We detected elevated I/10 expression as early as 3 days post-injury, in line with previous findings in injured muscle (Novak et al., 2014). Network modeling of the regulatory 
core of post-injury $\mathrm{M} \varphi \mathrm{s}$ revealed a cycle attractor mainly characterized by oscillations in Hif1a, Stat1, and $I / 10$ activation. Validation in vitro showed that $/ / 10$ is upregulated under hypoxic conditions, indicating either hypoxia-mediated $/ / 10$ induction (Cai et al., 2013) or stabilization of I/10 mRNA (Powell et al., 2000). This upregulation is most likely followed by IL-10mediated auto-regulation (Sarkar et al., 2008). Our data support the idea that the transition from the pro-inflammatory to the anti-inflammatory phenotype in vivo is conditioned not only by the tissue microenvironment, but also by cell-intrinsic factors.

We also detected post-transcriptional regulation of $\mathrm{M} \varphi$ deactivation. Our in silico mRNA stability analysis supports the finding that inflammation-induced mRNAs are less stable (Kratochvill et al., 2011) due to their longer $3^{\prime}$-UTRs enriched in AREs, the binding element for TTP. Moreover, we found that miRNAs potentially control immune response-related genes and that, while TTP-driven mRNA decay occurs in response to induced inflammation, the suppression of inflammation in the healthy heart may also involve a contribution from miRNA activity. We also found that miRNAs potentially downregulate cell proliferation during the inflammatory phase, whereas with the resolution of inflammation $\mathrm{M} \varphi$ s regain the ability to proliferate (Varga et al., 2016). Together, the enrichment in inflammatory-related mRNAs with longer and ARE-enriched $3^{\prime}$-UTR regions, the increase in lincRNAs, and the lack of TFs specific to cluster IV suggest post-transcriptional regulation of these genes.

In recent years, multiple lincRNAs have been linked to the immune response and CVD (Skroblin and Mayr, 2014), but it remains unclear how these molecules act within cells. Based on the ceRNA hypothesis (Salmena et al., 2011), we identified several mRNA-lincRNA-miRNA motifs. One of these motifs may indicate that Neat 1 indirectly supports pro-inflammatory reactions as an additional binding partner for the immunesuppressive miRNA miR-30b, which is induced by a hypoxic environment (Choudhry and Mole, 2016). Targeted deletion studies will be needed to assess the specific functions of altered lincRNAs involved in $\mathrm{M} \varphi$ activation.

In summary, our study provides insight into $\mathrm{M} \varphi$ signal processing and transcriptional regulation in the healthy heart and at different stages post-injury. We anticipate that this dataset will serve as a resource for elucidating the role of CRMs and as a starting point for $\mathrm{M} \varphi$-based therapies to improve cardiac repair. Moreover, this dataset also has potential to identify novel targets for miRNA-based therapy and to elucidate the function and regulatory impact of activated lincRNAs.

\section{EXPERIMENTAL PROCEDURES}

Detailed description of experimental procedures and bioinformatics analysis are provided in Supplemental Experimental Procedures.

Mice and Myocardial Injury Model

Two- to 3-month-old male and female $\mathrm{CX}_{3} \mathrm{CR}^{\mathrm{GFP} /+}$ (Jung et al., 2000) and C57BL/6 mice (Charles River) were used. All animal procedures were conducted in accordance with European Union (EU) Directive 2010/526/EC, enforced in Spanish law under Real Decreto 53/2013. Cryoinjury was induced as previously described (van Amerongen et al., 2008). Animals were sacrificed on days 3,7 , and 30 post-injury, and hearts were isolated. Animals not subjected to surgery were included as the physiological condition (day 0 ).

\section{Cell Sorting and RNA Isolation}

Single-cell suspensions were sorted with a BD FACSAria II cell sorter (BD Biosciences) using the gating strategy shown in Figures S2A, S2B, S5B and S5C. Total RNA was isolated using the miRNeasy Micro Kit (QIAGEN). RNA quality and quantity were measured using the 2100 Bioanalyzer (Agilent Technologies).

\section{RNA-Seq}

For RNA-seq, total RNA was reverse transcribed and amplified using the Ovation RNA-Seq System V2 (NuGEN). Amplified cDNA was sonicated to 100- to 300-bp fragments and used with the TruSeq DNA Sample Preparation, Version 2, Kit (Illumina) to generate index-tagged sequencing libraries. Libraries were analyzed in a 2100 Bioanalyzer (Agilent Technologies) and then sequenced in a Genome Analyzer IIx (Illumina) to generate single 75-bp reads.

\section{Microarrays}

Total RNA was labeled using the miRNA Microarray System with miRNA Complete Labeling and Hyb Kit (Agilent Technologies), and then hybridized to SurePrint G3 Mouse miRNA Microarray slides (release 19.0) containing 1,247 mouse mature miRNA probes (Agilent Technologies).

\section{Partial Deconvolution Analysis}

The R package CellMix (Gaujoux and Seoighe, 2013) was used for in silico gene expression deconvolution analysis. Partial deconvolution of gene expression from $\mathrm{M} \varphi \mathrm{s}$ isolated at various post-injury stages was performed using the in vivo control sample (CRMs) and in vitro derived M1 (BMDMs activated with LPS plus IFN- $\gamma$ ) and M2 (BMDMs activated with IL-4 plus IL-13) specific signature profiles downloaded from GSE53321 (Li et al., 2015). Data were normalized, log transformed, and adjusted for batch effects using the comBat function implemented in the R package sva (Leek et al., 2012).

\section{Transcriptional Networks}

Pathway analysis was performed with PathVisio (Kutmon et al., 2015). The mouse pathway collection from WikiPathways (Kelder et al., 2012) was used to perform an over-representation analysis with the transcriptomics dataset. The pathways were ranked based on a standardized difference score (z score). Pathways with a $z$ score $>2.0$, p value $<0.05$, and minimum of four measured genes were considered significant. Enriched pathways were imported as networks into cytoscape using the WikiPathways app and the top ten most significant pathways were subsequently merged into a PKN (Rodriguez et al., 2015). The PKN was further extended with protein-protein interactions (first neighbors) extracted from Ingenuity software (https://www.ingenuity.com/) between the genes in the pathways and DEGs. The jActiveModules cytoscape app (Ideker et al., 2002) was used to identify active modules within the molecular interaction network. For the highest scoring active module, SCCs were calculated using the BiNoM app (Zinovyev et al., 2008). In the mathematical theory of graphs, a graph is strongly connected if there is a path between all pairs of vertices. BoolSim software was used to identify attractors of the SCC network (Garg et al., 2009).

\section{DATA AND SOFTWARE AVAILABILITY}

The accession number for the raw and processed sequencing data reported in this study is GEO: GSE97147.

\section{SUPPLEMENTAL INFORMATION}

Supplemental Information includes Supplemental Experimental Procedures, seven figures, and six tables and can be found with this article online at https://doi.org/10.1016/j.celrep.2018.03.029.

\section{ACKNOWLEDGMENTS}

We thank S. Bartlett (CNIC) for editorial assistance and the CNIC Cellomics and Genomics Units for technical help. This work was supported by grants from the Spanish Ministry of Economy and Competitiveness (SAF201564287R and SAF2015-71878-REDT) to M.R., and Fundación Marató TV3 
(121931) and the European Commission FP7 (CardioNext-ITN-608027) to M.R. and A.G.A. L.A.-H. is funded by a fellowship from La Caixa-CNIC. The CNIC is supported by MEIC and the Pro CNIC Foundation, and is a Severo Ochoa Center of Excellence (MEIC award SEV-2015-0505).

\section{AUTHOR CONTRIBUTIONS}

L.A.-H., V.T., M.C., A.K., and V.N. performed experiments. L.A.-H., V.T., and M.C. analyzed experimental data. W.W. and F.S.-C. performed bioinformatics analysis. W.W. and I.C. performed network analysis. W.W. and M.I. performed lincRNA analysis. A.G.A. and I.X. provided critical suggestions. W.W., L.A.-H., F.S.-C., and M.R. wrote the manuscript. F.S.-C. designed the bioinformatics analysis strategy. M.R. conceived and designed the project and experiments.

\section{DECLARATION OF INTERESTS}

The authors declare no competing interests.

Received: November 15, 2017

Revised: February 5, 2018

Accepted: March 7, 2018

Published: April 10, 2018

\section{REFERENCES}

Albert, R. (2007). Network inference, analysis, and modeling in systems biology. Plant Cell 19, 3327-3338.

Barreau, C., Paillard, L., and Osborne, H.B. (2006). AU-rich elements and associated factors: are there unifying principles? Nucleic Acids Res. 33, 7138-7150. Braun, D.A., Fribourg, M., and Sealfon, S.C. (2013). Cytokine response is determined by duration of receptor and signal transducers and activators of transcription 3 (STAT3) activation. J. Biol. Chem. 288, 2986-2993.

Cai, Z., Luo, W., Zhan, H., and Semenza, G.L. (2013). Hypoxia-inducible factor 1 is required for remote ischemic preconditioning of the heart. Proc. Natl. Acad. Sci. USA 110, 17462-17467.

Cho, C.H., Koh, Y.J., Han, J., Sung, H.K., Jong Lee, H., Morisada, T., Schwendener, R.A., Brekken, R.A., Kang, G., Oike, Y., et al. (2007). Angiogenic role of LYVE-1-positive macrophages in adipose tissue. Circ. Res. 100, e47-e57.

Choudhry, H., and Mole, D.R. (2016). Hypoxic regulation of the noncoding genome and NEAT1. Brief. Funct. Genomics 15, 174-185.

Colombo, T., Farina, L., Macino, G., and Paci, P. (2015). PVT1: a rising star among oncogenic long noncoding RNAs. BioMed Res. Int. 2015, 304208.

Davies, L.C., Jenkins, S.J., Allen, J.E., and Taylor, P.R. (2013). Tissue-resident macrophages. Nat. Immunol. 14, 986-995.

Driscoll, W.S., Vaisar, T., Tang, J., Wilson, C.L., and Raines, E.W. (2013). Macrophage ADAM17 deficiency augments CD36-dependent apoptotic cell uptake and the linked anti-inflammatory phenotype. Circ. Res. 113, 52-61.

Epelman, S., Lavine, K.J., Beaudin, A.E., Sojka, D.K., Carrero, J.A., Calderon, B., Brija, T., Gautier, E.L., Ivanov, S., Satpathy, A.T., et al. (2014). Embryonic and adult-derived resident cardiac macrophages are maintained through distinct mechanisms at steady state and during inflammation. Immunity 40 , 91-104.

Fujiu, K., Shibata, M., Nakayama, Y., Ogata, F., Matsumoto, S., Noshita, K., Iwami, S., Nakae, S., Komuro, I., Nagai, R., and Manabe, I. (2017). A heartbrain-kidney network controls adaptation to cardiac stress through tissue macrophage activation. Nat. Med. 23, 611-622.

Garg, A., Mohanram, K., Di Cara, A., De Micheli, G., and Xenarios, I. (2009). Modeling stochasticity and robustness in gene regulatory networks. Bioinformatics 25, i101-i109.

Gaujoux, R., and Seoighe, C. (2013). CellMix: a comprehensive toolbox for gene expression deconvolution. Bioinformatics 29, 2211-2212.

Gautier, E.L., Shay, T., Miller, J., Greter, M., Jakubzick, C., Ivanov, S., Helft, J., Chow, A., Elpek, K.G., Gordonov, S., et al.; Immunological Genome
Consortium (2012). Gene-expression profiles and transcriptional regulatory pathways that underlie the identity and diversity of mouse tissue macrophages. Nat. Immunol. 13, 1118-1128.

Gaziel-Sovran, A., Segura, M.F., Di Micco, R., Collins, M.K., Hanniford, D., Vega-Saenz de Miera, E., Rakus, J.F., Dankert, J.F., Shang, S., Kerbel, R.S., et al. (2011). miR-30b/30d regulation of GalNAc transferases enhances invasion and immunosuppression during metastasis. Cancer Cell 20, 104-118.

Ginhoux, F., and Guilliams, M. (2016). Tissue-resident macrophage ontogeny and homeostasis. Immunity 44, 439-449.

Glass, C.K., and Saijo, K. (2010). Nuclear receptor transrepression pathways that regulate inflammation in macrophages and T cells. Nat. Rev. Immunol. 10, 365-376.

Gosselin, D., Link, V.M., Romanoski, C.E., Fonseca, G.J., Eichenfield, D.Z., Spann, N.J., Stender, J.D., Chun, H.B., Garner, H., Geissmann, F., and Glass, C.K. (2014). Environment drives selection and function of enhancers controlling tissue-specific macrophage identities. Cell 159, 1327-1340.

Gosselin, D., Skola, D., Coufal, N.G., Holtman, I.R., Schlachetzki, J.C.M., Sajti, E., Jaeger, B.N., O'Connor, C., Fitzpatrick, C., Pasillas, M.P., et al. (2017). An environment-dependent transcriptional network specifies human microglia identity. Science 356, eaal3222.

Harel-Adar, T., Ben Mordechai, T., Amsalem, Y., Feinberg, M.S., Leor, J., and Cohen, S. (2011). Modulation of cardiac macrophages by phosphatidylserinepresenting liposomes improves infarct repair. Proc. Natl. Acad. Sci. USA 108, 1827-1832.

Heidt, T., Courties, G., Dutta, P., Sager, H.B., Sebas, M., Iwamoto, Y., Sun, Y., Da Silva, N., Panizzi, P., van der Laan, A.M., et al. (2014). Differential contribution of monocytes to heart macrophages in steady-state and after myocardial infarction. Circ. Res. 115, 284-295.

Hilgendorf, I., Gerhardt, L.M., Tan, T.C., Winter, C., Holderried, T.A., Chousterman, B.G., Iwamoto, Y., Liao, R., Zirlik, A., Scherer-Crosbie, M., et al. (2014). Ly-6Chigh monocytes depend on Nr4a1 to balance both inflammatory and reparative phases in the infarcted myocardium. Circ. Res. 114, 1611-1622.

Hu, X., Paik, P.K., Chen, J., Yarilina, A., Kockeritz, L., Lu, T.T., Woodgett, J.R., and Ivashkiv, L.B. (2006). IFN- $\gamma$ suppresses IL-10 production and synergizes with TLR2 by regulating GSK3 and CREB/AP-1 proteins. Immunity 24, 563-574.

Hulsmans, M., Clauss, S., Xiao, L., Aguirre, A.D., King, K.R., Hanley, A., Hucker, W.J., Wülfers, E.M., Seemann, G., Courties, G., et al. (2017). Macrophages facilitate electrical conduction in the heart. Cell 169, 510-522.e20.

Ideker, T., Ozier, O., Schwikowski, B., and Siegel, A.F. (2002). Discovering regulatory and signalling circuits in molecular interaction networks. Bioinformatics 18 (Supp/ 1), S233-S240.

Imamura, K., Imamachi, N., Akizuki, G., Kumakura, M., Kawaguchi, A., Nagata, K., Kato, A., Kawaguchi, Y., Sato, H., Yoneda, M., et al. (2014). Long noncoding RNA NEAT1-dependent SFPQ relocation from promoter region to paraspeckle mediates IL8 expression upon immune stimuli. Mol. Cell 53, 393-406.

Jung, S., Aliberti, J., Graemmel, P., Sunshine, M.J., Kreutzberg, G.W., Sher, A., and Littman, D.R. (2000). Analysis of fractalkine receptor $\mathrm{CX}_{3} \mathrm{CR} 1$ function by targeted deletion and green fluorescent protein reporter gene insertion. Mol. Cell. Biol. 20, 4106-4114.

Kaelin, W.G., Jr., and Ratcliffe, P.J. (2008). Oxygen sensing by metazoans: the central role of the HIF hydroxylase pathway. Mol. Cell 30, 393-402.

Kelder, T., van lersel, M.P., Hanspers, K., Kutmon, M., Conklin, B.R., Evelo, C.T., and Pico, A.R. (2012). WikiPathways: building research communities on biological pathways. Nucleic Acids Res 40, D1301-D1307.

Knorr, M., Münzel, T., and Wenzel, P. (2014). Interplay of NK cells and monocytes in vascular inflammation and myocardial infarction. Front. Physiol. 5, 295.

Kratochvill, F., Machacek, C., Vogl, C., Ebner, F., Sedlyarov, V., Gruber, A.R., Hartweger, H., Vielnascher, R., Karaghiosoff, M., Rülicke, T., et al. (2011). Tristetraprolin-driven regulatory circuit controls quality and timing of mRNA decay in inflammation. Mol. Syst. Biol. 7, 560. 
Kutmon, M., van lersel, M.P., Bohler, A., Kelder, T., Nunes, N., Pico, A.R., and Evelo, C.T. (2015). PathVisio 3: an extendable pathway analysis toolbox. PLoS Comput. Biol 11, e1004085.

Lamb, D.J., Modjtahedi, H., Plant, N.J., and Ferns, G.A. (2004). EGF mediates monocyte chemotaxis and macrophage proliferation and EGF receptor is expressed in atherosclerotic plaques. Atherosclerosis 176, 21-26.

Lambert, J.M., Lopez, E.F., and Lindsey, M.L. (2008). Macrophage roles following myocardial infarction. Int. J. Cardiol. 130, 147-158.

Lavin, Y., Winter, D., Blecher-Gonen, R., David, E., Keren-Shaul, H., Merad, M., Jung, S., and Amit, I. (2014). Tissue-resident macrophage enhancer landscapes are shaped by the local microenvironment. Cell 159, 1312-1326.

Leek, J.T., Johnson, W.E., Parker, H.S., Jaffe, A.E., and Storey, J.D. (2012). The sva package for removing batch effects and other unwanted variation in high-throughput experiments. Bioinformatics 28, 882-883.

Li, L., Ng, D.S., Mah, W.C., Almeida, F.F., Rahmat, S.A., Rao, V.K., Leow, S.C., Laudisi, F., Peh, M.T., Goh, A.M., et al. (2015). A unique role for p53 in the regulation of M2 macrophage polarization. Cell Death Differ. 22, 1081-1093.

Meyer, I.S., Jungmann, A., Dieterich, C., Zhang, M., Lasitschka, F., Werkmeister, S., Haas, J., Müller, O.J., Boutros, M., Nahrendorf, M., et al. (2017). The cardiac microenvironment uses non-canonical WNT signaling to activate monocytes after myocardial infarction. EMBO Mol. Med. 9, 1279-1293.

Mogilyansky, E., and Rigoutsos, I. (2013). The miR-17/92 cluster: a comprehensive update on its genomics, genetics, functions and increasingly important and numerous roles in health and disease. Cell Death Differ. 20, 1603-1614.

Nahrendorf, M., Swirski, F.K., Aikawa, E., Stangenberg, L., Wurdinger, T., Figueiredo, J.L., Libby, P., Weissleder, R., and Pittet, M.J. (2007). The healing myocardium sequentially mobilizes two monocyte subsets with divergent and complementary functions. J. Exp. Med. 204, 3037-3047.

Novak, M.L., Weinheimer-Haus, E.M., and Koh, T.J. (2014). Macrophage activation and skeletal muscle healing following traumatic injury. J. Pathol. 232, 344-355.

Pearce, E.L., Mullen, A.C., Martins, G.A., Krawczyk, C.M., Hutchins, A.S., Zediak, V.P., Banica, M., DiCioccio, C.B., Gross, D.A., Mao, C.A., et al. (2003). Control of effector $\mathrm{CD}^{+} \mathrm{T}$ cell function by the transcription factor Eomesodermin. Science 302, 1041-1043.

Pinto, A.R., Paolicelli, R., Salimova, E., Gospocic, J., Slonimsky, E., BilbaoCortes, D., Godwin, J.W., and Rosenthal, N.A. (2012). An abundant tissue macrophage population in the adult murine heart with a distinct alternatively-activated macrophage profile. PLoS One 7, e36814.

Powell, M.J., Thompson, S.A., Tone, Y., Waldmann, H., and Tone, M. (2000). Posttranscriptional regulation of IL-10 gene expression through sequences in the $3^{\prime}$-untranslated region. J. Immunol. 165, 292-296.

Rhinn, M., and Dollé, P. (2012). Retinoic acid signalling during development. Development 139, 843-858.

Rodgers, L.S., Lalani, S., Hardy, K.M., Xiang, X., Broka, D., Antin, P.B., and Camenisch, T.D. (2006). Depolymerized hyaluronan induces vascular endothelial growth factor, a negative regulator of developmental epithelial-tomesenchymal transformation. Circ. Res. 99, 583-589.

Rodriguez, A., Crespo, I., Androsova, G., and del Sol, A. (2015). Discrete logic modelling optimization to contextualize prior knowledge networks using PRUNET. PLoS One 10, e0127216.

Rusinova, I., Forster, S., Yu, S., Kannan, A., Masse, M., Cumming, H., Chapman, R., and Hertzog, P.J. (2013). Interferome v2.0: an updated database of annotated interferon-regulated genes. Nucleic Acids Res. 41, D1040-D1046. Salmena, L., Poliseno, L., Tay, Y., Kats, L., and Pandolfi, P.P. (2011). A ceRNA hypothesis: the Rosetta Stone of a hidden RNA language? Cell 146, 353-358. Sarkar, S., Sinsimer, K.S., Foster, R.L., Brewer, G., and Pestka, S. (2008). AUF1 isoform-specific regulation of anti-inflammatory IL10 expression in monocytes. J. Interferon Cytokine Res. 28, 679-691.

Sharova, L.V., Sharov, A.A., Nedorezov, T., Piao, Y., Shaik, N., and Ko, M.S. (2009). Database for mRNA half-life of 19977 genes obtained by DNA micro- array analysis of pluripotent and differentiating mouse embryonic stem cells. DNA Res. 16, 45-58.

Sharpe, A.H., Wherry, E.J., Ahmed, R., and Freeman, G.J. (2007). The function of programmed cell death 1 and its ligands in regulating autoimmunity and infection. Nat. Immunol. 8, 239-245.

Shen-Orr, S.S., Tibshirani, R., Khatri, P., Bodian, D.L., Staedtler, F., Perry N.M., Hastie, T., Sarwal, M.M., Davis, M.M., and Butte, A.J. (2010). Cell type-specific gene expression differences in complex tissues. Nat. Methods 7, 287-289.

Sica, A., Erreni, M., Allavena, P., and Porta, C. (2015). Macrophage polarization in pathology. Cell. Mol. Life Sci. 72, 4111-4126.

Skroblin, P., and Mayr, M. (2014). "Going long": long non-coding RNAs as biomarkers. Circ. Res. 115, 607-609.

Sugiura, S., Lahav, R., Han, J., Kou, S.Y., Banner, L.R., de Pablo, F., and Patterson, P.H. (2000). Leukaemia inhibitory factor is required for normal inflammatory responses to injury in the peripheral and central nervous systems in vivo and is chemotactic for macrophages in vitro. Eur. J. Neurosci. 12, 457-466.

Suttles, J., and Stout, R.D. (2009). Macrophage CD40 signaling: a pivotal regulator of disease protection and pathogenesis. Semin. Immunol. 21, 257-264.

Sweet, M.J., Leung, B.P., Kang, D., Sogaard, M., Schulz, K., Trajkovic, V., Campbell, C.C., Xu, D., and Liew, F.Y. (2001). A novel pathway regulating lipopolysaccharide-induced shock by ST2/T1 via inhibition of Toll-like receptor 4 expression. J. Immunol. 166, 6633-6639.

Swirski, F.K., Nahrendorf, M., Etzrodt, M., Wildgruber, M., Cortez-Retamozo, V., Panizzi, P., Figueiredo, J.L., Kohler, R.H., Chudnovskiy, A., Waterman, P., et al. (2009). Identification of splenic reservoir monocytes and their deployment to inflammatory sites. Science 325, 612-616.

Takeda, N., O’Dea, E.L., Doedens, A., Kim, J.W., Weidemann, A., Stockmann, C., Asagiri, M., Simon, M.C., Hoffmann, A., and Johnson, R.S. (2010). Differential activation and antagonistic function of HIF- $\alpha$ isoforms in macrophages are essential for NO homeostasis. Genes Dev. 24, 491-501.

Tooze, R.M., Stephenson, S., and Doody, G.M. (2006). Repression of IFN- $\gamma$ induction of class II transactivator: a role for PRDM1/Blimp-1 in regulation of cytokine signaling. J. Immunol. 177, 4584-4593.

van Amerongen, M.J., Harmsen, M.C., Petersen, A.H., Popa, E.R., and van Luyn, M.J.A. (2008). Cryoinjury: a model of myocardial regeneration. Cardiovasc. Pathol. 17, 23-31.

Varga, T., Mounier, R., Horvath, A., Cuvellier, S., Dumont, F., Poliska, S. Ardjoune, H., Juban, G., Nagy, L., and Chazaud, B. (2016). Highly dynamic transcriptional signature of distinct macrophage subsets during sterile inflammation, resolution, and tissue repair. J. Immunol. 196, 4771-4782.

Vausort, M., Wagner, D.R., and Devaux, Y. (2014). Long noncoding RNAs in patients with acute myocardial infarction. Circ. Res. 115, 668-677.

Wan, E., Yeap, X.Y., Dehn, S., Terry, R., Novak, M., Zhang, S., Iwata, S., Han X., Homma, S., Drosatos, K., et al. (2013). Enhanced efferocytosis of apoptotic cardiomyocytes through myeloid-epithelial-reproductive tyrosine kinase links acute inflammation resolution to cardiac repair after infarction. Circ. Res. 113 1004-1012.

Yan, X., Zhang, H., Fan, Q., Hu, J., Tao, R., Chen, Q., Iwakura, Y., Shen, W., Lu, L., Zhang, Q., and Zhang, R. (2017). Dectin-2 deficiency modulates Th1 differentiation and improves wound healing after myocardial infarction. Circ. Res. $120,1116-1129$.

Yu, R.Y.-L., Wang, X., Pixley, F.J., Yu, J.J., Dent, A.L., Broxmeyer, H.E., Stanley, E.R., and Ye, B.H. (2005). BCL-6 negatively regulates macrophage proliferation by suppressing autocrine IL-6 production. Blood 105, 1777-1784.

Zhang, X., Zhu, D., Wei, L., Zhao, Z., Qi, X., Li, Z., and Sun, D. (2015). OSM enhances angiogenesis and improves cardiac function after myocardial infarction. BioMed Res. Int. 2015, 317905.

Zinovyev, A., Viara, E., Calzone, L., and Barillot, E. (2008). BiNoM: a Cytoscape plugin for manipulating and analyzing biological networks. Bioinformatics 24 , 876-877. 


\title{
MT4-MMP deficiency increases patrolling monocyte recruitment to early lesions and accelerates atherosclerosis
}

\author{
Cristina Clemente ${ }^{1}$, Cristina Rius ${ }^{2,3}$, Laura Alonso-Herranz ${ }^{4}$, Mara Martín-Alonso ${ }^{1}$, Ángela Pollán ${ }^{1}$, \\ Emilio Camafeita (10 5 ${ }^{5}$, Fernando Martínez (10 6 ${ }^{6}$, Rubén A. Mota1, Vanessa Núñez ${ }^{4}$, Cristina Rodríguez ${ }^{3,7}$, \\ Motoharu Seiki ${ }^{8}$, José Martínez-González ${ }^{3,9}$, Vicente Andrés ${ }^{2,3}$, Mercedes Ricote ${ }^{4}$ \& Alicia G. Arroyo (1) 1,10
}

Matrix metalloproteinases are involved in vascular remodeling. Little is known about their immune regulatory role in atherosclerosis. Here we show that mice deficient for MT4-MMP have increased adherence of macrophages to inflamed peritonea, and larger lipid deposits and macrophage burden in atherosclerotic plaques. We also demonstrate that MT4-MMP deficiency results in higher numbers of patrolling monocytes crawling and adhered to inflamed endothelia, and the accumulation of $\mathrm{Mafb}+$ apoptosis inhibitor of macrophage $(A I M)+$ macrophages at incipient atherosclerotic lesions in mice. Functionally, MT4-MMPnull Mafb+AIM+ peritoneal macrophages express higher AIM and scavenger receptor CD36, are more resistant to apoptosis, and bind acLDL avidly, all of which contribute to atherosclerosis. CCR5 inhibition alleviates these effects by hindering the enhanced recruitment of MT4-MMP-null patrolling monocytes to early atherosclerotic lesions, thus blocking $\mathrm{Mafb}+\mathrm{AIM}+$ macrophage accumulation and atherosclerosis acceleration. Our results suggest that MT4-MMP targeting may constitute a novel strategy to boost patrolling monocyte activity in early inflammation.

\footnotetext{
${ }^{1}$ Matrix Metalloproteinases in Angiogenesis and Inflammation Group, Centro Nacional de Investigaciones Cardiovasculares Carlos III (CNIC), Melchor Fernández Almagro 3, 28029 Madrid, Spain. ${ }^{2}$ Molecular and Genetic Cardiovascular Pathophysiology Group, Centro Nacional de Investigaciones Cardiovasculares Carlos III (CNIC), Melchor Fernández Almagro 3, 28029 Madrid, Spain. ${ }^{3}$ CIBER de Enfermedades Cardiovasculares (CIBERCV), Madrid, Spain. ${ }^{4}$ Nuclear Receptor Signaling Group, Centro Nacional de Investigaciones Cardiovasculares Carlos III (CNIC), Melchor Fernández Almagro 3,28029 Madrid, Spain. ${ }^{5}$ Proteomics Unit, Centro Nacional de Investigaciones Cardiovasculares Carlos III (CNIC), Melchor Fernández Almagro 3,28029 Madrid, Spain. ${ }^{6}$ Bioinformatics Unit, Centro Nacional de Investigaciones Cardiovasculares Carlos III (CNIC), Melchor Fernández Almagro 3, 28029 Madrid, Spain. ${ }^{7}$ Institut de Recerca del Hospital de la Santa Creu i Sant Pau-Programa ICCC, IIB-Sant Pau, Sant Antoni Maria Claret 167, 08025 Barcelona, Spain. ${ }^{8}$ Division of Cancer Cell Research, Institute of Medical Science, University of Tokyo, 4-6-1 Shirokanedai, Minato-ku, Tokyo 108-8639, Japan. ${ }^{9}$ Instituto de Investigaciones Biomédicas de Barcelona (IIBB-CSIC), IIB-Sant Pau, Rosselló 161, 08036 Barcelona, Spain. ${ }^{10}$ Present address: Centro de Investigaciones Biológicas (CIB-CSIC), Ramiro de Maeztu 9, 28040 Madrid, Spain. Correspondence and requests for materials should be addressed to A.G.A. (email: agarroyo@cnic.es)
} 
A therosclerosis (AT) is a chronic inflammatory disease with local manifestations in the vasculature in the form of complex multi-cellular atherosclerotic lesions ${ }^{1}$. Cells of the innate immune response, particularly monocytes recruited by the inflamed endothelium and their derived macrophages in the plaque, are essential contributors to the initiation, progression, and eventual rupture of atherosclerotic lesions by mechanisms including the engulfment of LDL particles and the formation of lipid-overloaded foam cells ${ }^{2,3}$. However, the view that inflammation derives from recruited monocytes differentiating into macrophages in the plaque has been challenged and a more complex scenario is envisaged ${ }^{4}$. Macrophages differentiate from monocytes in response to micro-environmental stimuli in the plaque, giving rise to distinct subsets that either contribute to inflammation or favor resolution ${ }^{5}$. Macrophage heterogeneity within atherosclerotic lesions has attracted interest due to its possible therapeutic implications. In mice, macrophages in early atherosclerotic plaques are mainly derived from recruited monocytes, whereas macrophage proliferation is more important in advanced plaques ${ }^{6}$. It remains unclear how macrophage heterogeneity is regulated and contributes to AT initiation and progression. The two main circulating monocyte populations, classical monocytes (Ly6C high in the mouse) and patrolling monocytes (Ly6 $\mathrm{C}^{\mathrm{low}}$ ), are recruited to the inflamed aorta via distinct chemokine-receptor pathways ${ }^{7,8}$. Classical monocytes have been assigned proinflammatory functions in AT, whereas patrolling monocytes have been considered to have a protective, pro-resolution role; however, it remains unclear how these monocyte populations, particularly patrolling monocytes, contribute to distinct macrophage subsets in the plaque and to AT progression ${ }^{8}$.

Macrophages are central actors in the vascular remodeling associated with plaque progression. This vascular remodeling involves key actions of matrix metalloproteinases (MMPs) on the extracellular matrix and vascular smooth muscle cells ${ }^{9,10}$. Less is known, however, about the role of MMPs in regulating inflammatory cells in AT. MT4-MMP (also named MMP17) is anchored to the plasma membrane through a glycophosphatidylinositol anchor that confers distinct features to this protease by positioning it at enriched lipid membrane domains ${ }^{11,12}$. MT4-MMP is expressed by macrophages but its role in inflammation is illdefined $^{13,14}$. MT4-MMP was first proposed to process pro-TNFa, but peritoneal macrophages lacking MT4-MMP release normal amounts of $\mathrm{TNFa}^{15}$, indicating alternative functions of MT4MMP in inflammation. We recently reported that MT4-MMPnull mice are more prone to angiotensin II-induced thoracic aorta aneurysms and to neointima formation in response to carotid ligation $^{16}$. Whether MT4-MMP has roles in inflammatory vascular pathologies such as AT has not been explored.

Here we show that the crawling of patrolling monocytes on the inflamed endothelium is regulated by MT4-MMP-dependent cleavage of $\mathrm{aM}$ integrin (Itgam/CD11b), and that this monocyte subset contributes to the accumulation of Mafb+apoptosis inhibitor of macrophage (AIM)+-expressing macrophages in incipient plaques and to overall AT progression. As patrolling monocytes have beneficial effects in infections and the prevention of lung metastasis 8,17 , our results also suggest the therapeutic potential of boosting patrolling monocyte activity through MT4MMP targeting.

\section{Results}

MT4-MMP-null macrophages accumulate in atherosclerotic plaques. The peritoneal cavity contains two main macrophage subsets: resident or large peritoneal macrophages (LPM; $\left.\mathrm{CD} 11 \mathrm{~b}{ }^{\mathrm{hi}} / \mathrm{F} 4 / 80^{\mathrm{hi}}\right)$ and inflammation-induced/monocyte-derived small peritoneal macrophages (SPM; CD $\left.11 \mathrm{~b}^{\text {med }} \mathrm{F} 4 / 80^{\mathrm{lo} / \mathrm{med}}\right)^{18}$
(Fig. 1a). MT4-MMP is not expressed in resident $\mathrm{LPM}^{15}$ but becomes expressed in SPM, the main population present $72 \mathrm{~h}$ after thioglycollate (TG) injection (Supplementary Fig. 1a); the function of MT4-MMP in SPMs remains unknown. Although we observed no differences in the number of resident macrophages, fewer SPMs were collected $72 \mathrm{~h}$ after TG injection in the peritoneal lavage of MT4-MMP-null mice compared with wild types (Fig. 1b) in spite of similar messenger RNA levels of chemokine receptors $^{19}$ (Supplementary Fig. 1b). In parallel, significantly more macrophages were found adhered to the inflamed MT4MMP-null peritoneum (Fig. 1c). This hyper-adhesive phenotype correlated with elevated cell-surface expression of aM integrin (CD11b/Itgam/Mac-1) in SPMs as assessed by flow cytometry (Fig. 1d). There was no change in Itgam mRNA expression (Fig. 1e). Significantly more C3-opsonized sheep erythrocytes were bound to MT4-MMP-deficient SPM than to wild-type cells, confirming $\alpha \mathrm{M}$ integrin activity (Fig. 1f). Moreover, MT4-MMPdeficient macrophages covered a significantly larger area than wild-type cells after adhesion for $24 \mathrm{~h}$ to the aM integrin ligand fibrinogen, indicating accelerated cell spreading, a post-ligand binding event; this difference was abolished by the specific antiaM integrin inhibitory antibody M1/70 (Fig. 1g).

The hyper-adhesion of MT4-MMP-null macrophages to the inflamed peritoneum prompted us to explore their behavior in other inflammatory contexts such as the inflamed aortic vessel wall during AT. To test this, low-density lipoprotein receptor-null $\left(\mathrm{Ldlr}^{-/}\right)$mice were irradiated and transplanted with bone marrow (BM) cells from either wild-type or MT4-MMP-null mice. We observed proper engraftment and no differences in BM and blood cell populations after 4 weeks on a normal diet (Supplementary Fig. 2a, b). Transplanted mice were then placed on a high-fat diet (HFD) for different periods; weight gain and serum biochemical parameters (glucose, triglycerides, and cholesterol) were similar in both groups throughout the experiment (Supplementary Fig. 2c,d). First, we confirmed that MT4-MMP was expressed in macrophages in the aortic sinus of $\mathrm{Ldlr}^{-1-}$ mice transplanted with MT4-MMP-null BM cells (MT4-MMPlacZ/lacZ cells) after 1 and 8 weeks fed a HFD (Supplementary Fig. 2e). We next analyzed the macrophage content in atherosclerotic plaques developed 8 weeks after HFD, finding that macrophages (Mac3+) were significantly more abundant in the aortic sinus of $\mathrm{Ldll}^{-/-}$mice transplanted with MT4-MMP-null BM cells (Fig. 2a). This increased macrophage burden at 8 weeks correlated with significantly larger lipid lesions in the aortic arch after 12 weeks on the HFD, as revealed by en face Red Oil staining (Fig. 2b). Moreover, neointima area in the aortic sinus was comparable between groups at all time points after HFD (Supplementary Fig. 2f). Analysis of Stary classification $^{20}$ revealed that $\mathrm{Ldlr}^{--}$mice transplanted with MT4-MMPdeficient BM cells had significantly more advanced lesions after 8 and 12 weeks on the HFD than counterparts transplanted with wild-type BM (Fig. 2c, d and Supplementary Fig. 2g); in particular, MT4-MMP-deficient BM recipients tended to have larger necrotic cores and showed significantly thicker fibrous caps after 12 weeks on HFD (Fig. 2e). Similar results were obtained in double $L d l r / M T 4-M M P-n u l l$ mice fed a HFD. These mice nearly recapitulated the phenotype of $\mathrm{Ldlr}^{-/-}$mice transplanted with MT4-MMP-null BM, showing an increased AT burden in the aortic arch and more advanced plaques after 16 weeks of HFD (Supplementary Fig. 3a-d). In this mouse model, MT4-MMP protein and mRNA expression in aorta extracts was low in early stages ( 8 weeks after HFD) but progressively increased in established AT (16 weeks after HFD); a similar difference was observed between human arteries with arterial intimal thickening (early lesions) and those with established atherosclerotic lesions (Supplementary Fig. $4 \mathrm{a}-\mathrm{c}$ ). Of note, in early mouse 
atherosclerotic plaques of $\mathrm{MT} 4-\mathrm{MMP}^{+/+} / \mathrm{Ldlr}^{-/-}$mice (8 weeks after HFD), MT4-MMP expression was mainly restricted to macrophages (Supplementary Fig. 4d), indicating that MT4MMP deficiency appears to principally impact AT progression through its effect on these cells.
Macrophage burden in the atherosclerotic plaque is mostly determined by the balance between early monocyte recruitment and late macrophage proliferation/cell death ${ }^{21}$. After 8 weeks of HFD, plaques from $\mathrm{Ldlr}^{-/}$mice transplanted with MT4-MMPnull $\mathrm{BM}$ showed variable macrophage proliferation but no a
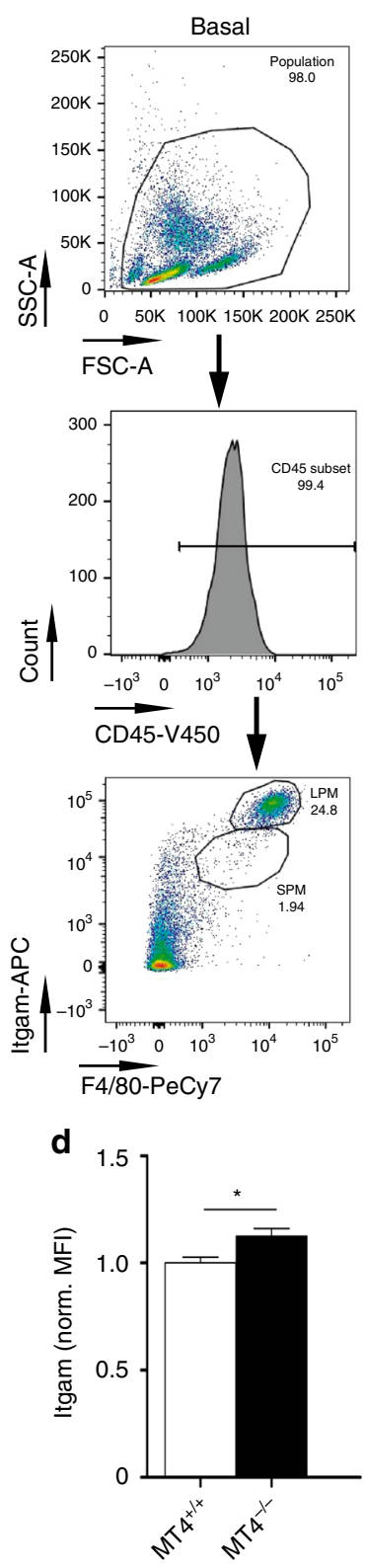

g

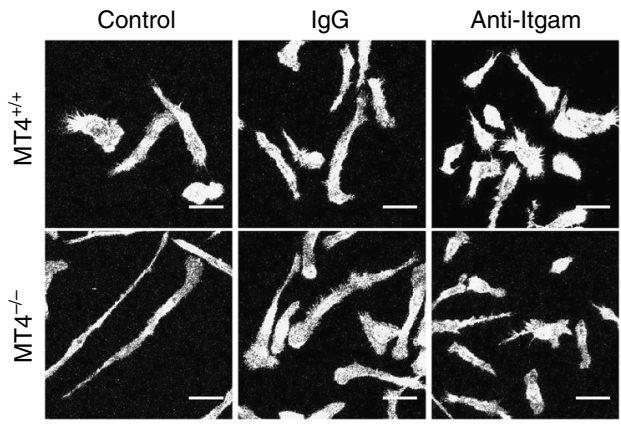

e b
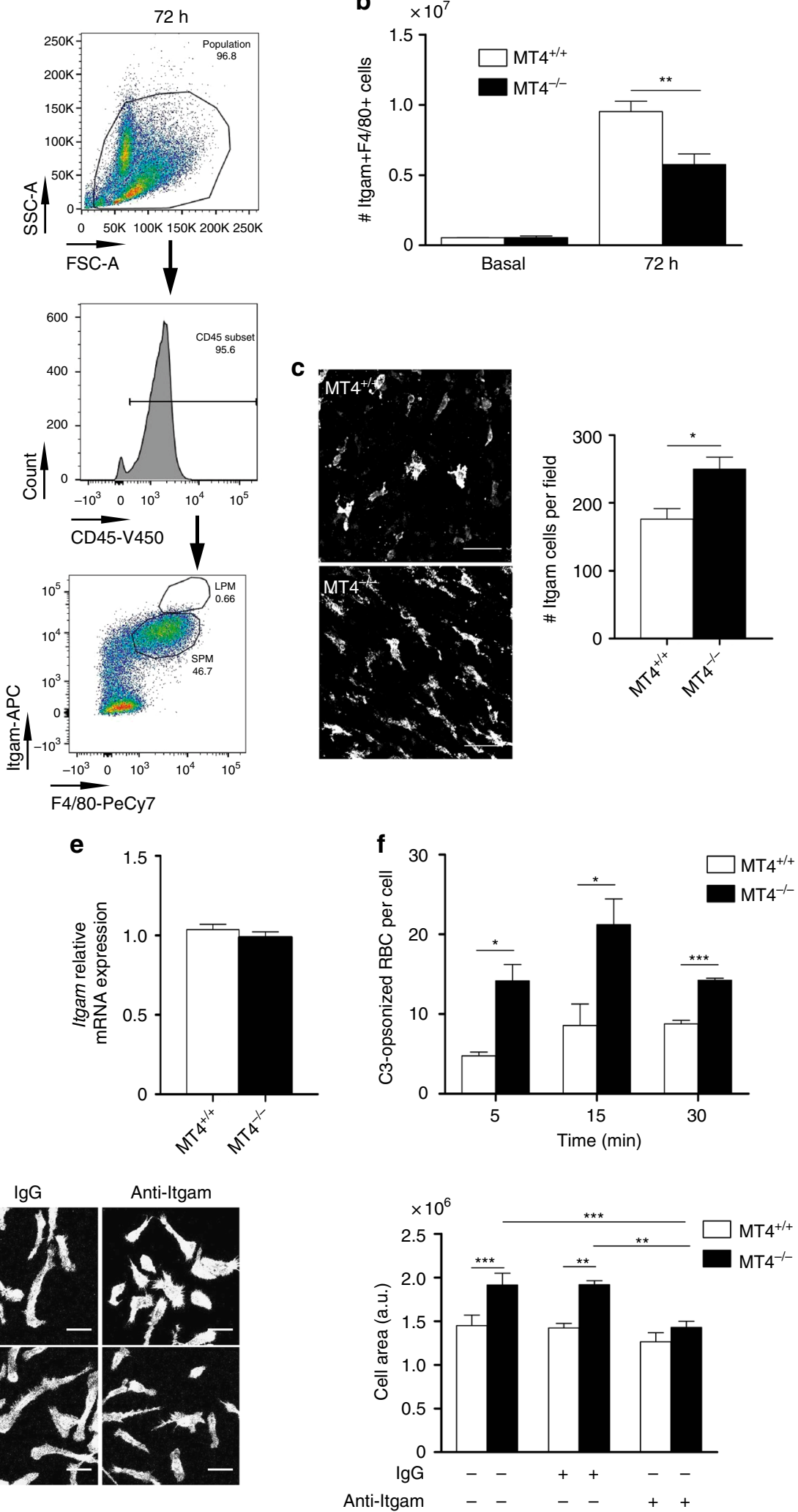
significant increase compared with wild-types $(\sim 33 \pm 21 \%$ versus $\sim 25 \pm 10 \% \mathrm{Mac} 3+/ \mathrm{Ki} 67+$ cells), and cell apoptosis was a rare event $(<1 \%$ cleaved caspase-3-positive cells). We also assessed a possible influence of MT4-MMP absence in macrophage egression from inflamed tissues. TG-stimulated macrophages nearly disappeared from the peritoneal cavity in response to lipopolysaccharide (LPS), regardless the genotype with minor contribution of local death and similar numbers found of wild-type and MT4-MMP-null egressed macrophages in the spleen (Supplementary Fig. 5). These data argued in favor of enhanced monocyte recruitment during early $\mathrm{AT}$ as the main contributor to increased macrophage burden.

MT4-MMP absence boosts patrolling monocyte crawling. Blood monocyte abundance was similar in $\mathrm{Ldlr}^{--}$mice transplanted with MT4-MMP-null or wild-type BM cells (1.4\% $\pm 0.5 \%$ and $1.3 \% \pm 0.2 \%$, respectively); however, before starting the HFD, lack of MT4-MMP was associated with a significantly lower percentage of circulating patrolling Ly $6 \mathrm{C}^{\text {low }}$ monocytes and these cells displayed increased cell surface levels of $\alpha \mathrm{M}$ integrin, similar to MT4-MMP-null SPMs (Figs 3a and 1c).

Increased cell-surface aM integrin in MT4-MMP-null patrolling monocytes and SPMs (Figs $3 \mathrm{a}$ and $1 \mathrm{~d}$ ), with no changes in mRNA expression, pointed to posttranslational regulation by MT4-MMP. Both MT4-MMP and aM integrin were located in lipid-rich domains and MT4-MMP-null peritoneal macrophages contained significantly higher levels of $\alpha \mathrm{M}$ integrin in these domains (Supplementary Fig. 6a, b). MT4-MMP-null mice were then injected intraperitoneally (i.p.) with lentivirus encoding green fluorescent protein (GFP) and either full-length MT4-MMP or the catalytic dead mutant (E248A) (Fig. 3b). Analysis of peritoneal macrophages at 5 days post injection showed that expression of full-length MT4-MMP yielded normal cell-surface aM integrin levels in infected MT4-MMP-null macrophages $(\mathrm{GFP}+\mathrm{Itgam}+\mathrm{F} 4 / 80+)$; in contrast, infection with the catalytic dead mutant yet resulted in higher surface $\alpha \mathrm{M}$ integrin levels than observed in wild-type macrophages, demonstrating that MT4-MMP catalytic activity regulates aM integrin cell-surface levels in vivo (Fig. 3c). We next used the Cleavpredict software application $^{22}$ to identify possible direct MT4-MMP cleavage sites in $\alpha \mathrm{M} \beta 2$ integrin. The predicted and exposed sites were filtered according to the peptide cleavage matrix in the MEROPS database, and candidate cleavage sites were selected in the $\alpha \mathrm{M}$ integrin chain (Itgam) between positions 970 and 1000, close to the transmembrane (TM) domain (Fig. 3d and Supplementary Data 1). In silico modeling of interaction between the human $\alpha \mathrm{M} \beta 2$ integrin heterodimer and the human MT4MMP dimer confirmed $\mathrm{EN}^{977} \mathrm{LS}$ as the only candidate $\alpha \mathrm{M}$ integrin cleavage site accessible to the MT4-MMP catalytic center (Fig. 3d, e). This site is conserved in the mouse aM integrin chain but not in the related $\alpha \mathrm{L}$ integrin chain in humans or mice. Incubation of the human recombinant MT4-MMP catalytic domain with a synthetic peptide $\mathrm{R}^{969}-\mathrm{R}^{987}$ from the human aM integrin sequence resulted in significant cleavage at the $\mathrm{aM}$ integrin $\mathrm{EN}^{977} \mathrm{LS}$ site, as assessed by mass spectrometry (Fig. 3f, g).

Crawling of patrolling Ly6 $\mathrm{C}^{\text {low }}$ monocytes on the inflamed endothelium depends on $\alpha \mathrm{M} \beta 2$ integrin $^{23}$ and we therefore next analyzed the in vivo behavior of patrolling monocytes by intravital microscopy of cremaster muscle stimulated with CCL2, an essential chemokine in AT development ${ }^{24,25}$. Only a small number of circulating monocytes, corresponding to patrolling monocytes (CD115+Ly6 $\left.\mathrm{C}^{\mathrm{low}}\right)$, can crawl on the inflamed endothelium ${ }^{26}$. MT4-MMP-null mice had significantly higher numbers of crawling monocytes on CCL2-inflamed endothelium than wild types (Fig. 4a, b and Supplementary Movies 1, 2) with no major differences in crawling velocity, distance traveled, or confinement index (Supplementary Fig. 7a). Similar total number of monocytes (CD115+Ly6G-) were observed rolling or adhered to the CCL2-inflamed endothelium (Fig. 4c), indicating a selective effect of MT4-MMP absence in patrolling monocyte behavior. Moreover, the increased crawling of MT4-MMP-null patrolling monocytes was abolished when aM integrin was blocked with the inhibitory antibody M1/70 (Fig. 4a, b and Supplementary Movies 1-4). MT4-MMP-null mice also had fewer neutrophils rolling on the inflamed endothelium, suggesting their retention by crawling patrolling monocytes, as reported in other contexts (Supplementary Fig. $7 \mathrm{~b})^{23}$.

MT4-MMP absence increases Mafb+AIM+ macrophages in early AT. Low efficiency is a common limitation for the analysis of patrolling monocyte recruitment to the inflamed endothelium of atherosclerotic plaques ${ }^{21,27}$. Still, whole-mount staining showed significantly more patrolling monocytes (CD115+Ly6C-) adhered to the endothelium of the lesser curvature of the aortic arch in MT4-MMP-null BM-transplanted $\mathrm{Ldlr}^{-/-}$mice than in similar mice transplanted with wild-type cells after 3 days on the HFD (Fig. 5a); no between-genotype differences were detected in cell surface levels of CCR5, the chemokine receptor involved in patrolling monocyte recruitment $^{27}$ and CCR2 $\left(\mathrm{MFI}_{\mathrm{CCR} 5}=452 \pm 53\right.$ and $498 \pm 47$, and $\mathrm{MFI}_{\mathrm{CCR} 2}=592 \pm 65$ and $613 \pm 75$ in patrolling monocytes from wild-type and $\mathrm{MT} 4^{-/-}$-BMT $\mathrm{Ldlr}^{-/-}$mice, respectively). Classical monocytes $(\mathrm{CD} 115+\mathrm{Ly} 6 \mathrm{C}+)$ were recruited at higher proportion at this incipient stage $\mathrm{e}^{21,27}$ but similarly regardless the genotype (Fig. 5a). Notably, MT4-MMP-null sorted patrolling monocytes adoptively transferred into $\mathrm{Ldlr}^{-/}$mice also adhered at higher numbers to the lesser curvature of the aorta after 3 days on the HFD compared with wild types confirming the cell autonomous impact of MT4-MMP absence on patrolling monocyte behavior (Fig. 5b and Supplementary Fig. 8).

Fig. 1 Enhanced trapping of MT4-MMP-null peritoneal macrophages due to increased $\alpha$ M integrin (Itgam) levels and activity. a Representative flow cytometry dot plots and histograms of mouse peritoneal macrophages stained for CD45, Itgam, and F4/80 in basal conditions (left) and $72 \mathrm{~h}$ after thioglycollate (TG) injection (right). b Number of macrophages (Itgam+F4/80+) collected in the peritoneal eluate of wild-type and MT4-MMP-null mice at the indicated times after TG injection; $n=3$ mice in basal and $n=12$ mice at $72 \mathrm{~h}$ per genotype in one in basal and four in $72 \mathrm{~h}$ independent experiments, respectively. c Representative confocal microscopy images (left) and quantification (right) of monocytes/macrophages (Itgam+) in the peritoneal membrane $72 \mathrm{~h}$ after TG injection; $n=6$ mice per genotype in two independent experiments; scale bar, $50 \mu \mathrm{m}$. $\mathbf{d}$ Flow cytometry analysis of Itgam cellsurface levels in TG-elicited macrophages (Itgam+F4/80+) obtained $72 \mathrm{~h}$ after TG injection; $n=20$ mice per genotype in four independent experiments. e qPCR analysis of Itgam mRNA in TG-elicited macrophages adhered to plastic overnight; $n=6$ samples per genotype in two independent experiments. $\mathbf{f}$ Itgam integrin affinity assessed as the number of C3-opsonized red blood cells (RBCs) bound to TG-elicited peritoneal macrophages adhered to glass; $n=6$ samples per genotype from two independent experiments. $\mathbf{g}$ Representative fluorescence images of TG-elicited macrophages adhered to fibrinogen for $24 \mathrm{~h}$ and labeled for F-actin in the presence or absence of Itgam blocking antibody M1/70 or IgG isotype control (left). The histogram shows quantification of the cell area (right). Scale bar, $30 \mu \mathrm{m} . n=6$ samples per genotype in two independent experiments. Data were tested by two-way ANOVA followed by Bonferroni's post test in $\mathbf{f}$, by two-tailed Student's t-test in $\mathbf{b}, \mathbf{c}, \mathbf{d}$, and $\mathbf{e}$, and by one-way ANOVA followed by Bonferroni's post test in g. Results are expressed as mean \pm SEM. ${ }^{\star} p<0.05$, ${ }^{\star *} p<0.01$, and ${ }^{\star \star *} p<0.001$ 
a
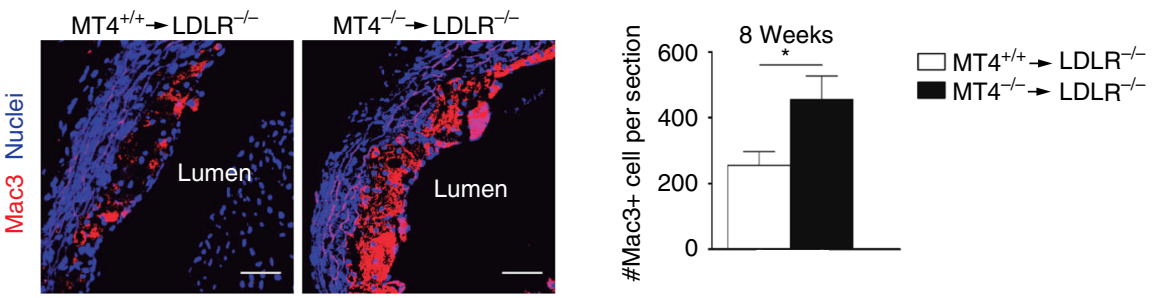

b

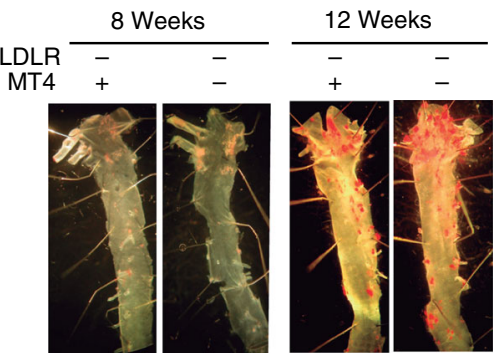

C
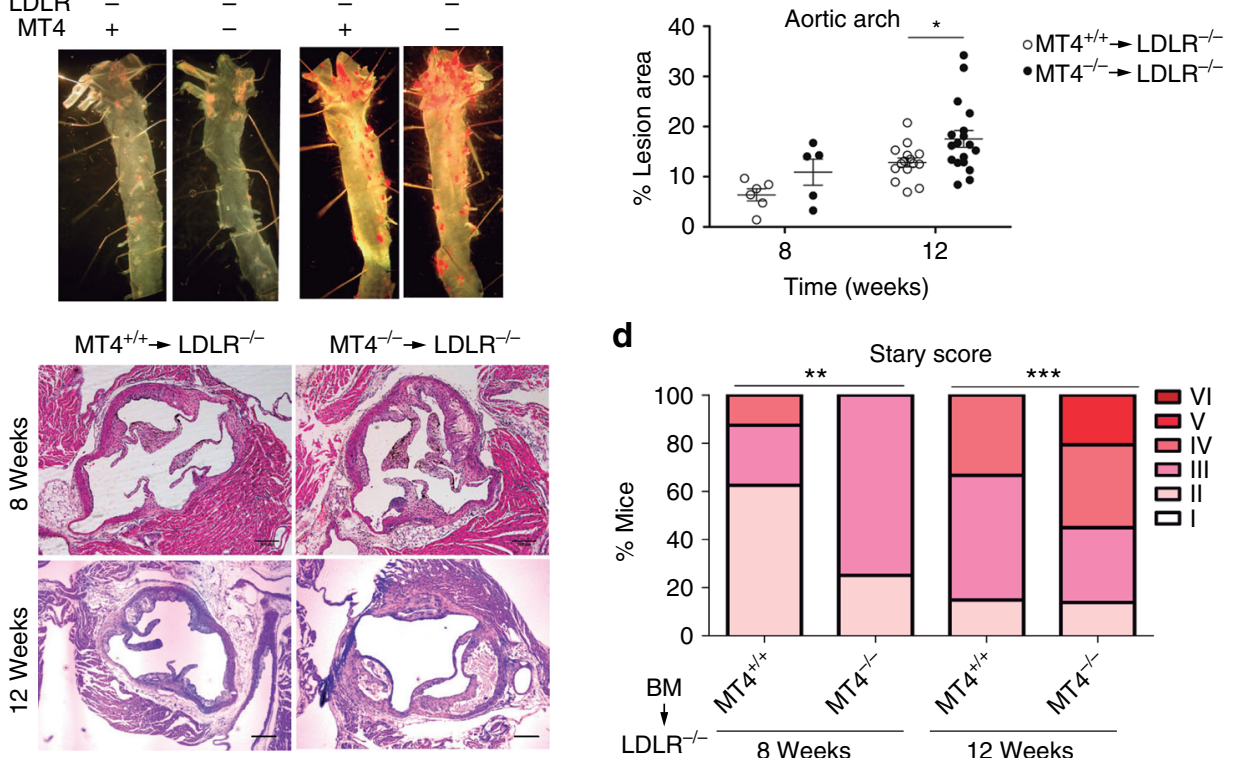

d
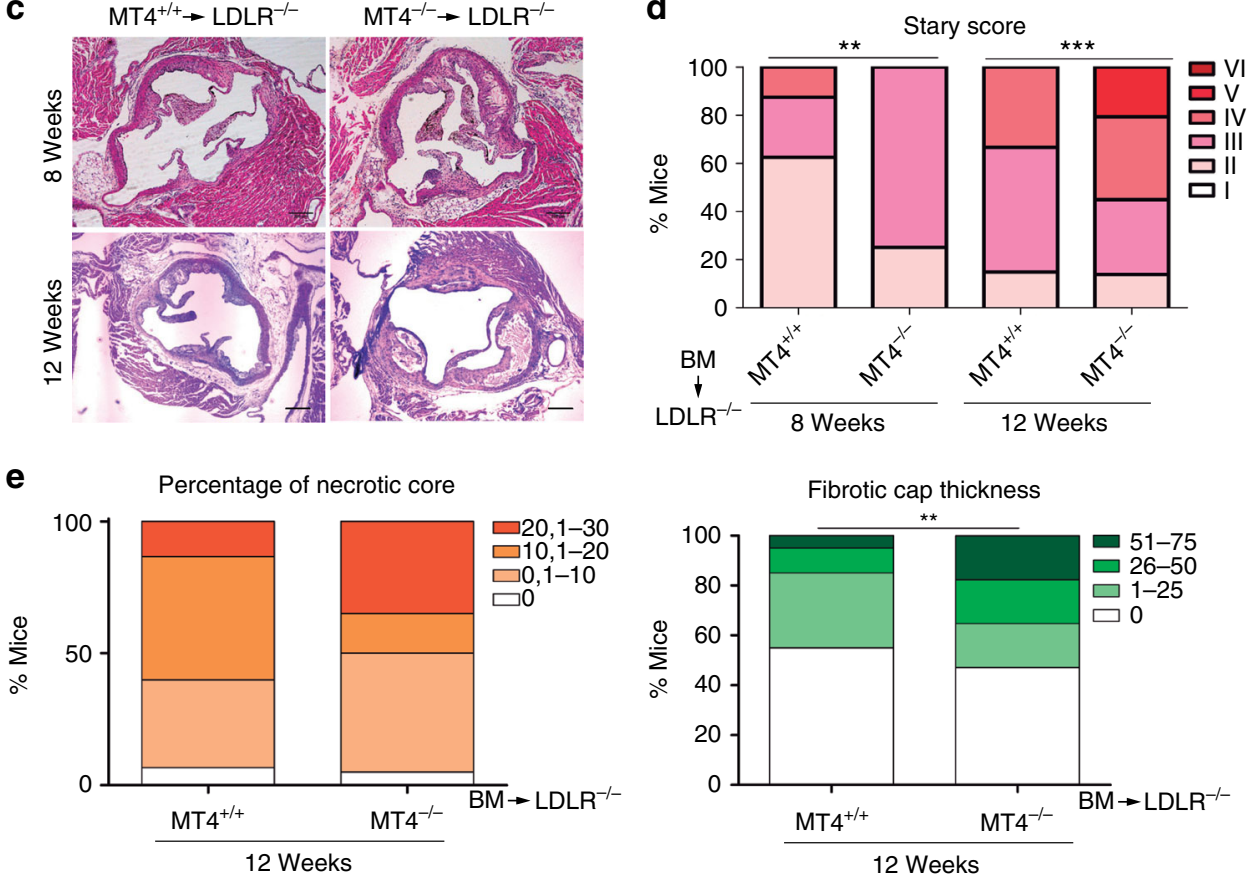

Fig. 2 Lack of MT4-MMP in BM-derived cells results in increased macrophage burden in atherosclerotic plaques and accelerated AT. a Representative images of Mac3 immunostaining (red; nuclei in blue) in transverse sections of aortas from $\mathrm{Ldlr}^{-/-}$mice transplanted with $\mathrm{MT4}^{-M M P^{+/+}}\left(\mathrm{MT}^{+/ /+}\right.$) or MT4-MMP ${ }^{-/-}\left(\mathrm{MT4}^{-/-}\right)$BM cells and fed a HFD for 8 weeks; scale bar, $20 \mu \mathrm{m}$. The right panel shows Mac3-positive cells quantified by Image J. $n=6$ mice per genotype in two independent experiments. $\mathbf{b}$ Representative images of en face Oil Red-stained aortas from BM-transplanted Ldlr ${ }^{\prime /-}$ and fed a HFD for 8 or 12 weeks (left) and graph shows the area (\%) of Oil Red-positive lesions in the aortic arch (right); $n=6$ and $n=16$ mice per genotype for 8 and 12 weeks in two and three independent experiments, respectively. c Representative images of transverse sections of aortic sinus stained with H\&E of BMtransplanted $L d l r^{-/-}$mice; scale bar, $200 \mu \mathrm{m}$. d Stary scoring (I-VI) of aortic lesions of BM-transplanted Ldlr ${ }^{-/-}$mice, shown as a percentage of all mice for each condition after feeding a HFD for 8 or 12 weeks; $n=6$ and $n=16$ mice per genotype and time point in two and three independent experiments. e Bar graphs show the percentage of BM-transplanted $L d r^{-/-}$mice for each range of $\%$ of necrotic area (left) and fibrotic cap thickness (right) after 12 weeks of HFD; $n=16$ mice per genotype in three independent experiments. Data were tested by two-tailed Student's $t$-test in a, by two-way ANOVA followed by Bonferroni's post test in $\mathbf{b}$, and by $\chi^{2}$-test for a trend in $\mathbf{d}$, e. Results are expressed as mean \pm SEM. ${ }^{\star} p<0.05$, ${ }^{\star \star} p<0.01$, and ${ }^{\star \star \star} p<0.001$

Although patrolling monocytes express genes related to cholesterol sensing and responses, their contribution to plaque lipid accumulation remains poorly characterized ${ }^{21}$. Analysis of incipient plaques after 7 days on the HFD showed no significant differences in macrophage number between $\mathrm{Ldlr}^{-/-}$mice transplanted with MT4-MMP-null or wild-type cells (Fig. 6a, b). We next explored whether increased recruitment of patrolling monocytes influences macrophage subset composition rather than their abundance.
Patrolling monocytes initiate a macrophage differentiation program in response to infection by upregulating Mafb in the peritoneal cavity ${ }^{26}$, and this transcription factor can promote $\mathrm{AT}^{26,28}$. After 7 days on the HFD, incipient plaques from $\mathrm{MT}^{-/-}$-transplanted $\mathrm{Ldlr}^{-/-}$mice contained significantly more ( 3-fold) Mac3+ macrophages with nuclear Mafb (49.6 $\pm 15 \%)$ than those from mice transplanted with wild-type cells $(22.7 \pm$ $10 \%$; Fig. $6 \mathrm{a}, \mathrm{b})$, and this subset seemed to be more proliferative $(\sim 1.5$-fold $)$ in $\mathrm{MT}^{-/-}$-transplanted $\mathrm{Ldlr}^{-/}$mice. All 
a

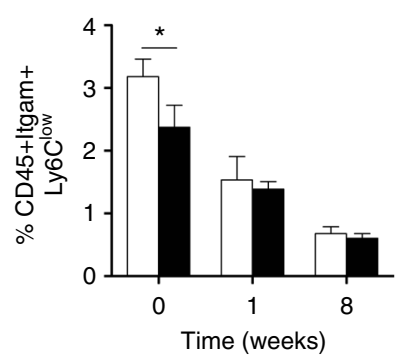

b

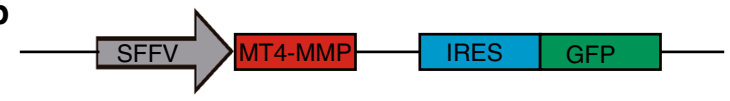

d

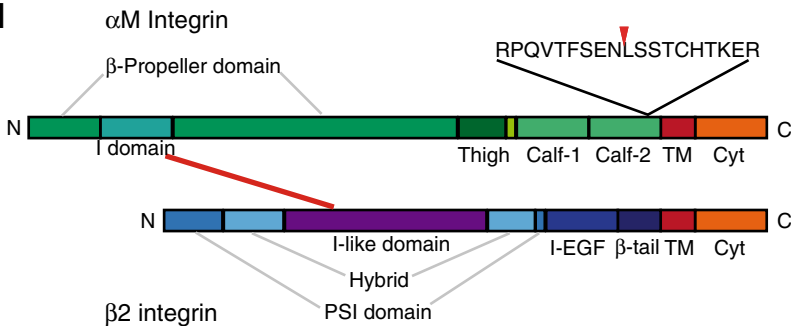

f RPQVTFSENLSSTCHTKER
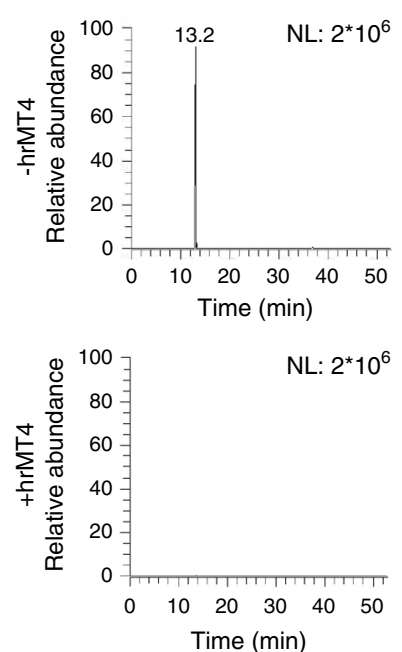

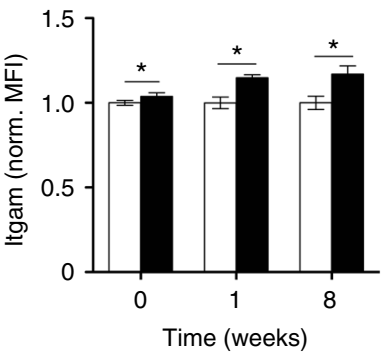

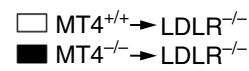

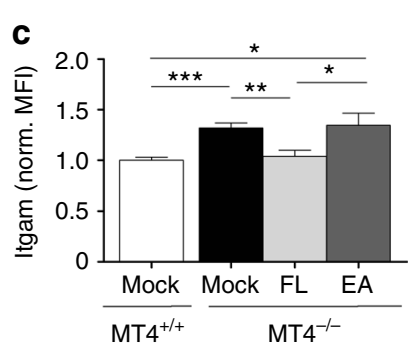

e

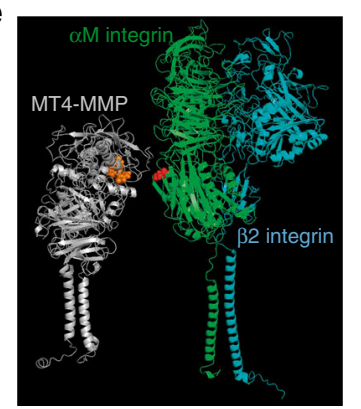

g $\square$ Peptide

Peptide + hrMT4-MMP

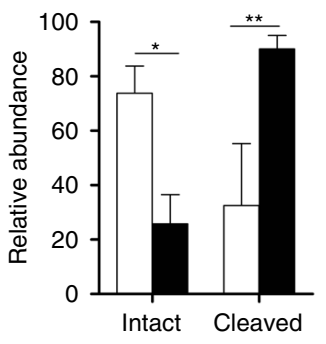

Fig. 3 The protease MT4-MMP can cleave the $\alpha M$ integrin chain (Itgam). a Percentage of circulating patrolling monocytes (CD45+Itgam+Ly6Clow, excluding granulocytes) and the normalized mean fluorescence intensity (MFI) of Itgam cell-surface levels in patrolling monocytes from $L d l^{-1} /$ - mice transplanted with MT4-MMP $+/+$ or MT4-MMP ${ }^{-/-}$BM cells and fed a HFD for 0,1 , or 8 weeks; $n=12, n=6$, and $n=6$ mice in basal, 1 week and 8 weeks per genotype; four independent experiments in basal and two independent experiments at 1 and 8 weeks. b Design of lentiviral (LV) vector with SFFVdriven Mmp17 (MT4-MMP) expression and IRES-driven expression of green fluorescent protein (GFP). c LV encoding full-length mouse MT4-MMP (FL), the catalytic inactive mutant (E248A, EA), or GFP only (mock) were i.p. injected into MT4-MMP-null mice. Itgam cell surface levels were assessed by flow cytometry in the infected peritoneal macrophages (GFP+Itgam+F4/80+) 5 days after infection; $n=6$ mice per condition in two independent experiments. d Depiction of human $\alpha M \beta 2$ integrin domains, indicating the predicted cleavage site at position 977 in the Calf- 2 domain of human $\alpha M$ integrin. e In silico model of human MT4-MMP dimer (gray) and $\alpha M \beta 2$ integrin ( $\alpha$ M chain, green; $\beta 2$ chain, blue) showing the putative cleavage site between N977 and L978 (red) in the $\alpha M$ chain, and the catalytic active center in the MT4-MMP dimer (orange). $\mathbf{f}$ Representative extracted ion chromatogram of peptides obtained after incubation of the synthetic human $\alpha M$ integrin peptide RPQVTFSENLSSTCHTKER in the presence or absence of human recombinant MT4-MMP catalytic domain (hrMT4). $\mathbf{g}$ Quantification of the relative abundance of the intact RPQVTFSENLSSTCHTKER and N-terminal peptide fragments in each condition; $n=4$ independent experiments. Data were tested by two-way ANOVA followed by Bonferroni's post test in $\mathbf{a}$, by one-way ANOVA followed by Bonferroni's post test in $\mathbf{c}$, and by two-tailed Student's $t$-test in $\mathbf{g}$. IRES, internal ribosome entry site; SFFV, spleen focus-forming virus. Results are expressed as mean \pm SEM. ${ }^{\star} p<0.05$, ${ }^{\star *} p<0.01$, and ${ }^{\star \star \star} p<0.001$

macrophages with nuclear Mafb also expressed AIM (apoptosis inhibitor of macrophages; Fig. $6 \mathrm{a}, \mathrm{b}$ ), which promotes survival of lipid-loaded macrophages ${ }^{29}$. In this line, a trend to reduced macrophage apoptosis (Mac3+/cleaved caspase-3+ cells) was apparent in incipient plaques of $\mathrm{MT}^{-/-}$-transplanted $\mathrm{Ldlr}{ }^{-/-}$ mice $(\sim 6 \pm 2 \%$ vs $\sim 8 \pm 3 \%$ in those transplanted with wild-type cells). The increase in Mac3+ macrophages expressing AIM in the incipient plaques from $\mathrm{MT}^{-/-}$-transplanted $\mathrm{Ldlr}^{--}$mice 

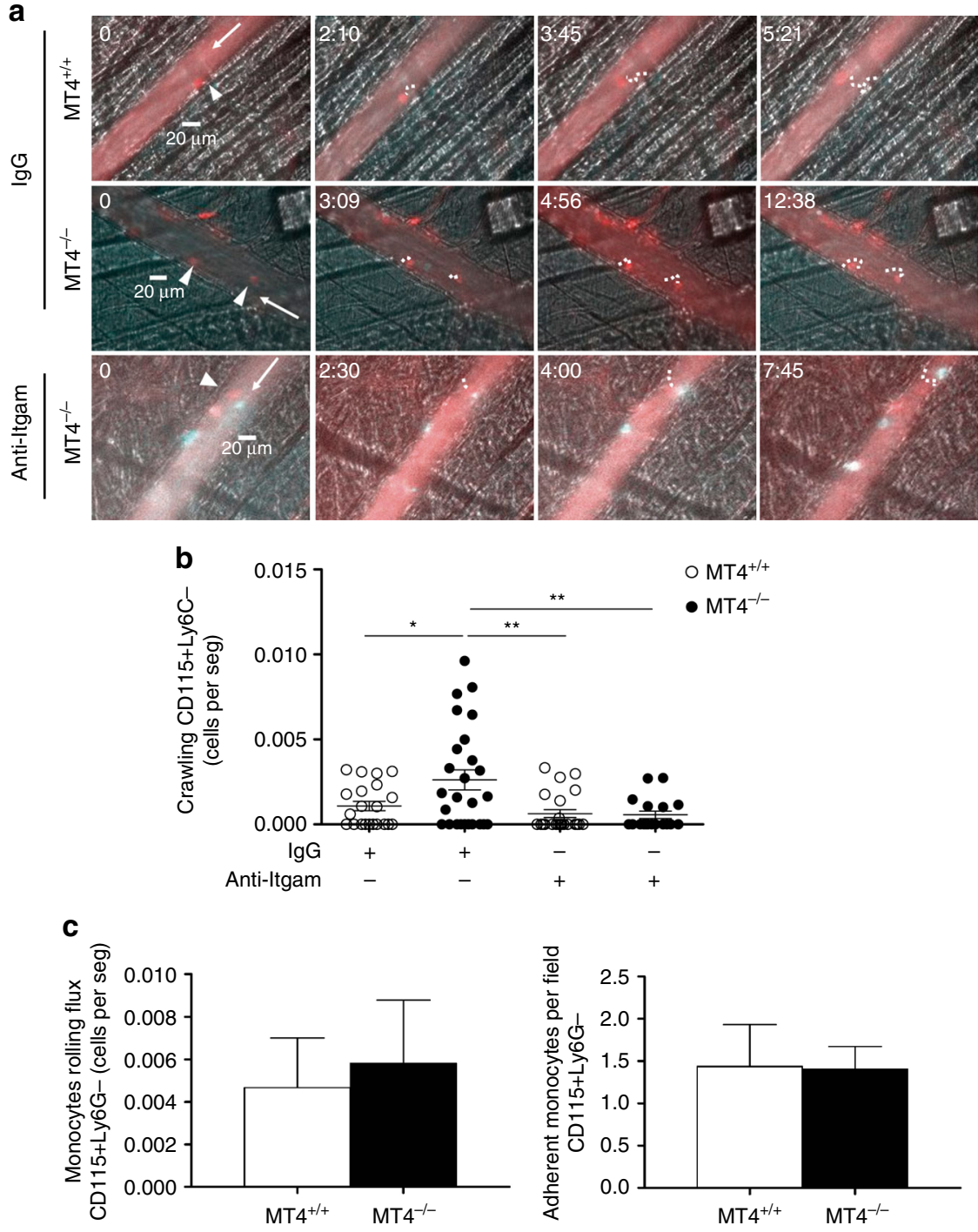

Fig. 4 Enhanced $\alpha M$ integrin-dependent crawling of MT4-MMP-null patrolling monocytes on CCL2-inflamed endothelium. a Representative intravital microscopy images of CD115+/Ly6C-patrolling monocytes (CD115 in red and Ly6C in green) crawling on the CCL2-inflamed endothelium in the cremaster muscle of wild-type $\left(\mathrm{MT4}^{+/+}\right)$and MT4-MMP-null $\left(\mathrm{MT4}^{-/-}\right)$mice; the recording was performed in the presence of anti-Itgam blocking antibody (M1/70) or lgG isotype control. Arrowheads, arrows, and dots respectively indicate individual patrolling monocytes, blood flow, and monocyte trajectory. Time of recording is indicated. $\mathbf{b}$ The graph shows the numbers of crawling patrolling monocytes recorded in $\mathbf{a}$ in every venule from five independent mice per genotype and condition in two independent experiments. c Quantification of CD115+Ly6G- rolling (left) and adherent (right) monocytes in the CCL2inflamed endothelium in the cremaster muscle of wild-type $\left(\mathrm{MT}^{+/+}\right)$and MT4-MMP-null $\left(\mathrm{MT4}^{-/-}\right)$mice. $n=8$ mice per genotype in two independent experiments. Data were tested by one-way ANOVA followed by Bonferroni's post test in $\mathbf{b}$ and by two-tailed Student's $t$-test in $\mathbf{c}$. Results are expressed as mean \pm SEM. ${ }^{\star} p<0.05,{ }^{\star \star} p<0.01$, and ${ }^{\star \star \star} p<0.001$

( $39 \pm 6 \%$ vs $27.6 \pm 9 \%$ in those transplanted with wild-type cells) remained up to 8 weeks but was no longer observed in advanced plaques after 12 weeks on a HFD (Supplementary Fig. 9a, b). AIM also participates in oxLDL uptake ${ }^{30}$. Accordingly, $\sim 50 \%$ of $\mathrm{Mafb}+$ macrophages were positive for adipophilin in wild-type $\mathrm{BM}$-transplanted $\mathrm{Ldlr}^{-1-}$ mice and this proportion was significantly higher $(\sim 70 \%)$ in $\mathrm{Ldlr}^{-/-}$mice transplanted with MT4-MMP-null BM cells (Fig. 6c, d).

To further understand the influence of MT4-MMP absence on the functional phenotype of Mafb+AIM+ macrophages, we analyzed TG-elicited peritoneal macrophages ${ }^{27}$. Mirroring the accumulated subset observed in incipient atherosclerotic plaques, significantly more MT4-MMP-null macrophages contained Mafb at the nucleus ( $60 \%$, threefold) compared with wild types $(\sim 20 \%)$, and they also expressed higher levels of total and cellsurface AIM, detected by immunostaining and flow cytometry (Fig. 7a-c); Mafb and Cd5l (Aim) mRNA levels showed no differences (Supplementary Fig. 10a). Increased AIM expression resulted in significantly lower numbers of apoptotic MT4-MMPnull peritoneal macrophages after cycloheximide treatment (Fig. 7d). AIM also increases CD36-mediated oxLDL uptake and foam-cell formation ${ }^{30}$. Flow cytometry analysis revealed significantly increased cell-surface CD36 expression in TGelicited MT4-MMP-null macrophages and these cells were more efficient at acLDL binding than wild types (Fig. 7e, f); no differences were detected in Cd36 mRNA levels (Supplementary Fig. 10a). Further analysis showed that MT4-MMP-null peritoneal macrophages did not differ from wild types in the mRNA levels of proinflammatory cytokines (Illb, Tnfa, and Il6) or antiinflammatory cytokines (Illo and Tgfb) (Supplementary Fig. 10b).

CCR5 inhibition hinders accelerated AT in MT4-MMP absence. To prove that enhanced recruitment of patrolling monocytes in MT4-null BMT $\mathrm{Ldlr}^{-/-}$mice fed the HFD for 3 days 
a
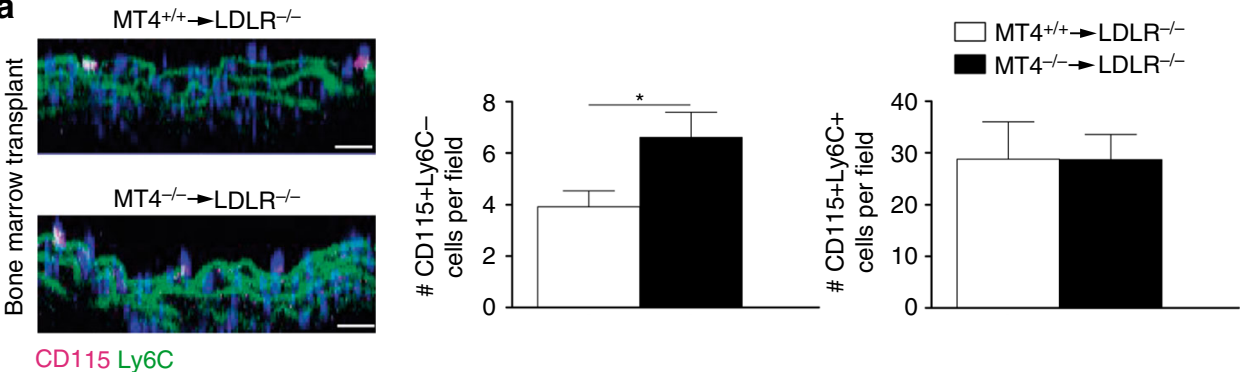

CD115 Ly6C

b
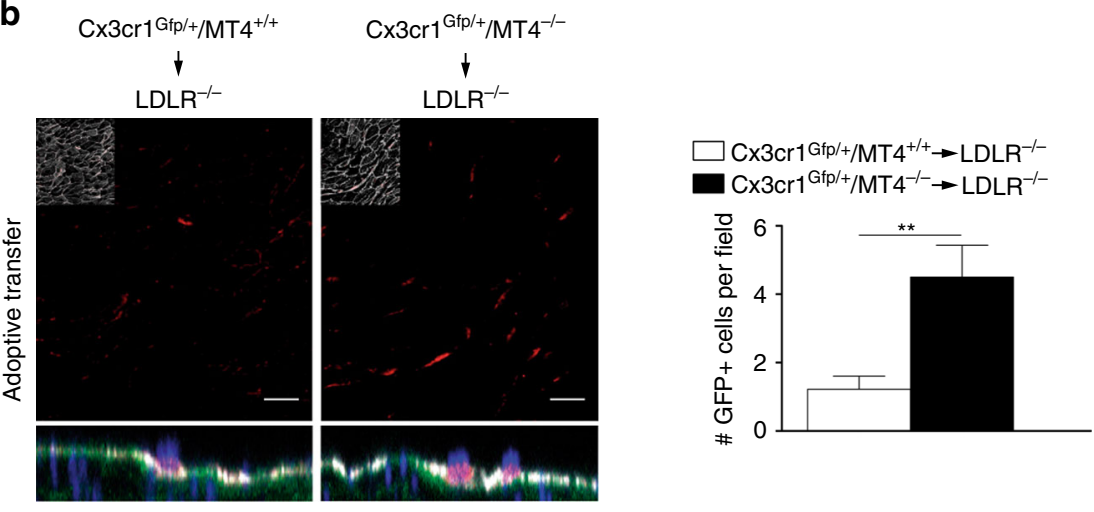

GFP CD31

Fig. 5 Increased recruitment of MT4-MMP-null patrolling monocytes in incipient atherosclerotic lesions. a Representative orthogonal XZ view images of whole-mount-stained lesser curvature of the aortic arch from Ldlr $^{-/-}$mice transplanted with MT4-MMP $+/+$or MT4-MMP M $/-^{-}$BM cells and fed a HFD for 3 days. Samples were stained for CD115 (magenta) and Ly6C (green); elastin autofluorescence (green) and nuclei (Hoechst, blue). The bar graph (right) shows the quantification of the number of patrolling (CD115+Ly6C-) and classical monocytes (CD115+Ly6C + ) in the aorta lumen; $n=6$ mice per genotype in two independent experiments. $\mathbf{b}$ Representative confocal microscopy images of whole-mount-stained lesser curvature of the aortic arch from $\mathrm{Ldll}^{-/-}$mice adoptively transfer with $\mathrm{C} \times 3 \mathrm{cr} 1^{\mathrm{Gfp} /+} \mathrm{MT4} 4 \mathrm{MMP}+/+$ or $\mathrm{C} \times 3 \mathrm{cr} 1^{\mathrm{Gfp} /+}$ MT4-MMP-/- patrolling monocytes and fed a HFD for 3 days. Samples were stained for GFP (red) and CD31 (gray); elastin autofluorescence (green) and nuclei (Hoechst, blue). A z-stack of the confocal microscopy sections close to the lumen (with an inset of CD31 staining) is shown to the top and the orthogonal XZ view of the merged images to the bottom. Scale bar, $20 \mu \mathrm{m}$. The bar graph (right) shows the quantification of the number of transferred monocytes (GFP+) in the aorta lumen; $n=9$ mice per genotype in two independent experiments. Data were tested by Student's $t$-test. Results are expressed as mean \pm SEM. ${ }^{\star} p<0.05,{ }^{\star \star} p<0.01$

(Fig. 5a) was promoting Mafb+AIM+ macrophage accumulation and AT acceleration at later stages (Figs. 6a, b and 2), we sought to selectively block patrolling monocyte recruitment. For that, we used Maraviroc (MRV), a CCR5 antagonist used in the clinic $^{31}$, as patrolling monocyte preferentially employ this receptor to enter atherosclerotic plaques ${ }^{27}$. Daily treatment of mice with MRV reduced the low numbers of patrolling monocytes ${ }^{27}$ consistent with decreased recruitment and abolished the enhanced adherence of patrolling monocytes to the aorta of MT4-null BMtransplanted $\mathrm{Ldlr}^{-/-}$mice after 3 days on the HFD (Fig. 8a). Concomitantly, MRV also led to loss of the increased abundance in $\mathrm{Mafb}+\mathrm{AIM}+$ macrophages at 7 days and in total macrophages at 8 weeks on the HFD in MT4-null BMT $\mathrm{Ldlr}^{-/}$mice overall delaying AT progression, as shown by quantification of lipid deposits, neointima area, and Stary score, to similar levels than those observed in MRV-treated $\mathrm{Ldlr}^{-/}$mice transplanted with wild-type cells ${ }^{32}$ (Fig. 8b-f and Supplementary Fig. 11a-c).

The data obtained with the CCR5 antagonist demonstrate that the atherosclerotic phenotype observed in the absence of MT4MMP is related to its primary impact on the enhanced early recruitment of patrolling monocytes to the inflamed aorta.

\section{Discussion}

Patrolling monocytes exert their surveillance activity within the vasculature, where they recognize endothelial damage and promote repair ${ }^{23}$. A vascular protective function for patrolling monocytes in inflammation was supported by the exacerbated AT in mice lacking the orphan nuclear receptor Nur77/Nr4a1, which present a dramatic reduction in Ly6C ${ }^{\text {low }}$ patrolling monocyte production $^{2,8,33}$. These mice have, however, other defects such as a proinflammatory shift of Nur77-null macrophages, which could in part mediate the observed phenotype ${ }^{33}$. Moreover, a separate study did not detect changes in lipid lesions in $L d l r$-null mice transplanted with Nur77-9- $\mathrm{BM}^{34}$, and therefore debate has persisted about the atheroprotective role of patrolling monocytes. Our findings in MT4-MMP-null mice provide the first evidence for a contribution of patrolling monocytes to a proatherogenic $\mathrm{Mafb}+\mathrm{AIM}+$ macrophage subset in early plaques. The contribution of patrolling monocytes to AT may also be clarified by a recent mouse model targeting a super-enhancer that ablates Nur77-dependent Ly6Clow monocytes, while preserving Nur77 expression in tissue macrophages and macrophage responses to inflammation ${ }^{35}$.

Macrophage burden mainly depends on monocyte recruitment in early plaques and on local macrophage proliferation in advanced plaques ${ }^{6,36}$. Established atherosclerotic lesions in MT4MMP-null transplanted HFD-fed $\mathrm{Ldlr}^{-/}$mice had an increased macrophage abundance unrelated to differences in proliferation. Although Ly6C ${ }^{\text {low }}$ patrolling monocytes are recruited early to incipient plaques in a CCR5-dependent manner ${ }^{37}$, the mechanisms that govern their crawling, adherence, and recruitment to the plaque remain poorly defined ${ }^{8}$. Our study identifies MT4MMP-mediated cleavage of $\alpha \mathrm{M}$ integrin as a mechanism for finetuned regulation of patrolling monocyte crawling. MT4-MMP 
a

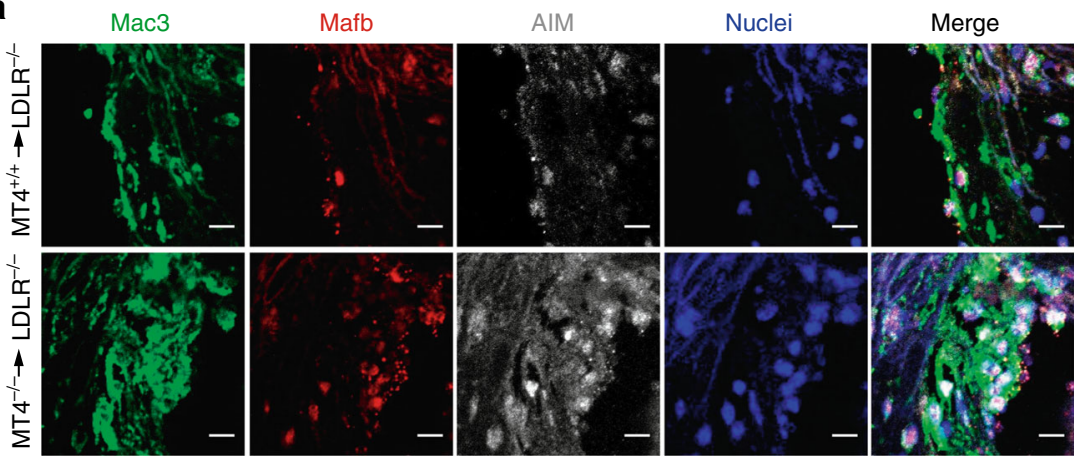

b
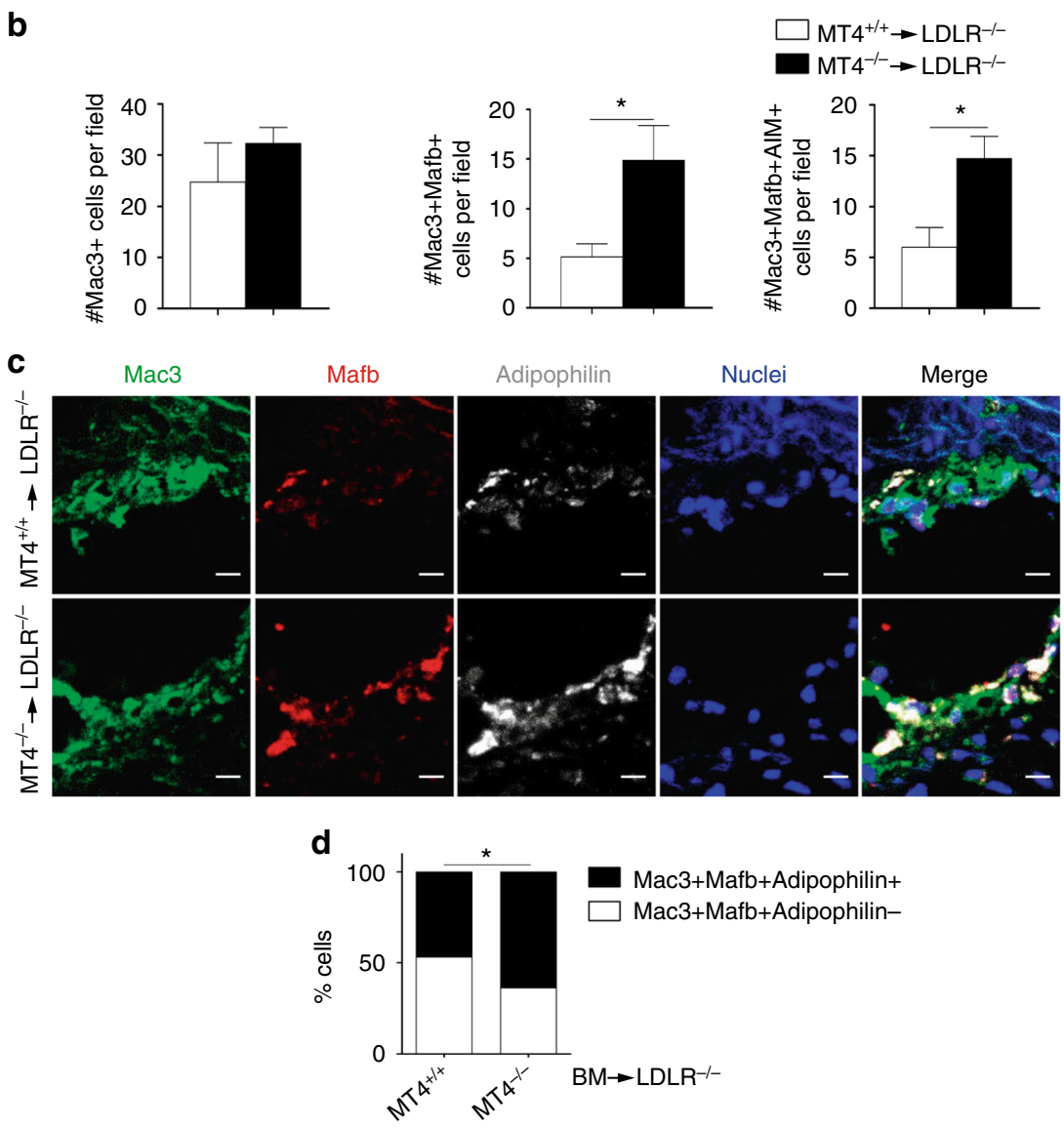

Fig. 6 Lack of MT4-MMP in patrolling monocytes leads to the accumulation of Mafb+AIM+ macrophages in incipient atherosclerotic plaques. a Representative images of transverse sections of aortic sinus from $\mathrm{Ldll}^{-/-}$mice transplanted with MT4-MMP ${ }^{+/+}\left(\mathrm{MT4}^{+/+}\right)$or $\mathrm{MT4}^{-\mathrm{MMP}^{-/-}}\left(\mathrm{MT}^{-/-}\right) \mathrm{BM}^{-}$ cells and fed a HFD for 1 week; sections were labeled for Mac3 (green), Mafb (red), and AIM (white), and with Hoechst (blue; nuclei); scale bar, 10 um. b Number of Mac3+ cells (left), Mac3+Mafb+ cells (middle), and Mac3+Mafb+AIM+ cells (right) in the plaques of BM-transplanted Ldlr ${ }^{-/-}$mice fed a HFD for 1 week. c Representative images of transverse sections of aortic sinus from BM-transplanted Ldlr ${ }^{-/-}$mice fed a HFD for 1 week; sections were labeled for Mac3 (green), Mafb (red), and adipophilin (white), and with Hoechst (blue; nuclei); scale bar, $10 \mu \mathrm{m}$. d Relative \% of adipophilin-positive and adipophilin-negative cells within the Mac3+Mafb+ population of BM-transplanted Ldlr/- mice (1 week on HFD); $n=7$ mice per genotype in two independent experiments. Data were tested by two-tailed Student's $t$-test in $\mathbf{b}$ and by Fisher's exact test in $\mathbf{d}$. Results are expressed as mean \pm SEM. ${ }^{\star} p<0.05$

absence thus resulted in enhanced adhesion of patrolling monocytes on the inflamed endothelium and therefore their recruitment to incipient atherosclerotic plaques in a cell autonomous manner as shown by adoptive transfer experiments. Attention has also focused on macrophage heterogeneity in the atherosclerotic plaque, with new subsets being characterized, adding Mox, Mhem, and M4 macrophages to the established M1 and M2 categories $^{5}$. As patrolling monocytes express genes for cholesterol sensing and response $\mathrm{e}^{21}$, it is of particular interest to determine whether their recruitment to the plaque influences macrophage composition, lipid handling, and overall AT progression. In this regard, patrolling monocytes are more prone to develop into CD11c + cells in the plaque, but the function of these CD11c+ cells in AT was not elucidated ${ }^{27,38}$. We confirmed the presence of more CD11c + cells in incipient plaques from $\mathrm{MT}^{-/-}$-transplanted $\mathrm{Ldll}^{-/-}$mice ( $\sim 2$-fold), but these cells contained fewer lipids than $\mathrm{CD} 11 \mathrm{c}+$ cells in mice transplanted with wild-type $\mathrm{BM}$, suggesting a limited contribution to the observed atherosclerotic phenotype (data not shown). Macrophages in MT4MMP-null-derived plaques had an elevated accumulation of 
a
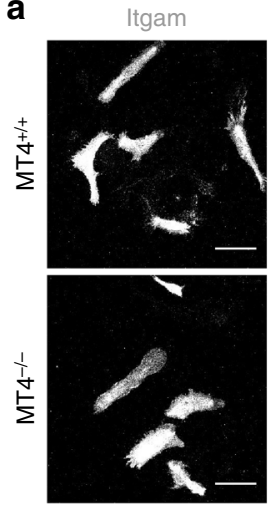

b

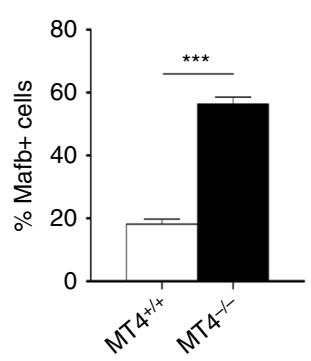

Mafb
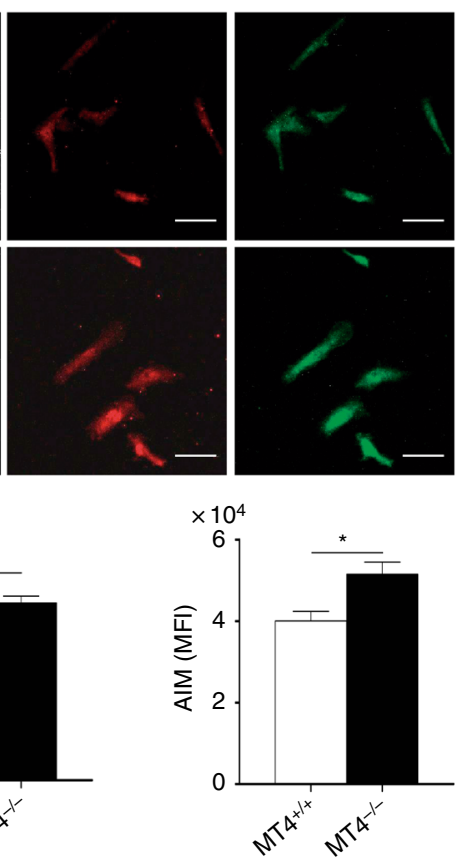

AIM

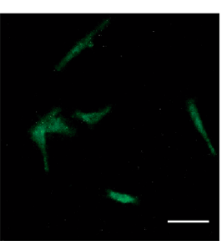

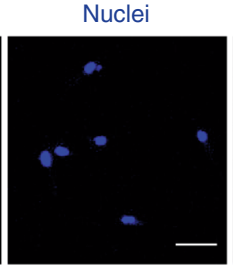
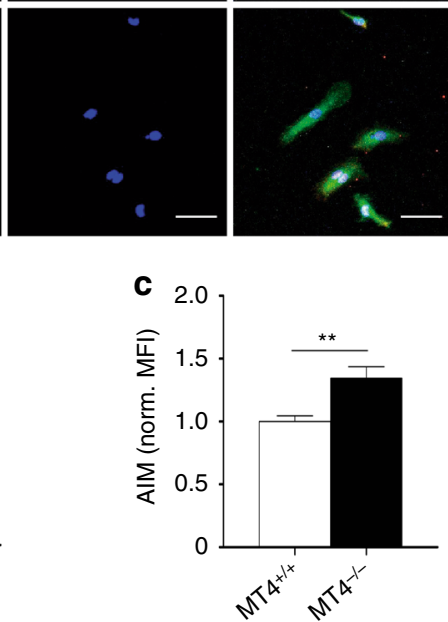

d

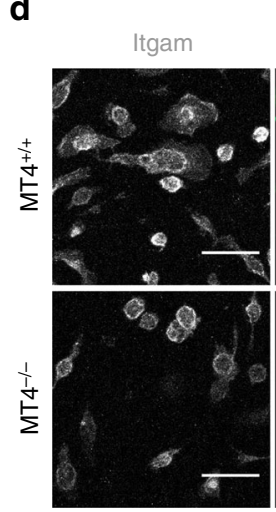

e

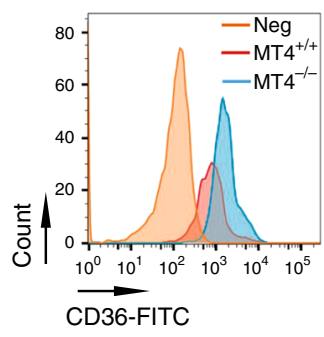

Cleaved

\begin{abstract}
Caspase3
\end{abstract}
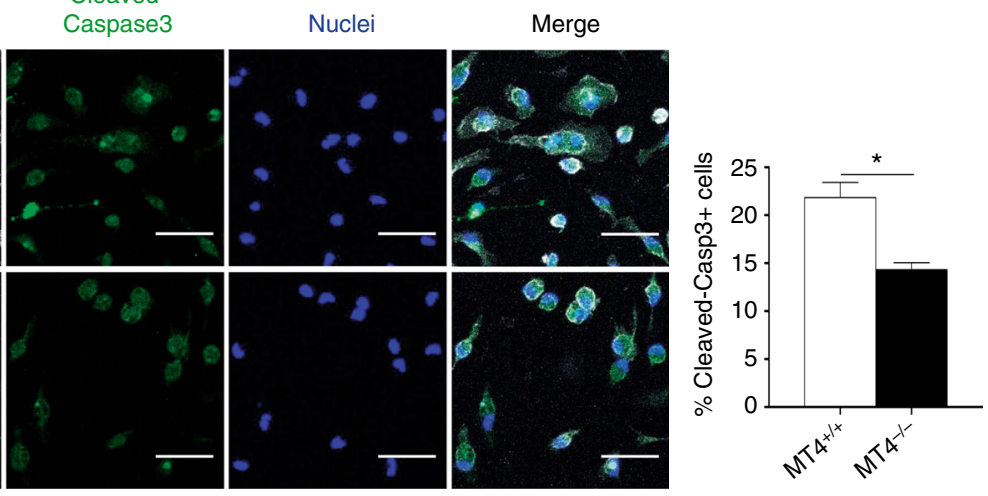

f $\times 10^{4}$
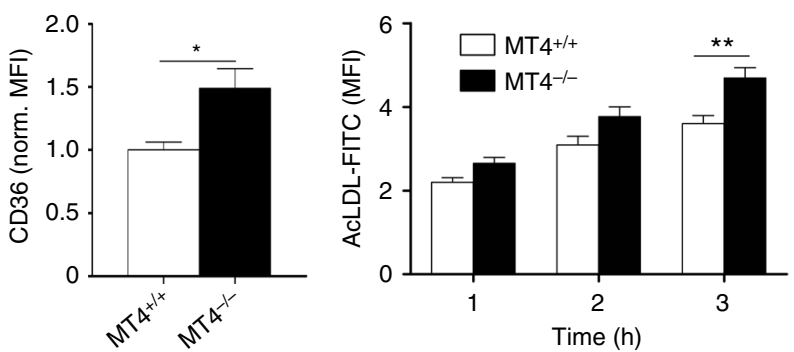

Fig. 7 MT4-MMP-null Mafb+/AIM+ peritoneal macrophages exhibit above-normal CD36 at the cell surface and enhanced acLDL binding. a Representative images of MT4-MMP ${ }^{+/+}\left(\mathrm{MT}^{+/+}\right)$or $\mathrm{MT4}^{-\mathrm{MMP}^{-/-}}\left(\mathrm{MT}^{-/-}\right)$mouse peritoneal macrophages elicited by $72 \mathrm{~h}$ TG stimulation and labeled for Itgam (white), Mafb (red), and AIM (green), and with Hoechst (blue, nuclei); scale bar, $20 \mu \mathrm{m}$. b Graphs show the percentage of cells Mafb+ in the nuclei (left) and the MFI of AIM within Mafb+ cells (right); $n=6$ in two independent experiments. c Quantification of normalized MFI of AIM analyzed by flow cytometry in $\mathrm{MT}^{+/+}$or $\mathrm{MT}^{-/-}$mouse peritoneal macrophages elicited by 72 -hour TG stimulation; $n=6$ in two independent experiments. $\mathbf{d}$ Representative images of TG-elicited $\mathrm{MT}^{+/+}$or $\mathrm{MT}^{-/-}$mouse peritoneal macrophages treated with cycloheximide $\left(100 \mu \mathrm{g} \mathrm{ml} \mathrm{I}^{-1}\right)$ for $6 \mathrm{~h}$ and labeled for Itgam (white) and cleaved-caspase 3 (green) and Hoechst (blue, nuclei); scale bar, $20 \mu \mathrm{m}$. Quantification of the percentage of cleaved-caspase 3-positive cells is shown on the right; $n=3$ in one experiment. e Representative flow cytometry histogram plot of CD36 staining in TG-elicited MT4 ${ }^{+/+}$or MT4 ${ }^{-/-}$ mouse peritoneal macrophages (left) and quantification of normalized MFI (right); $n=6$ in two independent experiments. $\mathbf{f} M F I$ of AcLDL-FITC binding to TG-elicited $\mathrm{MT}^{+/+}$or $\mathrm{MT}^{-/-}$mouse peritoneal macrophages for the indicated times; $n=6$ in two independent experiment. Data were tested by Student's t-test in $\mathbf{b}, \mathbf{c}, \mathbf{d}$, and $\mathbf{e}$, and by two-way ANOVA followed by Bonferroni's post test in $\mathbf{f}$. Results are expressed as mean \pm SEM. ${ }^{\star} p<0.05,{ }^{\star \star} p<$ 0.01 , and ${ }^{\star \star \star} p<0.001$ 
nuclear Mafb similar to observations in other contexts, thus supporting the idea that Mafb may be an intrinsic signature of patrolling monocyte differentiation into macrophages, regardless the inflammatory context ${ }^{26}$. Mafb+ lipid-loaded macrophages have been reported in mouse and human established atherosclerotic plaques, but the origin of this subset was not elucidated $^{28}$. Mac3 + Mafb + macrophages also expressed AIM (apoptosis inhibitor of macrophages), which by inhibiting foamcell apoptosis and favoring oxLDL uptake ${ }^{28-30}$ may underlie the larger lipid lesions developed in the aortas of $\mathrm{MT}^{-/-}$-transplanted $\mathrm{Ldlr}^{-/-}$mice after 12 weeks on the HFD. Data obtained with the CCR5 inhibitor confirmed the dependence of patrolling monocytes on this receptor for their efficient recruitment to the plaque and the existence of non-CCR5 factors whose functional significance remains to be determined ${ }^{27}$. CCR5 inhibitor data also argue in favor of increased early recruitment of patrolling monocytes to athero-prone aorta areas as the primary contributor to $\mathrm{Mafb}+\mathrm{AIM}+$ macrophage abundance and AT acceleration in the absence of MT4-MMP. Notably, the phenotype was not restricted to the atherosclerotic context, since we also observed $\mathrm{Mafb}+\mathrm{AIM}+$ macrophage accumulation in TG-elicited MT4MMP-null peritoneal macrophages. Furthermore, these macrophages exhibited higher levels of cell-surface AIM and of CD36 (a gene expressed by patrolling monocytes ${ }^{21}$ ) and bound acLDL more avidly ${ }^{39}$, in line with the role assigned to AIM in favoring CD36-mediated oxLDL uptake and foam-cell formation ${ }^{30}$.

a

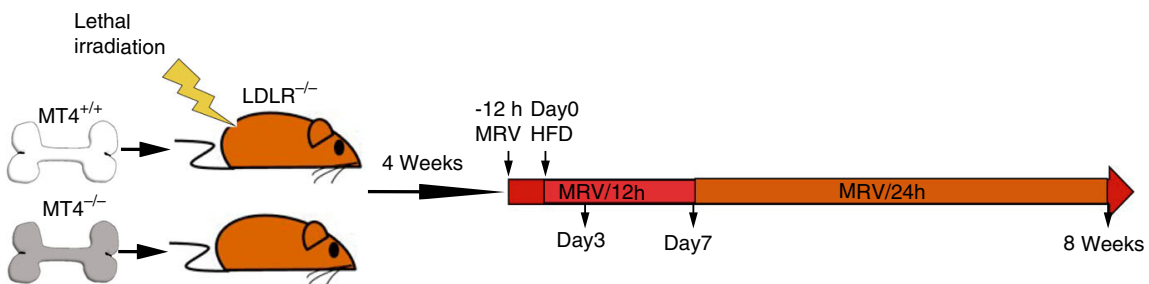

b
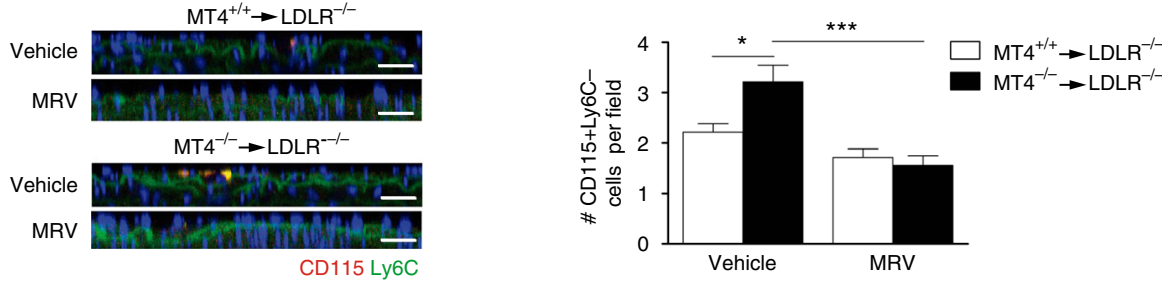

C
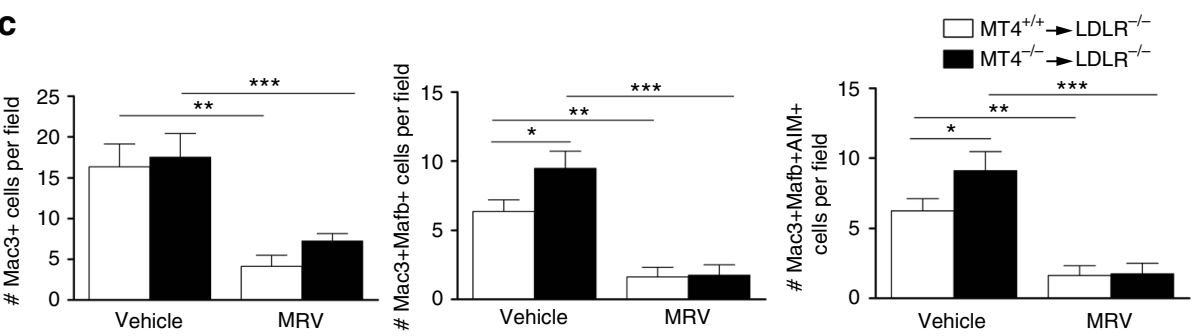

d
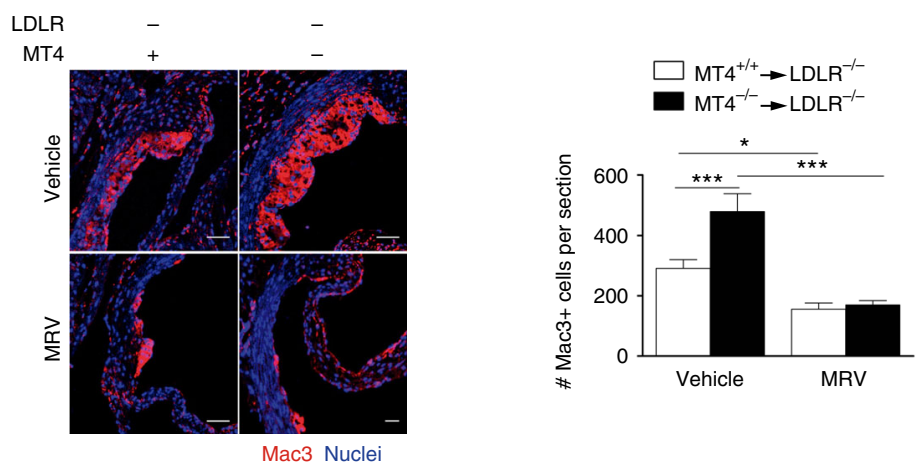

e

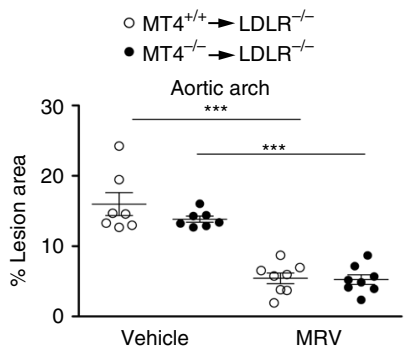

f

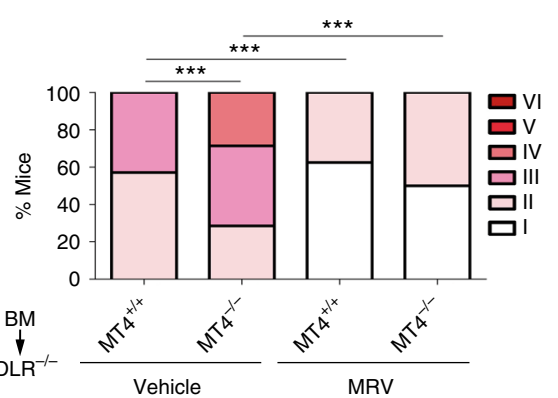


Interestingly, the functional outcome of high CD36 levels in MT4-MMP-null Mac3+Mafb+AIM+ macrophages may be further shaped by environmental factors: in a lipid-rich milieu like AT, CD36 expression would favor disease progression; however, in contexts such as bacterial infection or amyloid deposition, CD36 might promote phagocytosis and resolution ${ }^{40}$. The Mac3 $+\mathrm{Mafb}+\mathrm{AIM}+$ subset seems to be unique within the multidimensional model of macrophage plasticity ${ }^{41}$, with cytokine profiling indicating no shift to a proinflammatory or antiinflammatory phenotype; however, amplified $\mathrm{\alpha M}$ integrin-mediated signaling in MT4-MMP-null macrophages may still produce changes in certain cytokines, such as CXCL2 ${ }^{42}$. Cooperation of $\mathrm{aM}$ integrin with CD36 and TLR2 in cell-surface lipid domains on macrophages has been shown to promote lipid accumulation and downmodulate the inflammatory response ${ }^{43}$; future studies will elucidate whether this cooperation takes place in Mac3 $+\mathrm{Mafb}+\mathrm{AIM}+$ macrophages, particularly in the absence of MT4-MMP. Our results identify a unique apoptosis-resistant, lipid-prone, and non-inflammatory Mac3+Mafb+AIM+ subset that contributes to AT progression; the relation of this subset to subsets previously reported in the atherosclerotic plaque (Mox, M (Hem), $\mathrm{M}(\mathrm{Hb})$, and $\mathrm{M} 4)^{5}$ deserves further analysis. In light of these results, combined strategies targeting $\mathrm{Mafb}+$ and $\mathrm{Mafb}-$ macrophages may prove to be more effective at ameliorating AT progression. Determining whether patrolling monocyte-derived macrophages still have a pro-resolution role at later stages in established AT lesions would require the use of inducible depletion strategies.

This report also describes the first MT4-MMP function in monocytes/macrophages unrelated to the previously proposed pro-TNFa processing ${ }^{5,13,14}$. We identify the $\mathrm{aM}$ integrin chain (Itgam), present in lipid membrane microdomains, as a novel MT4-MMP substrate ${ }^{12,44,45}$, and the lentiviral strategy indicates that MT4-MMP catalytic activity regulates $\alpha \mathrm{M}$ integrin cell surface levels in patrolling monocytes also in vivo. Serine proteases and MMP-9 cleave the $\beta 2$ integrin chain ${ }^{46,47}$ and this shedding is thought to allow leukocyte detachment after endothelial adhe$\operatorname{sion}^{48,49}$. We identified an MT4-MMP cleavage site at position $\mathrm{N}^{977}$ of the $\alpha \mathrm{M}$ integrin chain, which is conserved in human and mouse $\alpha \mathrm{M}$ integrin but not in the related $\alpha \mathrm{L}$ integrin chains of either species. In response to vessel injury or inflammation, patrolling monocytes change their crawling pattern and shift to $\mathrm{\alpha M} \beta 2$ integrin dependence for vascular monitoring $23,26,50$. MT4MMP-mediated cleavage of aM integrin would likely destabilize the integrin heterodimer ${ }^{51}$ allowing patrolling monocytes to detach once their surveillance function on the inflamed endothelium is performed. These results thus also position $\alpha \mathrm{M} \beta 2$ integrin as a major regulator of patrolling monocyte behavior in
$\mathrm{AT}$, in which its role had remained unclear ${ }^{52-54}$. Interaction of aM 32 integrin with ICAM-1, von Willebrand factor, fibrinogen, or CCN1 at athero-prone sites ${ }^{5-58}$ might downregulate Foxp1 and induce $\mathrm{c}-\mathrm{fms} \mathrm{s}^{59}$, and hence influence MT4-MMP and Mafb expression (data not shown and ${ }^{60}$ ) as well as macrophage differentiation and/or proliferation.

This study has potential translational implications related to the atheroprotective action of MT4-MMP when present in BMderived patrolling monocytes, with its expression increasing steadily with AT progression in mouse aorta and human coronary arteries. Genome-wide association studies will help to determine whether mutations in the MT4-MMP gene (MMP17) correlate with increased susceptibility to AT. Finally, patrolling monocytes have beneficial intravascular actions in infection, lung metastasis, and Alzheimer's disease ${ }^{8,17,61}$, and our results suggest that short-term MT4-MMP targeting may offer a new therapeutic strategy to boost these activities.

\section{Methods}

Animal procedures. MT4-MMP-deficient mice were generated as previously described $^{15}$. Ldlr-deficient and $C \times 3 c r 1^{\mathrm{Gfp} /+}$ mice $^{62}$ were obtained from Jackson Laboratories. All mouse strains were on the C57BL/6 background. MT4-MMP ${ }^{-/}$ $-/ \mathrm{Ldl}^{-/-}$and MT4-MMP ${ }^{-/} / \mathrm{C} \times 3 \mathrm{crl}{ }^{-\mathrm{Gfp} /+}$ mice were obtained by crossing MT4MMP-deficient mice with $\mathrm{Ldll}^{-/-}$or $\mathrm{C} \times 3 \mathrm{cr} \mathrm{I}^{\mathrm{Gfp} /+}$ mice. Mice used in this study included: $n=58 \mathrm{C} 57 \mathrm{BL} / 6, n=67 \mathrm{MT}^{-\mathrm{MMP}^{-/-}}, n=154 \mathrm{Ldlr}^{-/-}, n=20 \mathrm{MT} 4$ $\mathrm{MMP}^{-/-} / \mathrm{Ldlr}^{-/-}, n=10 \mathrm{Cx} 3 \mathrm{cr} 1^{\mathrm{Gfp} /+}$, and $n=10 \mathrm{MT}^{-}-\mathrm{MMP}^{-/-} / \mathrm{C} \times 3 \mathrm{crl} \mathrm{-}^{\mathrm{Gfp} /+}$. Mice were housed in the Centro Nacional de Investigaciones Cardiovasculares Carlos III (CNIC) Animal Facility under pathogen-free conditions and according to institutional guidelines. Animal studies were approved by the local ethics committee (CNIC Committee for Animal Welfare permit number CNIC-01/13 and local government of Madrid permit number PROEX 34/13) and conformed to directive 2010/63EU and recommendation 2007/526/EC regarding the protection of animals used for experimental and other scientific purposes, enforced in Spanish law under RD1201/2005. No statistical methods were used to pre-estimate the animal sample size and mice were randomly allocated to experimental groups. To induce atherosclerotic plaques, 3-month-old male mice were fed a HFD (ssniff, E15721-34) ad libitum for the indicated time. For BM transplantation, lethally irradiated (9 Gy) 8-week-old male $\mathrm{Ldlr}^{-1-} \mathrm{MT} 4-\mathrm{MMP}^{+/+}$mice received tail vein injections of BM cells $\left(10^{7}\right)$ obtained from tibias and femurs of euthanized donor $\mathrm{Ldlr}^{+/+} \mathrm{MT} 4-\mathrm{MMP}^{+/+}$or $\mathrm{Ldlr}^{+/+} \mathrm{MT} 4-\mathrm{MMP}^{-/-}$mice. After 4 weeks on standard chow diet, transplanted mice were placed on the HFD for the indicated time. For CCR5 blocking, MRV ( $25 \mu \mathrm{g} / \mathrm{g}$ ) or vehicle (5\% dimethyl sulfoxide and $0.5 \% \mathrm{HCl}$ $0.1 \mathrm{~N}$ in distilled water) were administered to BM transplanted $\mathrm{Ldlr}^{-1-}$ mice by oral gavage every $12 \mathrm{~h}$ for 3 days, 7 days, or during the first week, and then every $24 \mathrm{~h}$ for a further 7 weeks until the end of the experiments. MRV was first administered at the end of the day previous to HFD feeding and last administered $2 \mathrm{~h}$ before sacrificing the mice. For adoptive transfer experiments, patrolling monocytes were sorted from the spleen of MT4-MMP $+/+/ C x 3 \mathrm{crl}-\mathrm{Gfp} /+$ and MT4-MMP ${ }^{-/-} / \mathrm{C} \times 3 \mathrm{cr} 1-$ $\mathrm{Gfp} /+$ mice as Lin (B220 (BD Pharmingen, 51.01122J), CD3 (BD Pharmingen, 51.01082J), Ly6G (BD Biosciences, 551461), and NK1.1 (BD Biosciences, 553165))negative, GFP-positive and Ly6C-negative cells. Patrolling monocytes $\left(5 \times 10^{5}\right)$ were injected intravenously into 3-month-old male $\mathrm{Ldlr}^{-1-}$ mice; the mice were fed on the HFD for 3 days and then killed and the aortas processed for whole-mount staining. Investigators were not blinded during the analysis of mouse samples.

Fig. 8 CCR5 inhibition results in loss of enhanced recruitment of patrolling monocytes, Mafb+AIM+ macrophage accumulation and AT acceleration in MT4-MMP-null BMT Ldlr ${ }^{-/-}$mice. a Scheme depicts the experimental design of CCR5 blocking strategy by Maraviroc (MRV) administration as described in M\&M. b Representative orthogonal XZ view of confocal microscopy images of whole mount-stained aortic arch from Ldll $/ /-$ mice transplanted with MT4-MMP $+/+$ or MT4-MMP $/-$ BM cells, fed the HFD for 3 days and treated with MRV or vehicle. Samples were stained for CD115 (red) and Ly6C (green); elastin autofluorescence (green) and nuclei (Hoechst, blue) are also shown. Scale bar, $20 \mu \mathrm{m}$. The bar graph (right) shows the quantification of the number of patrolling monocytes (CD115+Ly6C-) in the aorta lumen; $n=7$ vehicle and $n=8$ MRV mice per genotype in two independent experiments. $\mathbf{c}$ Bar graphs show the quantification of the number of Mac3+ cells (left), Mac3+Mafb+ cells (middle), and Mac3+Mafb+AIM+ cells (right) in the plaques of BM-transplanted $\mathrm{Ldll}^{-/-}$mice fed a HFD for 1 week and treated with Maraviroc or vehicle. $n=8$ mice per genotype and condition in two independent experiments. d Representative microscopy images of transverse sections of aortic sinus from BM-transplanted Ldlr ${ }^{-/-}$mice fed a HFD for 8 weeks and treated with Maraviroc or vehicle; sections were labeled for Mac3 (red) and Hoechst (blue; nuclei) (upper, scale bar, $50 \mu \mathrm{m}$ ) and graph shows the quantification of the number of Mac3+ cells in the plaque (lower). $n=7$ vehicle and $n=8$ MRV BM-transplanted mice per genotype in two independent experiments. e Graph showing the lesion area of aortas stained with Oil Red from BM-transplanted Ldll-/- mice fed a HFD for 8 week and treated with MRV or vehicle. $n=7$ and $n=8$ mice for Vehicle and MRV mice per genotype in two independent experiments. $\mathbf{f}$ Stary scoring (I-VI) of transverse aortic H\&Estained sections from BM-transplanted $L d \mathrm{dl}^{-/}{ }^{-}$mice fed a HFD for 8 weeks and treated with Maraviroc or vehicle, shown as a percentage of all mice for each score. $n=7$ vehicle and $n=8$ MRV BM-transplanted mice per genotype in two independent experiments. Data were tested by one-way ANOVA followed by Bonferroni's post test in b-e and by $\chi^{2}$-test for a trend in $\mathbf{f}$. Results are expressed as mean $\pm \operatorname{SEM} .{ }^{\star} p<0.05,{ }^{\star \star} p<0.01$, ${ }^{\star \star \star} p<0.005$ 
Human artery sampling and preservation. Human coronary arteries $(n=25)$ were collected from freshly excised hearts during transplant operations at the Hospital de la Santa Creu i Sant Pau (HSCSP, Barcelona, Spain). The study was approved by the Hospital de la Santa Creu i Sant Pau Ethics Committee (04/2016) and was conducted according to the Declaration of Helsinki. Written informed consent was obtained from each patient. Immediately after surgical excision, arteries were dissected, cleaned of connective tissue, and examined under a dissecting microscope. Vessel samples were frozen in liquid nitrogen and stored at $80^{\circ} \mathrm{C}$ for later protein or RNA extraction. Human samples were classified as early lesions (presenting only thickening of the intima) and established atherosclerotic lesions (presenting smooth muscle cells in the intima)

Genotyping of BM-transplanted mice. Blood samples were obtained from BMtransplanted mice 4 weeks after transplantation. White blood cells were isolated using Lympholyte (Cedarlane, CL5031) and DNA was extracted by isopropanol precipitation. PCR was performed using the following primers: forward WT: $5^{\prime}$ TCAGACACAGCCAGATCAGG-3', forward KO 5'-AATATGCGAAGTGGACCTGG-3', and reverse (common to WT and KO) $5^{\prime}$-AGCAA-

CACGGCATCCACTAC- $3^{\prime}$. PCR was conducted at $94^{\circ} \mathrm{C}$ for $2 \mathrm{~min}$ followed by 40 cycles of $95^{\circ} \mathrm{C}$ for $40 \mathrm{~s}, 58^{\circ} \mathrm{C}$ for $40 \mathrm{~s}$, and $72^{\circ} \mathrm{C}$ for $1 \mathrm{~min}$, and a final elongation at $72{ }^{\circ} \mathrm{C}$ for $10 \mathrm{~min}$.

Biochemical analysis. Total mouse serum cholesterol, triglycerides, and glucose were measured using the Dimensions RxL Max system (Siemens Healthineers).

Atherosclerotic lesion analysis. Hearts and aortas from euthanized mice were fixed with $4 \%$ of paraformaldehyde overnight at $4{ }^{\circ} \mathrm{C}$. Adventitial fat and connective tissue were removed from aortas under a dissecting microscope. Whole aortas were opened longitudinally to expose the entire luminal surface and stained with $0.2 \%$ Oil Red O (Sigma-Aldrich, O0625) in 78\% methanol. Images were acquired with a Nikon SMZ800 stereomicroscope (Nikon, Japan) coupled to a Nikon Coolpix 4500 digital color camera (Nikon). The Oil Red-positive area was measured using Image J (https://imagej.nih.gov/ij/; National Institutes of Health, Bethesda, MD).

Histological and immunohistochemical analysis. Mouse hearts and aortas were perfused with phosphate-buffered saline (PBS), extracted, fixed in $4 \%$ paraformaldehyde for $24 \mathrm{~h}$ at $4{ }^{\circ} \mathrm{C}$, embedded in paraffin, and cut in $5 \mu \mathrm{m}$ transverse sections for immunostaining or hematoxylin and eosin staining. Deparaffinized sections were rehydrated, and antigens were retrieved at $95^{\circ} \mathrm{C}$ for $20 \mathrm{~min}$ in citrate buffer $\mathrm{pH} 6$ or (for cleaved caspase-3 staining only) Tris-EDTA buffer $\mathrm{pH} 9$. Sections were then left to cool to room temperature for $2 \mathrm{~h}$. Antigen-retrieved paraffin sections and cryosections were blocked and permeabilized for $1 \mathrm{~h}$ at room temperature in PBS containing $0.3 \%(\mathrm{w} / \mathrm{v})$ Triton X-100, 5\% bovine serum albumin (BSA), 5\% goat serum, and a 1:100 dilution of anti-CD16/CD32 (24g2, BD Pharmingen 553142). For immunofluorescence, sections were stained with antiMac3 (Santa Cruz Biotechnology, sc-19991), anti-MT4 (Abnova, PAB4785), antibeta-galactosidase (rabbit, Abcam ab4761), anti-Ki67 (Abcam, ab16667), anticleaved caspase-3 (Cell Signaling Technology, 9661 S), anti-CD11c (eBiosciences, 11-014-81), anti-Mafb (Santa Cruz Biotechnology, sc-10022), anti-AIM (GeneTex, GTX37448), or anti-adipophilin (Novus Biologicals, NB110-40887) at $4{ }^{\circ} \mathrm{C}$ overnight or with anti-CD11b 647 (eBiosciences, 51-0112-82) for $2 \mathrm{~h}$ at room temperature. Primary antibodies were detected with corresponding fluorescent-labeled secondary antibodies. Samples were mounted in Fluoromount-G (SouthernBiotech, 0100-01) containing Hoechst 33342. Images were acquired on an inverted confocal microscope (LSM700, Carl Zeiss) fitted with a $\times 25$ oil-immersion objective. Images were processed with Zen2009 Light Edition system (Carl Zeiss). Quantification was performed with Image J (https://imagej.nih.gov/ij/; National Institutes of Health) or CellProfiler software (Broad institute).

Real time quantitative PCR. Total RNA was isolated with TRIzol reagent (Invitrogen) using Maxtract high-density columns (Qiagen, ref. 1038988). Isolated RNA was treated with DNAse I (Sigma-Aldrich, D5025) and reverse transcribed using the High-Capacity cDNA Reverse Transcription Kit (Applied Biosystems). For mouse samples, quantitative PCR (qPCR) was performed with SYBR Green PCR master mix (Applied Biosystem) in a CFX384 detection system (Bio-Rad). Primers used in this study are listed in Supplementary Table 1. Data were normalized to the expression levels of $36 \mathrm{~b} 4$ and cyclophilin mRNA within individual samples. For human samples, qPCR was performed using TaqMan probes for human MMP17 (Hs00211754_m1) and normalized to the expression levels of TBP

(Hs99999910_m1). All samples were analyzed in triplicate and RNA levels (CNRQ; calibrated normalized relative quantity) were calculated with Biogazelle qBase PLUS.

Western blotting. Protein extracts from human coronary artery samples were prepared in ice-cold lysis buffer containing $50 \mathrm{mM}$ Tris- $\mathrm{HCl} \mathrm{pH} \mathrm{7.5,1 \%} \mathrm{(w/v)}$ Triton X-100, $150 \mathrm{mM} \mathrm{NaCl}$, and $1 \mathrm{mM}$ dithiothreitol, and supplemented with protease inhibitors ${ }^{63}$. Mouse atheroma samples were obtained from paraffin embedded samples, removing the paraffin, dewaxing, and rehydrating as follows: samples were placed in a tube and incubated for $30 \mathrm{~min}$ at $65^{\circ} \mathrm{C}$ with $1 \mathrm{ml}$ xylene and incubated at room temperature with rotation. Samples were then dehydrated through $100 \%$ ethanol $(2 \times 1 \mathrm{~h}), 96 \%$ ethanol $(30 \mathrm{~min}), 70 \%$ ethanol $(30 \mathrm{~min})$, and PBS $(2 \times 20 \mathrm{~min})$. Samples were lysed in $20 \mathrm{mM}$ Tris-HCl, pH 7.5 containing $2 \%$ SDS and protease inhibitors for $20 \mathrm{~min}$ at $100^{\circ} \mathrm{C}$ and $2 \mathrm{~h}$ at $60{ }^{\circ} \mathrm{C}$. After centrifugation at 13,000 r.p.m. for $15 \mathrm{~min}$ at $4{ }^{\circ} \mathrm{C}$, proteins from peritoneal macrophages were extracted in a buffer containing $10 \mathrm{mM}$ Tris- $\mathrm{HCl} \mathrm{pH} 7.5,1 \%(\mathrm{w} / \mathrm{v})$ Triton $\mathrm{X}-114,150 \mathrm{mM} \mathrm{NaCl}$, and protease inhibitors; samples were heated for 5 min at $30{ }^{\circ} \mathrm{C}$ to separate hydrophilic and lipophilic phases. Proteins were separated by $10 \%$ SDS-polyacrylamide gel electrophoresis, transferred to nitrocellulose membranes, and blocked with 5\% non-fat milk. Primary antibodies used were antiMT4-MMP (Abcam, ab51075), anti-CD11b (Abcam, ab75476), anti-caveolin1 (Cell Signaling, 3267 S), anti- $\alpha$-actin (Dako, M0851), and anti-tubulin (SigmaAldrich, T6074). After overnight incubation at $4{ }^{\circ} \mathrm{C}$ and washes, bound primary antibody was detected by incubation for $1 \mathrm{~h}$ with donkey-anti-rabbit (IRDyeTM $800 \mathrm{CW}$ or $680 \mathrm{CW}, 1 / 10,000$, Odyssey) or donkey-anti-mouse (IRDyeTM $800 \mathrm{CW}$ or $680 \mathrm{CW}, 1 / 10,000$, Odyssey) secondary antibodies, followed by visualization with the Odyssey Infrared Imaging System (LI-COR Biosciences). Raw western blotting images are presented in Supplementary Fig. 12.

\section{In silico modeling of MT4-MMP dimer/ltgam-Itgb2 integrin heterodimer.}

Fasta sequences of mature human MT4-MMP/MMP17, Itgam, and Itgb2 proteins were analyzed with locally implemented I-Tasser suite v4.4 for threading modeling ${ }^{64}$. Selected models were those with minimal energy and correct folding (best structural alignment to templates). In these models, the TM domain is buried in the protein core. Therefore, angles in this region (TM plus C-term) were fixed according to the predicted secondary structure and a refinement cycle was performed with the membrane framework of Rosetta suite v3.5 release 2015.38.58158 (www.rosettacommons.org) ${ }^{65}$. To dock dimeric MT4-MMP to Itgam-Itgb2, the monomers modeled previously were positioned according to the published dimeric interface using pymol v1.8 (www.pymol.org) and the new dimeric model was used as the initial template. Using this model as input, with the same spanfile and constraints as before, a new dimer model was generated using the $m p \_d o c k$ application from the membrane framework of Rosetta suite v3.5 release 2015.38.58158 in each case ${ }^{65}$. Using the obtained dimer models, the MT4-MMPItgam-Itb2 complex was modeled by a similar approach.

Identification of cleavage sites and in vitro digestion assay. Cleavage sites for MT4-MMP in $\alpha \mathrm{M} \beta 2$ integrin were identified by Cleavpredict ${ }^{22}$ (http://cleavpredict sanfordburnham.org/) and the predicted and exposed sites were then filtered according to the peptide cleavage matrix in the MEROPS database (http://merops sanger.ac.uk/). Conservation of cleavage sites in the mouse and human $\alpha \mathrm{M}$ and $\alpha \mathrm{L}$ integrin chains was checked in Uniprot (http://www.uniprot.org/align/). The $\alpha \mathrm{M}$ integrin peptide (RPQVTFSENLSSTCHTKER) was synthetized at the Centro de Investigaciones Biológicas (CIB, CSIC, Madrid) and incubated with hrMT4-MMP (RP-77535, Thermo Fisher Scientific) for $2 \mathrm{~h}$ at $37^{\circ} \mathrm{C}$ in water. The resulting peptides were assayed by high-resolution parallel reaction monitoring on an Easy nLC 1000 nano-HPLC apparatus (Thermo Fisher Scientific) coupled to a hybrid quadrupole-orbitrap mass spectrometer (Q Exactive, Thermo Scientific). The peptides were separated at $200 \mathrm{~nL} \mathrm{~m}^{-1}$ in a continuous gradient consisting of $8-30 \%$ B for $15 \mathrm{~min}$ and $30-90 \%$ B for $2 \mathrm{~min}(B=90 \%$ acetonitrile, $0.1 \%$ formic acid) and ionized using a Picotip emitter nanospray needle (New Objective, Woburn, MA, USA). Each mass spectrometric (MS) run consisted of enhanced FTresolution spectra (15,000 resolution) in the $400-1400 \mathrm{~m} \mathrm{z}^{-1}$ range followed by data-independent tandem MS spectra of seven parent ions acquired during the chromatographic run. The AGC target value in the Orbitrap for the survey scan was set to $1,500,000$ and fragmentation was performed at $27 \%$ normalized collision energy with a target value of 250,000 ions. Data were analyzed with Xcalibur 2.2 (Thermo Fisher Scientific).

Peritoneal macrophage analysis. Primary mouse peritoneal macrophages were obtained from MT4-MMP ${ }^{+/+}$or MT4-MMP ${ }^{-/-}$mice by i.p. lavage with $10 \mathrm{ml}$ cold PBS $72 \mathrm{~h}$ after i.p. injection of $3 \%(\mathrm{w} / \mathrm{v})$ TG. Macrophages were counted, pelleted, and resuspended in RPMI-1640 (Sigma-Aldrich) supplemented with $2.5 \%$ fetal bovine serum, $10 \mathrm{mM}$ HEPES, $50 \mathrm{UI} \mathrm{ml}^{-1}$ penicillin, $50 \mu \mathrm{g} \mathrm{ml}^{-1}$ streptomycin, 1 $\mathrm{mM}$ sodium pyruvate, and $0.1 \mathrm{mM}$ non-essential amino acids, and plated on coverslips for spreading experiments or on plastic tissue culture dishes for mRNA or protein analyses. Freshly isolated peritoneal cells were used for flow cytometry. For MafB and AIM immunofluorescence analysis of TG-elicited peritoneal macrophages, cells were plated on glass coverslips (500,000 cells per $12 \mathrm{~mm}$-diameter coverslip) for $24 \mathrm{~h}$, fixed with $4 \%$ paraformaldehyde for $10 \mathrm{~min}$ at room temperature, and blocked and permeabilized for $30 \mathrm{~min}$ at room temperature in PBS containing $0.3 \%(\mathrm{w} / \mathrm{v})$ Triton $\mathrm{X}-100,5 \% \mathrm{BSA}, 5 \%$ goat serum, and a $1: 100$ dilution of anti-CD16/CD32 (24g2, BD Pharmingen 553142). Fixed cells were stained with anti-Mafb (Santa Cruz Biotechnology, sc-10022) and anti-AIM (GeneTex, GTX37448) overnight at $4^{\circ} \mathrm{C}$, and with anti-CD11b 647 (eBiosciences, 51-0112-82) for $2 \mathrm{~h}$ at room temperature, followed by the corresponding fluorescent-labeled secondary antibodies. Apoptosis was assessed by treating TG-elicited peritoneal 
macrophages with cycloheximide $\left(100 \mu \mathrm{g} \mathrm{ml}^{-1}\right)$ for $6 \mathrm{~h}$ and staining fixed cells with anti-cleaved caspase 3 (Cell Signaling, 9661 S) as described above. Samples were mounted in Fluoromount-G (SouthernBiotech, 0100-01) containing Hoechst 33342. Images were acquired on an inverted confocal microscope (LSM700, Carl Zeiss) fitted with a $\times 25$ oil-immersion objective. Images were processed and analyzed using Image J (https://imagej.nih.gov/ij/; National Institutes of Health). For C3 and acLDL binding assays, TG-elicited peritoneal macrophages were plated over coverslips or left in suspension and incubated with C3-opsonized sheep red blood cells (RBCs) or with $1 \mu \mathrm{g} \mathrm{ml}^{-1}$ acLDL-FITC (Invitrogen, L-23380) for the indicated times at $37^{\circ} \mathrm{C}$; the number of RBC per macrophage was then counted and the fluorescence intensity of AcLDL-FITC quantitated by flow cytometry. Macrophage egression was assessed as described ${ }^{22}$. In brief, TG-elicited peritoneal macrophages from MT4-MMP ${ }^{+/+}$or MT4-MMP $\mathrm{MP}^{-/-}$mice were labeled with PKH26 or PKH67 probes (Sigma-Aldrich MINI26 and MINI67), respectively, and mixed 1:1. Dual-labeled macrophages $\left(5 \times 10^{5}\right)$ were injected i.p. into C57BL6 mice previously stimulated with TG i.p. for $72 \mathrm{~h}$. LPS $(1 \mu \mathrm{g})$ or PBS was then injected i.p. and after $4 \mathrm{~h}$ mice were killed and peritoneal macrophages and spleen obtained for flow cytometry analysis.

In vivo macrophage infection. Lentiviruses encoding full-length mouse MT4MMP, MT4-MMP E248A (catalytic inactive mutant), or GFP alone (mock) were generated as described ${ }^{16}$. Virus was i.p. injected into MT4-MMP ${ }^{+1+}$ or MT4$\mathrm{MMP}^{-l-}$ mice at $\sim 1 \times 10^{8} \mathrm{pfu} \mathrm{m}^{-1}$. After 5 days, cells were collected and analyzed by flow cytometry.

Flow cytometry. Blood and BM samples from killed mice were blocked for $15 \mathrm{~min}$ at $4{ }^{\circ} \mathrm{C}$ in PBS containing 5\% BSA and a 1:100 dilution of anti-CD16/CD32 (24g2, BD Pharmingen, 553142). Samples were then stained for $30 \mathrm{~min}$ at $4^{\circ} \mathrm{C}$ with antiCD11b 647 (eBiosciences, 51-0112-82) or biotinylated (BD Pharmingen, 51.01712 J), anti-CD45 V450 (eBiosciences, 48-0451-82), anti-Ly6C FITC (BD Bioscience, 553104) or APC (BD Pharmingen, 560595), anti-CCR5 PE (eBioscience, 12.195112 ), and anti-CCR2 (Biolegend, 150607) primary antibodies and with streptavidin PE (BD Bioscience, 554061) secondary reagent. Erythrocytes in blood samples were lysed with FACS Lysis Solution (BD Biosciences, 349202) for $7 \mathrm{~min}$ at room temperature. Before gating, granulocytes were excluded by FCS/SSC. Peritoneal macrophages were collected on the indicated days after TG administration and blocked with BSA/anti-CD16/CD32. Macrophages were then stained for $30 \mathrm{~min}$ at $4{ }^{\circ} \mathrm{C}$ with anti-CD11b 647 (eBiosciences, 51-0112-82), anti-CD45 V450 (eBiosciences, 48-0451-82), anti-F4/80 Pe-Cy7 (Biolegend, 123114), anti-AIM (GeneTex, GTX37448), and anti-CD36 (Cascade BioScience, ABM-5525) antibodies; for quantification of dead cells, Hoechst 33258 (Sigma, 861405) was added 5 min previous to flow cytometry analysis. Data were acquired in a FACSCanto III cytometer (BD) and analyzed using FlowJo software (Tree Star).

Cell spreading assay. Peritoneal macrophages were plated onto fibrinogen-coated coverslips $(500,000$ cells per $12 \mathrm{~mm}$-diameter coverslip) for $24 \mathrm{~h}$, fixed with $4 \%$ paraformaldehyde for $10 \mathrm{~min}$ at room temperature, stained with phalloidin-texas red (Invitrogen, T-7471, 1:100) for $2 \mathrm{~h}$, and mounted in Fluoromount-G (SouthernBiotech, 0100-01) containing Hoechst 33342. Images were acquired with a confocal microscope (Nikon A1R) fitted with an $\times 20$ air objective. Images were processed and analyzed using Image J (https://imagej.nih.gov/ij/; National Institutes of Health)

Whole-mount staining of peritoneal membranes. Peritoneal membranes were collected $72 \mathrm{~h}$ after TG administration, cleaned under a dissecting microscope, and fixed with $4 \%$ paraformaldehyde overnight at $4{ }^{\circ} \mathrm{C}$. Samples were blocked and permeabilized for $30 \mathrm{~min}$ at room temperature in PBS containing $0.1 \%$ Triton X$100,5 \%$ BSA, 5\% goat serum (Jackson, 005-000-001), and 1:100 anti-CD16/CD32 (24g2, BD Pharmingen, 553142). Samples were then incubated with anti-CD11b 647 (eBiosciences, $51-0112-82$ ) overnight at $4{ }^{\circ} \mathrm{C}$ and mounted in Fluoromount-G (SouthernBiotech, 0100-01) containing Hoechst 33342. Images were acquired with an inverted confocal microscope (LSM700, Carl Zeiss) fitted with a $\times 10$ air objective. Images were processed with Zen2009 Light Edition (Carl Zeiss), and quantified using Image J (https://imagej.nih.gov/ij/; National Institutes of Health).

Intravital microscopy in the cremaster muscle. Intravital microscopy in the cremaster muscle was performed as described ${ }^{25}$. Mice were anesthetized and the cremaster muscle was dissected free of surrounding tissues and exteriorized onto an optical clear viewing pedestal. The muscle was cut longitudinally with a cautery and held extended at the corners of the exposed tissue using surgical suture. To maintain the correct temperature and physiological conditions, the muscle was perfused continuously with warmed Tyrode's buffer. Four hours before surgery, animals were injected intrascrotally with $345 \mathrm{ng}$ of CCL2 (Preprotech, 250-10) ${ }^{66}$ The cremasteric microcirculation was then observed using a Leica DM6000-FS intravital microscope fitted with an Apo $\times 40$ NA 1.0 water-immersion objective and a DFC350-FX camera. LASAF software was employed for acquisition and image processing. Monocytes were stained by i.v. injection of CD115-PE (Biolegend, 135505) and Ly6C-APC (Biolegend, 128016), and in another set of experiments neutrophils were stained by injection of Ly6G-PE (BD Biosciences, 551461).
Three-to-five randomly selected venules $(25-40 \mu \mathrm{m}$ diameter) were analyzed per mouse, and leukocyte-endothelium interaction was measured in $350 \mu \mathrm{m}$ vessel segments for $5 \mathrm{~min}$. When indicated, the aM integrin (Itgam) blocking antibody M1/70 (eBioscience, 16-0112) or IgG isotype control (eBioscience, 16-4031) was injected intravenously $\left(4 \mathrm{mg} \mathrm{kg}^{-1}\right)$ before intravital microscopy ${ }^{26}$.

Statistical analysis. All data are shown as mean \pm SEM. Normal distribution of the values was checked and statistical analysis performed with Prism Software (GraphPad Prism 5) using the test indicated in the figure legend. Outlier values were excluded using the online GraphPad outlier test. Statistical significance was assigned at ${ }^{*} p<0.05,{ }^{* *} p<0.01$, and ${ }^{* *} p<0.001$.

Data availability. All relevant data are available from the authors upon request.

Received: 23 February 2017 Accepted: 7 February 2018

Published online: 02 March 2018

\section{References}

1. Hansson G. K. Regulation of immune mechanisms in atherosclerosis. Ann. N. Y. Acad. Sci. 947, 157-165 (2001).

2. Hamers, A. A. et al. Bone marrow-specific deficiency of nuclear receptor Nur77 enhances atherosclerosis. Circ. Res. 110, 428-438 (2012).

3. Hansson, G. K. \& Hermansson, A. The immune system in atherosclerosis. Nat. Immunol. 12, 204-212 (2011).

4. Randolph, G. J. The fate of monocytes in atherosclerosis. J. Thromb. Haemost. 7, 28-30 (2009).

5. Chinetti-Gbaguidi, G., Colin, S. \& Staels, B. Macrophage subsets in atherosclerosis. Nat. Rev. Cardiol. 12, 10-17 (2015).

6. Robbins, C. S. et al. Local proliferation dominates lesional macrophage accumulation in atherosclerosis. Nat. Med. 19, 1166-1172 (2013).

7. Soehnlein, O. et al. Distinct functions of chemokine receptor axes in the atherogenic mobilization and recruitment of classical monocytes. EMBO Mol. Med. 5, 471-481 (2013).

8. Thomas, G., Tacke, R., Hedrick, C. C. \& Hanna, R. N. Nonclassical patrolling monocyte function in the vasculature. Arterioscler. Thromb. Vasc. Biol. 35, 1306-1316 (2015).

9. Lin, J., Kakkar, V. \& Lu, X. Impact of matrix metalloproteinases on atherosclerosis. Curr. Drug Targets 15, 442-453 (2014).

10. Newby, A. C. Matrix metalloproteinases regulate migration, proliferation, and death of vascular smooth muscle cells by degrading matrix and non-matrix substrates. Cardiovasc. Res. 69, 614-624 (2006).

11. Itoh, Y. et al. Membrane type 4 matrix metalloproteinase (MT4-MMP, MMP17) is a glycosylphosphatidylinositol-anchored proteinase. J. Biol. Chem. 274, 34260-34266 (1999).

12. Sohail, A. et al. MT4-(MMP17) and MT6-MMP (MMP25), a unique set of membrane-anchored matrix metalloproteinases: properties and expression in cancer. Cancer Metastas. Rev. 27, 289-302 (2008).

13. English, W. R. et al. Membrane type 4 matrix metalloproteinase (MMP17) has tumor necrosis factor-alpha convertase activity but does not activate proMMP2. J. Biol. Chem. 275, 14046-14055 (2000).

14. Gauthier, M. C. et al. Expression of membrane type-4 matrix metalloproteinase (metalloproteinase-17) by human eosinophils. Int J. Biochem Cell Biol. 35, 1667-1673 (2003).

15. Rikimaru, A. et al. Establishment of an MT4-MMP-deficient mouse strain representing an efficient tracking system for MT4-MMP/MMP-17 expression in vivo using beta-galactosidase. Genes Cells 12, 1091-1100 (2007).

16. Martin-Alonso, M. et al. Deficiency of MMP17/MT4-MMP proteolytic activity predisposes to aortic aneurysm in mice. Circ. Res. 117, e13-e26 (2015).

17. Hanna, R. N. et al. Patrolling monocytes control tumor metastasis to the lung. Science 350, 985-990 (2015).

18. Ghosn, E. E. et al. Two physically, functionally, and developmentally distinct peritoneal macrophage subsets. Proc. Natl Acad. Sci. USA 107, 2568-2573 (2010).

19. Gautier, E. L., Ivanov, S., Lesnik, P. \& Randolph, G. J. Local apoptosis mediates clearance of macrophages from resolving inflammation in mice. Blood 122, 2714-2722 (2013).

20. Stary, H. C. et al. A definition of advanced types of atherosclerotic lesions and a histological classification of atherosclerosis. A report from the Committee on Vascular Lesions of the Council on Arteriosclerosis, American Heart Association. Arterioscler. Thromb. Vasc. Biol. 15, 1512-1531 (1995).

21. Randolph, G. J. Mechanisms that regulate macrophage burden in atherosclerosis. Circ. Res. 114, 1757-1771 (2014). 
22. Kumar, S., Ratnikov, B. I., Kazanov, M. D., Smith, J. W. \& Cieplak, P. CleavPredict: a platform for reasoning about matrix metalloproteinases proteolytic events. PLoS ONE 10, e0127877 (2015).

23. Carlin, L. M. et al. Nr4al-dependent Ly6C(low) monocytes monitor endothelial cells and orchestrate their disposal. Cell 153, 362-375 (2013).

24. Charo, I. F. \& Taubman, M. B. Chemokines in the pathogenesis of vascular disease. Circ. Res 95, 858-866 (2004).

25. Rius, C. \& Sanz, M. J. Intravital microscopy in the cremaster muscle microcirculation for endothelial dysfunction studies. Methods Mol. Biol. 1339, 357-366 (2015).

26. Auffray, C. et al. Monitoring of blood vessels and tissues by a population of monocytes with patrolling behavior. Science 317, 666-670 (2007).

27. Tacke, F. et al. Monocyte subsets differentially employ CCR2, CCR5, and CX3CR1 to accumulate within atherosclerotic plaques. J. Clin. Invest 117, 185-194 (2007).

28. Hamada, M. et al. MafB promotes atherosclerosis by inhibiting foam-cell apoptosis. Nat. Commun. 5, 3147 (2014).

29. Arai, S. et al. A role for the apoptosis inhibitory factor AIM/Spalpha/Api6 in atherosclerosis development. Cell Metab. 1, 201-213 (2005).

30. Amezaga, N. et al. Human scavenger protein AIM increases foam cell formation and CD36-mediated oxLDL uptake. J. Leukoc. Biol. 95, 509-520 (2014).

31. Pozo-Balado, M. M. et al. Maraviroc reduces the regulatory T-cell frequency in antiretroviral-naive HIV-infected subjects. J. Infect. Dis. 210, 890-898 (2014).

32. Cipriani, S. et al. Efficacy of the CCR5 antagonist maraviroc in reducing early, ritonavir-induced atherogenesis and advanced plaque progression in mice. Circulation 127, 2114-2124 (2013).

33. Hanna, R. N. et al. NR4A1 (Nur77) deletion polarizes macrophages toward an inflammatory phenotype and increases atherosclerosis. Circ. Res. 110, 416-427 (2012).

34. Chao, L. C. et al. Bone marrow NR4A expression is not a dominant factor in the development of atherosclerosis or macrophage polarization in mice. $J$. Lipid Res. 54, 806-815 (2013).

35. Thomas, G. D. et al. Deleting an Nr4al super-enhancer subdomain ablates Ly6Clow monocytes while preserving macrophage gene function. Immunity 45, 975-987 (2016).

36. Randolph, G. J. Proliferating macrophages prevail in atherosclerosis. Nat. Med. 19, 1094-1095 (2013).

37. Gautier, E. L., Jakubzick, C. \& Randolph, G. J. Regulation of the migration and survival of monocyte subsets by chemokine receptors and its relevance to atherosclerosis. Arterioscler. Thromb. Vasc. Biol. 29, 1412-1418 (2009).

38. Wu, H. et al. Functional role of CD11c+ monocytes in atherogenesis associated with hypercholesterolemia. Circulation 119, 2708-2717 (2009).

39. Kunjathoor, V. V. et al. Scavenger receptors class A-I/II and CD36 are the principal receptors responsible for the uptake of modified low density lipoprotein leading to lipid loading in macrophages. J. Biol. Chem. 277, 49982-49988 (2002).

40. Febbraio, M. \& Silverstein, R. L. CD36: implications in cardiovascular disease. Int J. Biochem. Cell Biol. 39, 2012-2030 (2007).

41. Schultze, J. L. Reprogramming of macrophages--new opportunities for therapeutic targeting. Curr. Opin. Pharmacol. 26, 10-15 (2016).

42. Walzog, B. et al. A role for beta(2) integrins (CD11/CD18) in the regulation of cytokine gene expression of polymorphonuclear neutrophils during the inflammatory response. FASEB J. 13, 1855-1865 (1999).

43. Almeida, P. E. et al. Differential TLR2 downstream signaling regulates lipid metabolism and cytokine production triggered by Mycobacterium bovis BCG infection. Biochim. Biophys. Acta 1841, 97-107 (2014).

44. Fabbri, M. et al. Dynamic partitioning into lipid rafts controls the endoexocytic cycle of the alphaL/beta2 integrin, LFA-1, during leukocyte chemotaxis. Mol. Biol. Cell 16, 5793-5803 (2005).

45. Leitinger, B. \& Hogg, N. The involvement of lipid rafts in the regulation of integrin function. J. Cell Sci. 115, 963-972 (2002).

46. Zen, K. et al. Cleavage of the CD11b extracellular domain by the leukocyte serprocidins is critical for neutrophil detachment during chemotaxis. Blood 117, 4885-4894 (2011).

47. Vaisar, T. et al. MMP-9 sheds the beta2 integrin subunit (CD18) from macrophages. Mol. Cell Proteom. 8, 1044-1060 (2009).

48. Evans, B. J. et al. Shedding of lymphocyte function-associated antigen-1 (LFA-1) in a human inflammatory response. Blood 107, 3593-3599 (2006).

49. Drbal, K. et al. A proteolytically truncated form of free CD18, the common chain of leukocyte integrins, as a novel marker of activated myeloid cells. Blood 98, 1561-1566 (2001).
50. Sumagin, R., Prizant, H., Lomakina, E., Waugh, R. E. \& Sarelius, I. H. LFA-1 and Mac-1 define characteristically different intralumenal crawling and emigration patterns for monocytes and neutrophils in situ. J. Immunol. 185, 7057-7066 (2010)

51. Wang, W., Fu, G. \& Luo, B. H. Dissociation of the alpha-subunit Calf-2 domain and the beta-subunit I-EGF4 domain in integrin activation and signaling. Biochemistry 49, 10158-10165 (2010).

52. Cao, C., Lawrence, D. A., Strickland, D. K. \& Zhang, L. A specific role of integrin Mac-1 in accelerated macrophage efflux to the lymphatics. Blood 106, 3234-3241 (2005).

53. Merched, A., Tollefson, K. \& Chan, L. Beta2 integrins modulate the initiation and progression of atherosclerosis in low-density lipoprotein receptor knockout mice. Cardiovasc. Res. 85, 853-863 (2010).

54. Yakubenko, V. P., Bhattacharjee, A., Pluskota, E. \& Cathcart, M. K. alphaMbeta(2) integrin activation prevents alternative activation of human and murine macrophages and impedes foam cell formation. Circ. Res. 108, 544-554 (2011).

55. Nageh, M. F. et al. Deficiency of inflammatory cell adhesion molecules protects against atherosclerosis in mice. Arterioscler. Thromb. Vasc. Biol. 17, 1517-1520 (1997)

56. Methia, N., Andre, P., Denis, C. V., Economopoulos, M. \& Wagner, D. D. Localized reduction of atherosclerosis in von Willebrand factor-deficient mice. Blood 98, 1424-1428 (2001).

57. Orr, A. W. et al. The subendothelial extracellular matrix modulates NFkappaB activation by flow: a potential role in atherosclerosis. J. Cell Biol. 169, 191-202 (2005).

58. Imhof, B. A. et al. CCN1/CYR61-mediated meticulous patrolling by Ly6Clow monocytes fuels vascular inflammation. Proc. Natl Acad. Sci. USA 113, E4847-E4856 (2016).

59. Shi, C. et al. Integrin engagement regulates monocyte differentiation through the forkhead transcription factor Foxp1. J. Clin. Invest. 114, 408-418 (2004).

60. Cuevas, V. D. et al. MAFB determines human macrophage anti-inflammatory polarization: relevance for the pathogenic mechanisms operating in multicentric carpotarsal osteolysis. J. Immunol. 198, 2070-2081 (2017).

61. Michaud, J. P., Bellavance, M. A., Prefontaine, P. \& Rivest, S. Real-time in vivo imaging reveals the ability of monocytes to clear vascular amyloid beta. Cell Rep. 5, 646-653 (2013).

62. Jung, S. et al. Analysis of fractalkine receptor CX(3)CR1 function by targeted deletion and green fluorescent protein reporter gene insertion. Mol. Cell Biol. 20, 4106-4114 (2000).

63. Mendez-Barbero, N. et al. A major role for RCAN1 in atherosclerosis progression. EMBO Mol. Med 5, 1901-1917 (2013).

64. Yang, J. et al. The I-TASSER Suite: protein structure and function prediction. Nat. Methods 12, 7-8 (2015).

65. Alford, R. F. et al. An integrated framework advancing membrane protein modeling and design. PLoS Comput. Biol. 11, e1004398 (2015).

66. Tan, J. H. et al. Tyrosine sulfation of chemokine receptor CCR2 enhances interactions with both monomeric and dimeric forms of the chemokine monocyte chemoattractant protein-1 (MCP-1). J. Biol. Chem. 288, 10024-10034 (2013).

\section{Acknowledgements}

We thank Ángel Colmenar and Laura Balonga for technical support, the BioBanco VIH (Hospital Gregorio Marañón, Madrid) for providing essential reagents, and Simon Bartlett for English editing. This study was supported by grants from the Spanish Ministry of Economy, Industry and Competitiveness (MEIC; RD12/0042/0023 [FEDER cofunded] and SAF2014-52050R and SAF2017-83229R to A.G.A., SAF2015-64287R and SAF2015-71878-REDT to M.R., RD12/0042/0053 [FEDER cofunded] and SAF2015-64767-R to J.M-G., and SAF2016-79490-R and RD12/0042/0028 [FEDER cofunded] to V.A.) and from La Marató TV3 Foundation. C.C., M.M-A., and L.A-H. were funded by fellowships from the Spanish Ministry of Education, MEIC, and La Caixa-CNIC, respectively. C.R. was funded by a competitive postdoctoral contract grant FPDI-2013-17423 from MEIC. The CNIC is supported by the Spanish MEIC and the Pro-CNIC Foundation, and is a Severo Ochoa Center of Excellence (MEIC award SEV-2015-0505).

\section{Author contributions}

C.C. performed and analyzed most of AT and macrophage experiments. A.P. and R.A M. performed and analyzed some AT experiments in $\mathrm{Ldlr}^{-/-}$and BM-transplanted $L_{d l r^{-/-}}$mice. V.N. helped with BM transplants and Oil Red aorta analysis. C.R. performed and analyzed intravital microscopy experiments. L.A.-H. performed and analyzed qPCR. M.M.-A. helped in digestion assays. E.C. performed and analyzed mass spectrometry experiments. F.M. performed in silico protein modeling. C.R. and J. M-G analyzed human samples. M.S. provided MT4-MMP-deficient mice. V.A. supervised 
intravital microscopy assays. M.R. provided $L d l r^{-/-}$and $\mathrm{Cx} 3 \mathrm{crl} 1^{\mathrm{Gfp} /+}$ mice, and critical suggestions. A.G.A. designed and supervised the research and wrote the paper.

\section{Additional information}

Supplementary Information accompanies this paper at https://doi.org/10.1038/s41467018-03351-4.

Competing interests: The authors declare no competing interests.

Reprints and permission information is available online at http://npg.nature.com/ reprintsandpermissions/

Publisher's note: Springer Nature remains neutral with regard to jurisdictional claims in published maps and institutional affiliations. (c) (i) Open Access This article is licensed under a Creative Commons Attribution 4.0 International License, which permits use, sharing, adaptation, distribution and reproduction in any medium or format, as long as you give appropriate credit to the original author(s) and the source, provide a link to the Creative Commons license, and indicate if changes were made. The images or other third party material in this article are included in the article's Creative Commons license, unless indicated otherwise in a credit line to the material. If material is not included in the article's Creative Commons license and your intended use is not permitted by statutory regulation or exceeds the permitted use, you will need to obtain permission directly from the copyright holder. To view a copy of this license, visit http://creativecommons.org/ licenses/by/4.0/.

(C) The Author(s) 2018 

